\title{
Process optimization of thermal modification of Chilean Eucalyptus nitens plantation wood
}

\author{
Dissertation \\ In partial fulfillment of the requirements of the doctoral degree \\ „Doctor rerum naturalium“ \\ of the Faculty of Forest Sciences and Forest Ecology \\ Georg-August University Göttingen \\ within the $\mathrm{PhD}$ program Material Forschung Holz (MAFO Holz) \\ of the Georg-August University School of Science (GAUSS)
}

Submitted by

Maximilian Enrique Wentzel Vietheer

Born in Santiago, Chile

Göttingen, 2018 



\section{Members of the examination board}

First Referee: Prof. Dr. Holger Militz, Department of Wood Biology and Wood Products, Burckhardt Institute, Faculty of Forest Sciences and Forest Ecology, Georg-August University, Göttingen, Germany.

Second referee: PD Dr. habil. Christian Brischke, Department of Wood Biology and Wood Products, Burckhardt Institute, Faculty of Forest Sciences and Forest Ecology, Georg-August University, Göttingen, Germany.

\section{Further members of the examination board}

Prof. Dr. Carsten Mai, Department of Wood Biology and Wood Products, Burckhardt Institute, Faculty of Forest Sciences and Forest Ecology, Georg-August University, Göttingen, Germany.

Prof Dr. Andrea Polle, Department of Forest Botany and Tree Physiology, Büsgen Institute, Faculty of Forest Sciences and Forest Ecology, Georg-August University, Göttingen, Germany.

Prof. Dr. Christian Ammer, Department of Silviculture and Forest Ecology of the Temperate Zones, Faculty of Forest Sciences and Forest Ecology, Georg-August University, Göttingen, Germany.

Prof Dr. Dr. h.c František Hapla, Department of Wood Biology and Wood Products, Burckhardt Institute, Faculty of Forest Sciences and Forest Ecology, Georg-August University, Göttingen, Germany. 



\section{Acknowledgments}

First, I would like to start by thanking Prof. Dr. Holger Militz for letting me work on my PhD in his department. I am very thankful for all the guiding, scientific discussions and expertise, but especially by his support and encouragement during the whole process.

I am very grateful for the advice, constructive discussions, suggestions and all the help and support given to me by my co-authors Dr. Michael Altgen, Dr. Marco Fleckenstein, PD Dr. habil. Christian Brischke, Dr. habil Tamás Hoffmann, Dr. Aldo Rolleri, Dr. Óscar González-Prieto and Tim Koddenberg, specially Michael , as he was an excellent guide on all things thermal modification and very helpful in the planning of the experiments.

Furthermore, a big thanks to my friends and colleagues at the department of Wood Biology and Wood Products and the Materialforschung Holz (MaFo Holz) promotion program, and all the people I have met the last couple of years here in Göttingen, they made my stay extremely enjoyable. Extra special thanks to Michael Starck and Fritz Wilhelms, who shared office 1.106 with me, for enduring me and for sharing music of dubious quality, Dr. Philipp Schlotzhauer, Christoph Stiehm, Dr. Vladimirs Biziks, Philipp Sauerbier, and to the guys from my football groups, SV Eddigehausen 1922 e.V and Torpedo Göttingen.

Finally, I would also like to thank the Chilean government and its CONICYT BecasChile scholarship for giving me the opportunity to study for a post graduate degree abroad.

This thesis is dedicated to my Chilean and German families for all the encouragement and support they given me along the way. 



\section{Abstract}

Eucalyptus nitens is one of the most important fast growing plantation species in Chile. Currently it is mostly used for pulp and paper, but in recent years there has been a growing market for solid wood products to increase the economic returns, and an increasing interest on producing high quality materials from this species. Thermal modification technologies show potential to produce high quality material and have been used for other eucalypt species. Temperatures vary between 150 and $240^{\circ} \mathrm{C}$ and the limitation of oxygen content in the process is the most common feature of the thermal modifications currently available on the market. Main differences are the shielding gases used (steam or nitrogen for example) and the pressure applied to open or closed processes. Open processes work under atmospheric pressure, mostly use superheated steam, and are considered "dry processes", as the wood moisture content (MC) decreases considerably during the process. Closed systems enable elevated pressure levels during the modification, which makes the modification process faster. They are considered "wet/moist processes", as the MC during the process is higher than in the closed system. The elevated MC, in conjunction with the accumulation of carboxylic acids in the wood, has been suggested as the main cause of the accelerated degradation of the wood during these processes. However, it still remains unclear if the properties of thermally modified wood from open and closed processes are significantly different. These differences need to be explored to avoid the use of thermally modified wood with properties that do not fit for specific products or applications.

To further understand the mechanism and the differences between these two types of modifications and to analyse the potential of $E$. nitens as thermally modified wood, the material was modified in a closed system under elevated pressure generated by steam and controlled relative humidity (30 and $100 \% \mathrm{RH}$ ) at temperatures between 150 and $170^{\circ} \mathrm{C}$, and in an open system with a standard thermal modification procedure under saturated steam between 160 and $230^{\circ} \mathrm{C}$. The chemical composition (hemicelluloses, cellulose, lignin, extractives, acetic acid, formic acid, total phenols, cellulose degree of polymerization and degree of crystallinity) was measured. Selected mechanical properties (modulus of elasticity (MOE), modulus of rupture (MOR), resistance to impact milling (RIM) and deflection and work in bending) were assessed and the influence of the chemical changes on these properties was analysed. Changes in wood anatomy during modification were examined and the reversible and irreversible effects of the hygroscopicity were investigated. All these properties were compared using the corrected mass 
loss (CML), which is the oven dry mass loss of extractive free wood, to analyse the differences/similarities between both thermal modification processes.

The chemical changes made it possible to differentiate between open and closed system modifications, as the strongest differences between the modifications were specifically the hemicelluloses (xyloses), acid content and cellulose degree of polymerization. Even if the mechanical and anatomical properties showed no significant differences between the open and closed processes, MOR showed a strong correlation with those chemical changes, influencing the deflection and work in bending. These differences could be clearly be seen when comparing open and closed system modifications with similar CML. The differences between open and closed systems were also noticeable in the reversible changes in equilibrium moisture content (EMC) and volumetric swelling $\left(\mathrm{S}_{\max }\right)$ after continuous water soaking cycles. These cycles partially lessened the reduction in EMC and $S_{\max }$ after the modification processes. This is related in the open system modification to the removal of the drying related effects of amorphous polymers, while the removal of the cell wall bulking effect was the main effect in the closed system modifications at high RH. These effects also influence the mechanical and chemical properties of the modified wood.

It was shown in an experimental run that thermally modified E. nitens wood has the potential to be used for decking material, as it fulfils all the requirements regarding the surface hardness, anti-swelling efficiency (ASE), EMC, volumetric swelling, and abrasion resistance to be used as decking material. Overall, the results obtained in this study can be used as guidelines for the selection of the type of modification to be used for this species, which will depend on the desired properties of the final product and the quantity of material to be produced. 


\section{Zusammenfassung}

Eucalyptus nitens ist eine der wichtigsten schnell wachsenden Plantagenbaumarten in Chile. Sein Holz wird hauptsächlich für Zellstoff und Papier verwendet, seit einigen Jahren gibt es jedoch, durch ein steigendes Interesse an hochwertigen Produkten aus dieser Holzart, einen wachsenden Markt für Massivholzprodukte, wodurch finanzielle Erträge erhöht werden. Thermische Modifizierungstechnologien haben ihr Potenzial bei der Herstellung von qualitativ hochwertigem Material bereits unter Beweis gestellt und wurden schon für andere Eukalyptusarten (zum Beispiel Eucalyptus globulus) verwendet.

Temperaturen zwischen 150 und $240{ }^{\circ} \mathrm{C}$ und die Begrenzung des Sauerstoffgehalts im Prozess sind die Charakteristika der thermischen Modifizierungen, die aktuell auf dem Markt verfügbar sind. Die Prozesse unterscheiden sich durch die verwendeten Arbeitsgase (zum Beispiel Wasserdampf oder Stickstoff) und den Druck, der in offenen oder geschlossenen Prozessen herrscht. Offene Verfahren arbeiten unter Atmosphärendruck und verwenden häufig überhitzten Wasserdampf. Diese Verfahren gelten als „Trockenprozesse“, da die Holzfeuchte während des Prozesses stark abnimmt. Geschlossene Systeme arbeiten mit Überdruck während der Modifikation, wodurch die Modifikationsdauer reduziert wird. Sie gelten als „FeuchtProzesse", da die Holzfeuchte während und nach des Prozesses höher ist als beim offenen Prozessen. Die erhöhte Holzfeuchte bei die geschlossene Prozessen, in Verbindung mit der Akkumulation von Carbonsäuren im Holz, wird als Hauptursachen für die beschleunigte Degradation des Holzes angesehen. Es ist jedoch ungeklärt, ob sich Eigenschaften von thermisch modifiziertem Holz aus offenen und geschlossenen Prozessen signifikant unterscheiden. Diese Unterschiede sollen in der vorliegenden Arbeit untersucht werden, um eine den Eigenschaften entsprechende Verwendung und Anwendung von thermisch modifiziertem E. nitens Holz zukünftig zu gewährleisten.

Um die Mechanismen und die Unterschiede zwischen diesen beiden Modifizierungssystemen besser $\mathrm{zu}$ verstehen, und das Potential von E. nitens als thermisch modifiziertes Holz zu analysieren, wurde das Material in einem geschlossenen und einem offenen System modifiziert. Beim geschlossenen Verfahren fand die Modifizierung unter hohem Druck, der durch Dampf erzeugt wurde, kontrollierter relativer Feuchtigkeit (30 und $100 \%$ RH), und bei Temperaturen zwischen 150 und $170{ }^{\circ} \mathrm{C}$ statt; im offenen System erfolgte sie unter Sattdampf zwischen 160 und $230{ }^{\circ} \mathrm{C}$. Die chemische Zusammensetzung (Hemicellulosen, Cellulose, Lignin, 
Extraktstoffe, Essigsäure, Ameisensäure, Phenole, Polymerisationsgrad der Cellulose und Kristallinitätsgrad) wurden analysiert. Ausgewählte mechanische Eigenschaften (Elastizitätsmodul (MOE), Biegefestigkeit (MOR), strukturelle Integrität und Durchbiegung und Biegearbeit) wurden bestimmt und der Einfluss chemischer Veränderungen auf diese Eigenschaften diskutiert. Veränderungen in der Holzanatomie nach der Modifikation wurden untersucht und die reversiblen und irreversiblen Effekte auf die Hygroskopizität näher betrachtet. Die so für beide Modifizierungsprozesse erhaltenen Materialkennwerte wurden unter Verwendung des korrigierten Massenverlusts (CML), der dem Masseverlust von extraktfreien Holz entspricht, verglichen.

Chemischen Veränderungen zeigten am deutlichsten den Unterschied zwischen dem offenen und geschlossenen Prozess. Die Hemicellulosen (z.B. Xylose), der Säuregehalt und der Polymerisationsgrad der Cellulose unterschieden sich am stärksten. Auch wenn die mechanischen und anatomischen Eigenschaften keine signifikanten Unterschiede zwischen den beiden Systemen aufwiesen, zeigte der Elastizitätsmodul eine Korrelation mit den chemischen Veränderungen, was die Durchbiegung und Biegearbeit beeinflusst und auf ein spröderes Holz nach Modifizierung im geschlossenen System hindeutet. Diese Unterschiede waren beim Vergleich offener und geschlossener Systemmodifikationen mit ähnlicher CML deutlich zu erkennen. Auch bei den reversiblen Änderungen der Gleichgewichtsfeuchte (EMC) und der volumetrischen Quellung $\left(\mathrm{S}_{\max }\right)$ nach Wassersättigung und Trockungszyklen zeigten sich Unterschiede. Diese Zyklen verringerten teilweise den Einfluss der Modifizierung auf die EMC und $S_{\max }$. Dies ist im offenen System bedingt durch die Entfernung der trocknungsbedingten Effekte von amorphen Polymeren, und beim geschlossenen Systen durch die Beseitigung des Zellwandfülleffekts bei hohem Druck. Die beschriebenen Effekte beeinflussen auch die mechanischen und chemischen Eigenschaften des modifizierten Holzes.

Weiterhin wurde gezeigt, dass thermisch modifiziertes Holz von E. nitens das Potenzial hat, für Terrassendielen verwendet zu werden. Die Ergebnisse zeigten, dass dieses Material alle Anforderungen hinsichtlich Oberflächenhärte, Anti-Schwellungseffizienz (ASE), Gleichgewichtsfeuchtigkeitsgehalt, Volumenquellung und Abriebfestigkeit erfüllt. Es lässt sich somit sagen, dass sich die in dieser Studie erhaltenen Ergebnisse als Richtlinien für die Auswahl des Modifizierungssystems benutzen lassen, die von den gewünschten Eigenschaften des Endprodukts und der Menge des herzustellenden Materials abhängt. 


\section{Table of Contents}

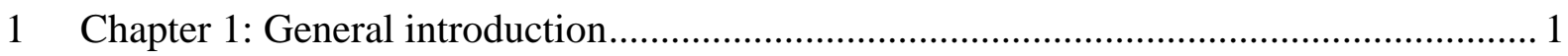

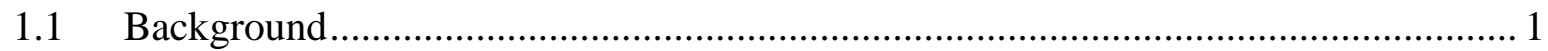

1.2 State of the art

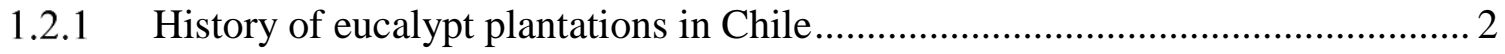

1.2.2 Use of E. nitens plantations in Chile .......................................................... 3

1.2.3 Challenges with the use of E.nitens solid wood ........................................... 5

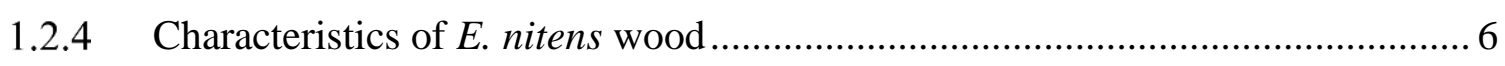

1.2.5 Current E nitens market........................................................................ 7

1.2.6 Chemical modification treatments............................................................ 9

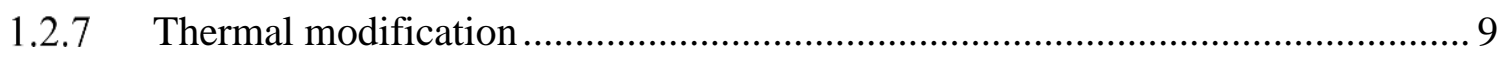

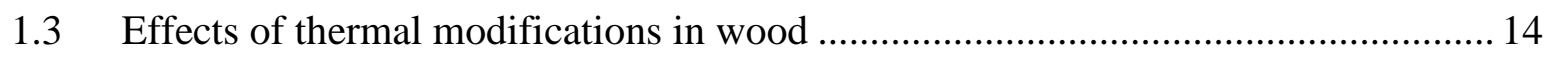

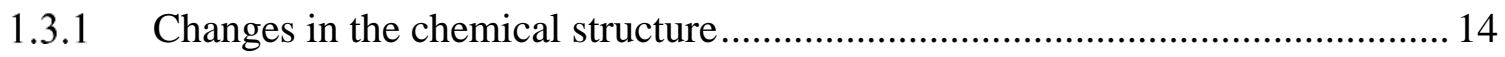

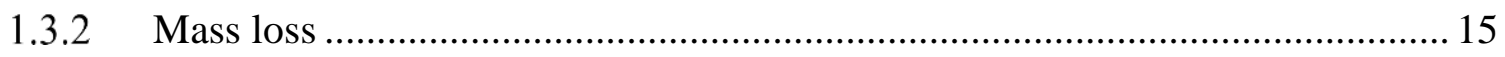

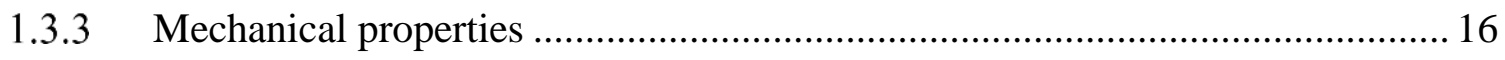

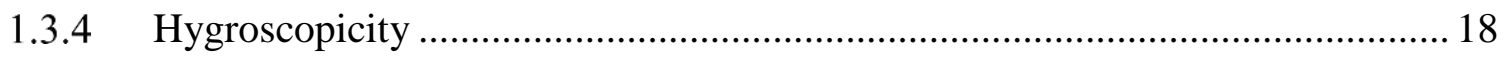

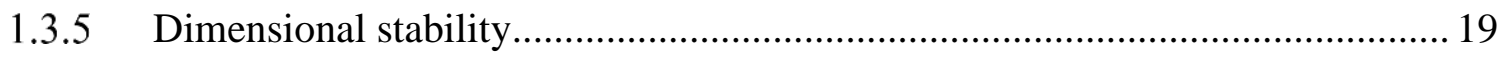

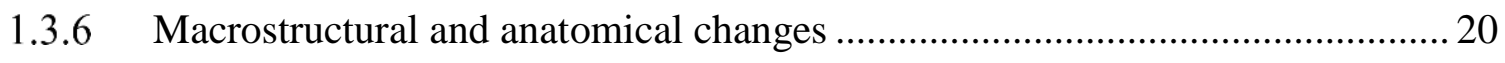

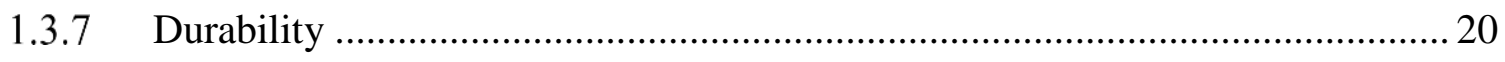

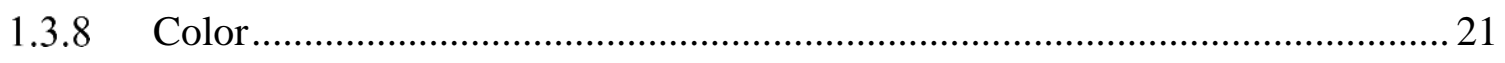

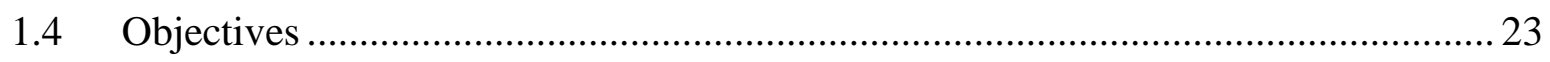

1.5 List of publications in peer-reviewed journals ................................................ 24

1.6 Other publications on thermal wood modification ........................................... 25

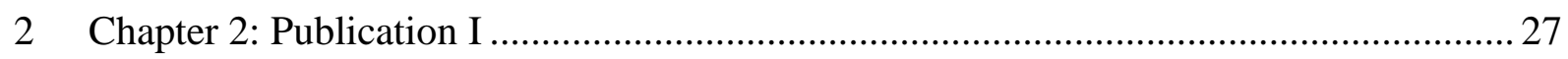

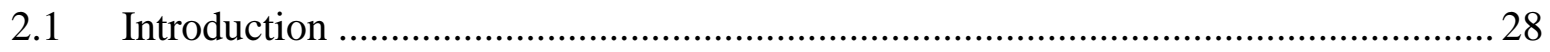

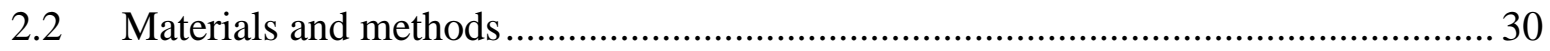

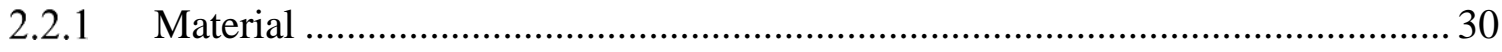




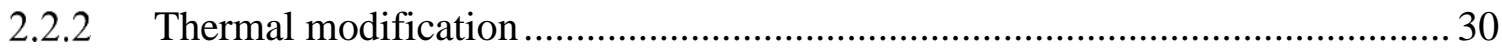

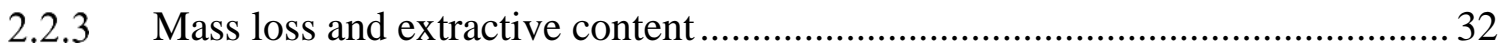

2.2.4 Determination of acetic and formic acid by HPLC .......................................... 33

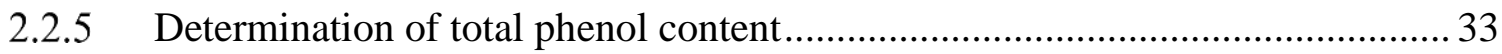

2.2.6 Determination of structural polymers...................................................... 34

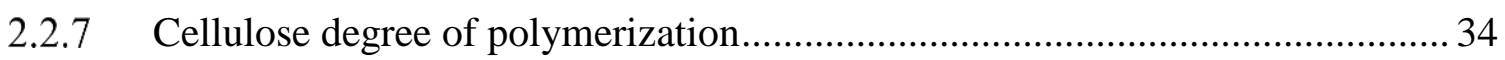

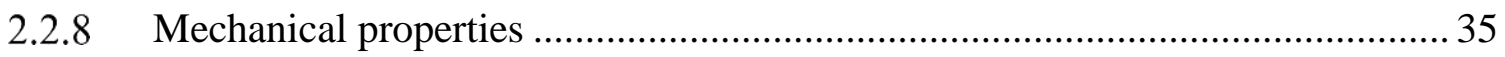

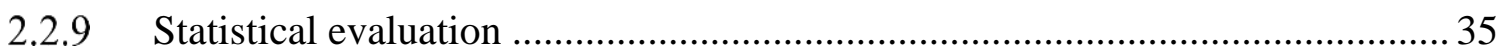

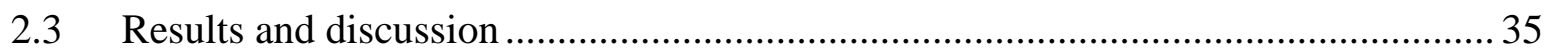

2.3.1 Chemical composition and mass loss changes .............................................. 35

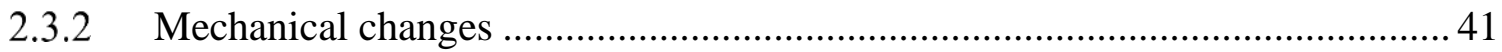

2.3.3 Correlation between chemical and mechanical changes ................................. 42

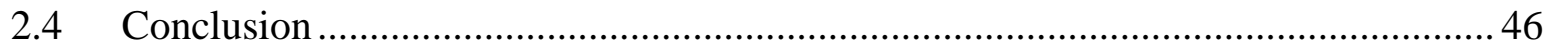

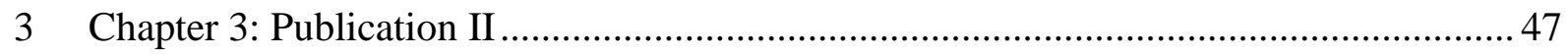

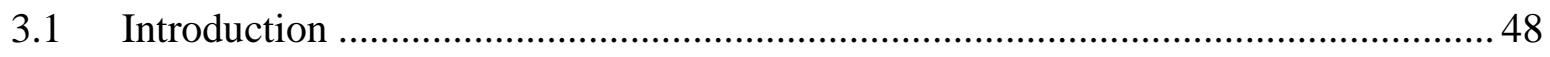

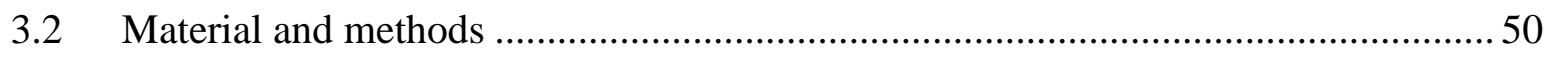

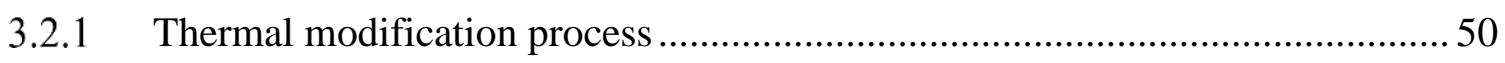

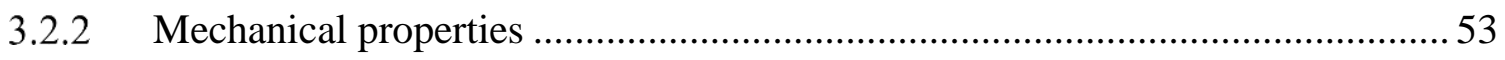

3.2.3 High-Energy Multiple Impact test (HEMI) ................................................. 55

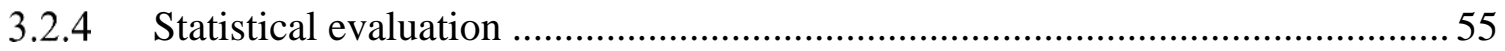

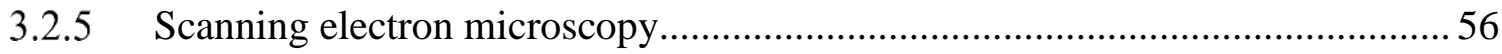

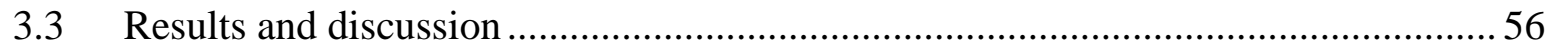

3.3.1 Static and dynamic mechanical properties ................................................ 56

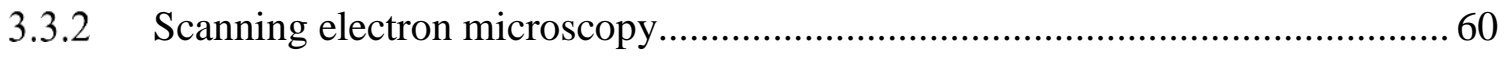

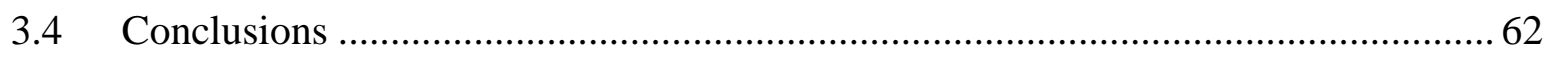

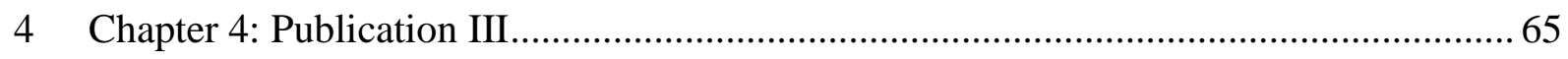

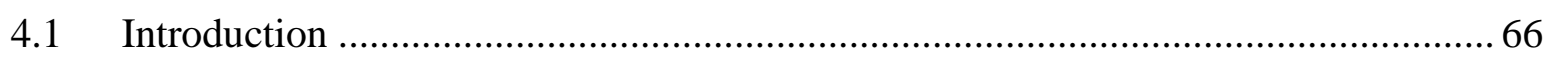

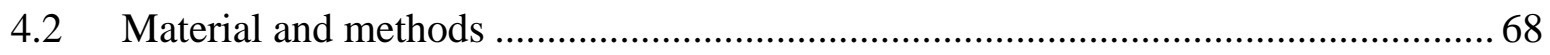




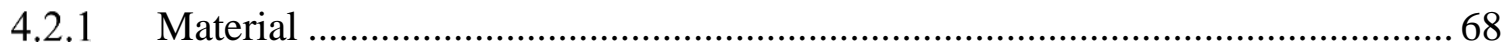

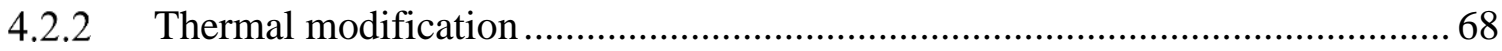

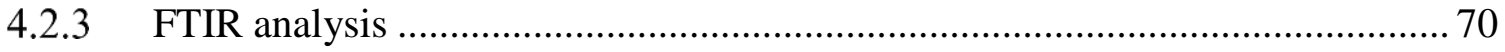

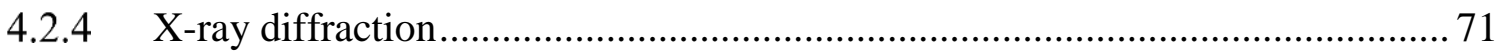

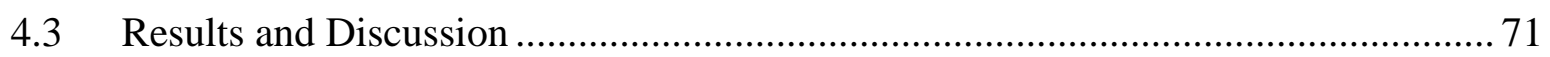

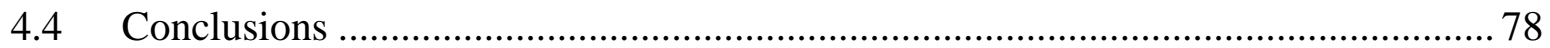

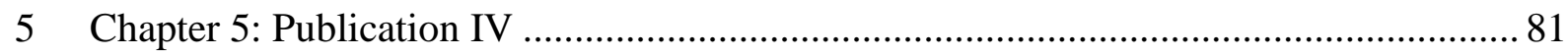

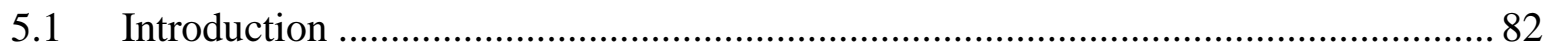

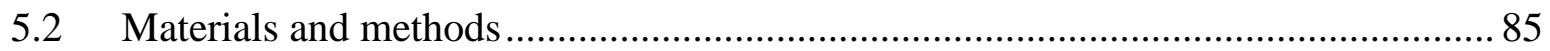

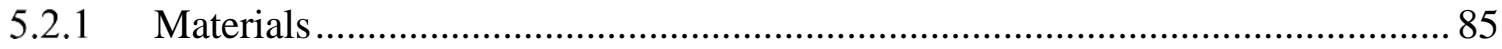

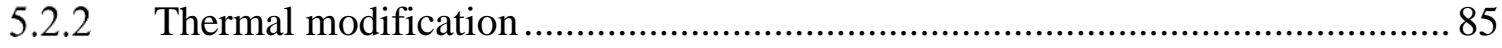

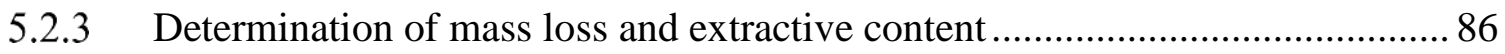

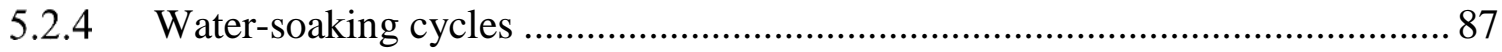

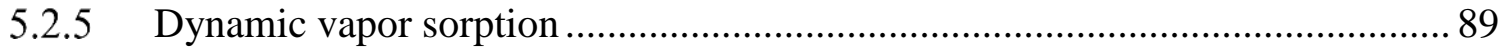

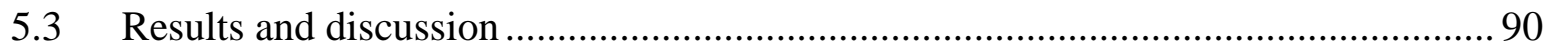

5.3.1 Changes in mass, moisture and extractive content by thermal modification ..... 90

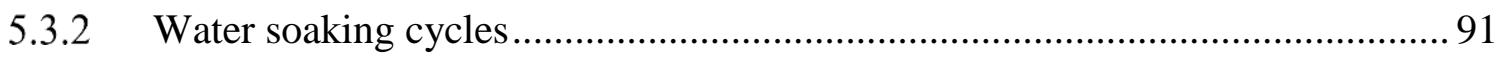

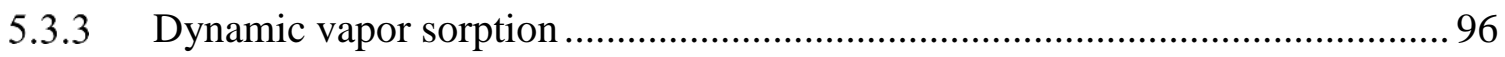

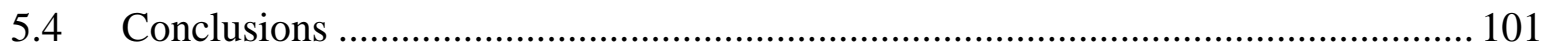

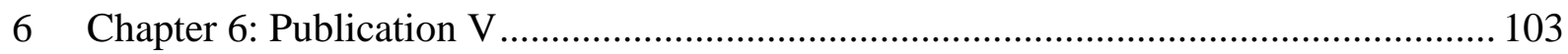

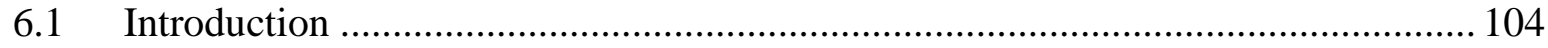

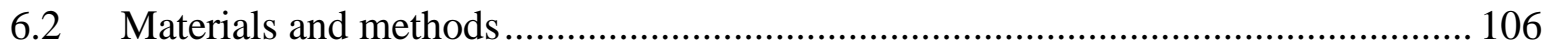

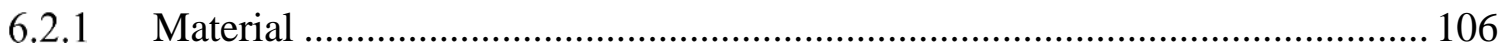

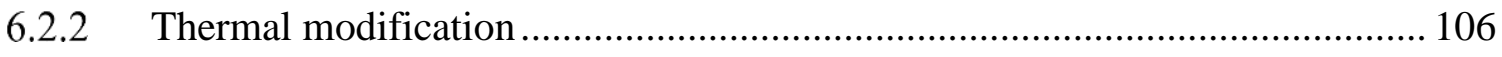

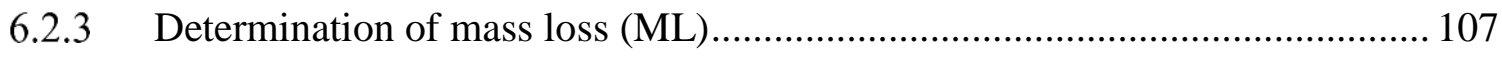

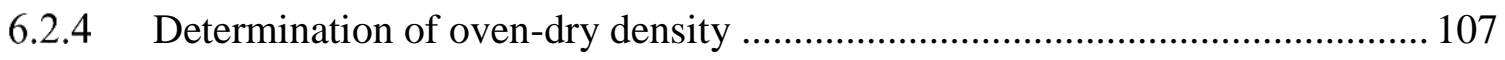

6.2.5 Determination of equilibrium moisture content (EMC), volumetric swelling

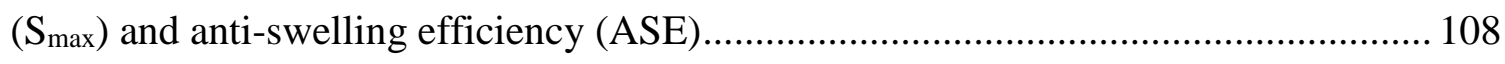




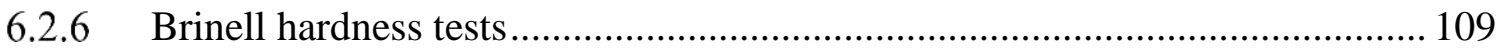

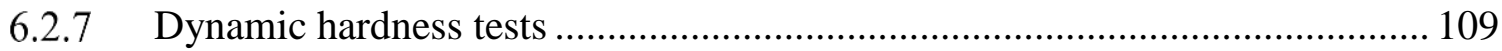

6.2.8 Resistance to abrasion: Shaker test ............................................................ 109

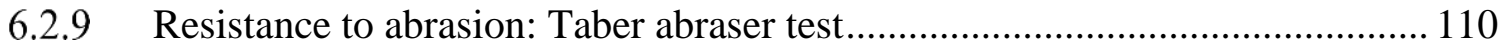

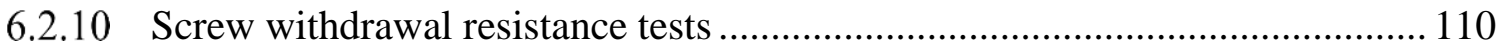

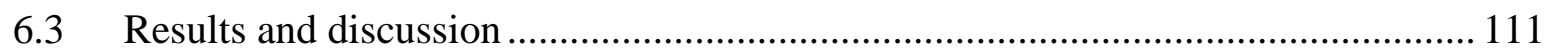

6.3.1 Changes in mass, oven dry density, EMC, swelling and ASE by thermal modification

6.3.2 Changes in hardness, abrasion and screw withdrawal by thermal modification....

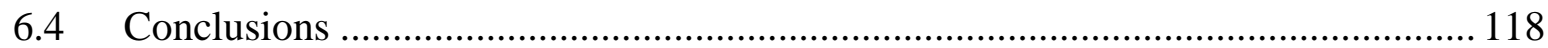

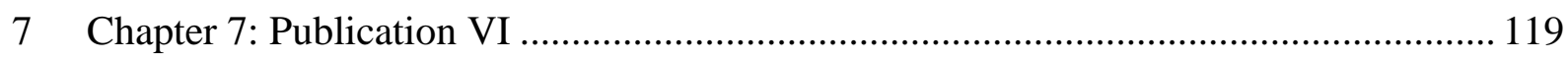

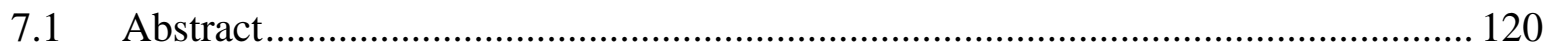

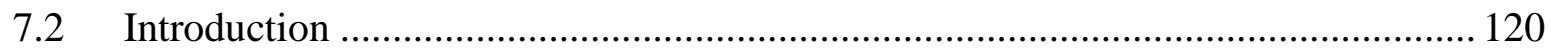

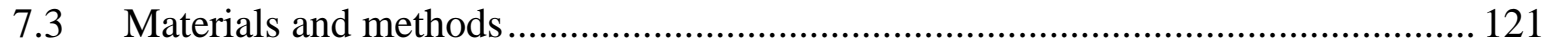

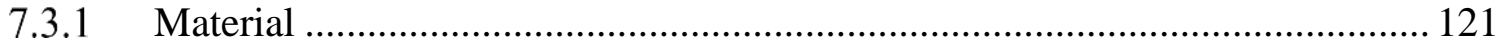

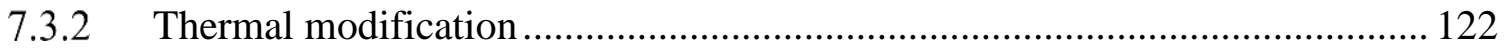

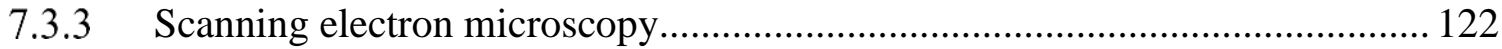

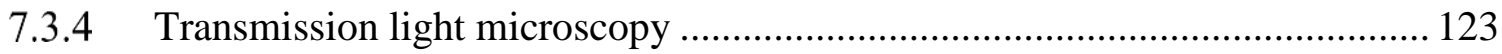

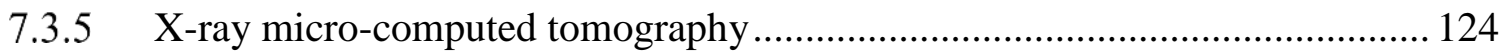

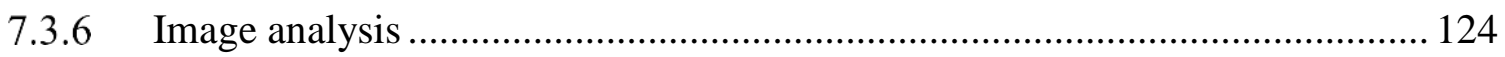

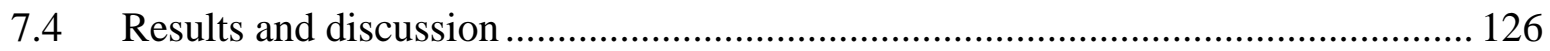

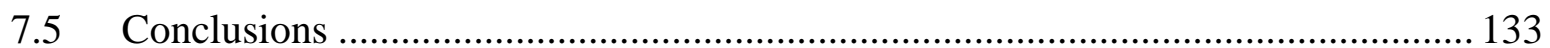

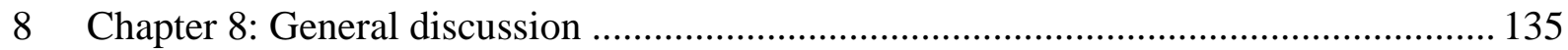

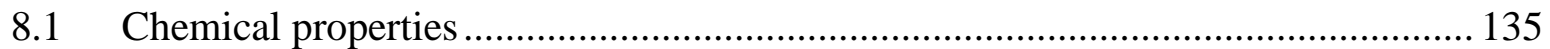

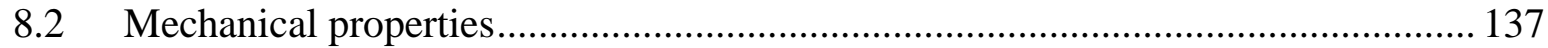

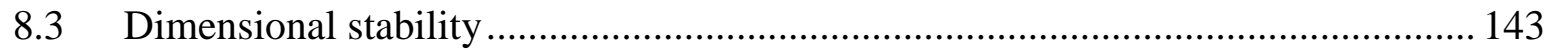

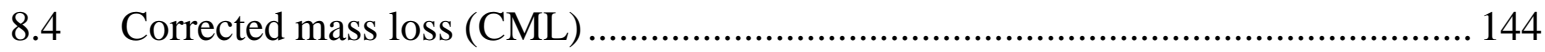




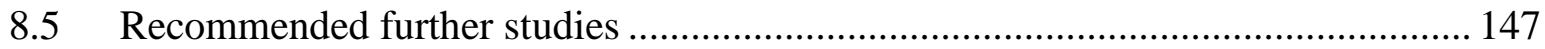

8.6 Potential of thermally modified E. nitens for the Chilean market......................... 148

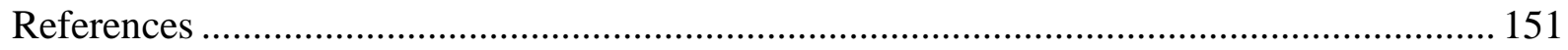

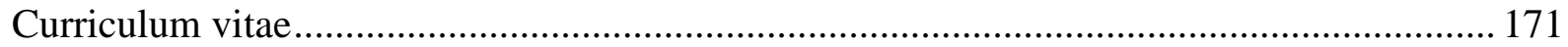





\section{Chapter 1: General introduction}

\subsection{Background}

There is interest in Chile to widen the use of solid wood products, especially from fast growing plantation species such as Eucalyptus nitens (Shining Gum), which is a species with great adaptability to the climate conditions in the southern part of the country. The plantation of this species has grown in importance in recent years due to its excellent growth rates, positioning it into the second fastest growing species in Chile, after Pinus radiata, and better cold and frost resistance than Eucalyptus globulus (Blue Gum), the most used hardwood plantation species (INFOR 2014). For the time being, most of the plantations are used for the production of wood for cellulose, but there is an increasing amount of plantations of this species being planted, which means that there will be more raw material available in the coming years. Some of the plantations aim to be used for solid wood products by seeking to produce logs that are free of knots, known as clear wood. This opens the possibility to study the potential uses of this material as a viable alternative to the most used wood species in Chile ( $P$. radiata).

Currently, there are still some drawbacks regarding solid wood from E. nitens, such as low dimensional stability, variation in color and relatively low resistance against microorganisms, which could potentially limit its use for solid wood products. That is why thermal modification is a possible good alternative to solve some of these drawbacks and to add value to the wood, as it can be used as an alternative to natural wood for decking, façade cladding, window scantlings, garden furniture, fences, poles, flooring and paneling (Scheiding 2018).

Thermal modification has been used as a commercially viable technology for over two decades. There are several different types of processes, with temperature ranging between $160^{\circ}$ and $240^{\circ} \mathrm{C}$. They can be differentiated by the operating conditions, either steam, vacuum, nitrogen or other conditions that limit the presence of oxygen and can be separated in open systems, under atmospheric pressure, or closed systems, processes under pressure or vacuum to name a few (Militz and Altgen 2014). The changes that occur due to thermal modification are gradual and depend on the process conditions. In general, there is a decrease in mass, swelling, equilibrium moisture content (EMC), mechanical properties and an increase in durability (Hill 2006). However, it remains unclear whether the properties of thermally modified wood from open and closed systems differ significantly. Currently, there are no general quality control 
systems for thermally modified wood products that are available on the market (Willems et al. $2015 b$ ), thus there is a need to analyze the differences between modifications to avoid the use of thermally modified wood with properties that are inappropriate for a specific use or product.

\subsection{State of the art}

\subsubsection{History of eucalypt plantations in Chile}

In Chile, plantations are producing almost all the wood needed for industrial purposes, covering the national market and the exportations. Thanks to this, the use of native forest has been strictly limited and regulated, so that it can regrow under a recovery and management program. Plantations in Chile are composed of fast growing species, mainly $P$. radiata, a species that originates from California, USA. It was introduced by the end of the $19^{\text {th }}$ century, but the big boom of plantations started in the mid-sixties. As of 2014, there are 1.4 million hectares plantations of this species. The second species of importance is E. globulus, originally from southern Australia and also introduced in the late $19^{\text {th }}$ century. It was used for firewood and poles, until the amount of plantations started to grow in the eighties due to its potential as material for pulp and paper. Nowadays, there are about 570,000 hectares planted. The third species of importance is E. nitens, also originally from southern Australia and introduced in the sixties by the Instituto Forestal (INFOR), which is part of the Agriculture Ministry of the Chilean government, as part of program to introduce new species to repopulate large areas that were available for afforestation. This species also started to grow exponentially in the eighties for the same uses as E. globulus. As of 2014, there are about 250,000 hectares plantations, which amounts to $10.5 \%$ of the total plantations in Chile, for an overall 840,000 hectares of eucalypt species, including smaller ones like E. regnans. As for the rest of the plantation species, there are about 200,000 hectares, covering Acacia, Atriplex, Populus, Pseudotsuga and other smaller eucalypt species (INFOR 2014; INFOR 2015).

There was an increase on the research of genetics in many eucalypt species in the late 1980s by intensifying the selection of seeds from species that maximize the use of the wood. This research was not only based on having better growth and higher volumetric yield, but a better response to low quality soils, scarce water availability and frost, and in terms of what products to obtain, a better pulp yield, solid wood and high quality veneer sheets (INFOR 2014). Preliminary tests in selected zones with low temperatures in southern Chile from the early 1970s to the mid-1980s showed that E. nitens, E. regnans and E. delegatensis had volumetric rates 
above $50 \mathrm{~m}^{3}$ per hectare per year, exceeding the volumetric rates of E. globulus and P. radiata, mostly due to the higher survival rate of those species to lower temperatures and frost (Prado et al. 1986). At the same time INFOR started trials incorporating the origin of the seeds, something that was previously not considered, due to the limited number of provenances which were available at the beginning of the program. Trials were established with several provenances for the most outstanding species and this later resulted in tests of complete collections of provenances of seeds in which progenies were also considered. This gave rise to the genetic improvement programs that started in 1991, establishing the bases for the genetic improvement of eucalyptus in the country (Infante et al. 1991). Since then, the eucalyptus trees have strongly increased their participation in forest plantations from about 33,000 in 1980 to the current 840,000 hectares in 2014, mostly E. globulus and E. nitens (INFOR 2015).

The recent increase of E. nitens plantations is a good example of the incorporation of a species to zones with low temperatures for repopulation, replacing the species that were normally used (E. globulus). Besides the excellent growth, E. nitens presents higher cold resistance than the E. globulus. Even with a lower density, this is compensated with a greater growth. Thanks to those qualities, it has reached the third most planted species in Chile (INFOR 2014; INFOR 2015).

\subsubsection{Use of $\boldsymbol{E}$. nitens plantations in Chile}

Today, most of the eucalypt plantations are set up for short rotations, between 11 and 16 years, and mostly for pulpwood production. In comparison of the initial tests, these plantations have growing rates that vary between 13 to $26 \mathrm{~m}^{3}$ per hectare and 14 to $37 \mathrm{~m}^{3}$ per hectare for E. globulus and E. nitens respectively (Cabrera et al. 2013).

For other products, such as sawlogs and veneers, trials have been done, testing the intensity of pruning and thinning, with some plantations presenting growing rates up to $48 \mathrm{~m}^{3}$ per hectare and year. This kind of plantations have been multiplying over the years, as the market started to require high quality wood and greater economic returns from eucalypt plantations (Muñoz et al. 2005). The age of the plantations (as of 2015) are in its majority under 10 years (Figure 1.1), that is because most of the interest of E. nitens plantations was for pulp and paper, but in the future the plantations will tend to be used for solid wood (Muñoz et al. 2005), so there is a huge market potential in the following years for this wood species. The last couple of years a 
percentage of the E. nitens plantations has been managed with the objective to obtain high quality solid wood products, generating logs that are free of knots (clear wood), taking advantage of the excellent growth and large diameter that this species can achieve in short term rotations, shorter than the ones required by radiata pine. This leads to a great potential of the species to produce in relatively short rotations (between 15 and 19 years), so that it is possible to obtain, from the same tree, logs for sawn wood, pulp and plywood (Valencia and Cabrera 2007). At the moment INFOR estimates that 18,000 hectares of $E$. nitens show a certain degree of management for high quality logs (INFOR 2014).

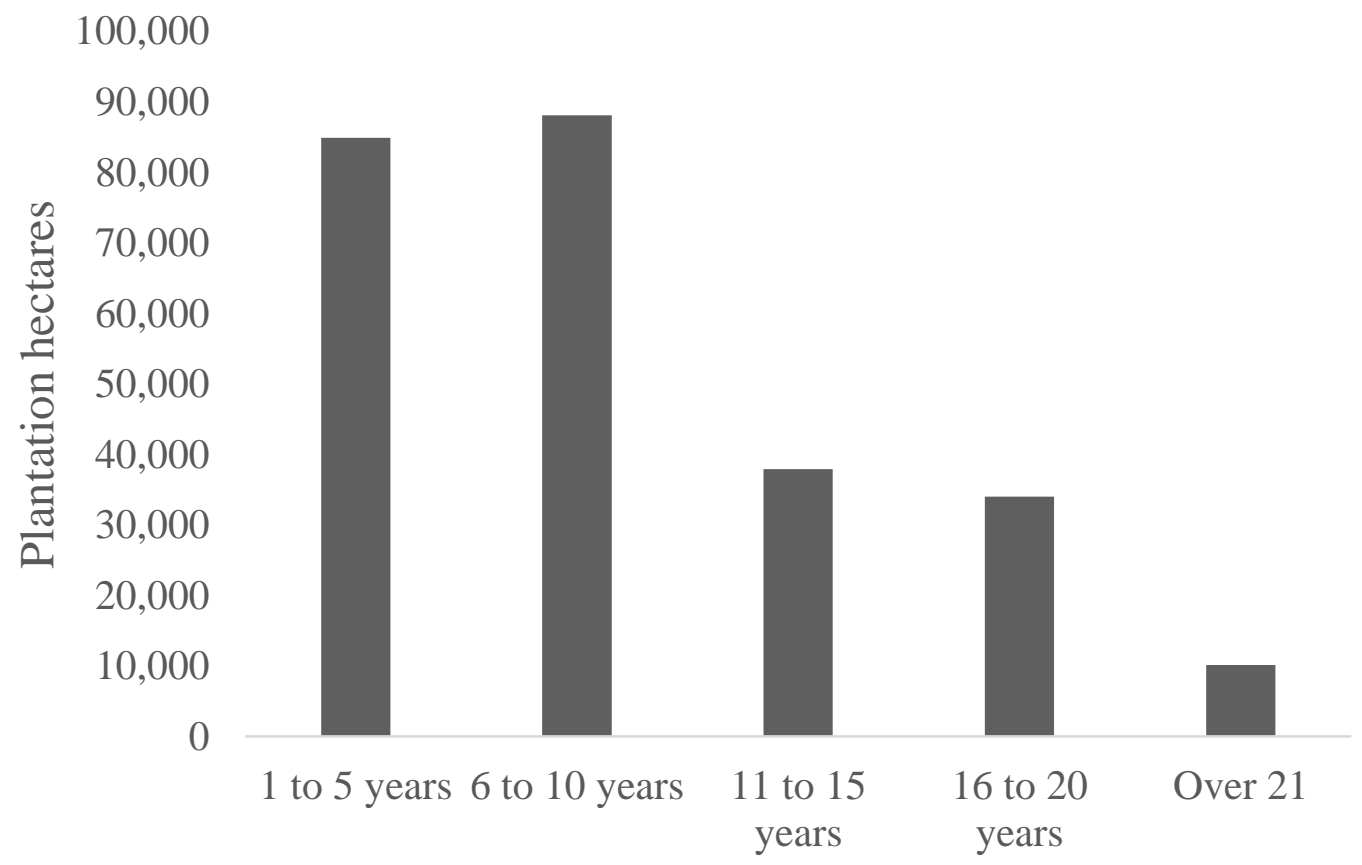

Figure 1.1: Age and hectares of E. nitens plantations in Chile as of 2014 (INFOR 2015).

Most of the wood from the plantation eucalypts is used for pulp (Table 1.1), about $58 \%$ of the total consumption. Wood chips are also very important, as they represent about $39 \%$ of the use of the wood, with $90 \%$ of the production exported. All the other products are still not so relevant, but there has been $46 \%$ increase in the quantity of sawn wood from 2014 to 2015 (INFOR 2015), which is a positive tendency for the market and shows that there is an interest to use this eucalypt wood for high end products. 
Table 1.1: Consumption of eucalyptus wood in the Chilean industry in 2015.

\begin{tabular}{|c|c|}
\hline Product & Thousands of $\mathrm{m}^{3}$ \\
\hline Pulp & 6,996 \\
\hline Sawnwood & 26 \\
\hline Panels and veneers & 278 \\
\hline Sawlogs for exports & 21 \\
\hline Wood chips & 4,772 \\
\hline Posts and poles & 3 \\
\hline
\end{tabular}

Oriented strand board (OSB) is one of the main uses for the wood chips, but most of it is exported to cellulose plants in Asia. In some cases, E.nitens wood is used in plywood, as it has advantages over other species, thanks to the large diameter pieces free of knots. They are mostly mixed with $P$. radiata, but there were also test with $100 \%$ E. nitens panels (Poblete and Burgos 2010). There is also big demand for fire wood, as the availability of this species is higher than the most common native species usually used, the proximity of plantations to distribution centers and the price. As for the sawn wood, the production is mostly used for furniture, decking and flooring.

\subsubsection{Challenges with the use of E.nitens solid wood}

The rate of use of a plantation E. nitens logs for solid wood depends on the following aspects: those associated with the formation of longitudinal splitting and torsions, which happen because of the growth stresses in the wood, and those associated with aspects of dimensional stability (contractions, internal collapse and cracks), which are mostly caused by differences in the speed of drying (moisture differences in the pieces of wood), generally appearing when the drying process is too fast. These drawbacks are related with various wood characteristics, decreasing the rate of use of the logs. The growth stresses are related to tension wood happening in the stem periphery in eucalypt species (Washusen et al. 2003), causing log splitting and excessive distortion, which in turn causes very poor sawing accuracy and further board splitting. Tension wood in form of bands also causes collapse and variable transverse and longitudinal shrinkage during drying (Touza Vázquez 2001; Washusen 2009), reducing the recovery and value of dried sawn products.

For the production of high quality logs, harvesting is the first step to obtain the desired product. The biggest challenge is the degree of growth tension of the tree, which is manifested in cracks at the ends of the log. The magnitude of the cracks can disqualify the log for solid wood 
production, so a proper management of the tree in the plantation is very important to minimize the crack formation. To process the logs that have cracks at the ends, the orientation of the cuts in the sawmill have to be selected according to the cracks, limiting the possible final products that could be obtained from the log. There are also models to avoid other drawbacks, like the growth tension, but they require slower sawn times, as the cuts have to be applied separately for each log to decrease the levels of tension (Touza Vázquez 2001).

The drying of E. nitens wood is a very complex process. At industrial level, air pre-drying is carried out for two to three months, depending on the atmospheric conditions of the area. Afterwards, a pre-drying process in the drying chamber is needed, then, the wood is reconditioned and then the final drying process can start. This complexity of the drying process has limited the use of this species to obtain solid wood products for smaller industries, because the process has to be slow, with low gradients of moisture loss, which also translates into a longer processing time than that required by radiata pine, the most used material in Chilean sawmills. The drying process is characterized by a rapid loss of water contained in the surface of the wood, which generates high moisture gradients, surface shrinkage and drying stresses that in turn cause surface and internal cracks that disqualifies the product for certain uses. However, when doing a proper classification of the wood, separating lateral and central tables, applying drying protocols of low gradients suitable for the species, and constantly monitoring this process, it is possible to obtain good material at the end of the process (INFOR 2014).

In summary, there are some technical challenges for obtaining good quality solid wood out of E. nitens plantations, but in the last couple of years there has been a steady research to solve them, starting from the plantations itself and their management to how to properly dry the wood avoiding the inherent characteristics of a relatively young tree.

\subsubsection{Characteristics of $\boldsymbol{E}$. nitens wood}

The dry solid wood presents the following characteristics: Brownish yellow to almost white in some cases (Figure 1.2) and a notorious growth ring (Paz and Pérez 1999). It presents a low natural durability in ground contact, classified as class IV as per the Australian Standard 56042005 (2005) (standard still in use in Chile for eucalypt species), which means that it has a low resistance to decay fungi and termite attacks. The basic density of plantation E. nitens is dependent of age, the site of the plantation and if the plantation management (pruning, thinning, 
final product objective). For example, plantations without any particular management: 460 $\mathrm{kg} / \mathrm{m}^{3}, 478 \mathrm{~kg} / \mathrm{m}^{3}$ and $554 \mathrm{~kg} / \mathrm{m}^{3}$ for 15,24 and 29 year old plantations respectively in Australia (Yang and Waugh 1996), $429 \mathrm{~kg} / \mathrm{m}^{3}, 433 \mathrm{~kg} / \mathrm{m}^{3}$ and $472 \mathrm{~kg} / \mathrm{m}^{3}$ for 7,10 and 13 year old plantations respectively in Chile (Peredo 1999). In general, the density of plantation E. nitens wood is lower than the other most used eucalypt plantations, E. globulus and E. grandis (INFOR 2014). It has to be noted that most of the general information of eucalypt species characteristics are derived from Australian publications, which are based on native trees, thus they tend to show higher values than what is presented by plantation wood, and are not recommended to be used when working with plantation wood.

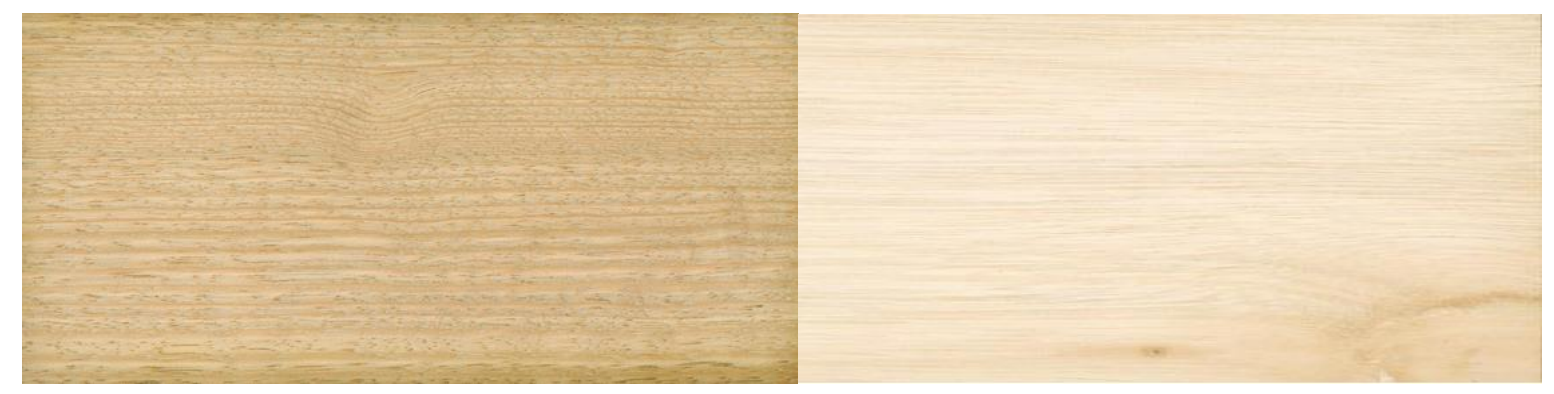

Figure 1.2: Color variations of E. nitens natural wood.

\subsubsection{Current $\boldsymbol{E}$ nitens market}

The current tendency in Chile shows that eucalypt plantations are increasing while $P$. radiata plantations have started to slightly decrease in the last couple of years (Figure 1.3). Long term invest in managed plantations destined for high quality logs for sawn timber could mean higher returns than in plantations destined for pulpwood. This also could bring benefits to smaller independent industries all over Chile (Valencia and Cabrera 2007). 


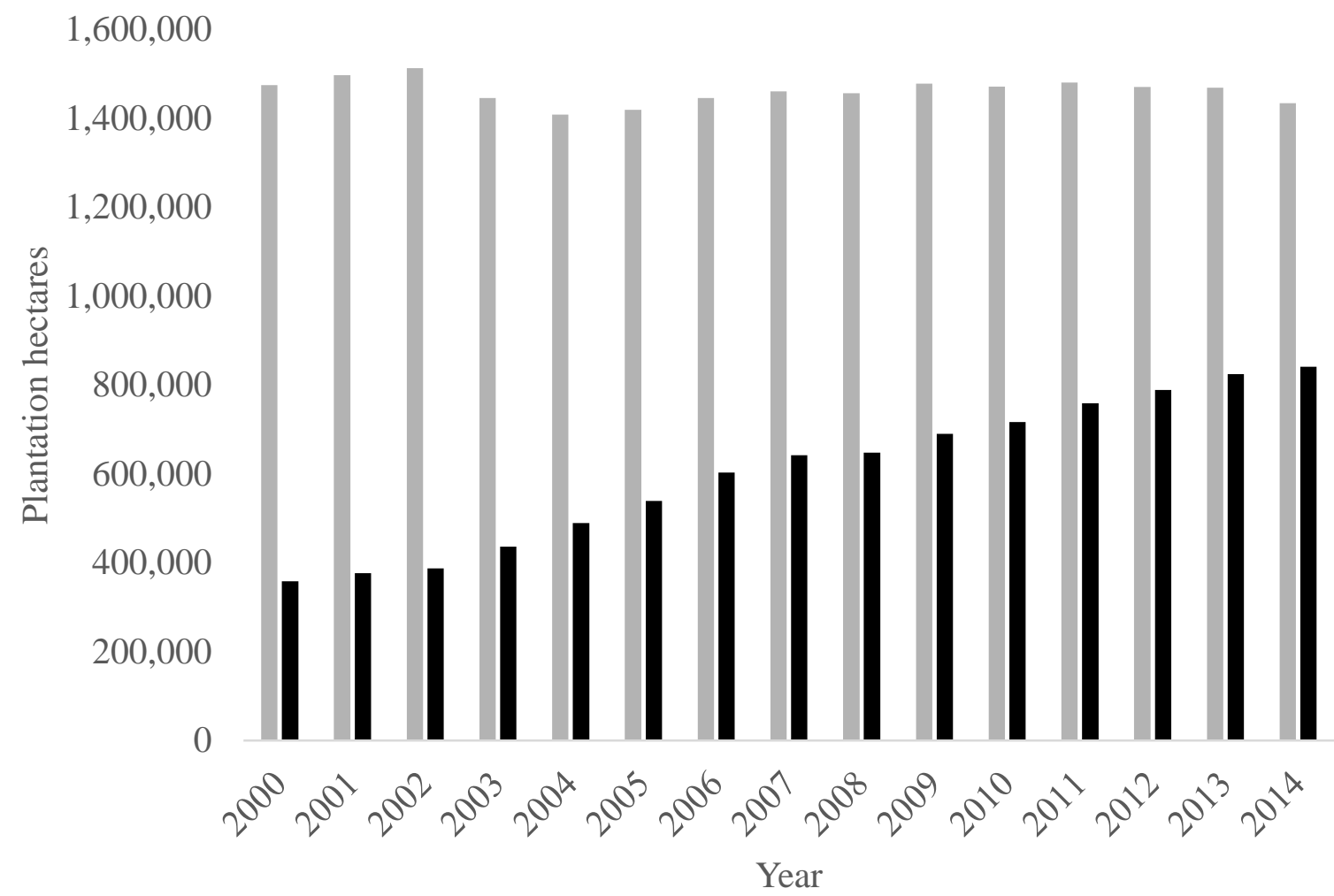

Figure 1.3: Plantations in hectares from the year 2000 to 2014. Grey, $P$. radiata, black, eucalypt species (INFOR 2015).

The domestic market prices for pulpwood logs in 2015 are about 26 US $\$$ for E. nitens and about 21 US\$ for $P$. radiata, but the $P$. radiata sawn logs cost about 46 US\$, more than double than pulpwood logs. There are no prices for sawn log out of eucalypt species, because there is still no market for it. Nonetheless, there are information about the nominal average export prices for E. nitens sawn wood, which is 225 US\$ free on board (FOB) $/ \mathrm{m}^{3}$, the same as radiata pine and lower than E. globulus (246 US\$ FOB/m³) (INFOR 2015). Even with the competitive price, there are currently difficulties to enter the national and international markets, because of some of the characteristics of the E. nitens wood (low dimensional stability, variation in color and durability) and the dominance of $P$. radiata as main raw material for almost all wood based products in Chile. This means that, for a better use of this wood species, the aim for future uses of this species should be used for alternative or high end products to open its own niche in the market. That is why is important to research for alternative uses of the material and ways to improve its characteristics. This can be achieved by wood modification, either chemical or thermal. 


\subsubsection{Chemical modification treatments}

Traditionally, biocides are used to impregnate the wood to increase the resistance against wood decay to extend the service life of the material. As an example, inorganic biocides, such as chromated copper arsenate (CCA), creosotes or ammonium based organic biocides, are used, as they are toxic for fungi, insects or a combination of both. The use of these chemicals can cause health and environmental related issues (Schultz and Nicholas 2008), as they have a tendency to leach from the treated wood when in service (Townsend et al. 2005). There are also difficulties related to how it has to be disposed after use (Voss and Willeitner 1993). The current tendency is to lower the use of these chemicals, so alternatives have been developed. One of those alternatives is the use of non-biocidal chemicals that aim to change the basic chemistry of the wood cell wall by penetrating it via impregnation, reacting when exposed to elevated temperatures during a curing step, and becoming immobilized inside the wood cell wall (Hill 2006). The acetylation of wood with acetic anhydride (Rowell 2014), or impregnation with furfuryl alcohol (furfurylation) (Lande et al. 2008), which are cell filling agents, or the use of N-methylol compounds, like 1,3-dimethylol-4,5-dihydroxyethyleneurea (DMDHEU), which penetrate the cell wood wall and reacts with the hydroxyl groups (Xie et al. 2014; Emmerich et al. 2017), are examples of these kinds of modifications. Due to the necessity for a full volume impregnation of these reactants to produce the modification, there are limitations of what kind of wood species to use. Eucalypt species tend to have a low permeability to liquids, as they tend to have permeable sapwood and impermeable heartwood due to tylosis formation and the occlusion of pores (da Silva et al. 2010), thus making eucalypt not particularly ideal for these kind of modifications. On the other hand, thermal wood modification requires no addition of chemicals, thus making it a more viable alternative.

\subsubsection{Thermal modification}

It has been known for a long time that elevated temperatures alter the properties of the wood, with experiments as far as hundred years ago (Tiemann 1915). The main effects are the changes in color (Tiemann 1917; Morita and Yamazumi 1987; Bekhta and Niemz 2003), reduction in hygroscopicity (Tiemann 1917; Seborg et al. 1953; Burmester 1975), an improved dimensional stability (Stamm and Hansen 1937; Burmester 1973; Giebeler 1983) and an elevated resistance against degradation but with a decrease in the mechanical strength (Stamm et al. 1946). The processes use treatment temperatures between $160^{\circ} \mathrm{C}$ and $240^{\circ} \mathrm{C}$, but under different operating 
conditions, either steam, vacuum, nitrogen or other elements that limit the presence of oxygen in the process (Esteves and Pereira 2009; Militz and Altgen 2014; Sandberg and Kutnar 2016). The current total annual production of thermally modified timber in Europe was estimated to be about 400,000 $\mathrm{m}^{3}$ (Scheiding 2018). Data for South America is not available, as currently there are not many industries working with this kind of modifications.

The types of thermal modifications that have been developed in the last decades can be seen in Table 1.2. The differences vary from the type of heat transfer; fluid contact means that the wood is in direct contact with the element that limits the presence of the oxygen, convective is the transfer of the heat by the movement of fluids or gases using heating plates or tubes made of steel, condensing is when steam is directly injected to the system and it is in contact with the wood during the heating process and plate contact is the direct contact of the wood to a heated plate, like the ones used to produce plywood. The reactor type used for thermal modification varies from a standard kiln used for drying but modified for the thermal modification, an immersion tank were the selected modification fluid and the wood are placed together for the modification, and an adapted autoclave, similar to the ones used for chemical modifications. The type of process can be separated into two groups: open systems, which work under atmospheric pressure, and closed system processes, such as processes using vacuum or steam pressure to control the atmosphere during the modification. The wood moisture state during process is also an important way to differentiate the modification processes, as it influences the properties of the material after the modification. There are processes were the wood is practically oven dry during the modification, where the wood is in a wet state or where it is in a moist state, with low moisture content during the modification. 


\begin{tabular}{|c|c|c|c|c|c|c|c|c|c|c|c|c|}
\hline \multicolumn{2}{|c|}{ 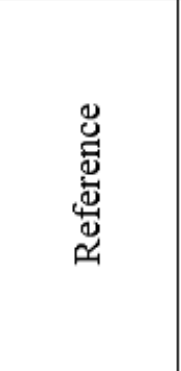 } & 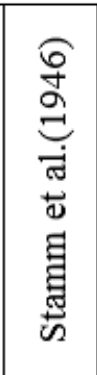 & 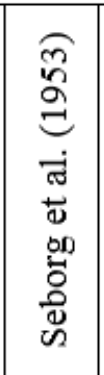 & 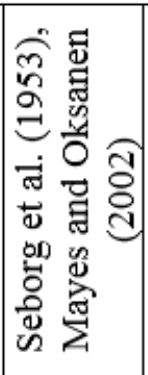 & 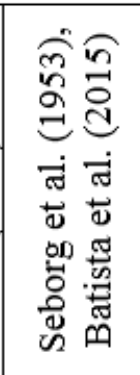 & 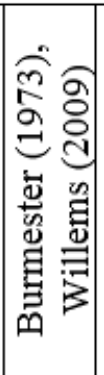 & 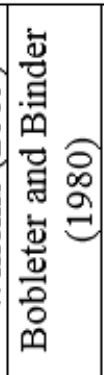 & 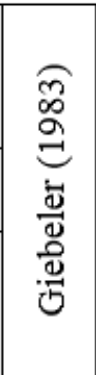 & 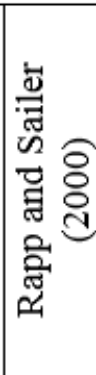 & 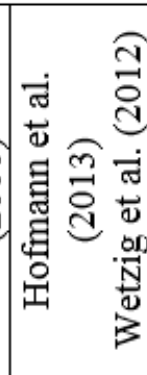 & 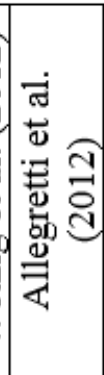 & 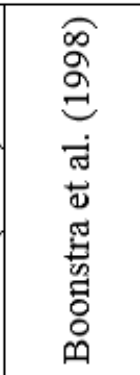 \\
\hline \multirow{2}{*}{ 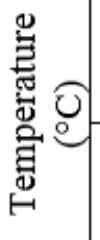 } & 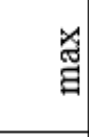 & $\stackrel{\circ}{\circ}$ & $\stackrel{\circ}{\circ}$ & শ્లి & $\stackrel{\circ}{\infty}$ & $\stackrel{\circ}{\infty}$ & $\stackrel{\infty}{\rightarrow}$ & $\stackrel{尺}{I}$ & ત્તે & 号 & స્తి & $\stackrel{n}{\infty}$ \\
\hline & 寻 & $\stackrel{0}{0}$ & $\stackrel{\text { ㄱ }}{\mathrm{N}}$ & $\stackrel{\infty}{-}$ & $\stackrel{\circ}{\circ}$ & $\stackrel{\circ}{\circ}$ & $\stackrel{\circ}{\circ}$ & & $\stackrel{\infty}{\infty}$ & 윽 & $\stackrel{\circ}{\circ}$ & $\stackrel{2}{0}$ \\
\hline \multirow{2}{*}{ 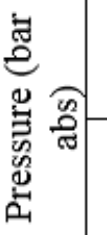 } & \multirow{2}{*}{ 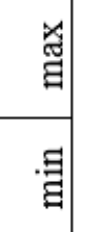 } & \multirow[b]{2}{*}{$\rightarrow$} & \multirow[b]{2}{*}{$\neg$} & \multirow[b]{2}{*}{-1} & 으 & $\infty$ & 윽 & \pm & \multirow[b]{2}{*}{-1} & \multirow{2}{*}{$\begin{array}{l}\infty \\
0 \\
0\end{array}$} & $\stackrel{m}{m}$ & $\infty$ \\
\hline & & & & & 0 & 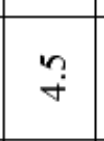 & 0 & $r$ & & & $\stackrel{0}{:}$ & \\
\hline \multicolumn{2}{|c|}{ 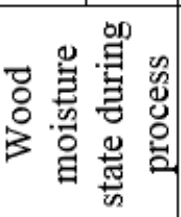 } & 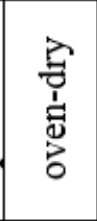 & $\begin{array}{l}\text { i⿱ } \\
\text { D } \\
\stackrel{1}{0} \\
0 \\
0\end{array}$ & 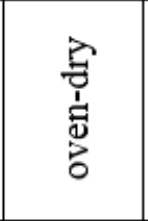 & 总 & 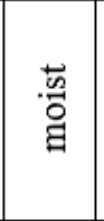 & 刕 & $\overrightarrow{\mathrm{D}}$ & $\begin{array}{l}\text { E⿱ } \\
\dot{1} \\
\dot{1} \\
0 \\
0\end{array}$ & 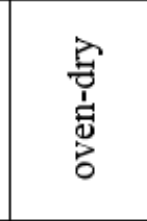 & $\begin{array}{l}\text { i⿱ } \\
\dot{i} \\
\stackrel{1}{0} \\
0\end{array}$ & 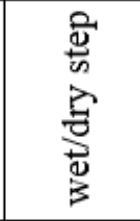 \\
\hline \multicolumn{2}{|c|}{ 况 } & 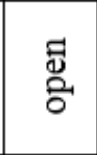 & $\begin{array}{l}\text { ఖี } \\
\text { 응 }\end{array}$ & 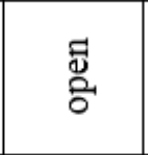 & 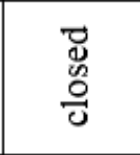 & 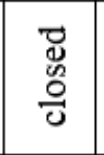 & 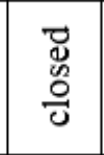 & 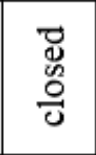 & $\begin{array}{l}\text { 苋 } \\
\text { ờ }\end{array}$ & 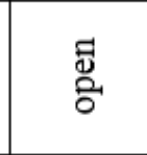 & 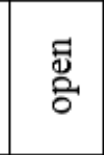 & 总 \\
\hline \multicolumn{2}{|c|}{ 壱 } & 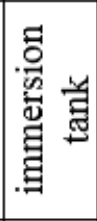 & 寻 & 表 & 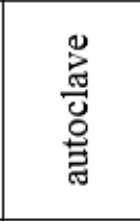 & 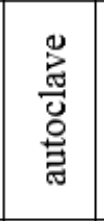 & 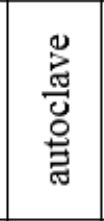 & 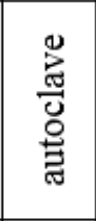 & 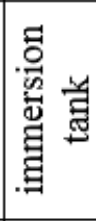 & 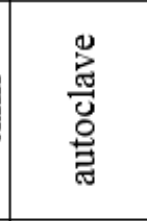 & 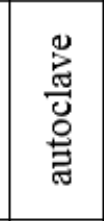 & 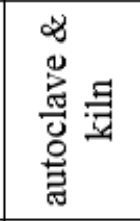 \\
\hline \multicolumn{2}{|c|}{ 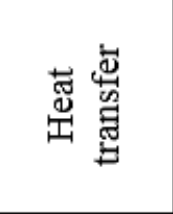 } & 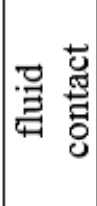 & 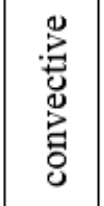 & 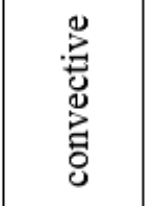 & 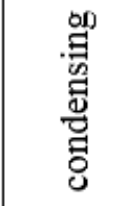 & 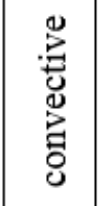 & 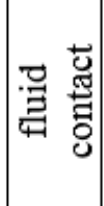 & 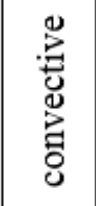 & 当 & 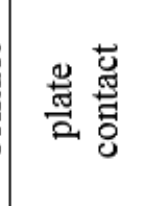 & 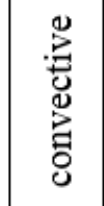 & 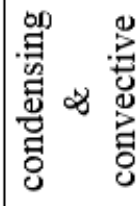 \\
\hline \multicolumn{2}{|c|}{ 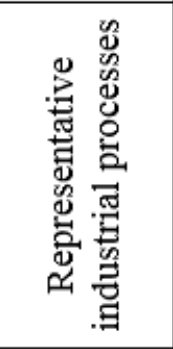 } & 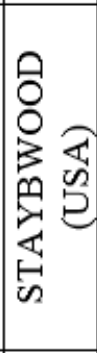 & 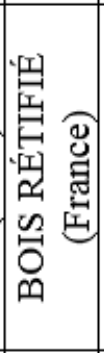 & 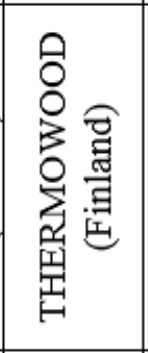 & 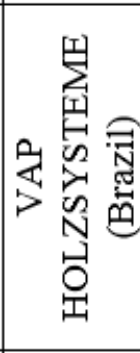 & 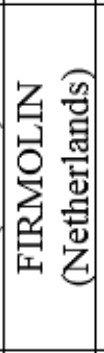 & & 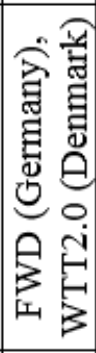 & 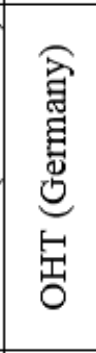 & 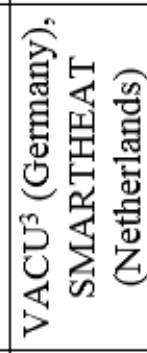 & 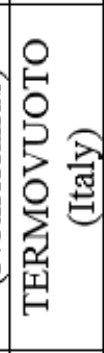 & 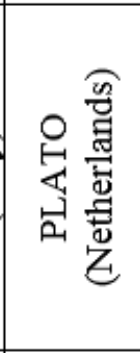 \\
\hline \multicolumn{2}{|c|}{ 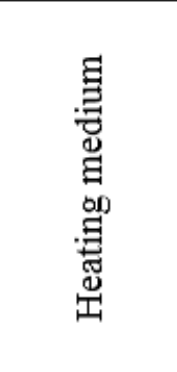 } & 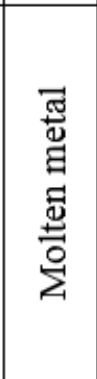 & 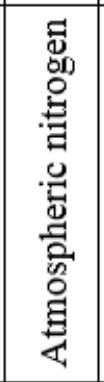 & 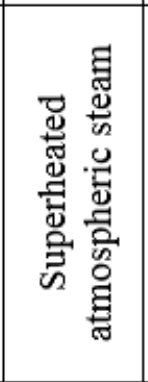 & 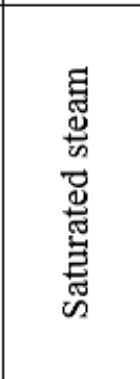 & 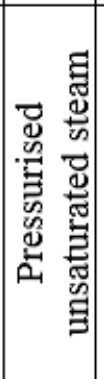 & 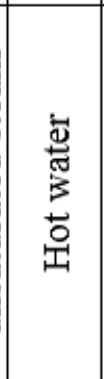 & 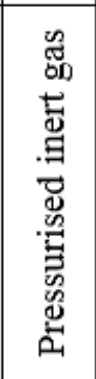 & 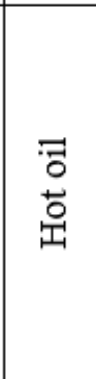 & 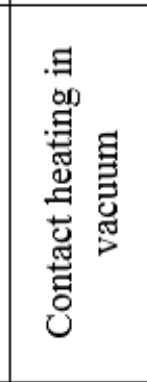 & 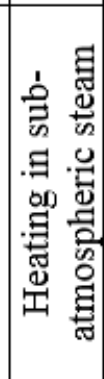 & 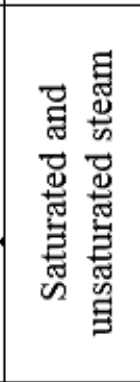 \\
\hline
\end{tabular}


A short introduction of a selection of commercially available processes:

ThermoWood: The most used and common thermal modification. This process is done under atmospheric pressure and steam as the heat transferring element. It is separated in three main phases. It can use green or kiln dried wood. The first phase consists of drying the wood at high temperature using heat and steam by rapidly raising the temperature to $100^{\circ} \mathrm{C}$ inside the kiln, and the slowly increasing it to $130^{\circ} \mathrm{C}$ to reduce the moisture content to about $0 \%$. The temperature inside the kiln is then increased between $185^{\circ} \mathrm{C}$ and $215^{\circ} \mathrm{C}$ for 2 or 3 hours (the temperature and time varies depending on the end product properties). The final phase consists of cooling the wood and to bring the moisture content up to 4 to $6 \%$ (Mayes and Oksanen 2002). The overheated steam atmosphere helps to prevent and avoid cracks while also inducing thermohydrolysis reactions.

FirmoLin: This process uses pre-dried wood and is performed in pressurized reactors, which allows to lower the treatment temperature and to shorten the production time. It has an active control on total pressure and the water vapor pressure as well. The process parameters of partial water vapor pressure and temperature of the reactor are set to a high relative humidity (high pressure) during hydrolysis in the first steps of the thermal treatment, and then gradually lower the relative humidity to allow the dehydration and cross-linking reactions (Boonstra et al. 1998) while also avoiding excessive drying. A process usually consists of four steps, a pre-vacuum process to assist reaching the desired pressure, following with a temperature increase between 10 to $12^{\circ} \mathrm{C}$ per hour until peak temperature is reached (between 150 to $180^{\circ} \mathrm{C}$ ). Finally, a holding step at the peak temperature for 2 to 3 hours, finishing with and cooling down step decreasing the temperature between 15 to $20^{\circ} \mathrm{C}$ per hour until it reaches $65^{\circ} \mathrm{C}$ (Willems 2009).

Wood Treatment Technology (WTT): This process uses pre-dried wood and is carried out in a pressurized autoclave cylinder of stainless steel to have a high energy and heat transfer system. The heat used in the process is produced by a gas- or oil-fired boiler that heats thermal oil. This is used as heat transfer medium for both the heating and the cooling phase, where the heat is ejected in a dry cooler. It can reach a pressure between 7 and 10 bar and the modification temperature can be set between $160^{\circ} \mathrm{C}$ to $210^{\circ} \mathrm{C}$ (Dagbro et al. 2010).

TERMOVUOTO: The process uses a reconstructed conventional vacuum kiln that can reach temperatures up to $250^{\circ} \mathrm{C}$. It is heated up with diathermic oil that circulates between the double 
layered steel of the kiln. When in vacuum, the heat is distributed with fans moved by external motors and the speed is proportional to the internal air pressure. It uses wood that is dried to about $0 \%$ moisture content. The process consists of a heating phase from $100^{\circ} \mathrm{C}$ to the peak modification temperature (between 160 and $220^{\circ} \mathrm{C}$ ), maintaining the temperature for a defined time (between 0.75 and 18 hours) and then a cooling process until the wood reaches $100^{\circ} \mathrm{C}$. The average vacuum pressure is also controlled during the process (Allegretti et al. 2012).

Plato Wood: This process uses green wood or conventional dried wood with moisture content of $14 \mathrm{o} 18 \%$. This process has 4 main steps. It starts with a hydrothermolysis that has a duration of 4 to 5 hours at temperatures between 150 and $190^{\circ} \mathrm{C}$ in humid conditions using saturated steam as the heating medium. It is followed by drying the wood to 9-10\% moisture content in a conventional industrial kiln. The third step is realized in a special stainless steel kiln heating the wood up to $150-190^{\circ} \mathrm{C}$ under dry conditions until it reaches moisture content close to $0 \%$. The final stage raises the moisture content to $4-6 \%$ by conditioning it. The time of treatment depends on the species, shape, thickness and final use of the modified wood (Boonstra et al. 1998).

$\mathbf{V a c u}^{3}$ (Timura): This method uses the advantages of fast wood moisture transport at a vacuum of 150 mbar ( $85 \%$ vacuum) that decreases the boiling point of water accelerating the drying of the wood, in conjunction with a well-regulated and efficient contact heat transfer (175 to $230^{\circ}$ C) using heating plates A special airbag system is used, which can reach a pressure up to 70 tons on the wood during the process, thus the deformation of the material is greatly reduced It can be used with wood at any initial moisture content and thicknesses (Wetzig et al. 2012). As a result of using the vacuum, the by products are condensed at the drying chamber wall and are taken out of the system. (Hofmann et al. 2013).

Retification process: This process is performed using wood with a $12 \%$ moisture content in a kiln under an inert atmosphere constituted from either nitrogen or carbon dioxide, producing a mild pyrolysis of the wood. The modification temperatures depend on the species used and can reach up to $240^{\circ} \mathrm{C}$ (Gerardin 2016). 


\subsection{Effects of thermal modifications in wood}

\subsubsection{Changes in the chemical structure}

The changes in the chemical composition of the wood start to be significant and can be quantified at modifications starting at peak temperatures of $120^{\circ} \mathrm{C}$ (Kollmann et al. 1969). There are many reactions happening simultaneously during the modification in all the wood components. Furthermore, the configuration of the constituents within the cell walls, their chemical bonds and intermediates that are derived from other reactions also influence the chemical changes (Fengel 1966; Kollmann et al. 1969). This makes the analysis of the chemical changes during the process itself rather difficult, so the analysis are mostly done after the process, using either wet chemistry to measure the relative contents the wood constituents (hemicelluloses, celluloses, lignin, extractives) (Alen et al. 2002; Esteves et al. 2008a), or proximate analysis such as analyzing spectra obtained from the CP-MAS ${ }^{13} \mathrm{C}$ NMR technique (Tjeerdsma et al. 1998; Mburu et al. 2007), infrared absorption (FTIR) spectra (Nuopponen et al. 2005; Tjeerdsma and Militz 2005; Esteves et al. 2013) or Raman scattering data (Nuopponen et al. 2005; Özgenç et al. 2017).

The first structural compounds to be thermally affected are the hemicelluloses, with their degradation starting by a deacetylation by a hydrolytic cleavage of the acetyl groups, which is released as acetic acid (Garrote et al. 1999; Garrote et al. 2001; Sundqvist et al. 2006). Besides acetic acid, formic acid and other organic acids also form during the thermal modification (Sundqvist et al. 2006). The acid catalyzation also forms furfural, formaldehyde and other aldehydes (Tjeerdsma et al. 1998). This increases the decomposition of the polysaccharides that form the hemicellulose (Tjeerdsma et al. 1998; Sivonen et al. 2002; Nuopponen et al. 2005). There is a loss in hydrogen bonds and a certain hydrolysis of the polymer chains into monomers and oligomers (Tjeerdsma et al. 1998; Garrote et al. 1999) which form degradation products, such as furfural and hydroxymethylfurfural from pentoses and hexoses respectively (Kotilainen et al. 2000; Nuopponen et al. 2005; Peters et al. 2009). Xylose, arabinose, galactose and mannose all decrease as the temperature of the thermal modification increases. The rate in which the carbohydrates degrade depends on the duration of the treatment, the severity of it, the type of the modification process (open or closed) and also which species is being used (Esteves and Pereira 2009). 
Cellulose is not as strongly affected as the hemicelluloses by the thermal modification process (Fengel 1967; Tjeerdsma et al. 1998; Tjeerdsma and Militz 2005). Nonetheless, there is hydrolytic cleveage in the less ordered amorphous regions of the cellulose microfibrils, which increases the degree of crystallinity (Bhuiyan et al. 2000; Bhuiyan et al. 2001; Sivonen et al. 2002), resulting in a decreasing accessibility of hydroxyl groups to water molecules (Bhuiyan and Hirai 2005; Boonstra and Tjeerdsma 2006), and produces changes in the degree of polymerization (DP) (Fengel 1967; Sweet and Winandy 1999).

Lignin is the most thermally stable component. This leads to a relative increase in its percentage after the thermal modification (Kollmann and Fengel 1965; Tjeerdsma and Militz 2005; Esteves et al. 2008a), but despite this increase, there are still chemical changes in the lignin composition. There is an increase in carbonyl groups (Kotilainen et al. 2000; Tjeerdsma and Militz 2005) and the ether linkages are cleaved, producing new free phenolic hydroxyl groups (Tjeerdsma et al. 1998; Nuopponen et al. 2005; Tjeerdsma and Militz 2005). There are also condensation reactions that, besides lignin, involve furfural and other degradation products (Tjeerdsma et al. 1998; Garrote et al. 1999).

Most of the natural wood extractives tend to be degraded, especially the most volatile ones, but new compounds are formed due to the degradation of wood cell wall components. Even despite that most of the original extractives of the wood disappear after the thermal modification, thermal degradation products may still remain inside the wood as new extractives (Esteves et al. 2008a; Poncsak et al. 2009). The amounts of the newly produced extractives will depend on the type of modification and the process conditions. The extractive content also tends to increase with mass loss, followed by a decrease at higher temperatures. This increase is a result of the formation of water and ethanol extractives due to the polysaccharide degradation (Esteves et al. 2008a).

\subsubsection{Mass loss}

The mass loss is usually used to check the severity of the thermal modification and the impact of the process conditions as it is strongly correlated to the changes in the wood properties during the thermal modification process (Metsä-Kortelainen et al. 2006; Brischke et al. 2007; Welzbacher et al. 2007; Esteves and Pereira 2009). It is also used to quantify the degradation effects of the thermal modifications (Zaman et al. 2000). There are also differences by the type 
of modification and wood, as open systems and softwoods present lower rates of mass loss than closed systems and hardwoods (Hill 2006). Using mass loss to compare between different processes is difficult, mostly because of the influence of the time, type, temperature, species and initial moisture content (Esteves and Pereira 2009). The mass loss is related to the depolymerization of cell wall constituents and the formation of degradation products, such as acids or furfurals, all of which vaporize at high temperatures causing losses in wood material (Fengel 1966; Alen et al. 2002). This can lead to some issues, as the majority of the natural extractives are removed the wood during the modification, causing a loss in dry mass even in cases where there is no degradation of wood cell wall components. This can be seen in the difference of mass loss between heartwood and sapwood of thermally modified Pinus sylvestris (Scots pine) in a similar modification, because the heartwood contains higher amounts of extractives that are emitted at elevated temperatures (Metsä-Kortelainen 2011). Some of the thermal degradation products can accumulate and be fixed to the wood cell wall at high temperatures (Altgen et al. 2016b). Obataya et al (2002) have recommended that the ML should be measured after the extraction of all water soluble degradation products. By deducing the extractives from the dry mass before and after modification a more precise calculation of the mass loss is achieved, which could also be used to compare between different modifications (Altgen et al. 2016b).

\subsubsection{Mechanical properties}

The resistance to bending in static tests, also known as modulus of rupture (MOR), is affected by the thermal modification. Several reports (Tjeerdsma et al. 1998; Poncsák et al. 2006; Esteves et al. 2007b; Borrega and Kärenlampi 2008b) show reduced MOR, depending on treatment conditions, up to $50 \%$. The decrease of the MOR is a consequence of reduced tensile strength and reduced compression strength (Boonstra et al. 2007b). There have been cases where there was a slight increase in MOR after a mild thermal modification with minor mass losses (Kubojima et al. 2000; Shi et al. 2007b). However, the decrease in dynamic strength (often measured as impact bending strength) is more severe. This is related to the loss in flexibility because of the changes in the composition of hemicelluloses and lignin (Kubojima et al. 2000; Boonstra et al. 2007b). The work to maximum load in bending is also strongly reduced by the thermal modification (LeVan et al. 1990; Poncsák et al. 2006; Borrega and Kärenlampi 2008b; Altgen and Militz 2016). The reduction is higher in the inelastic region above the proportional limit than in the elastic region of the load deflection curve (Kubojima et 
al. 2000; Phuong et al. 2007; Borrega and Kärenlampi 2008b). The decrease of these properties is related to the brittleness of the modified wood, as it is higher than in the unmodified wood (Phuong et al. 2007; Weigl et al. 2012).

On the other hand, the effect of the thermal modification on the modulus of elasticity (MOE) tends to be more limited even at thermal modification at higher temperatures (Tjeerdsma et al. 1998; Kubojima et al. 2000; Boonstra et al. 2007b). In some cases the MOE can be even higher than the unmodified wood (Kubojima et al. 2000; Santos 2000; Borrega and Kärenlampi 2008b; Lekounougou et al. 2011; Rautkari et al. 2014).

Hardness also tends to reduce after thermal modification in the radial and tangential directions at high temperatures. This reduction can be related to the lower mass and lower density after the thermal modification process (Brischke et al. 2005; Sundqvist et al. 2006) and to the increasing temperatures and treatment times (Korkut et al. 2008; Meyer et al. 2011), but it has been shown that at lower temperatures a slight increase could be measured (Kocaefe et al. 2008b). The increase could be related to the condensation process in hemicelluloses and lignin while they are being degraded to form new chemical bonds (Tjeerdsma et al. 1998; Sivonen et al. 2002; Sundqvist et al. 2006).

The reason of the decrease in the mechanical properties can be related to the changes in the cell wall chemistry, such as the degradation of hemicelluloses, changes in the lignin composition causing cross-links and the increased crystallinity and depolymerization of the hemicelluloses (Winandy and Rowell 1984; Tjeerdsma et al. 1998; Kubojima et al. 2000; Boonstra et al. 2007b; Kocaefe et al. 2008a; Windeisen et al. 2009). Small variations in the linear backbone chain of the hemicelluloses (xylose, mannose, arabinose and galactose) can have a large impact on the overall strength (Sjostrom 1981). The cleavage of these side groups, between the lignin and hemicelluloses, releases the linkage by which one microfibril of a wood fiber shares the load with another microfibril (LeVan et al. 1990). Cellulose and hemicelluloses are linked between themselves and lignin, with lignin holding the microfibrils formed by cellulose chains that are covered by hemicelluloses. Removing the hemicelluloses increases the crystalline part in wood material, which in turn relatively increases the cellulose component. This replaces the flexible hemicellulose-cellulose-hemicellulose bond with the more rigid cellulose-cellulose bond, decreasing the flexibility of the material (Kocaefe et al. 2008a). Physical changes in the wood cell wall, such as an increased hydrogen-bonding between polymers caused by the drying of 
the wood during modification, can increase the stiffness on the wood cell matrix (Suchy et al. 2010), thus influencing some mechanical properties. The extension on how much the properties are changed depends on the process conditions and the species used.

\subsubsection{Hygroscopicity}

Hygroscopicity is usually measured by the equilibrium moisture content (EMC). The decrease of EMC is the main effect of the thermal modification. This was already reported by Tiemann (1917), who showed that drying at high temperatures reduced the hygroscopicity of the wood. This has been confirmed in a number of studies using different species and thermal modification processes (Seborg et al. 1953; Tjeerdsma et al. 1998; Kamden et al. 2002; Esteves et al. 2007a; Esteves et al. 2007b; Jalaludin et al. 2010), as the EMC decreases in relation to the conditions of the modification process, such as the peak temperature and duration. The decrease of EMC is correlated to the mass loss during the modification process.

The wood water relations have still many aspects that are not completely understood (Engelund et al. 2013). One of the reasons of a decrease of the EMC is that less water is absorbed by the wood cell walls after a thermal modification due to a chemical change that reduce the water accessible hydroxyl groups. As the hemicelluloses contain far more water-accessible $\mathrm{OH}$ groups within the wood (Runkel 1954; Runkel and Lüthgens 1956), and tend to degrade faster during the modification (Alen et al. 2002), thus reducing the total amount of $\mathrm{OH}$ groups in the wood. The hemicelluloses that have the highest mobility and reactivity tend to be removed during the thermal modification (Borrega and Kärenlampi 2008a), therefore the water accessible hydroxyl groups are mostly eliminated (Willems 2014b). The increase of cellulose crystallinity (Bhuiyan and Hirai 2005; Boonstra and Tjeerdsma 2006) and the polycondensation reactions of lignin that result in further cross-linking (Tjeerdsma and Militz 2005; Boonstra and Tjeerdsma 2006; Esteves et al. 2008a) can also contribute to the increase of inaccessibility of the hydroxyl groups. Other mechanisms may also contribute to this effect, such as the formation of irreversible hydrogen bonds and a more tightly bonded wood structure as a result of wetting and re-drying at elevated temperatures, known as hornification (Borrega and Kärenlampi 2010), or a hindered expansion of nanopores, which can be interpreted as increased cell wall stiffness (Hill et al. 2012; Ringman et al. 2014; Altgen et al. 2016a). 
As with the EMC, the wettability also changes during the thermal modification in dependence of the process conditions (Petrissans et al. 2003; Gerardin et al. 2007; Kocaefe et al. 2008a). The reduction of the accessible hydroxyl groups is also likely the reason for the decrease of wettability after the thermal modification (Gerardin et al. 2007).

\subsubsection{Dimensional stability}

The decrease of the EMC due to thermal modification leads to an improvement of the dimensional stability of the wood. This is related to the swelling, as it is reduced by the thermal modification in relation to the intensity of the modification (Burmester 1973; Giebeler 1983; Dirol and Guyonnet 1993). Swelling is measured by the difference of wet and dry dimensions of the wood before and after water soaking. The reduction of swelling can be related to the closure of voids that were created by the removal of wood cell wall component during the thermal modification, resulting in the reduction of the dry dimensions (Burmester 1975; Gonzalez-Peña et al. 2009). The closing of voids can be caused by annealing and a rearrangement of the amorphous wood cell wall polymers due to the elevated temperatures (Obataya and Tomita 2002).

Anti-swelling efficiency (ASE) is used to quantify the improvement of the dimensional stability of the thermally modified wood, as it represents the difference between the swelling of modified and unmodified wood. This increase is dependent on the direction of the wood (tangential, radial, longitudinal) as the tangential direction is where a more substantial improvement can be seen (Esteves et al. 2007a; Esteves et al. 2007b; Esteves et al. 2008b).

The increase of wood dimensional stability is closely related to the decrease of hygroscopicity due to the chemical changes, such and the formation of polymers from sugars that are less hygroscopic than the ones before the modification (Dirol and Guyonnet 1993), although the preferential removal of hemicelluloses was not the main factor of the improvement of dimensional stability (Repellin and Guyonnet 2005). The loss of methyl radicals that leads to the increase of phenolic groups, which in turn lead to a higher lignin reactivity forming crosslinks (Tjeerdsma et al. 1998) can also be considered as part of the improvement of the dimensional stability. Other mechanisms are also part of the improvement of dimensional stability, such as thermal degradation products within the wood cell wall that can cause a cell wall bulking effect. These degradation products occupy the nanopores, which then cannot be 
fully filled with water, thus contributing to the improvement of the dimension stability. These degradation products can be removed by extraction, thus decreasing the dimensional stability of the thermally modified wood (Biziks et al. 2015; Altgen et al. 2016a).

\subsubsection{Macrostructural and anatomical changes}

The development of cracks and other defects can be usually related to the raw material used, such as growth stresses or drying related issues. Thermal modifications work under high temperatures, which influence the increase of moisture gradients that lead to high internal stresses that can be released as cracks (Oltean et al. 2007). If the material was carefully selected, the crack development can be minimized, although issues such as non-visible micro-cracks can develop into more severe cracks (Hanhijärvi et al. 2003). Nonetheless, it is difficult to differentiate if the defects were already present in the material or occurred because of the thermal modification. The changes in the anatomical structure could also be related to the formation of cracks and other defects, such as cell collapse and surface deformation (Boonstra et al. 2006a; Boonstra et al. 2006b). The typical anatomical defects include micro-cracks that start in the middle lamella and damage to the pits, the axial tracheid walls and the parenchyma cells in wood rays and resin canals (Boonstra et al. 2006a; Boonstra et al. 2006b; Awoyemi and Jones 2011; Biziks et al. 2013), micro-cracks between the S1 and the S2 layers in the corners in the cells (Fengel and Wegener 1984) and also a reduction of the wood cell wall thickness (Bernabei and Salvatici 2016). These defects can also appear because of the decomposition of the wood cell wall constituents due to the elevated temperatures (Cheng et al. 2007). These anatomical changes, in combination to the stress related to elevated temperatures caused during the thermal modification, can also be one of the causes of the formation of cracks.

It is important to be aware of the changes at the anatomical level of the modified wood, but the actual impact is not as important and influential as the changes in the chemistry of the material (Awoyemi and Jones 2011; Militz and Altgen 2014).

\subsubsection{Durability}

Thermal modification processes increase the resistance against rot caused by decay fungi, with the reduction depending on the mass loss caused by the treatment temperature (Hakkou et al. 2006; Boonstra et al. 2007a; Welzbacher et al. 2007; Mohareb et al. 2012). The efficacy of this effect is strongly correlated to the wood species used, the type of fungus and the thermal 
modification conditions (Militz and Altgen 2014). Welzbacher and Rapp (2002) compared the durability of different thermal modification processes (Thermowood, OHT, Plato and Rectified) using a selection of fungi. They showed a high resistance to brown rot (Coniophora puteana) and white rot (Coriolus versicolor) and a slightly lower improvement against Oligoporus placenta, but they all showed less mass loss than the untreated wood, increasing the durability class of the woods used. Nonetheless, is important to mention that to achieve higher durability classes using low quality woods, strong reduction of mechanical properties are to be expected (Welzbacher and Rapp 2007). Mold growth was not affected by the thermal modification, mostly due to the formation of hemicellulose degradation products (Boonstra et al. 2007a). On the other hand, the resistance in contact to the soil does not improve with the thermal modifications (Kamden et al. 2002), which was also shown for modified eucalypt species (Knapic et al. 2018).

The enhanced durability can be explained by the changes in the chemical composition of the wood cell wall, such as the removal of the hemicelluloses, which are one of the main nutrients for the development of fungi (Hakkou et al. 2006), stable free radicals that may act as antioxidants limiting the spread of the fungi at the initial stages of decay (Willems et al. 2010) or the modification of the wood polymers (Weiland and Guyonnet 2003; Hakkou et al. 2006).

As for termite attacks, it was shown that the modified wood of Pinus pinaster was still highly degraded by them in a non-choice feeding test (Surini et al. 2012). It was also shown that in some cases the wood can even become less durable to termite attacks due to the removal of some termite inhibiting compounds, as shown by Shi et al.(2007a) in modified Pinus sylvestris at $215^{\circ} \mathrm{C}$.

\subsubsection{Color}

The modified wood tends to get browner as the modification intensifies. These color changes are related to the treatment intensity (Bekhta and Niemz 2003; Johansson and Moren 2006; Esteves et al. 2008b; de Cademartori et al. 2013). It can be used as an indicator of the thermal modification strength, as there was a good linear correlation with the treatment intensity (Brischke et al. 2007). Thermally modified wood color turns grey after natural or artificial weathering, as the surface color is not stable due to a low resistance of the new formed polymers towards degradation against UV light (Jämsä et al. 2000; Huang et al. 2012). It is recommended 
to treat the surface with coatings or light stabilizers. Jämsä et al. (2000) reported that the substrate for the tested coating systems was comparable to unmodified wood and no alterations for the coatings were needed, but on the other hand, de Moura et al. (2013) showed poor performances of the selected coating systems used in their report. The selection of the coating systems is related to the wood species used and the modification conditions.

Biological durability and the change in color were considered outside of the scope of this dissertation and were not measured, because from literature (Hakkou et al. 2006; Boonstra et al. 2007a; Welzbacher et al. 2007; Mohareb et al. 2012) and recent reports on other eucalypt (Calonego et al. 2010) and hardwood species (Lekounougou and Kocaefe 2012; Chaouch et al. 2013) on decay resistance and color changes in modified eucalypt species (Esteves et al. 2008b; de Cademartori et al. 2013; Griebeler et al. 2018), it can be expected that the modified E. nitens behaves in comparable ways as earlier tested wood species. 


\subsection{Objectives}

There is interest to use plantation grown E. nitens wood for solid wood products. Adding value by using thermal modification processes would open new market possibilities for this species. Two modifications were selected in my research for this purpose: Thermowood (open), which is currently the most used process in the market, and WTT (closed), which is a relatively new technology with market potential and shorter process times. However, there is a need for a better understanding of the effects of the processes on the quality of the wood, as it is still unclear whether the properties of thermally modified wood from open and closed systems present significant differences. Therefore, the main objective of the thesis was to evaluate and compare the open and closed system modifications by analyzing the chemical, mechanical, physical and anatomical changes of thermally modified E. nitens. To achieve this, the following specific objectives were established:

- The overall effects that the thermal modifications have on the properties of the modified E. nitens wood.

- The changes in the wood properties influenced by each other (chemical, mechanical, physical, anatomical).

- The similarities/differences of the resulting properties from the diverse thermal modification processes and a comparison between modifications with the same corrected mass loss.

- The effects on the long term dimensional stability of the thermally modified wood from open or closed systems.

- Comparing the results from both modifications with similar modified eucalypt species.

- Analyzing the potential to use thermally modified wood from E. nitens for producing high end or alternative products for the Chilean and international markets.

The carried out investigations were separated in a general overview of the modified wood properties and how they influence each other (Publications I to III), the anatomical properties of the modified wood (Publications II and VI), the long term effects of the thermal modifications based on the reversible changes in hygroscopicity (Publication IV), the analysis of the corrected mass loss as a potential indicator of the thermal modification effect (Publications I to IV) and an experimental study on the potential of thermally modified E. nitens wood as a material for high end or alternative products (Publication V). 


\subsection{List of publications in peer-reviewed journals}

Publication I: Relation of chemical and mechanical properties of Eucalyptus nitens wood thermally modified in open and closed systems

Wentzel, M., Fleckenstein, M., Hofmann, T., Militz, H.; Wood Material Science \& Engineering (2018), in press (Online first). doi: 10.1080/17480272.2018.1450783.

Publication II: Dynamic and static mechanical properties of Eucalyptus nitens thermally modified in an open and closed reactor system

Wentzel, M., Brischke, C., Militz, H.; Maderas Ciencia y Tecnologia (2019), in press (Online first). doi: 10.4067/S0718-221X2019005000201

Publication III: Chemical analysis and cellulose crystallinity of thermally modified Eucalyptus nitens wood from open and closed reactor systems using FTIR and X-ray crystallography

Wentzel, M., Rolleri, A., Pesenti, H., Militz, H.; Manuscript submitted to European Journal of Wood and Wood Products, 24.07.18.

Publication IV: Analyzing reversible changes in hygroscopicity of thermally modified eucalypt wood from open and closed reactor systems

Wentzel, M., Altgen, M., Militz, H.; Wood Science and Technology (2018), Vol. 52(4): 889907. doi: 10.1007/s00226-018-1012-3.

Publication V: Thermally modified Eucalyptus nitens as material for decking

Wentzel, M., González-Prieto, O. Brischke, C, Militz, H.; Manuscript submitted to Drvna Industrija, 28.08.2018.

Publication VI: Anatomical characteristics of thermally modified Eucalyptus nitens wood in an open and closed reactor system

Wentzel, M, Koddenberg, T, Militz, H.; Wood Material Science \& Engineering (2019), in press (Online first). doi: 10.1080/17480272.2019.1572649 


\subsection{Other publications on thermal wood modification}

Mechanical behaviour of Eucalyptus nitens thermally modified in open and closed systems

Wentzel, M, Militz, H.; Proceedings of the Northern European Network for Wood Science and Engineering (WSE2017), (2017), Copenhagen, Denmark.

\section{Thermally modified Eucalyptus nitens as material for decking}

Wentzel, M., Brischke, C., González-Prieto, O., Militz, H.; Proceedings of the 10th European TMT Workshop, (2018), Dresden, Germany

Dynamic and static mechanical properties of Eucalyptus nitens thermally modified in an open and closed reactor system

Wentzel, M., Brischke, C. Militz. H; Proceedings of the 9th European Conference on Wood Modification, (2018), Arnhem, Netherlands

Nanoscale mechanical properties of wood: effects of heat treatment

Saleh, S., Wentzel, M., Militz, H., Volkert, C.; Proceedings of the Third COST Action FP1407 International Conference, (2017), Kuchl, Austria 



\section{Chapter 2: Publication I}

Relation of chemical and mechanical properties of Eucalyptus nitens wood thermally modified in open and closed systems

M. Wentzel ${ }^{1 *}$, M. Fleckenstein ${ }^{1}$, T. Hofmann ${ }^{2}$, H.Militz $^{1}$

${ }^{1}$ Department of Wood Biology and Wood Products, University of Göttingen, Faculty of Forest Science, Büsgenweg 4, 37077 Göttingen, Germany

${ }^{2}$ Institute of Chemistry, University of Sopron, Bajcsy-Zsilinszky u. 4, 9400 Sopron, Hungary

*corresponding author:

Phone: +495513922051

Fax: +49551399646

E-mail: mwentze@gwdg.de

ORCID: 0000-0002-5795-7589

Originally published in:

Wood Material Science \& Engineering

Taylor \& Francis

ISSN (Print) 1748-0272

ISSN (Online) 1748-0280

DOI: $\quad 10.1080 / 17480272.2018 .1450783$

Received: 22 November 2017

Accepted: 7 March 2018

Published online: 20 March 2018

htps://www.tandfonline.com/doi/full/10.1080/17480272.2018.1450783 
Abstract: In the present work Eucalyptus nitens was thermally modified in an open (atmospheric pressure) and a closed (under pressure) reactor system. The effect of the changes of the chemical composition on the mechanical properties was investigated. Hemicelluloses, cellulose, lignin, extractives, acetic acid, formic acid, total phenols and the cellulose degree of polymerization (DP) as well as modulus of elasticity (MOE) and modulus of rupture (MOR) were measured for each modification. The results indicated that the closed system modification, particularly at high pressure, presented stronger variations on the chemical structure of the modified wood than the modifications in the open system. In both modifications MOR showed a better correlation with the chemical changes than the MOE, especially xylose, cellulose DP, lignin and total phenols. These correlations suggest a tendency of a more brittle wood in the closed system modification at high pressure than in the modifications in the open system. Results can be used as a reference for future applications of thermally modified E. nitens wood.

Keywords: Eucalypt, thermal modification, extractives, structural polymers, mechanical properties

\subsection{Introduction}

There are about 250,000 ha of Eucalyptus nitens (Shining Gum) plantations in Chile, which amount to $10.5 \%$ of the total plantations in Chile in 2014 (INFOR 2015). Its primary use is for pulpwood production, but in recent years there has been an interest to widen the use from this fast growing tree species for solid wood products to increase economic returns (Muñoz et al. 2005; INFOR 2014). Thermal modifications offer a good alternative to produce high quality material from this species that could be used for deckings, claddings, windows, doors, flooring, garden products and even saunas or bathrooms (Militz and Altgen 2014).

In the last decades thermal modifications have been commercially used, with processes such as ThermoWood (Mayes and Oksanen 2002), Plato Wood (Boonstra et al. 1998), FirmoLin (Willems 2009; Willems 2014a), WTT (Dagbro et al. 2010) or TERMOVUOTO (Allegretti et al. 2012) to name a few. All the processes use treatment temperatures between $150^{\circ} \mathrm{C}$ and $240^{\circ} \mathrm{C}$ and use different operating conditions to limit the presence of oxygen in the process, such as presence of a shield gas (either steam, nitrogen or other elements), a dry or humid environment and how the heat is transferred (convection or conduction). There are open system processes, which work under atmospheric pressure, and closed system processes, such as processes using vacuum or steam pressure (Hill 2006; Militz and Altgen 2014). 
Strong chemical changes occur during the modification process, starting with a degradation of the hemicelluloses by deacetylation followed by a depolymerisation caused by the released carboxylic acids, such as formic and acetic acid (Boonstra and Tjeerdsma 2006; Sundqvist et al. 2006), and a reduction of the acetyl content (Tjeerdsma et al. 1998; Tjeerdsma and Militz 2005). The lignin polymer network is also modified, as the ether linkages are cleaved and new free phenolic hydroxyl groups are formed (Tjeerdsma et al. 1998; Nuopponen et al. 2005; Tjeerdsma and Militz 2005). Cellulose is the wood constituent that is least transformed, but at higher temperatures there are changes in the amorphous region of the cellulose (Tjeerdsma et al. 1998; Tjeerdsma and Militz 2005) which increase the degree of crystallinity (Bhuiyan et al. 2000), and produces changes in the degree of polymerization (DP) of cellulose (Sweet and Winandy 1999). There is also a decrease of mass after thermal modification processes (Kollmann and Schneider 1963; Esteves et al. 2007a), which varies depending on the species and the intensity of the modification, a loss in mechanical strength (Boonstra et al. 1998; Tjeerdsma et al. 1998; Kubojima et al. 2000) and higher brittleness (Phuong et al. 2007) that can lead to limitations of its use.

Results have been published that relate chemical changes, such as the influences of the variation of cellulose, hemicellulose and extractives (Windeisen et al. 2009), the degradation of hemicelluloses, crystallization of cellulose and variation of lignin structure (Kocaefe et al. 2008a), the DP of cellulose and content of hemicelluloses (Kačíková et al. 2013), with the mechanical wood properties of the modified species. However, the impact of the process conditions should also be taken into consideration, as it is an indispensable knowledge for the requirements for the end use of the modified wood. There are differences between open and closed system modifications, as modifying under high pressure and under controlled relative humidity the oven dry state of the wood can be avoided even at high temperatures (Altgen et al. 2016b), while an open system the moisture content reaches almost $0 \%$ at the pre-drying step, which could cause shrinkage stresses. Also, by increasing the pressure in the closed system, it prevents excessive vaporization of the degradation products. This affects the chemical properties during the different thermal modifications and its relation to the mechanical properties. Therefore it is crucial to know the impact of the different thermal modification processes in order to assure the quality of the modified wood and fulfil the requirements of the end products and applications. 
The aim of the present study was to analyse the effect of changes in the chemical composition on the mechanical properties under open and closed system modifications of E. nitens wood. Results were compared and statistically evaluated to unveil relationships between modification conditions and changes in chemical and mechanical properties. Results can contribute to the efficient and economic use of $E$. nitens wood as a thermally modified material.

\subsection{Materials and methods}

\subsubsection{Material}

E. nitens wood that comes from 19 year old plantations in the Región del Bío-Bío in Chile was used. Slats with dimensions of $20 \times 50 \times 650 \mathrm{~mm}^{3}$ (radial $\mathrm{x}$ tangential $\mathrm{x}$ longitudinal) with an average density of $663 \mathrm{~kg} / \mathrm{m}^{3}$ were prepared from conventionally kiln-dried mature wood with an average moisture content (MC) of $12 \%( \pm 0.85 \%)$, avoiding major defects and large knots. This was done to minimize effects such as cracks during the process. For each modification process 10 slats were used.

\subsubsection{Thermal modification}

Thermal modification processes were performed in a laboratory-scale treatment reactor. A stainless steel vessel with a volume of 651 was used to place the samples. This can be heated up to $260^{\circ} \mathrm{C}$ with electric heating cables and was cooled down to room temperature with a system of water cooling coils. The water vapour was produced by heating an external water reservoir that is directly connected to the vessel. Exhaust valves were used for the release of excess pressure (Willems 2009). This reactor can be used as either an open or as a closed system.

The open system was a process similar to a Thermowood procedure (Mayes and Oksanen 2002). It starts with raising the temperature inside the vessel at $12^{\circ} \mathrm{C}$ per hour up to $100^{\circ} \mathrm{C}$, followed by a pre-drying at a heating rate of $2 \mathrm{C}$ per hour up to $130^{\circ} \mathrm{C}$. Afterwards the temperature ramps up at $12^{\circ} \mathrm{C}$ per hour ${ }^{1}$ to the desired modification temperature presented in Table I, where it is hold up for 3 hours. Finally the temperature decreases at a rate of $-20^{\circ} \mathrm{C}$ per hour per hour until it reaches $65^{\circ} \mathrm{C}$.

In the case of he closed system modification, the WTT process (Willems 2009) was used. It is separated in four steps: a 50 min holding step at pre-vacuum at $<14 \mathrm{kPa}$, temperature increase 
in a rate of $12^{\circ} \mathrm{C}$ per hour per hour until modification temperature (Table 2.1), a holding step at the peak temperature for 3 hours and a temperature decrease in a rate of $20^{\circ} \mathrm{C}$ per hour ${ }^{1}$ per hour up to $65^{\circ} \mathrm{C}$. It is important to note that the complete duration of the modification processes is shorter in the closed system than in the open system (Table 2.1).

Table 2.1: Peak temperature, maximum pressure, peak duration, total process duration of both modifications (open and closed) and the RH applied in the thermal modifications in the closed systems as well as the final moisture content (MC) after each modification process and the standard deviation of the peak temperature, max pressure and final MC. The hold time at peak temperature was 3 hours for all processes.

\begin{tabular}{|c|c|c|c|c|}
\hline \multicolumn{5}{|c|}{ Closed System } \\
\hline $\begin{array}{l}\text { Peak temperature } \\
\qquad\left(\mathrm{C}^{\circ}\right)\end{array}$ & $\begin{array}{c}\text { Max pressure } \\
(\mathrm{MPa})\end{array}$ & RH (\%) & $\begin{array}{l}\text { Final MC } \\
\qquad(\%)\end{array}$ & $\begin{array}{c}\text { Total } \\
\text { process } \\
\text { duration }(\mathrm{h})\end{array}$ \\
\hline $150 \pm 1.00$ & $0.14 \pm 0.007$ & 30 & $4.50 \pm 0.49$ & 16.5 \\
\hline $160 \pm 1.14$ & $0.18 \pm 0.007$ & 30 & $3.85 \pm 0.46$ & 18 \\
\hline $170 \pm 0.95$ & $0.23 \pm 0.003$ & 30 & $3.20 \pm 0.36$ & 19 \\
\hline $150 \pm 2.65$ & $0.47 \pm 0.008$ & 100 & $5.27 \pm 0.88$ & 16.5 \\
\hline $160 \pm 2.51$ & $0.61 \pm 0.012$ & 100 & $4.94 \pm 0.87$ & 18 \\
\hline $170 \pm 1.36$ & $0.77 \pm 0.034$ & 100 & $4.62 \pm 0.77$ & 19 \\
\hline \multicolumn{5}{|c|}{ Open System } \\
\hline $\begin{array}{l}\text { Peak temperature } \\
\qquad\left(\mathrm{C}^{\circ}\right)\end{array}$ & $\begin{array}{c}\text { Max pressure } \\
(\mathrm{MPa})\end{array}$ & RH (\%) & $\begin{array}{l}\text { Final MC } \\
\qquad(\%)\end{array}$ & $\begin{array}{c}\text { Total } \\
\text { process } \\
\text { duration }(\mathrm{h})\end{array}$ \\
\hline $160 \pm 1.09$ & atmospheric & - & $3.34 \pm 0.25$ & 30.2 \\
\hline $180 \pm 1.00$ & atmospheric & - & $2.04 \pm 0.19$ & 33 \\
\hline $200 \pm 1.18$ & atmospheric & - & $2.04 \pm 0.19$ & 35.5 \\
\hline $210 \pm 1.04$ & atmospheric & - & $2.18 \pm 0.30$ & 37 \\
\hline $220 \pm 1.00$ & atmospheric & - & $2.25 \pm 0.16$ & 38.2 \\
\hline $230 \pm 1.10$ & atmospheric & - & $2.44 \pm 0.12$ & 39.5 \\
\hline
\end{tabular}




\subsubsection{Mass loss and extractive content}

To measure the mass loss caused by the thermal modification, the final moisture content was measured by difference of dry weight using small pieces collected from each slat. The dry mass from the small sections and the mass loss (ML) were calculated using the formulas described by Metsä-Kortelainen et al. (2006).

The degradation products of the cell wall carbohydrates accumulate in the wood during modifications at high temperatures (Altgen et al. 2016b). Hence the extractives have to be deducted from the dry mass loss when analysing the effects of modification at elevated pressures. In this study this was performed on all modifications (open and closed systems) so that the corrected mass loss (CML) could be used to compare the results obtained. The CML of oven-dry samples before and after each modification of each individual slat was calculated based on the dry and extractive-free weight of the wood before (unmodified) and after each process. It has to be noted that the wood material to be tested was neither dried nor extracted prior each modification process.

The extractive content was measured using a similar method described in the Solvent Extractives of Wood and Pulp Test Method T 204 cm-07 (TAPPI 1997). Material from several slats of each process as well as from unmodified references were grounded in a cutting mill and sieved to a particle size between $0.2-0.63 \mathrm{~mm}$. $5 \mathrm{~g}$ of dry wood particles for each process were extracted with a Soxhlet apparatus using $150 \mathrm{ml}$ of distilled hot water and then extracted for 8 hours. The extractive content was then determined gravimetrically in relation to the initial oven dry mass before the Soxhlet process. The amount of extractives was calculated in grams of extractives in 100 grams of wood as presented in Eq. 2.1.

$$
\text { Extractives }=\frac{\left(W_{b e}-W_{a e} * 100\right.}{W_{b e}},
$$

Equation 2.1

where $\mathrm{W}_{\mathrm{be}}$ is the dry weight of the wood before extraction in grams, and $\mathrm{W}_{\mathrm{ae}}$ is the dry weight of the wood after extraction in grams. There were trials that included an extraction with a 1:2 mixture of ethanol-cyclohexane after the distilled hot water extraction with additional extractive contents between 0.2 to $0.7 \%$, which were similar results obtained by Altgen et al. (2016b) with European beech, so it can be concluded that most of the compounds were removed by the distilled hot water, thus it was the only solvent used in this study. 
The corrected mass loss (CML) was measured as described by Altgen et al. (2016b), where first the extractives are deducted from the dry weight of the selected wood slats to calculate their corrected weight using Eq. 2.2.

$$
C_{w}=\operatorname{Dr} y_{w}-\left(\frac{\text { Dry } y_{w} * \text { Extractives }}{100}\right),
$$

Equation 2.2

where Dry $\mathrm{w}_{\mathrm{w}}$ is the dry weight of the slat in grams. Then, the CML can be calculated using the following equation (Eq. 2.3).

$$
C M L=\frac{\left(D r y_{c w b}-D r y_{c w a}\right) * 100}{D r y_{c w b}},
$$

where Dry $\mathrm{c}_{\mathrm{cwb}}$ is the corrected dry weight of the slat before the modification process in grams and Dry $\mathrm{y}_{\mathrm{cwa}}$ is the corrected dry weight after the modification process in grams. Measurements were done in duplicate for each modification.

\subsubsection{Determination of acetic and formic acid by HPLC}

For the determination of acetic and formic acid contents the samples were extracted by soaking $2.5 \mathrm{~g}$ of grounded wood with similar size as the ones used for the extractive content in $30 \mathrm{ml}$ distilled water for $24 \mathrm{~h}$ at room temperature; the extract was filtered, and the particles were washed with distilled water to a final volume of $100 \mathrm{ml}$. Formic acid and acetic acid were measured by high-performance liquid chromatographic (HPLC) separation (Shimadzu LC-20 equipment, Shimadzu Corporation, Kyoto, Japan) using a Bio-Rad Aminex HPX-87H column (Bio-Rad Laboratories Inc., Hercules, USA) at $60{ }^{\circ} \mathrm{C}$, with $0.6 \mathrm{ml} \mathrm{min}{ }^{-1}$ flow of $0.005 \mathrm{M} \mathrm{H}_{2} \mathrm{SO}_{4}$ mobile phase, and UV detection at 210-240 nm. Concentrations were given in $\mathrm{mg} / 100 \mathrm{~g}$ dry wood. The measurements were taken in duplicate.

\subsubsection{Determination of total phenol content}

Total phenol content was measured using the Folin-Ciocâlteu assay (Singleton and Rossi 1965) applying quercetin (Sigma-Aldrich, Budapest, Hungary) as the standard. Folin-Ciocâlteu reagent was obtained from Merck (Darmstadt, Germany). Results were expressed in mg equivalents of quercetin/ g dry wood. Mesurements were performed using a Hitachi U-1500 type spectrophotometer (Hitachi Ltd., Tokyo, Japan) at $760 \mathrm{~nm}$. Measurements were done in triplicate. 


\subsubsection{Determination of structural polymers}

Wood polymers were investigated using extractive free wood. Holocellulose was measured based on the separation of the lignin by sodium chloride as presented by Wise et al. (1946). Cellulose was measured using the alpha-, beta- and gamma-cellulose in pulp TAPPI test method 203 (TAPPI 2009), where it was separated from the hemicellulose using a sodium hydroxide solution. The obtained cellulose is usually called the alpha-cellulose, and was used to measure the cellulose degree of polymerization (DP). It has to be noted that the chemical dosage, temperature and period of reaction could affect the degradation of cellulose during the isolation process (Hallac and Ragauskas 2011). Lignin is obtained using the NREL (National Renewable Energy Laboratory) standard Determination of Structural Carbohydrates and Lignin in Biomass (Sluiter et al. 2008), where a two-step acid hydrolysis is used to fractionate the wood. The filtered solution from the measurement of lignin was used to identify and measure the carbohydrates (glucose, xylose, mannose and arabinose) using a Waters 1525 binary HPLC pump attached to a Waters 717plus Autosampler and a Waters 2414 refractive index detector (Waters GmbH, Eschborn, Germany). Parts of the procedure to measure the carbohydrates are based on the standard Determination of Structural Carbohydrates and Lignin in Biomass (Sluiter et al. 2008), with portions of the procedure being similar to the ASTM E1758-01 Standard Test Method for Determination of Carbohydrates in Biomass by High Performance Liquid Chromatography (ASTM 2015). As part of the test, a set of calibration standards was prepared with defined concentration ranges using standard sugar samples (AppliChem, Darmstadt, Germany) to be able to quantify the respective amounts of carbohydrates for each hydrolyzed solution. All the values are presented as a percentage of the initial dry mass of each sample and all measurements were done in duplicate.

\subsubsection{Cellulose degree of polymerization}

The cellulose DP of the laboratory obtained alpha-cellulose was measured using the capillary viscometer method (TAPPI 2013) recommended by Hallac and Ragauskas (2011). It involves dissolving cellulose in $0.5 \mathrm{M}$ cupriethylenediamine solution. $0.25 \mathrm{~g}$ of dry cellulose is added to $25 \mathrm{~mL}$ of distilled water and $25 \mathrm{~mL}$ of cupriethylenediamine solution and then shacked to solubilize. The DP was then calculated using the formulas presented by Jahan and Mun (2005) for the intrinsic viscosities ( $\mathrm{n}_{\mathrm{int}}$ ) (Shitola et al. 1963) and the viscometric average DP using the Mark-Houwink-Sakurada equation with the constant suggested by Evans and Wallis (1989) $\left(\mathrm{DP}^{0.90}\right)($ Eq. 2.4 and 2.5). All analyses were done twice for each modification. 


$$
\begin{array}{ll}
n_{\text {int }}=954 * \log (\text { T APPI viscocity })-325, & \text { Equation } 2.4 \\
D P^{0.90}=1.65 * n_{\text {int }}, & \text { Equation } 2.5
\end{array}
$$

\subsubsection{Mechanical properties}

A three-point bending test based on the DIN 52186 (1978) bending test norm was performed on a universal testing machine (Zwick Roell Z010, Zwick, Ulm, Germany) on wood samples with dimensions of $10 \times 10 \times 180 \mathrm{~mm}^{3}$ (radial $\times$ tangential $\times$ longitudinal) that were conditioned at $20^{\circ} \mathrm{C} / 65 \% \mathrm{RH}$ before the test. At least 15 samples per modification were tested. The span length of the samples was $150 \mathrm{~mm}$ and the load was applied in the transversal direction with the testing speed adjusted individually for each modification to be able to cause the failure of the samples within $90 \pm 30 \mathrm{~s}$. A load decrease of $10 \%$ or more of the maximum load was defined as a failure. Modulus of elasticity (MOE) (MPa) and modulus of rupture (MOR) (MPa) (bending strength) were measured as described in DIN 52186 (1978).

\subsubsection{Statistical evaluation}

Statistical analysis was performed to correlate selected chemical changes with mechanical properties using the Pearson Correlation Coefficient Test using the STATISTICA Software package Version 13.1 (StatSoft Inc., Tulsa, USA).

\subsection{Results and discussion}

\subsubsection{Chemical composition and mass loss changes}

Chemical composition results are presented in Table II. The results of the chemical composition of the unmodified sample were similar to the ones presented for E.nitens by Niemz et al. (2004) (3.4\% extractives, lignin $22.4 \%$, holocellulose + pentosanes $78.1 \%$ ).

The extractive content increases in the closed system as the temperature rises, with the exception of the modifications at higher pressure, as it reaches its peak at $160^{\circ} \mathrm{C}(13.2 \%)$ and decreases to $10.1 \%$ at $170^{\circ} \mathrm{C}$, while in the open system the highest extractive content is at $210^{\circ} \mathrm{C}$ $(12.7 \%)$, following by a decrease up to $7.4 \%$ at $230^{\circ} \mathrm{C}$. The difference is a result of which reaction was faster, either the formation of degradation products or their vaporization at elevated temperatures. Similar results were obtained with E. globulus modified in an autoclave 
heat treatment and oven heating where the extractive content was lower at the highest modification conditions $\left(200^{\circ} \mathrm{C}\right.$ and 12 hour treatment time and $190^{\circ} \mathrm{C}$ and 24 hour treatment time for autoclave and oven modification respectively) than at modifications at shorter treatment times (Esteves et al. 2008a). It was also expected that the closed system modifications would have higher amounts of extractives than in the open system, but for some modifications in this study, the contents were similar. The longer time to complete the open system modification (Table 2.1) could be the reason that the extractive contents were similar.

ML, in our case CML, is also related to the degradation of the wood (Zaman et al. 2000), which makes it a suitable comparison point and is usually referred as an indicator of the quality of the modification, as it is linked to many properties of the modified wood (Welzbacher and Rapp 2007; Esteves and Pereira 2009). The CML in the closed system showed tendencies that were similar to what was presented by Altgen et al. (2016b) with European beech, as the CML increases with higher pressure and the same temperature (Table 2.2). Altgen et al. (2016b) showed that, although an improved heat transfer and reduced evaporative cooling could be a factor in the accelerated degradation reactions, temperature can be excluded as the sole factor for the degradation of wood in modifications under high pressure. The open system modification tends to show a higher CML as the temperature rises, with the exception of the modification at $220^{\circ} \mathrm{C}(16.8 \%)$, which was lower than $210^{\circ} \mathrm{C}(18.7 \%)$. The influence of the extractives can be a reason for this, as they are higher at $210^{\circ} \mathrm{C}$ (Table II). The mass loss in autoclave modifications (open system) at similar temperatures performed in other eucalypt species, such as E. grandis (from $12.63 \%$ at $180^{\circ} \mathrm{C}$ and $16.91 \%$ at $220^{\circ} \mathrm{C}$ ), E.saligna (from $12.77 \%$ at $180^{\circ} \mathrm{C}$ and $19.12 \%$ at $220^{\circ} \mathrm{C}$ ) (de Cademartori et al. 2015) and $8.7 \%$ at $190^{\circ} \mathrm{C}$ and $12.1 \%$ at $200^{\circ} \mathrm{C}$ for E. globulus (Esteves et al. 2007b), show a tendency of an increase in mass loss at higher modification temperatures, but it has to be noted that they did not use the CML in their data. 
Table 2.2: Average values and standard deviation of cellulose DP, corrected mass loss (CML) and the summative chemical composition of unmodified and thermally modified of E. nitens wood in an open and closed system. Values are given as mean \pm standard deviation.

\begin{tabular}{cc|cccc|c|c}
\hline $\begin{array}{c}\text { Temperature } \\
\left({ }^{\circ} \mathrm{C}\right)\end{array}$ & $\begin{array}{c}\text { RH } \\
(\%)\end{array}$ & $\begin{array}{c}\text { Extractives } \\
(\%)\end{array}$ & Lignin (\%) & Cellulose (\%) & $\begin{array}{c}\text { Hemicelluloses } \\
(\%)\end{array}$ & $\begin{array}{c}\text { Cellulose } \\
\text { DP }\end{array}$ & CML (\%) \\
\hline Unmodified & - & $4.7 \pm 0.31$ & $22.5 \pm 0.33$ & $48.3 \pm 0.40$ & $27.4 \pm 0.38$ & $930 \pm 14$ & - \\
& & & & & & & \\
150 & 30 & $6.0 \pm 0.38$ & $21.0 \pm 0.22$ & $50.1 \pm 0.28$ & $23.5 \pm 0.31$ & $850 \pm 31$ & $2.6 \pm 0.56$ \\
160 & 30 & $7.6 \pm 0.15$ & $23.1 \pm 0.19$ & $51.3 \pm 0.23$ & $17.6 \pm 0.32$ & $783 \pm 23$ & $5.0 \pm 0.63$ \\
170 & 30 & $8.4 \pm 0.28$ & $22.8 \pm 0.21$ & $53.9 \pm 0.25$ & $14.2 \pm 0.27$ & $714 \pm 27$ & $6.3 \pm 0.77$ \\
150 & 100 & $12.7 \pm 0.22$ & $25.4 \pm 0.18$ & $55.7 \pm 0.33$ & $5.9 \pm 0.30$ & $569 \pm 30$ & $11.4 \pm 1.26$ \\
160 & 100 & $13.2 \pm 0.24$ & $26.5 \pm 0.23$ & $53.7 \pm 0.36$ & $6.5 \pm 0.33$ & $427 \pm 20$ & $18.6 \pm 1.63$ \\
170 & 100 & $10.1 \pm 0.18$ & $31.8 \pm 0.15$ & $49.7 \pm 0.29$ & $10.3 \pm 0.33$ & $356 \pm 26$ & $20.5 \pm 1.82$ \\
& & & & & & & \\
160 & - & $6.8 \pm 0.38$ & $20.8 \pm 0.26$ & $52.2 \pm 0.37$ & $18.8 \pm 0.40$ & $805 \pm 18$ & $5.4 \pm 0.37$ \\
180 & - & $9.0 \pm 0.40$ & $23.5 \pm 0.27$ & $48.6 \pm 0.33$ & $18.7 \pm 0.36$ & $863 \pm 22$ & $7.9 \pm 0.53$ \\
200 & - & $12.3 \pm 0.10$ & $23.7 \pm 0.12$ & $52.5 \pm 0.21$ & $10.4 \pm 0.29$ & $589 \pm 11$ & $14.6 \pm 0.88$ \\
210 & - & $12.7 \pm 0.16$ & $27.4 \pm 0.13$ & $49.3 \pm 0.19$ & $10.8 \pm 0.24$ & $648 \pm 15$ & $18.7 \pm 0.58$ \\
220 & - & $9.1 \pm 0.26$ & $28.6 \pm 0.21$ & $50.2 \pm 0.24$ & $11.8 \pm 0.27$ & $630 \pm 3$ & $16.8 \pm 1.23$ \\
230 & - & $7.4 \pm 0.15$ & $36.9 \pm 0.23$ & $45.8 \pm 0.32$ & $12.2 \pm 0.41$ & $466 \pm 19$ & $19.3 \pm 1.31$ \\
\hline
\end{tabular}

Cellulose has a highly ordered crystalline structure which provides a high stability to the cellulose chains and protects them against acid attack during hydrolysis (Fengel and Wegener 1984). There is a limited occurrence of cellulose degradation during the hydro-thermolysis of wood (Boonstra and Tjeerdsma 2006), but it appears that under moist conditions there is a stimulating effect on the crystallization of amorphous cellulose (Bhuiyan et al. 2000). Cellulose is related to the strength of the wood fiber, so a reduction of its degree of polymerization (DP), which represents the length of the cellulose chain, would cause a reduction in the strength properties of the wood (Sweet and Winandy 1999). Cellulose content in the modified wood tends to be higher at higher temperatures at low pressure modification, up to $53.9 \%$ at $170^{\circ} \mathrm{C}$, whereas the contrary happens at higher pressure, with the modification at $150^{\circ} \mathrm{C}$ having $55.7 \%$ of cellulose. At higher temperatures $200^{\circ} \mathrm{C}$ presents the higher cellulose content (52.5\%), while modifications at 210 and $220^{\circ} \mathrm{C}$ have similar contents (around 50\%) and the modification at $230^{\circ} \mathrm{C}$ being lowest at $45.8 \%$ (Table II). The higher amounts of cellulose content in relation to the unmodified sample can be related to the depolymerization of the hemicellulose chains, while the lower amount of cellulose content at $230^{\circ} \mathrm{C}$ can be related to the increase of the lignin 
content. In both high and low pressure modification, the cellulose DP tends to get shorter with higher temperatures (Table 2.2). Particularly at high pressure and $170^{\circ} \mathrm{C}$ the cellulose DP is almost a third shorter than at the unmodified samples (930 to 356). At the modifications in the open system there is no constant degradation of the cellulose DP chains as the temperature rises, having similar results between 210 and $220^{\circ} \mathrm{C}$ (648 and 630 respectively). Both were longer than at $200^{\circ} \mathrm{C}(589)$, while the shortest cellulose DP was at $230^{\circ} \mathrm{C}(466)$. It has to be noted that the isolation of cellulose from wood involves risk for some degradation that can result in a reduced molecular weight. The results were similar to what Kačíková et al. (Kačíková et al. 2013) presented in Norway spruce, where the cellulose DP decreased at higher temperatures.

The cleavage of the side chain constituents (arabinose and galactose) is followed by the degradation of the main chain constituents (mannose, glucose and xylose), with the corresponding pentoses and hexoses being dehydrated to furfurals and hydroxymethylfurfurals (Bobleter and Binder 1980). In all modifications the xylose content decreased from lower to higher temperatures, with galactose and mannose completely absent in the high pressure and almost completely absent at high temperatures in the open system modification (Table 2.3). The results were similar to the ones obtained by Esteves et al. (2008b) with E. globulus, de Moura et al. with E. grandis (2012) and Araújo et al. (2017) with various eucalypt species after a torrefaction with gradual heating from 160 to $230^{\circ} \mathrm{C}$. 
Table 2.3: Average values of the carbohydrate composition in relation to total sugars of the unmodified and thermally modified of E. nitens wood in an open and closed system.

\begin{tabular}{cc|cccc}
\hline $\begin{array}{c}\text { Temperature } \\
\left({ }^{\circ} \mathrm{C}\right)\end{array}$ & $\begin{array}{c}\text { RH } \\
(\%)\end{array}$ & $\begin{array}{c}\text { Glucose } \\
(\%)\end{array}$ & $\begin{array}{c}\text { Xylose } \\
(\%)\end{array}$ & $\begin{array}{c}\text { Galactose } \\
(\%)\end{array}$ & Mannose \\
\hline Unmodified & - & 72.34 & 26.25 & 0.76 & 0.66 \\
150 & 30 & 72.24 & 22.99 & 3.74 & 1.02 \\
160 & 30 & 78.38 & 19.26 & 1.58 & 0.78 \\
170 & 30 & 82.29 & 15.93 & 1.16 & 0.62 \\
150 & 100 & 86.58 & 12.27 & 0.00 & 1.16 \\
160 & 100 & 96.89 & 2.36 & 0.00 & 0.75 \\
170 & 100 & 97.86 & 1.22 & 0.00 & 0.91 \\
& & & & & \\
160 & - & 79.09 & 17.49 & 2.61 & 0.82 \\
180 & - & 76.24 & 19.57 & 2.91 & 1.28 \\
200 & - & 89.78 & 9.83 & 0.00 & 0.38 \\
210 & - & 89.74 & 9.59 & 0.07 & 0.60 \\
220 & - & 90.29 & 8.91 & 0.16 & 0.64 \\
230 & - & 96.02 & 3.29 & 0.14 & 0.55 \\
\hline
\end{tabular}

There is an increase in lignin at higher temperatures in all modifications, which is related to the fact that lignin has a higher thermal stability than the other elements in wood, but also to its condensation reactions. As the lignin content increases, the hemicellulose content decreases. The process temperature, duration of treatment and the pressure influence the degradation of the hemicelluloses and the release of acids (Belkacemi et al. 1991). At higher temperatures there are more hemicellulose cleavage products due to depolymerisation, and the production of more reactive intermediates, such as furfurals, which cause more cross linking reactions that increase the lignin polymer network and probably increase the relative proportion of crystalline cellulose (Boonstra and Tjeerdsma 2006). In this study, this tendency was not present in the modification at high pressure, where it reached its lowest value at $150^{\circ} \mathrm{C}(5.9 \%)$. This could be related to the higher acid content present at that temperature (Table 2.4), as it is a factor that affects the hydrolysis of hemicelluloses and the accessibility of the reactants (Belkacemi et al. 1991). In the case of the open system, there was no significant difference between $200^{\circ} \mathrm{C}$ and $210^{\circ}$, but there was slight increase of the hemicellulose content until $230^{\circ} \mathrm{C}$. In general, the 
hemicellulose content decreases at higher temperatures (Esteves and Pereira 2009). In our case, this slight increase could be related to the decrease of the extractive content and the increase of the lignin content, specifically at $230^{\circ} \mathrm{C}$ (Table 2.2).

High concentrations of acids build up in closed systems, with the most prevalent acids being acetic and formic acid (Garrote et al. 2001; Sundqvist et al. 2006). Acetic acid has an atmospheric boiling point at around $118^{\circ} \mathrm{C}$, while formic acid has it around $101^{\circ} \mathrm{C}$, thus they are vaporized and emitted during a modification in an open system (Hofmann et al. 2013; Altgen et al. 2014). As the acidic catalysed hydrolysis affects the degradation of lignocellulosic material (Garrote et al. 1999), it shows the influence in the modified wood under pressure (Altgen et al. 2016a), as there is a higher acetic acid content at lower temperatures in modifications at high pressure, while at the open system the highest acetic acid content is at $220^{\circ} \mathrm{C}$ and the lowest at $230^{\circ} \mathrm{C}$. As for the formic acid, it is at its highest in the modifications at high pressure and modification temperatures of 160 and $170^{\circ} \mathrm{C}$, whereas in the closed system it reaches its higher values at 200 and $210^{\circ} \mathrm{C}$ (Table 2.4).

The concentration of phenolic compounds increases as the pressure and temperature raises in the closed system, while in the open system it reaches its peak at $230^{\circ} \mathrm{C}$, but at $220^{\circ} \mathrm{C}$ the total phenol is lower than at 200 and $210^{\circ} \mathrm{C}$ (Table 2.4). The modification at $100 \% \mathrm{RH}$ showed the highest amount of total phenolic compounds, so there are more phenols produced at high pressure and are probably simple phenols with low molecular weight as stated by Hofmann et al. (2013). 
Table 2.4: Average values of formic and acetic acid content and average values and standard deviation of total phenol of unmodified and thermally modified of E. nitens wood in an open and closed system modification. Values are given as mean \pm standard deviation.

\begin{tabular}{|c|c|c|c|c|}
\hline $\begin{array}{c}\text { Temperature } \\
\left({ }^{\circ} \mathrm{C}\right)\end{array}$ & $\mathrm{RH}(\%)$ & $\begin{array}{c}\text { Formic } \\
\text { acid } \\
\text { (mg/100g } \\
\text { dry wood) }\end{array}$ & $\begin{array}{c}\text { Acetic } \\
\text { acid } \\
(\mathrm{mg} / 100 \mathrm{~g} \\
\text { dry wood) }\end{array}$ & $\begin{array}{c}\text { Total phenol } \\
\text { (mg/g dry } \\
\text { wood) }\end{array}$ \\
\hline Unmodified & - & 15.3 & 94.5 & $8.4 \pm 0.21$ \\
\hline 150 & 30 & 30.5 & 140.1 & $8.4 \pm 0.01$ \\
\hline 160 & 30 & 72.9 & 116.5 & $10.9 \pm 0.07$ \\
\hline 170 & 30 & 60.5 & 121.5 & $13.4 \pm 1.92$ \\
\hline 150 & 100 & 71.1 & 391.4 & $29.7 \pm 1.20$ \\
\hline 160 & 100 & 104.2 & 260.4 & $34.9 \pm 1.94$ \\
\hline 170 & 100 & 104.0 & 228.9 & $40.7 \pm 6.08$ \\
\hline 160 & - & 48.4 & 95.3 & $9.9 \pm 0.08$ \\
\hline 180 & - & 62.4 & 120.2 & $11.8 \pm 0.24$ \\
\hline 200 & - & 73.6 & 108.4 & $23.3 \pm 0.78$ \\
\hline 210 & - & 74.3 & 128.8 & $23.6 \pm 1.14$ \\
\hline 220 & - & 48.7 & 225.7 & $20.1 \pm 1.44$ \\
\hline 230 & - & 36.6 & 67.5 & $24.1 \pm 1.49$ \\
\hline
\end{tabular}

\subsubsection{Mechanical changes}

There is a decrease in the MOE as the temperature increases in the closed system, showing a clear influence of the pressure and temperature on this property, while in the open system modification there was an increase of MOE from 160 to $200^{\circ} \mathrm{C}$, followed by a decrease starting at $210^{\circ} \mathrm{C}$ (Table 2.5). This increase in MOE was also presented in a thermal modification of E. globulus (Santos 2000), although no type of treatment was mentioned, and in E. grandis and E. regnans (de Cademartori et al. 2015). Esteves et al. (2007a) also showed a slight increase at the lower modification temperatures, followed by a decrease of MOE at higher temperatures in modifications between $170^{\circ} \mathrm{C}$ and $200^{\circ} \mathrm{C}$ using E. globulus. 
MOR tends to decrease at the modifications at higher pressure in the closed system and at temperatures over $210^{\circ} \mathrm{C}$ in the open system. At $150^{\circ} \mathrm{C}$ the MOR is somewhat higher than the unmodified sample, whereas the values at 160 and $170^{\circ} \mathrm{C}$ were similar to the unmodified sample (Table 2.5). In general, there is a decrease in MOR in open thermal modification systems (Esteves and Pereira 2009), but there are cases in thermal modifications of other hardwood species, such as birch, where there was a slight increase in the MOR (Shi et al. 2007b).

Table 2.5: Average values and standard deviation of MOE and MOR of unmodified and thermally modified of unmodified and thermally modified of E. nitens wood in an open and closed system modification. Values are given as mean \pm standard deviation.

\begin{tabular}{|c|c|c|c|}
\hline Temperature $\left({ }^{\circ} \mathrm{C}\right)$ & RH (\%) & $\operatorname{MOE}(\mathrm{MPa})$ & $\operatorname{MOR}(\mathrm{MPa})$ \\
\hline Unmodified & - & $18449 \pm 959$ & $119 \pm 13$ \\
\hline 150 & 30 & $18761 \pm 1009$ & $131 \pm 11$ \\
\hline 160 & 30 & $17012 \pm 1233$ & $117 \pm 16$ \\
\hline 170 & 30 & $16305 \pm 1256$ & $117 \pm 9$ \\
\hline 150 & 100 & $16131 \pm 1740$ & $94 \pm 9$ \\
\hline 160 & 100 & $15059 \pm 1696$ & $89 \pm 15$ \\
\hline 170 & 100 & $14464 \pm 1228$ & $85 \pm 9$ \\
\hline 160 & - & $19084 \pm 1746$ & $132 \pm 19$ \\
\hline 180 & - & $19403 \pm 2098$ & $134 \pm 18$ \\
\hline 200 & - & $22224 \pm 1684$ & $119 \pm 14$ \\
\hline 210 & - & $17829 \pm 1624$ & $109 \pm 18$ \\
\hline 220 & - & $15775 \pm 1558$ & $90 \pm 15$ \\
\hline 230 & - & $14604 \pm 1411$ & $88 \pm 19$ \\
\hline
\end{tabular}

\subsubsection{Correlation between chemical and mechanical changes}

A Pearson correlation test was run to determine any relationship between the mechanical properties (MOE and MOR), the chemical variations of selected properties (lignin, hemicelluloses, xylose, cellulose DP and total phenols) and the CML in the open and closed system modifications. In the case of the closed system modifications there was a strong negative 
relationship between MOE and MOR with the CML, lignin and total phenols, meaning that when there was a decrease of these properties, the MOE and MOR had a tendency to increase. There was also a strong positive relationship between hemicelluloses, xyloses and cellulose DP, which means that when these properties decrease, the MOE and MOR would also decrease. In the case of the MOE for the open system, no property showed a significant correlation. MOR had a strong negative relationships with the CML and lignin content and a strong positive relationships with xylose and cellulose DP (Table 2.6).

Table 2.6: Pearson correlation coefficients for MOE and MOR in relation to corrected mass loss and selected chemical changes in open and closed system. Significant correlations $(\mathrm{p}<0.05)$ were marked with an asterisk $(*)$.

Pearson correlation coefficient

\begin{tabular}{c|cc|cc}
\hline & \multicolumn{2}{|c|}{ Open } & \multicolumn{2}{c}{ Closed } \\
& MOE & MOR & MOE & MOR \\
\hline CML & -0.504 & $-0.871^{*}$ & $-0.921^{*}$ & $-0.955^{*}$ \\
Lignin & -0.806 & $-0.876^{*}$ & $-0.883^{*}$ & $-0.896^{*}$ \\
Hemicelluloses & -0.154 & 0.710 & $0.837^{*}$ & $0.906^{*}$ \\
Xylose & 0.489 & $0.902^{*}$ & $0.952^{*}$ & $0.975^{*}$ \\
Cellulose DP & 0.435 & $0.849^{*}$ & $0.938^{*}$ & $0.970^{*}$ \\
Total phenols & -0.254 & -0.748 & $-0.888^{*}$ & $-0.977^{*}$ \\
\hline
\end{tabular}

The main components of the cell wall (cellulose, hemicellulose, lignin) have different degrees of contribution to the strength of wood according to a hypothetical model presented by Winandy and Rowell (1984). A thermal modification affects the individual wood components and it can have an effect on the mechanical properties of the modified wood. The linear backbone chain of hardwood hemicelluloses is mainly the xylose. Because there is a higher amount of xylose than mannose, arabinose and galactose, small variations can have a large impact on the overall strength (Sjostrom 1981). LeVan et al. (1990) speculates that the cleavage of these side groups between the lignin and hemicelluloses release the linkage by which one microfibril of a wood fiber shares the load with another microfibril. This disruption of the load-sharing would result in increased brittleness, which would lead to a gradual reduction in strength in combination with the disruption of the hemicellulose backbone chains (Winandy and Rowell 1984; LeVan et al. 1990). The degradation or modification of hemicelluloses has also been suggested to be one of the primary influences for the loss of bending strength, as there was no depolymerisation 
or degradation of lignin or cellulose after a heat treatment (Sweet and Winandy 1999; Winandy and Lebow 2001). Cellulose and hemicelluloses are linked between themselves and lignin, with lignin being the "adhesive" that holds the microfibrils formed by cellulose chains that are covered by hemicelluloses. The removal of hemicelluloses increases the crystalline part in wood material which relatively increases the cellulose component. This replaces the flexible hemicellulose-cellulose-hemicellulose bond with the more rigid cellulose-cellulose bond, decreasing the flexibility of the material (Kocaefe et al. 2008a).

In the case of the thermally modified E. nitens wood, as the correlations from Table 2.6 show, xylose had a stronger correlation with the decrease of MOR in both open and closed system, whereas the hemicelluloses were not significantly correlated to this property in the open system. Due to those correlations, it would be recommendable to use xylose as the dependent variable to suggest brittleness in modified wood. The decreasing pattern in the xylose content and the decline in MOR at higher temperatures in each thermal modification shows that there is a relationship between strength properties and the degradation of the carbohydrates. This confirms the wood strength-wood chemical model that was suggested by Winandy and Rowell (1984).

The hemicellulose and xylose content are slightly higher in the modifications in open system than in the modification in the closed system at high pressure and $160^{\circ} \mathrm{C}$ and $170^{\circ} \mathrm{C}($ Table 2.2). The cellulose content tends to be higher in the modifications at high pressure, meaning that the hemicelluloses were affected more in the modifications under high pressure, which could mean that the cellulose crystallinity was also affected. This could explain the higher MOE values in the open system modifications, as it seems that the hemicelluloses were not affected as much as in the closed system modifications, something that also occurred in thermally modified aspen wood (Kocaefe et al. 2008a).

Sweet and Winandy (1999) suggest a theory that the acids in wood hydrolyse the cellulose chains, and since the cellulose DP is considered as primarily responsible for the strength of the wood fiber, the reduction of the length of the cellulose chains could cause a reduction in strength properties, which can be related to the mechanical properties of the wood. The results obtained in this study show that the cellulose DP had a tendency to decrease rapidly as the temperature raised in both low and high pressure closed system modifications. In the open system modifications there was no such constant decrease as the temperature raised, as the cellulose 
DP maintained a similar length between $210^{\circ}$ and $220^{\circ} \mathrm{C}$ (Table 2.2). This is related to the stronger correlations between MOR and cellulose DP in the closed system presented in Table VI, which could suggest that it would lead to a more brittle material that breaks at a quicker rate in the modifications under high pressure. It can also be seen that the formic and acetic acid has a higher content in closed system modification (Table 2.4), which also confirms the theory suggested by Sweet and Winandy (1999).

Phuong et al. (2007) concluded that the brittleness in Styrax tonkinesis increased significantly after heat treatment and that could be related to lignin relocation at low temperatures $\left(160^{\circ} \mathrm{C}\right)$ and loss of amorphous polysaccharides due to degradation. In the case of E.nitens, the lignin content increases similarly in both open and closed systems, but there is a stronger correlation for both MOE and MOR in the closed system, while also having a higher total phenol content, which could mean that the transformation of lignin during a closed system could produce higher amounts of phenolic extractives than the modification in an open system. This also suggests that the closed system modifications would tend to be more brittle than the ones in the open system.

For a direct comparison of modifications from the open and the closed system, the CML can be used. The closed system modification at $160^{\circ} \mathrm{C}$ and high pressure and the open system modification at $210^{\circ} \mathrm{C}$ show similar CML of 18.6 and $18.7 \%$ respectively. They present similar lignin and extractive content, but show significant differences in cellulose DP, cellulose and hemicellulose content (Table 2.2), xylose content (Table 2.3), total phenol and formic and acetic acid content (Table 2.4). The MOE and MOR were also lower in the closed system than in the open system modification (Table 2.5). Based on the previous analysis of the correlation between mechanical and chemical properties, at least when both modifications present the same CML, it can be said that the modification at $160^{\circ} \mathrm{C}$ and high pressure was more brittle than at $210^{\circ} \mathrm{C}$.

The results obtained show that the influence of pressure in the closed systems change the chemical properties to similar or even higher values as in the open system, even at shorter total process duration and lower modification temperatures (Table 2.1). This confirms that in this closed system the modification pressure influences more the chemical structure than the temperature (Altgen et al. 2016b). These changes influence the mechanical properties, especially at high pressure, suggesting that the modified wood obtained from those processes would tend to be more brittle than in the open system modification. 


\subsection{Conclusion}

Even at lower temperatures, and shorter total process duration times, modifications in a closed system under high pressure affected more the chemical structure of the modified wood than the modifications in the open system. In turn, it also affected the mechanical properties, as they were strongly correlated to the variations of xyloses, cellulose DP, lignin content and total phenols. This was related to the tendency of the wood to be more brittle in those modifications. The use of closed system modifications has its advantages for the industry, especially the fact that the modifications take less time and hence have a lower energy consumption, but some of the properties obtained could affect the types of products to produce. Taking this into consideration and knowing that the open system modification take longer to be completed, the obtained results in this study can be used as a reference for future applications of E. nitens modified wood. They could also be used to optimize thermal modification processes to adjust to the necessities of the wood market.

Acknowledgments: The first author would like to thank the CONICYT BECAS CHILE scholarship for the stay in the Georg-August-University Göttingen in Germany and the "Untersuchung der Strukturänderungen des Holzes durch thermische Modifizierungsverfahren" program that allowed to conduct part of the experiments in the University of Sopron in Hungary. 


\section{Chapter 3: Publication II}

Dynamic and static mechanical properties of Eucalyptus nitens thermally modified in an open and closed reactor system

Maximilian Wentzel $^{1 *}$, Christian Brischke ${ }^{1}$, Holger Militz ${ }^{1}$

${ }^{1}$ Department of Wood Biology and Wood Products, University of Göttingen, Faculty of Forest

Science, Büsgenweg 4, 37077 Göttingen, Germany

*corresponding author:

Phone: +495513922051

Fax: +49551399646

E-mail: mwentze@gwdg.de

ORCID: 0000-0002-5795-7589

Originally published in:

Maderas: Ciencia y tecnología

Universidad del Bío-Bío

ISSN (Print) 0717-3644

ISSN (Online) 0718-221X

DOI: $\quad 10.4067 / \mathrm{S} 0718-221 \mathrm{X} 2019005000201$

Received: July 102018

Accepted: August 282018

Published online: Ahead of print January 62019

https://scielo.conicyt.cl/scielo.php?pid=S0718-221X2019005000201\&script=sci_arttext 
Abstract: Eucalyptus nitens is a fast growing plantation species that has a good acclimation in Chile. It is commonly used for pulp and paper, but there is a growing market for solid wood products made from this species and an interest on producing high quality material. Thermal modification technology have been used to obtain high quality product out of fast growing plantation species. In this study we modified E. nitens to analyse the influences of the process conditions and evaluated its mechanical properties under several process conditions. The material was modified in a closed system under elevated pressure and controlled relative humidity (30 and $100 \% \mathrm{RH}$ ) at temperatures between 150 and $170^{\circ} \mathrm{C}$, and in an open system with a standard thermal modification procedure between 160 and $230^{\circ} \mathrm{C}$. Modulus of elasticity (MOE), modulus of rupture (MOR), deflection and work in bending (in elastic and inelastic proportions) and the resistance to impact milling (RIM) in High-Energy Multiple Impact (HEMI) tests were determined. Mass loss after each modification was also measured and correlated with the mechanical properties. Anatomical properties of selected modifications were analysed. There were no significant differences between open and closed system modifications in both mechanical and anatomical properties.

Keywords: Eucalyptus nitens, High-Energy Multiple Impact (HEMI) test, modulus of elasticity (MOE), modulus of rupture (MOR), thermal modification, wood anatomy

\subsection{Introduction}

Currently, Eucalyptus nitens plantation wood is mostly used for pulp and paper or biofuels, but there is an interest to widen the use of this fast growing tree species in Chile. Thermal modification technologies show potential to produce high quality material and open new markets for the use of this species. These processes use treatment temperatures between $150^{\circ} \mathrm{C}$ and $240^{\circ} \mathrm{C}$ under different operating conditions, either steam, vacuum, nitrogen that limit the presence of oxygen in the process (Hill 2006; Militz and Altgen 2014). They can be separated in open systems, in which the modification happens at atmospheric pressure (ThermoWood (Mayes and Oksanen 2002)), and closed systems, where the processes work under steam pressure such as FirmoLin (Willems 2009) and WTT (Dagbro et al. 2010), or vacuum (TERMOVUOTO (Allegretti et al. 2012)), to name a few examples. The wood composition changes when it is exposed to high temperatures, and as a consequence, it improves the biological durability (Hakkou et al. 2006; Boonstra et al. 2007b), and its dimensional stability (Boonstra and Tjeerdsma 2006; Tjeerdsma and Militz 2005), changing its mechanical properties (Esteves and Pereira 2009; Kubojima et al. 2000). These variations are closely related 
to the species and the process conditions. The static modulus of rupture (MOR) and the modulus of elasticity (MOE) are affected differently, as the MOR tends to decrease more than the MOE, as shown for thermal modifications of Betula papyrifera (Canadian white birch) (Poncsák et al. 2006) and Fagus sylvatica (European beech) (Tjeerdsma et al. 1998). In both species, MOE and MOR reduced with rising modification temperature. However, other authors showed that MOE of thermally modified wood can de higher than the reference values increased in certain thermal modifications (Kubojima et al. 2000; Santos 2000; Borrega and Kärenlampi 2008b; Lekounougou et al. 2011; Rautkari and Hill 2014). The structural integrity of wood is also affected by the thermal modification, as the degradation of hemicelluloses (Alen et al. 2002; Boonstra and Tjeerdsma 2006; Sundqvist et al. 2006) can cause an increased brittleness of the material (Phuong et al. 2007; Weigl et al. 2012). This also contributes to the decomposition of cell wall components, which are related to the mass loss, causing defects in the microscopic structure of the wood, such as cracking and cell wall collapse (Boonstra et al. 2006a; Boonstra et al. 2006b; Awoyemi and Jones 2011; Biziks et al. 2013). These structural defects may contribute to the mechanical changes of the thermally modified wood.

To quantitatively analyze the structural changes, a method was developed to determine the structural integrity of wood in relation of its resistance to impact milling (RIM). This is determined in a High-Energy Multiple Impact (HEMI) mill, which had been designed using steel balls of different size in a heavy vibratory mill for crushing wood samples. The process was developed to overcome the drawbacks of standard dynamic strength tests. Instead of using a high number of replicate wood specimens, the number of events that affect directly the wood can be multiplied (Brischke et al. 2006a; Brischke 2017).

The objective of this study was to examine the static mechanical behavior (MOE and MOR) and the dynamic mechanical behavior (HEMI test) of eucalypt wood after treatments in both open and closed reactor systems with the goal to analyze the influence of the process conditions. Selected samples from the open and closed modification systems were chosen to be analyzed with a scanning electron microscope (SEM) to reveal possible differences in the anatomical structure that could be influential in the changes of the mechanical properties. 


\subsection{Material and methods}

E. nitens wood that came from 19 year old plantations of the Región del Bío-Bío in Chile was used. Wood specimens with dimensions of $20 \times 50 \times 650 \mathrm{~mm}^{3}$ (radial $\mathrm{x}$ tangential $\mathrm{x}$ longitudinal) were prepared from kiln-dried wood that had an average moisture content (MC) of $12 \%$ avoiding knots and other visible flaws. For each modification process ten specimens were used.

\subsubsection{Thermal modification process}

Thermal modifications in an open and a closed systems were performed. The open system was a process similar to the Thermowood procedure (Mayes and Oksanen 2002), in which the first step is a pre-drying that starts at $100^{\circ} \mathrm{C}$ up to $130^{\circ} \mathrm{C}$ at a heating rate of $2^{\circ} \mathrm{C}$ per hour. Afterwards the temperature ramps up at $12^{\circ} \mathrm{C}$ per hour to the peak temperature, where it is hold up for 3 hours. Finally, the temperature decreased at a rate of $20^{\circ} \mathrm{C}$ per hour to $65^{\circ} \mathrm{C}$. In the case of the closed system modification, the WTT process (Willems 2009) was used. It consist of four steps: a 50 min holding step at pre-vacuum at $<14 \mathrm{kPa}$, temperature increase in a rate of $12^{\circ} \mathrm{C}$ per hour until modification temperature, a holding step at the peak temperature for 3 hours and a temperature decrease in a rate of $20^{\circ} \mathrm{C}$ per hour up to $65^{\circ} \mathrm{C}$. The total duration of the process was shorter in the closed system than in the open system. The list of modifications is presented in Table 3.1. Both processes were performed in a laboratory scale reactor in a stainless steel vessel with electric heating cables to heat up and cooling coils to cool down after the process. Exhaust valves were used to release the excess pressure. A gas washer was used to condense the volatiles produced by the modification. Water vapour was produced by heating an external water reservoir connected to the vessel. When using the equipment for closed system modifications, a pre-vacuum was applied $(13 \mathrm{kPa})$, with the water vapour pressure being adjusted by heating the water reservoir and discharging the excess pressure to maintain the relative humidity $(\mathrm{RH})$ constant. A scheme is presented in Figure 3.1. 


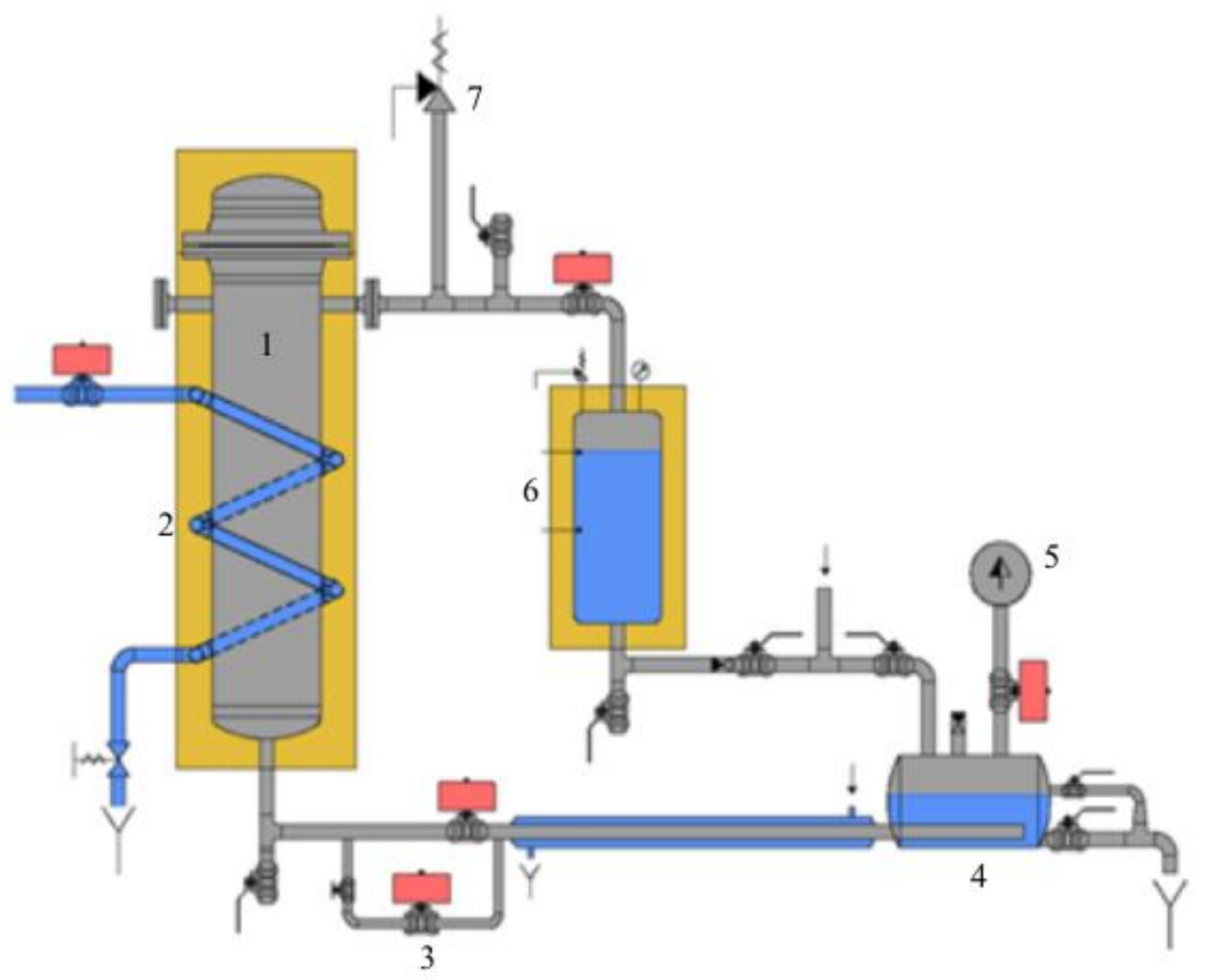

Figure 3.1: Scheme of the laboratory scale reactor. 1: Vessel for the wood specimens. 2: Cooling coil to regulate temperature inside the vessel. 3: Exhaust valves to regulate pressure. 4: Gas washer. 5: Vacuum pump. 6: Steam generator. 7: Safety valve. Adapted from Willems (2009). 
Table 3.1: Peak temperature, maximum pressure, extractive content, corrected mass loss (CML), moisture content (MC) and total process duration (TPD) of both modifications (open and closed) and the relative humidity (RH) applied in the thermal modifications in the closed systems. Duration of the modification at peak temperature was 3 hours for all processes.

Open System

\begin{tabular}{ccccccc}
\hline $\begin{array}{c}\text { Peak } \\
\text { temperature }\end{array}$ & $\begin{array}{c}\text { Max } \\
\text { pressure } \\
\left({ }^{\circ} \mathrm{C}\right)\end{array}$ & $\begin{array}{c}\text { RH } \\
(\mathrm{mPa})\end{array}$ & $\begin{array}{c}\text { Extractives } \\
(\%)\end{array}$ & $\begin{array}{c}\text { CML } \\
(\%)\end{array}$ & $\begin{array}{c}\text { FC } \\
(\%)\end{array}$ & $\begin{array}{c}\text { TPD } \\
(\%)\end{array}$ \\
\hline 160 & atmospheric & - & 6.76 & 5.37 & 3.34 & 30 \\
180 & atmospheric & - & 9.04 & 7.89 & 2.04 & 33 \\
200 & atmospheric & - & 12.29 & 14.61 & 2.04 & 35.5 \\
210 & atmospheric & - & 12.70 & 18.68 & 2.18 & 37 \\
220 & atmospheric & - & 9.12 & 16.78 & 2.25 & 38 \\
230 & atmospheric & - & 7.44 & 19.29 & 2.44 & 39.5 \\
\hline
\end{tabular}

Closed System

\begin{tabular}{ccccccc}
\hline $\begin{array}{c}\text { Peak } \\
\text { temperature }\end{array}$ & $\begin{array}{c}\text { Max } \\
\text { pressure } \\
(\mathrm{mPa})\end{array}$ & $\begin{array}{c}\text { RH } \\
(\%)\end{array}$ & $\begin{array}{c}\text { Extractives } \\
(\%)\end{array}$ & $\begin{array}{c}\text { CML } \\
(\%)\end{array}$ & $\begin{array}{c}\text { Final } \\
(\%)\end{array}$ & $\begin{array}{c}\text { TPD } \\
(\mathrm{C})\end{array}$ \\
\hline 150 & 0.14 & 30 & 5.96 & 2.55 & 4.50 & 16.5 \\
160 & 0.18 & 30 & 7.64 & 4.99 & 3.85 & 18 \\
170 & 0.23 & 30 & 8.41 & 6.29 & 3.20 & 19 \\
150 & 0.47 & 100 & 12.72 & 11.36 & 5.27 & 16.5 \\
160 & 0.61 & 100 & 13.16 & 18.57 & 4.94 & 18 \\
170 & 0.77 & 100 & 10.05 & 20.51 & 4.62 & 19 \\
\hline
\end{tabular}

The final wood MC was measured after each modification by difference of dry weight using small pieces collected from each specimen, so that this value could be extracted from the dry weight of each specimen. The degradation products of the cell wall carbohydrates accumulate in the wood during modifications at high temperatures (Altgen et al. 2016b). Hence, for a correct measurement of mass loss, the extractive content was measured as described by the Solvent Extractives of Wood and Pulp Test Method T 204 cm-07 (TAPPI 1997) using a Soxhlet 
apparatus. The corrected mass loss (CML) was calculated based on the dry and extractive-free weight of the wood before (unmodified) and after each process following eq. 3.1 and 3.2. It should be noted that the wood specimens were neither dried nor extracted prior to each modification process.

$$
O D_{E}=O D-(O D * E C / 100),
$$

Equation 3.1

where OD is the oven dry weight of small wood specimens in grams, EC is the extractive content and $\mathrm{OD}_{\mathrm{E}}$ is the oven dry and extractive free weight of the specimen. Now the CML can be calculated using Equation 2,

$$
C M L=\left(O D_{E B}-O D_{E A}\right) * 100 / O D_{E B}
$$

where $\mathrm{OD}_{\mathrm{EB}}$ is the oven dry and extractive free weight of the specimen before the modification process in grams and ODEA is the oven dry and extractive free weight of the specimen after the modification process in grams.

The increase of the extractive content is related to the generation of degradation products that outweighed their vaporization. By increasing the temperature beyond $210^{\circ} \mathrm{C}$ it seems that the vaporization of the degradation products increases more than the generation of them (Wentzel et al. 2018a). Thus there is a decrease in the $\mathrm{CML}$ at $220^{\circ} \mathrm{C}$ because the extractive content was less than at $210^{\circ} \mathrm{C}$ in the open system.

\subsubsection{Mechanical properties}

A three-point bending test according to DIN 52186 (1978) was conducted using a universal testing machine (Zwick Roell Z010, Zwick, Ulm, Germany) to measure the modulus of elasticity (MOE) and the modulus of rupture (MOR) (both in $\mathrm{Nmm}^{-2}$ ) on wood specimens of $10 \times 10 \times 180 \mathrm{~mm}^{3}$ (radial $\times$ tangential $\times$ longitudinal) that were conditioned at $20^{\circ} \mathrm{C} / 65 \% \mathrm{RH}$ before the test. At least 15 replicates per modification were tested. The span length of the samples was $150 \mathrm{~mm}$ and the load was applied in the transversal direction with the testing speed adjusted individually for each modification to allow failure of the samples within $90 \pm 30 \mathrm{~s}$. A load decrease of $10 \%$ or more of the maximum load was defined as failure. Deflection and work in bending were measured using the formulas presented by Altgen and Militz (2016). The 
elastic deflection was divided into elastic $\left(\delta_{\mathrm{e}}\right)$ and inelastic deflection $\left(\delta_{\mathrm{i}}\right)(\mathrm{mm})$ using the eq. 3.3 that is represented in Figure 3.2,

$$
\delta \mathrm{e}=P_{\max } * \delta / P,
$$

Equation 3.3

where $\mathrm{P}_{\max }$ is the maximum load $(\mathrm{N})$, P represents any load $(\mathrm{N})$ below the proportional limit and $\delta$ is the deflection $(\mathrm{mm})$ at the respective load P. The inelastic deflection $\left(\delta_{\mathrm{i}}\right)$ was calculated by subtracting the elastic deflection from the deflection at the maximum load. Work in bending $\left(\mathrm{W}_{\max }\right)(\mathrm{Nmm})$ was calculated as the area under the load deflection curve using eq. 3.4,

$$
W_{\max }=\int_{0}^{\delta_{\max }} P d \delta,
$$

Equation 3.4

Work in bending was separated into inelastic and elastic proportions $\left(\mathrm{W}_{\mathrm{e}}(\mathrm{N} \mathrm{mm})\right.$ and $\mathrm{W}_{\mathrm{i}}$ $(\mathrm{N} \mathrm{mm})$ respectively) as seen in Figure 3.2. The elastic proportion was calculated using eq. 3.5,

$$
W_{e}=\left(\delta_{e} / 2\right) * P_{\max },
$$

Equation 3.5

The inelastic work in bending $\left(\mathrm{W}_{\mathrm{i}}\right)$ was calculated by subtracting the elastic deflection from the deflection at the maximum load. All results are presented as a ratio with the average value of the reference set to 1 .

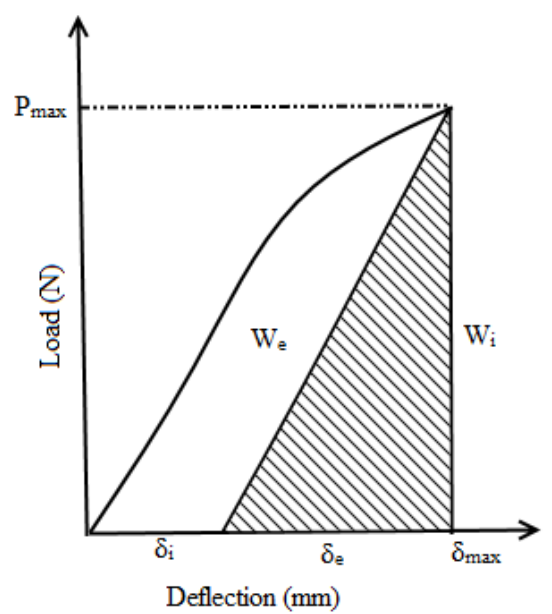

Figure 3.2: The schematic load-deflection curve of the three-point bending test. Maximum load $\left(\mathrm{P}_{\max }\right)$, deflection at maximum load $\left(\delta_{\max }\right)$, elastic deflection $\left(\delta_{\mathrm{e}}\right)$, inelastic deflection $\left(\delta_{\mathrm{i}}\right)$, elastic work in bending $\left(\mathrm{W}_{\mathrm{e}}\right)$ and inelastic work in bending $\left(\mathrm{W}_{\mathrm{i}}\right)$. Adapted from Altgen and Militz (2016). 


\subsubsection{High-Energy Multiple Impact test (HEMI)}

The development of the HEMI test had been described by Rapp et al. (2006) and Brischke et al. (2006b). In the present study, the process was adapted from the procedure presented by Brischke (2017): 20 oven-dry specimens of $10 \times 10 \times 10 \mathrm{~mm}$ were placed into a bowl of $140 \mathrm{~mm}$ inner diameter of a heavy impact ball mill (Herzog HSM 100, Osnabrück, Germany), together with one steel ball of $35 \mathrm{~mm}$ diameter, three steel balls of $12 \mathrm{~mm}$ diameter, and three steel balls of $6 \mathrm{~mm}$ diameter. The bowl was shaken for $60 \mathrm{~s}$ with a rotary frequency of $23.3 \mathrm{~s}^{-1}$ and a stroke of $12 \mathrm{~mm}$. The fragments of the 20 specimens were fractionated on a slit sieve with a slit width of $1 \mathrm{~mm}$ using an orbital shaker at an amplitude of $25 \mathrm{~mm}$ and a rotary frequency of $350 \mathrm{~min}^{-1}$ for $2 \mathrm{~min}$. The following values were calculated using eq. 3.6, 3.7 and 3.8:

$$
I=m_{20} / m_{\text {all }} * 100(\%),
$$

Where the degree of integrity (I) is the ratio of the mass of the 20 biggest fragments $\left(\mathrm{m}_{20}\right)$ to the mass of all fractions $\left(\mathrm{m}_{\mathrm{all}}\right)$ after the crushing process.

$$
F=m_{<1 m m} / m_{\text {all }},
$$

Equation 3.7

Where the fine fraction $(F)$ is the ratio of the mass that is sieved and has a diameter of less than $1 \mathrm{~mm}\left(\mathrm{~m}_{<1 \mathrm{~mm}}\right)$, to the mass of all fractions $\left(\mathrm{m}_{\text {all }}\right)$ multiplied by 100 .

$$
R I M=(I-3 * F)+300 / 400(\%), \quad \text { Equation } 3.8
$$

Where RIM is the resistance to impact milling and represents the value of the measure for the structural integrity of the material. All results are presented as a ratio with the average value of the reference set to 1 .

\subsubsection{Statistical evaluation}

Statistical analysis was performed to correlate selected chemical changes with mechanical properties using the Pearson Correlation Coefficient Test using the STATISTICA Software package Version 13.1 (StatSoft Inc., Tulsa, USA). 


\subsubsection{Scanning electron microscopy}

For the scanning electron microscopy (SEM) a ZEISS EVO ILS 15 (Carl Zeiss Microscopy $\mathrm{GmbH}$, Jena, Germany) was used. The specimens were taken from the wood before any mechanical test were performed. To obtain a smooth transversal surface, the samples were cut with a microtome knife. After mounting on an aluminum stub, the unmodified samples were carbon coated. Images were captured through detection of the secondary electrons. Working parameters were set to an accelerating voltage of $5 \mathrm{kV}$, a current of $40 \mathrm{pA}$, and a working distance of $8.5 \mathrm{~mm}$. The magnification used for imaging was 1000x. After taking the images, the samples were thermally modified. This was done to compare the differences before and after modification and to avoid some issues with the surface preparation, as the thermally treated samples tend to be brittle, making it difficult to obtain a smooth surface.

\subsection{Results and discussion}

\subsubsection{Static and dynamic mechanical properties}

The MOR ratio did not decrease at CML below 10\% (Figure 3.3a). At CML above 10\% the MOR ratio decreased up to 0.71 at $170^{\circ} \mathrm{C}$ and $100 \% \mathrm{RH}$, while at $230^{\circ} \mathrm{C}$ in the open system modification showed the highest decrease in the ratio (0.74). The loss of MOR at the higher temperatures, in both open and closed systems, can be related to the degradation of hemicelluloses (Zaman et al. 2000). This was confirmed by Wentzel et al. (2018b), where the degradation of xylans was closely related to the decrease of MOR. The degradation was higher in the closed system modifications due to the high concentrations of acids that build up because of the pressure, meaning that even at lower temperatures, closed system modifications can cause an increasing degradation of the hemicelluloses than high temperature modifications in the open system. This removal of hemicelluloses leads to distribution of stress over less cell wall material (related to CML) as one of its functions is to serve as stress transfer between lignin and reinforcing the cellulose microfibrils in the wood cell wall (Winandy and Lebow 2001). A decrease in the equilibrium moisture content (EMC) caused by the thermal modification may also play an important role in the decrease of MOR. Borrega and Kärenlampi (2008b) concluded that the mechanical properties were not only dependent of the mass loss, but also the relative humidity in the heating atmosphere, which influences the EMC of the wood after modification. In their study, MOR showed less decrease in modifications with lower EMC. In the case of the modified E. nitens, the EMC were shown to be lower in the open modification 
process (Wentzel et al. 2018a), which can be related to the slightly higher ratios presented in Figure 3.3a.

The MOE ratio decreases (Figure 3.3a) when the CML was above 10\% for both open and closed systems, although is less affected by the thermal modification than the MOR ratio. In the closed system the decrease in MOE is directly correlated to the CML, but in the open system modification there was an increase of the MOE ratio until $200^{\circ} \mathrm{C}$ reaching 1.2 (CML $15 \%$ ), after that point it started to decrease but without showing a direct relation between the CML and the MOE. Similar peaks of MOE have been reported in other species, such as Canadian white birch (Lekounougou et al. 2011), Picea abies (Norway spruce) (Borrega and Kärenlampi 2008b) and other eucalypt species, such as E. grandis and E. regnans (de Cademartori et al. 2015), and E. globulus (Santos 2000), although no type of treatment was mentioned in the latter.

The elastic deflection (Figure 3.3b) decreased with increasing CML in all the closed system modifications, while in the open system modification it was at its lowest at $200^{\circ} \mathrm{C}(0.72)$ and showed almost no variation in all other temperatures. On the other hand, the inelastic deflection was more sensitive to the thermal modification as it decreased further than the elastic deflection as the temperature rose on all the closed system modifications. The open system modifications showed a lower inelastic deflection ratio than in the closed system (Figure 3.3b), with its lowest peak being at $200^{\circ} \mathrm{C}(0.25)$. This could be related to an ultra-structural realignment that could cause to reduce the capabilities of the cell wall components for plastic flow (Altgen and Militz 2016). The results were similar to what was obtained for European beech (Altgen and Militz 2016) and Norway spruce (Borrega and Kärenlampi 2008b) in treatments in dry conditions. 

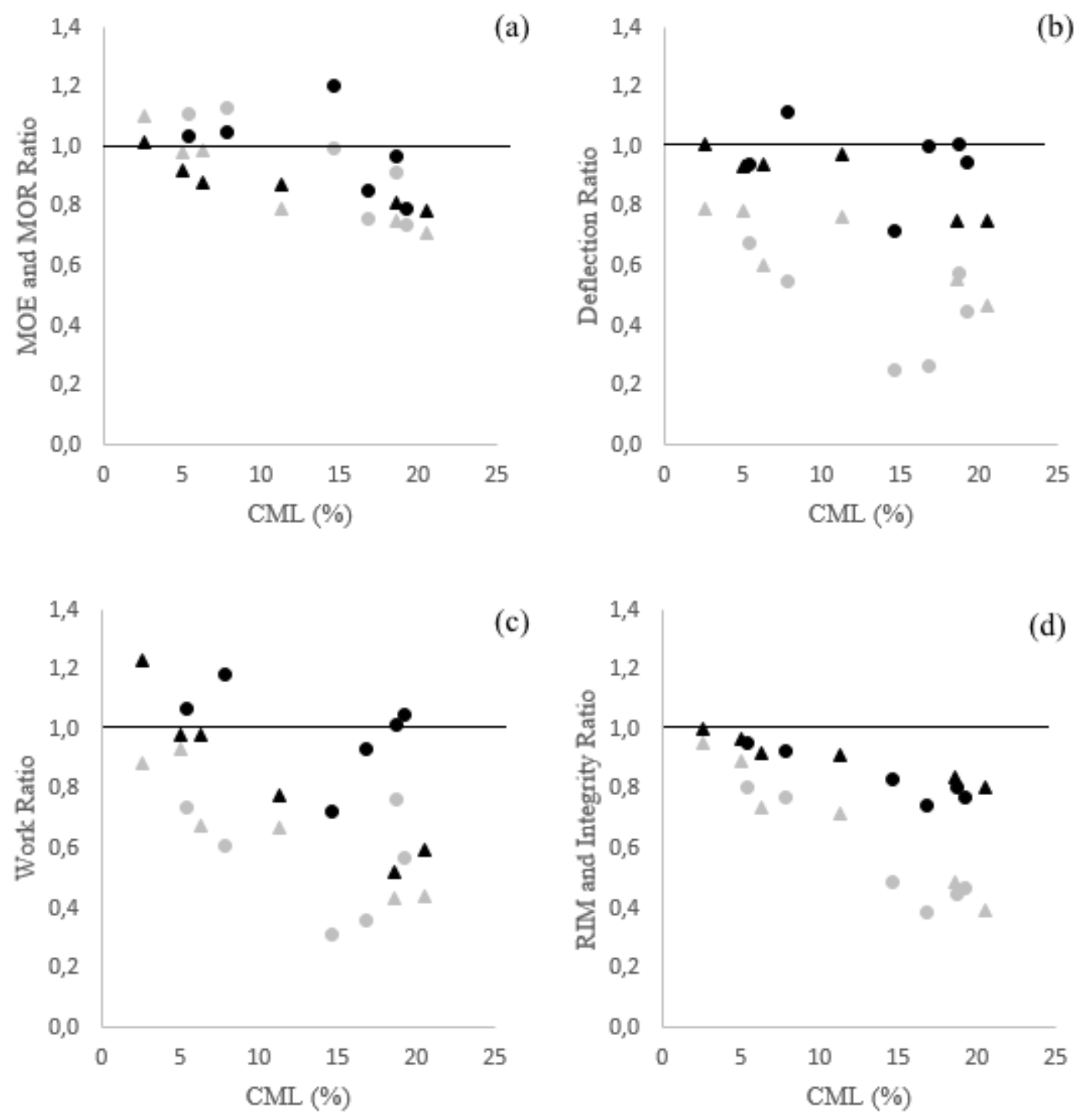

Figure 3.3: Ratio of MOE, MOR (a), inelastic and elastic deflection (b) and work (c) $(\mathrm{N}=15)$, RIM and integrity (d) ( $\mathrm{N}=20)$ as a function of CML. Circles represent open system modifications, triangles represent closed system modifications. Black represents MOE, elastic deflection, elastic work and RIM; grey represents MOR, inelastic deflection, inelastic work and degree of integrity. The line shows the unmodified reference value.

Elastic work ratio was higher at the lowest CML and then it decreased as the temperature rose in the closed system modifications at $30 \%$ and $100 \%$ RH. At the open system it slightly increased at the lowest CML, reaching its lowest point at $200^{\circ} \mathrm{C}(0.73)$. As for the closed system, it showed similar tendencies as the deflection, but with slightly higher ratios. At higher CML the elastic work showed no variation in relation to the reference sample. The inelastic work had a similar tendency as the elastic work in all the closed system modifications, meanwhile the closed system had its lowest ratio at $200^{\circ} \mathrm{C}(0.31)$ (Figure 3.3c). The changes 
could be associated to the inelastic deflection, as it influences the plastic flow, thus influencing negatively the work in bending (Altgen and Militz 2016).

There was a minor difference between open and closed modification systems in relation to the RIM and the degree of integrity. The slight differences between the modifications could be related to changes at a cell wall level, since the RIM is directly correlated with the decrease in microstructural integrity caused by heat-induced modification of the cell walls (Welzbacher et al. 2011). Both properties reduced when the temperature increased during the closed system modifications (Figure 3.3d). This reduction is in line with previous results (Brischke et al. 2006a; Rapp et al. 2006; Welzbacher and Rapp 2007; Welzbacher et al. 2011) confirming the strong correlation between RIM and the decrease in mass by heat treatment. On the other hand, in the open system the reduction of the RIM and the degree of integrity occurred until a CML of about $16.8 \%$ (modification at $220^{\circ} \mathrm{C}$ ) and then it slightly increased at $18.7 \%$ (modification at $\left.210^{\circ} \mathrm{C}\right) . \mathrm{CML}$ is related to the amount of extractive content, which also considers part of the degradation products caused by the thermal modification, deducted from the oven dry mass for its measurement, a higher degradation would mean a lower CML. When the E. nitens wood was modified over $210^{\circ} \mathrm{C}$, its relative content decreased (Wentzel et al. 2018b). As the RIM in the open system did not decrease linearly as the CML increased, it could mean that other chemical changes also could have influenced the RIM and should be taken into consideration when evaluating the results.

The correlations presented in Table 3.2 show that for the closed system significant positive correlations can be found between the dynamic (RIM and degree of integrity) and static (MOE, MOR) mechanical properties, which means that when one property increases or decreases, the other does too. The CML had also a significant negative correlation with the mechanical properties, as it increases when the mechanical properties decrease, confirming what was shown in Figure 3.3. Open system modification shows that MOE does not correlate with the other mechanical properties or the CML, whereas all the other properties correlate the same way as the closed system modification. 
Table 3.2: Pearson correlation coefficients for RIM, degree if integrity, MOE, MOR and CML in open and closed system modification. Significant correlations $(\mathrm{p}<0.05)$ were marked with an asterisk (*).

\begin{tabular}{|c|c|c|c|c|c|}
\hline & \multicolumn{5}{|c|}{ Closed system modification } \\
\hline & RIM & $\begin{array}{c}\text { Degree of } \\
\text { Integrity }\end{array}$ & MOE & MOR & CML \\
\hline RIM & 1.000 & $0.999 *$ & $0.964 *$ & $0.910^{*}$ & $-0.974^{*}$ \\
\hline $\begin{array}{l}\text { Degree of } \\
\text { Integrity }\end{array}$ & & 1.000 & $0.955^{*}$ & $0.903 *$ & $-0.975^{*}$ \\
\hline MOE & & & 1.000 & $0.921 *$ & $-0.925^{*}$ \\
\hline MOR & & & & 1.000 & $-0.952 *$ \\
\hline CML & & & & & 1.000 \\
\hline & & Open syst & m modif & ication & \\
\hline & RIM & $\begin{array}{c}\text { Degree of } \\
\text { Integrity }\end{array}$ & MOE & MOR & CML \\
\hline RIM & 1.000 & $0.974 *$ & 0.572 & $0.946^{*}$ & $-0.938^{*}$ \\
\hline $\begin{array}{c}\text { Degree of } \\
\text { Integrity }\end{array}$ & & 1.000 & 0.400 & $0.863^{*}$ & $-0.948^{*}$ \\
\hline MOE & & & 1.000 & 0.770 & -0.504 \\
\hline MOR & & & & 1.000 & $-0.870^{*}$ \\
\hline CML & & & & & 1.000 \\
\hline
\end{tabular}

When directly comparing two processes with similar CML from the open and closed system, the process at $160^{\circ} \mathrm{C}$ and $100 \% \mathrm{RH}$ and the process at $210^{\circ} \mathrm{C}$ had similar values $(18.57 \%$ and $18.68 \%$ respectively), there were some slight differences in all the ratios of their respective static mechanical properties (closed system presented lower values), but similar values in the dynamic mechanical properties.

\subsubsection{Scanning electron microscopy}

For this study, we focused on the development of cracks due to thermal modification. Previous studies show that there are no changes in the structure of ray parenchyma, vessels and fibers tissues before and after modification, as shown in E. grandis thermally modified up to $180^{\circ} \mathrm{C}$ 
(Batista et al. 2015) and birch and beech in a two-stage thermal treatment (Boonstra et al. 2006b). The same authors (Boonstra et al. 2006b) showed that radial cracks and broken cell walls perpendicular to the fiber direction resulted in cracks that could lead to different failures in the mechanical tests. This was corroborated by Biziks et al (2013), where voids and cracks were found on thermally treated birch. Figure 3.4 shows an unmodified E. nitens specimen. The wood cell walls of the fibers were all united by their respective middle lamellas (black arrows) and some of the pit connection between fibers can also be seen (white arrows). Figure 3.5 shows E. nitens thermally modified at $160^{\circ} \mathrm{C}$ and $100 \% \mathrm{RH}$ in a closed system and Figure 3.6 shows a specimen modified at $210^{\circ} \mathrm{C}$ in an open system. Both samples have the same CML (Table 1). It can be seen for both modifications, that the structure of the wood cell started to separate where the middle lamella was (black arrow in Figures 3.5 and 3.6) and cracks started to spread to the surrounding cells. Cracks also start to develop where pit connections where exposed (white arrows in Figure 3.5 and 3.6), which could be related to pit deaspiration, as described by Awoyemi and Jones (2011). Both crack developments happened in open and closed modifications, making it difficult to be certain that the process affects the wood structure differently. As with the mechanical properties, anatomical changes did not show significant differences between open and closed system modifications.

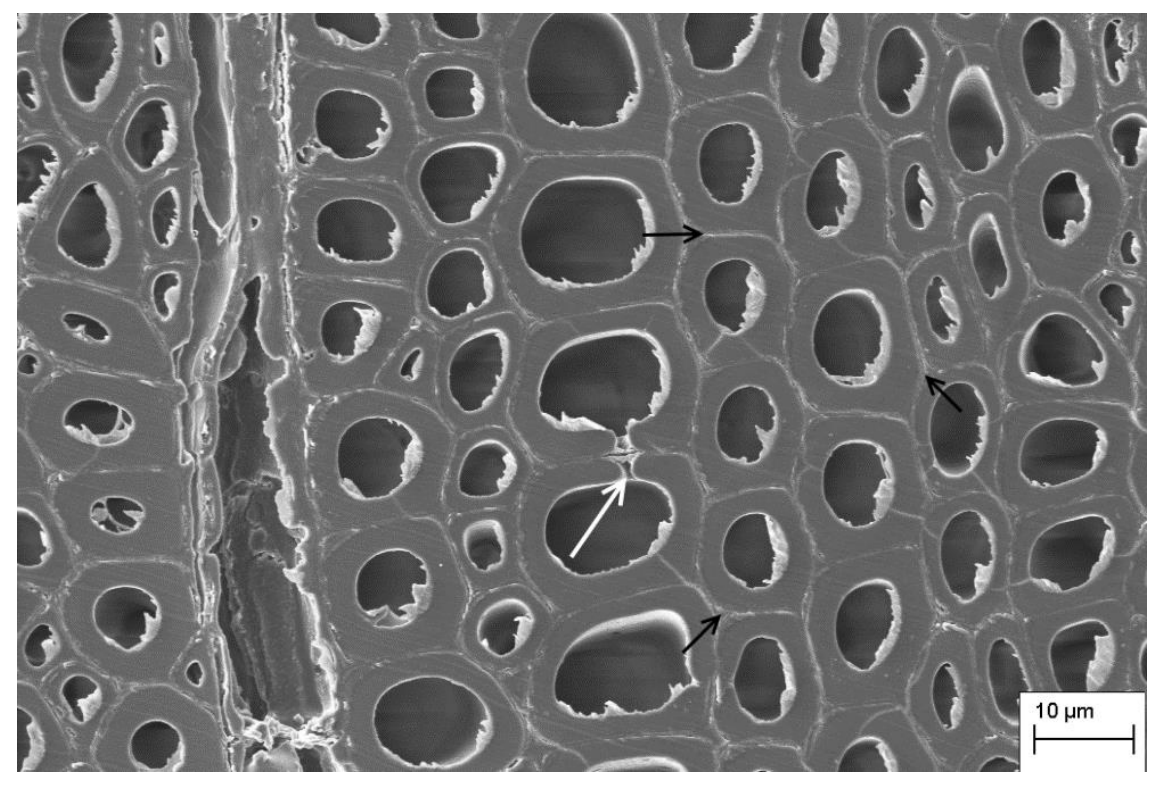

Figure 3.4: SEM image of unmodified specimen of E. nitens in the transversal direction. White arrow: Pit conection between wood cell wall of the fibers. Black arrows: Middle lamella. 

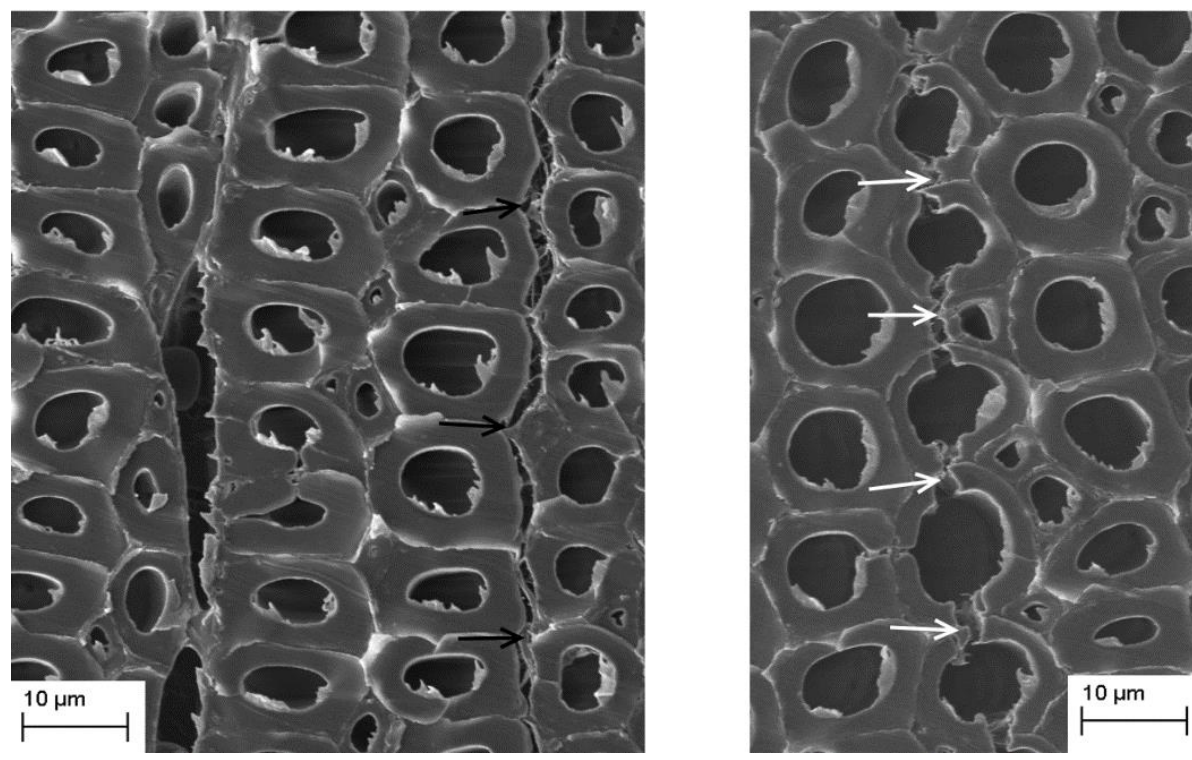

Figure 3.5: SEM images of thermally modified speciemens at $160^{\circ} \mathrm{C} 100 \% \mathrm{RH}$ in the closed system modification. White arrows: Pit conection between wood cell wall of the fibers. Black arrows: Middle lamella.
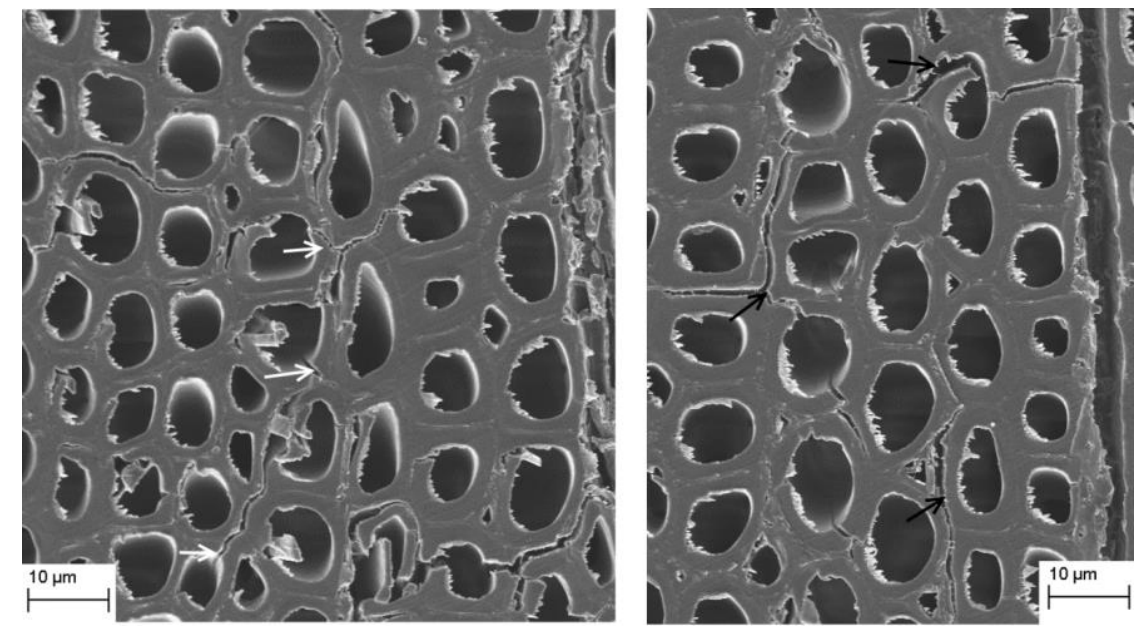

Figure 3.6: SEM images of thermally modified speciemens at $210^{\circ} \mathrm{C}$ in the open system modification. White arrows: Pit conection between wood cell wall of the fibers. Black arrows: Middle lamella.

\subsection{Conclusions}

In general, there was not a significant influence of the process conditions on the static and dynamic mechanical properties. Closed system modification led to slightly lower static mechanical properties of wood compared to open system modifications, the inelastic deflection and inelastic work were lower in the open system, and the differences in the dynamic mechanical properties were insignificant. There were also not mayor differences at the 
anatomical level between open and closed systems, as both presented similar crack developments. The cracks seem to initiate at the middle lamella or pits. To further distinguish the differences between open and closed system, it would be recommended to analyse the chemical structure of the modified wood using non-destructive techniques such as Raman spectroscopy or Fourier-transform infrared spectroscopy (FTIR). 



\section{Chapter 4: Publication III}

Chemical analysis and cellulose crystallinity of thermally modified Eucalyptus nitens wood from open and closed reactor systems using FTIR and X-ray crystallography

M. Wentzel ${ }^{1}$, A. Rolleri ${ }^{2}$, H. Pesenti ${ }^{3}$, H. Militz ${ }^{1}$

${ }^{1}$ Department of Wood Biology and Wood Products, University of Göttingen, Faculty of Forest Science, Büsgenweg 4, 37077 Göttingen, Germany

${ }^{2}$ Instituto de Bosques y Sociedad, Facultad de Ciencias Forestales y Recursos Naturales Universidad Austral de Chile, Valdivia, Chile

${ }^{3}$ Laboratorio de Cristalografía Aplicada, Facultad de Ingeniería, Universidad Católica de Temuco, Temuco, Chile

*corresponding author:

Phone: +495513922051

Fax: +49551399646

E-mail: mwentze@gwdg.de

ORCID: 0000-0002-5795-7589

Manuscript submitted to:

European Journal of Wood and Wood Products

Springer-Verlag Berlin Heidelberg

ISSN (Print) 0018-3768

ISSN (Online) 1436-736X 
Abstract: Currently there is a growing market for high quality solid wood products in Chile made from Eucalyptus nitens. Thermal modifications have been used to obtain such products out of fast growing species. The chemical and crystallinity changes of the modified wood were investigated using diffuse reflectance FTIR spectroscopy and crystalline analysis by X-Ray diffraction to analyze the difference between thermal modifications processes using pressure under wet conditions (closed system) and processes without pressure under dryer conditions (open system). In general, the FTIR spectra showed differences in the degradation of the hemicelluloses in the peaks of the $\mathrm{C}=\mathrm{O}$ linkages, but it showed almost no differences in the peaks that identify the lignin structure of the wood, as it was difficult to separate the different chemical reactions due to the depolymerization of lignin only observing the bands. Meanwhile, the degree of crystallinity showed a tendency to increase at high pressure in the closed system modifications and in elevated temperatures in the open system modifications, but no significant differences at low modification pressure and temperatures. Nonetheless, there were differences in FTIR spectra and cellulose crystallinity when directly comparing modifications with the same corrected mass loss under different conditions.

Keywords: Eucalyptus nitens, thermal modification, FTIR, cellulose crystallinity, X-ray crystallography

\subsection{Introduction}

There is interest in Chile to widen the use of solid wood products, especially from fast growing plantation species such as Eucalyptus nitens (Shining Gum). The plantation of this species has grown in importance in recent years because due to its excellent growth rates, positioning it into the second fastest growing species in Chile, after Pinus radiata, and better cold and frost resistance than Eucalyptus globulus (Blue Gum), the most used hardwood plantation species (INFOR 2014; INFOR 2015). There has been an interest to widen the use to solid wood products to increase the economic returns (Muñoz et al. 2005) and thermal modifications have been used to produce high quality material from plantation eucalypt species (Esteves et al. 2007a; de Cademartori et al. 2015; Batista et al. 2016; Wentzel et al. 2018b) that can be potentially used for windows, claddings, flooring, decking or garden products (Militz and Altgen 2014).

Thermal modification processes have been developed in the past decades, where the common features are temperatures between 160 and $240^{\circ} \mathrm{C}$ in an atmosphere with limited oxygen content (Hill 2006; Esteves and Pereira 2009; Militz and Altgen 2014). The main differences between 
the processes are the kind of shielding gas used (nitrogen or steam to name a few) and if the process is open or closed. Usually, open reactor systems work at atmospheric pressure using superheated steam, like the Thermowood ${ }^{\circledR}$ process (Mayes and Oksanen 2002), which has a high temperature drying step at the beginning of the process to avoid excessive drying rates during the actual modification temperature, but on the other hand it the relative humidity $(\mathrm{RH})$ of the wood reaches almost $0 \%$ at that step. As for the closed reactor systems, an example is the FirmoLin process (Willems 2009) where the pressure is generated using steam, which enables to control the RH inside the chamber thus preserving the wood moisture content during the process (Willems 2009; Altgen et al. 2016b)) and preventing excessive vaporization of the degradation products generated during the modification. The differences in the wood moisture content and the duration of the exposition to the peak modification temperature affect the chemical reactions and alter the temperature limit that induces the depolymerization of the cell wall constituents (Stamm and Hansen 1937; Seborg et al. 1953; Borrega and Kärenlampi 2008a). The first component to degrade are the hemicelluloses, where there is a hydrolysis of the polymer chains into oligomers and monomers, while also loosing hydrogen bonds (Tjeerdsma et al. 1998; Garrote et al. 1999). Cellulose is the least transformed wood component, as it is not as strongly affected by thermal degradation as the hemicelluloses, even if many chemical reactions are similar between them (Fengel 1967; Alen et al. 2002), but in the amorphous region of the cellulose microfibril hydrolytic cleavage takes place, which results in an increase of the relative crystallinity (Bhuiyan et al. 2000; Sivonen et al. 2002). Lignin is the component that is most thermally stable, as its relative percentage after a thermal modification usually increases (Alen et al. 2002; Esteves et al. 2008a), but there are still chemical changes happening in the lignin during the modification, such as cleavage of the methoxyl groups and a depolymerization of the lignin macromolecule to lower molecular weight compounds (Tjeerdsma et al. 1998; Sivonen et al. 2002) and also a higher concentration of phenolic groups (Runkel 1951; Kollmann and Fengel 1965). These chemical changes influence the loss in mechanical strength of the thermally modified wood (Tjeerdsma et al. 1998; Kubojima et al. 2000), while crystallinity particularly can influence the brittleness (Phuong et al. 2007) and the decrease of flexibility of the material (Kocaefe et al. 2008).

A quick method to measure the chemical changes is the use of Fourier-transform infrared spectroscopy (FTIR). The absorption observed in the FTIR spectra can be assigned to a mixture content of the functional groups $\mathrm{C}, \mathrm{H}$, and $\mathrm{O}$ that are present in celluloses, hemicelluloses, extractives, lignin and water in woody materials (Rodrigues et al. 1998). In thermal modified 
wood it has been used by Tjeerdesma and Militz (2005) analyzing Beech (Fagus silvatica) and Scots pine (Pinus sylvestris), and in the case of species similar to E. nitens, Esteves et al. (2013) used this method when analyzing thermally modified E. globulus wood. They used the $\mathrm{KBr}$ embedding method, as described by Faix and Böttcher (1992). Solid wood samples and thin slices have also been used, but to obtain reproducible spectra, the roughness and direction of the cut (radial, tangential or transversal) have to be identical (Pandey and Theagarajan 1997). To minimize the problems of the wood surface during the analysis, diffuse reflectance is a technique that allows the use of samples without previous preparation to obtain the spectra, as it is an in situ measurement that gives fast results in a reliable way.

X-ray diffraction has been used to measure and characterize the crystallinity of the cellulose (Segal et al. 1959; Isogai and Usuda 1990; Thygesen et al. 2005). It has also been used to measure the crystallinity in thermally modified wood (Dwianto et al. 1996; Bhuiyan et al. 2000; Bhuiyan et al. 2001) and even in thermally modified eucalypt species (Cheng et al. 2017). There is a tendency of increase of crystallinity after modification (Bhuiyan et al. 2000; Cheng et al. 2017), but it is not known if differences in the process conditions have an influence on the crystallinity. There are also no reports on measurements done directly in thermally modified solid wood samples.

The aim of the present study was to use a combination of FTIR and x-ray diffraction to have a deeper look on the chemical variation and measure the degree of crystallinity to further analyze the changes that occur during the different thermal modification processes.

\subsection{Material and methods}

\subsubsection{Material}

Wood from 19 year old Eucalyptus nitens plantations was obtained from the Región del BíoBío in Chile. Slats of $20 \times 50 \times 650 \mathrm{~mm}^{3}$ (radial $\times$ tangential $\times$ longitudinal) size were prepared from kiln-dried avoiding major defects and large knots. The slats had an average moisture content of $13 \%$ before the modification process. Ten slats per modification process were used.

\subsubsection{Thermal modification}

Thermal modification processes were performed in a laboratory-scale treatment reactor. The samples were placed in a stainless steel vessel with a volume of 651 that could be heated up to 
a maximum of $260^{\circ} \mathrm{C}$ with electric heating cables and is cooled down to room temperature using water cooling coils. Water vapor was produced by heating an external water reservoir connected to the vessel. Exhaust valves were used for the release of excess pressure. The treatment reactor can be used as either an open (without pressure, dry conditions) or as a closed (under pressure, wet conditions) system.

The open system modifications was similar to the ThermoWood® process (Mayes and Oksanen 2002). The first step is to rise the temperature $12^{\circ} \mathrm{C}$ per hour until it reaches $100^{\circ} \mathrm{C}$, followed by increasing the temperature $2^{\circ} \mathrm{C}$ per hour until $130^{\circ} \mathrm{C}$ to emulate the high temperature drying step of the ThermoWood ${ }^{\circledR}$ process. The third step was to increase the temperature $12^{\circ} \mathrm{C}$ per hour until it reaches the peak temperatures shown in Table 4.1. The peak temperature was then held for 3 hours. Afterwards the temperature was decreased $20^{\circ} \mathrm{C}$ per hour until it reached $65^{\circ} \mathrm{C}$, at that point the vessel was opened and the samples were taken out of it.

As for the modifications in the closed system, a similar schedule to the one used in the open system was used, but there was no high-temperature drying step applied, so the temperature was risen $12^{\circ} \mathrm{C}$ per hour until the peak temperature. It was also held for 3 hours and afterwards decrease $20^{\circ} \mathrm{C}$ per hour up to $65^{\circ} \mathrm{C}$. Pre-vacuum (ca. $13 \mathrm{kPa}$ ) was applied at the beginning of each thermal modification process. Peak temperatures, $\mathrm{RH}$ and maximum pressure applied in the closed system are shown in Table 4.1.

The final moisture content (MC) was measured by difference of dry weight using small pieces taken from each slat. The dry mass from the small sections and the mass loss (ML) were calculated using the formulas described by Metsä-Kortelainen et al. (2006), while the corrected mass loss (CML) was measured as described by Altgen et al. (2016b), where first the extractives are deducted from the dry weight of the selected wood slats to calculate their corrected weight. 
Table 4.1: Peak temperature, maximum pressure, relative humidity ( $\mathrm{RH})$, final moisture content (MC) and corrected mass loss (CML) determined for each modification. The hold time at peak temperature was 3 hours for all processes.

\begin{tabular}{|c|c|c|c|c|}
\hline $\begin{array}{c}\text { Peak } \\
\text { temperature } \\
\left({ }^{\circ} \mathbf{C}\right)\end{array}$ & $\begin{array}{c}\text { Max } \\
\text { pressure } \\
(\mathrm{MPa})\end{array}$ & $\begin{array}{l}\text { RH } \\
(\%)\end{array}$ & $\begin{array}{l}\text { MC } \\
(\%)\end{array}$ & $\begin{array}{c}\text { CML } \\
(\%)\end{array}$ \\
\hline \multicolumn{5}{|l|}{ Closed system } \\
\hline 150 & 0.14 & 30 & 4.5 & 2.6 \\
\hline 160 & 0.18 & 30 & 3.9 & 5.0 \\
\hline 170 & 0.23 & 30 & 3.2 & 6.3 \\
\hline 150 & 0.47 & 100 & 5.3 & 11.4 \\
\hline 160 & 0.61 & 100 & 4.9 & 18.6 \\
\hline 170 & 0.77 & 100 & 4.6 & 20.5 \\
\hline \multicolumn{5}{|c|}{ Open System } \\
\hline 160 & Atm. $^{\mathrm{a}}$ & - & 3.3 & 5.4 \\
\hline 180 & Atm. $^{\mathrm{a}}$ & - & 2.0 & 7.9 \\
\hline 200 & Atm. ${ }^{a}$ & - & 2.0 & 14.6 \\
\hline 210 & Atm. ${ }^{a}$ & - & 2.2 & 18.7 \\
\hline 220 & Atm. $^{\mathrm{a}}$ & - & 2.3 & 16.8 \\
\hline 230 & Atm. ${ }^{a}$ & - & 2.4 & 19.3 \\
\hline
\end{tabular}

${ }^{a}$ Atmospheric pressure

\subsubsection{FTIR analysis}

A FTIR chemical imaging system (PerkinElmer) was used to obtain the spectra from each modification and from untreated specimens. The system consists of a spectrophotometer Frontier that has two detectors, type DTGS NIR and MIR, both covering a range between $\left(14,700-350 \mathrm{~cm}^{-1}\right)$ with a resolution of $4 \mathrm{~cm}^{-1}$. The imager Spotlight 400, one detector type MCT MIR (7800- $720 \mathrm{~cm}^{-1}$ ) with a resolution $>2 \mathrm{~cm}^{-1}$, was used. The system can generate chemical spectra directly on the surface of the wood through chemical images. In this work, diffuse reflectance was used to obtain the spectra with resolution of $8 \mathrm{~cm}^{-1}$ and 32 scans. The spectra were baseline corrected using an interactive baseline correction and then they were normalized considering maximum ordinate value in the spectrum. 
The samples were cut to blocks of $10 \times 10 \times 10 \mathrm{~mm}^{3}$ (radial $\times$ tangential $\times$ longitudinal) and the conditioned at $20^{\circ} \mathrm{C} / 65 \% \mathrm{RH}$ for a month previous to the FTIR analysis. The radial surface was chosen for each analysis.

\subsubsection{X-ray diffraction}

The late wood from the radial surface of solid wood Eucalyptus nitens samples were positioned on sample holder of a Multifunctional Smartlab diffractometer (Rigaku Corporation, Japan). The equipment employs Ni-filtered $\mathrm{Cu}$ radiation ( $30 \mathrm{kV}$ and $40 \mathrm{~mA}$ ), $1 \mathrm{~mm}$ divergence slit, 0.3 $\mathrm{mm}$ anti-scatter slit, $5^{\circ}$ Soller slits and a Rigaku D/teX 250 detector. The alignment is regularly checked against the NIST SRM660c LaB6 powder standard (NISTS 2015). Patterns were collected in the $10-30^{\circ}$ range, counting $0.5^{\circ} / \mathrm{sec}$ per step of $0.01^{\circ}$. PDXL 2 v.2.7.3.0 software was used for patterns intensity analysis. The Crystalline Index (CI) was calculated according to the method of Segal et al. (1959). ). Three measurements per sample were done, as it is a proof of concept for the use of solid wood in the measurement of crystallinity, and due to the difficulty to align the late wood to the beam.

\subsection{Results and Discussion}

The bands at $1748 \mathrm{~cm}^{-1}$ represent the ketones and in free aldehyde present in lignin and hemicelluloses (Rodrigues et al. 1998; Michell and Higgins 2002). The $\mathrm{C}=\mathrm{O}$ linkage present strong absorptions in FTIR spectra between 1750 and $1700 \mathrm{~cm}^{-1}$, and the exact wavenumber depends of the functional group (carboxylic acid: at about 1725-1700 $\mathrm{cm}^{-1}$; ester, ketone: 1725 $1705 \mathrm{~cm}^{-1}$, aldehyde: $1740-1720 \mathrm{~cm}^{-1}$ ) and of its structural location (Esteves et al. 2013). As it can be seen in Figures 4.1, 4.2 and 4.3, all thermal modifications show a decrease in absorbance in this band as the temperature increases. The lower reactivity can be related to the decrease in free reactive hydroxyl groups in holocellulose due to the thermal degradation of the hemicelluloses, as it is more reactive than cellulose (Nguila Inari et al. 2007). There is a more noticeable decrease of this band decreasing in the modifications at 100\% RH (Figure 4.2). This is mostly due to the auto-hydrolysis during the modification, which results in the formation of acetic acid that accelerates the degradation (Garrote et al. 1999; Garrote et al. 2001). This decrease is also related to the variations in lignin due to esterification caused by the reaction of the produced acids with the wood cell wall (Tjeerdsma and Militz 2005). Wentzel et al. (2018b) shows that the acetic acid concentration was higher in the modifications at $100 \% \mathrm{RH}$, causing an increase of the degradation of hemicelluloses, particularly the xylans. This can be seen in 
the band around $1730 \mathrm{~cm}^{-1}$, which is the band that represents the acetoxy groups in xylan, and at the band around $1468 \mathrm{~cm}^{-1}$, which corresponds to the asymmetric deformation of $\mathrm{C}-\mathrm{H}$ bond of xylan (Michell and Higgins 2002). There is also a decrease around the peak at $1600 \mathrm{~cm}^{-1}$, which are related to $\mathrm{C}=\mathrm{C}$ unsaturated linkages and aromatic rings present in lignin (Rodrigues et al. 1998; Mitchel and Higgins 2002). The changes in this band were related to lignin condensation at the expense of conjugated carbonyl groups and to the carboxylation of polysaccharides (Chow 1971; Gonzalez-Peña et al. 2009).

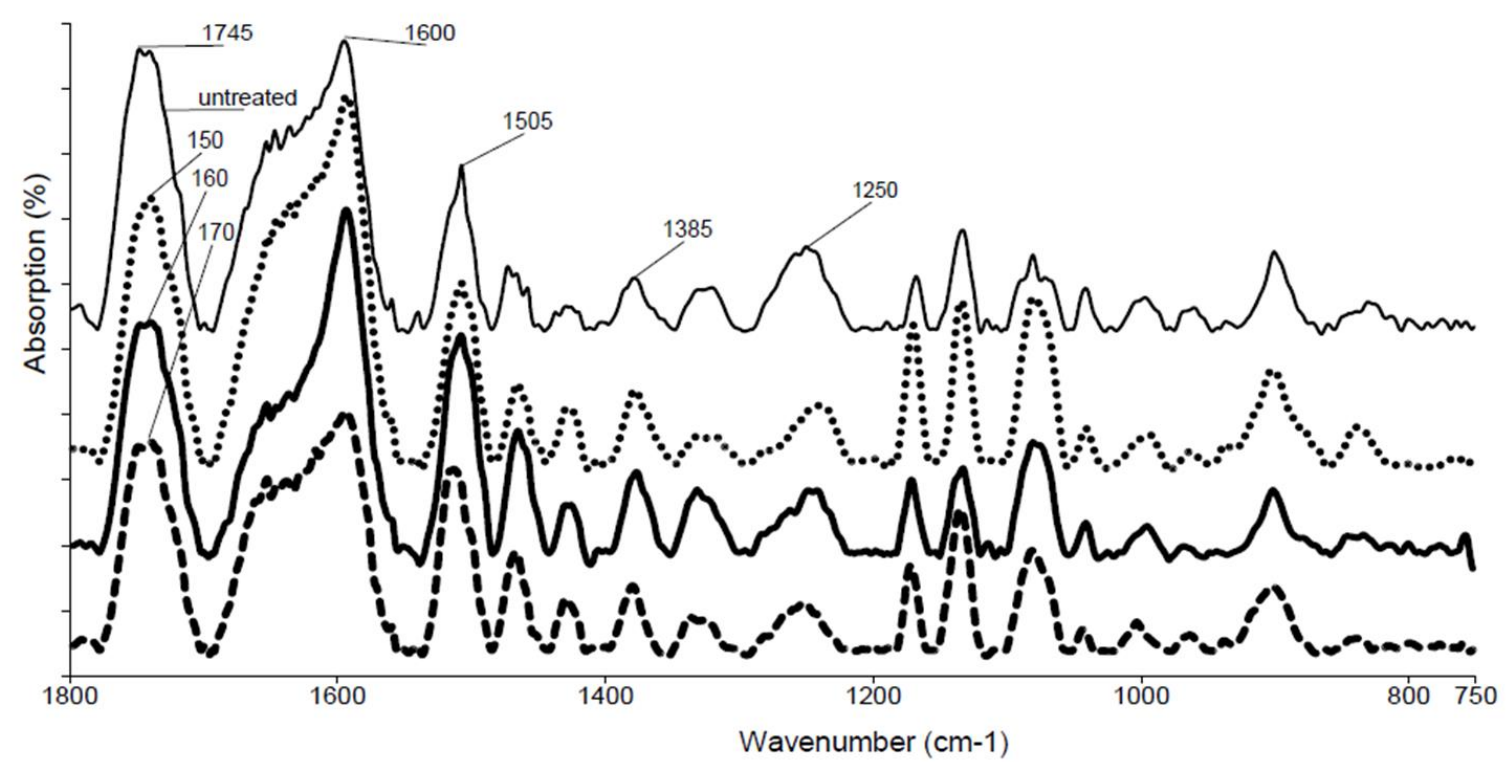

Figure 4.1: FTIR spectra of thermally modified E. nitens under pressure at 30\% RH and untreated sample. From top to bottom: Untreated, 150,160 and $170^{\circ} \mathrm{C}$ respectively. 


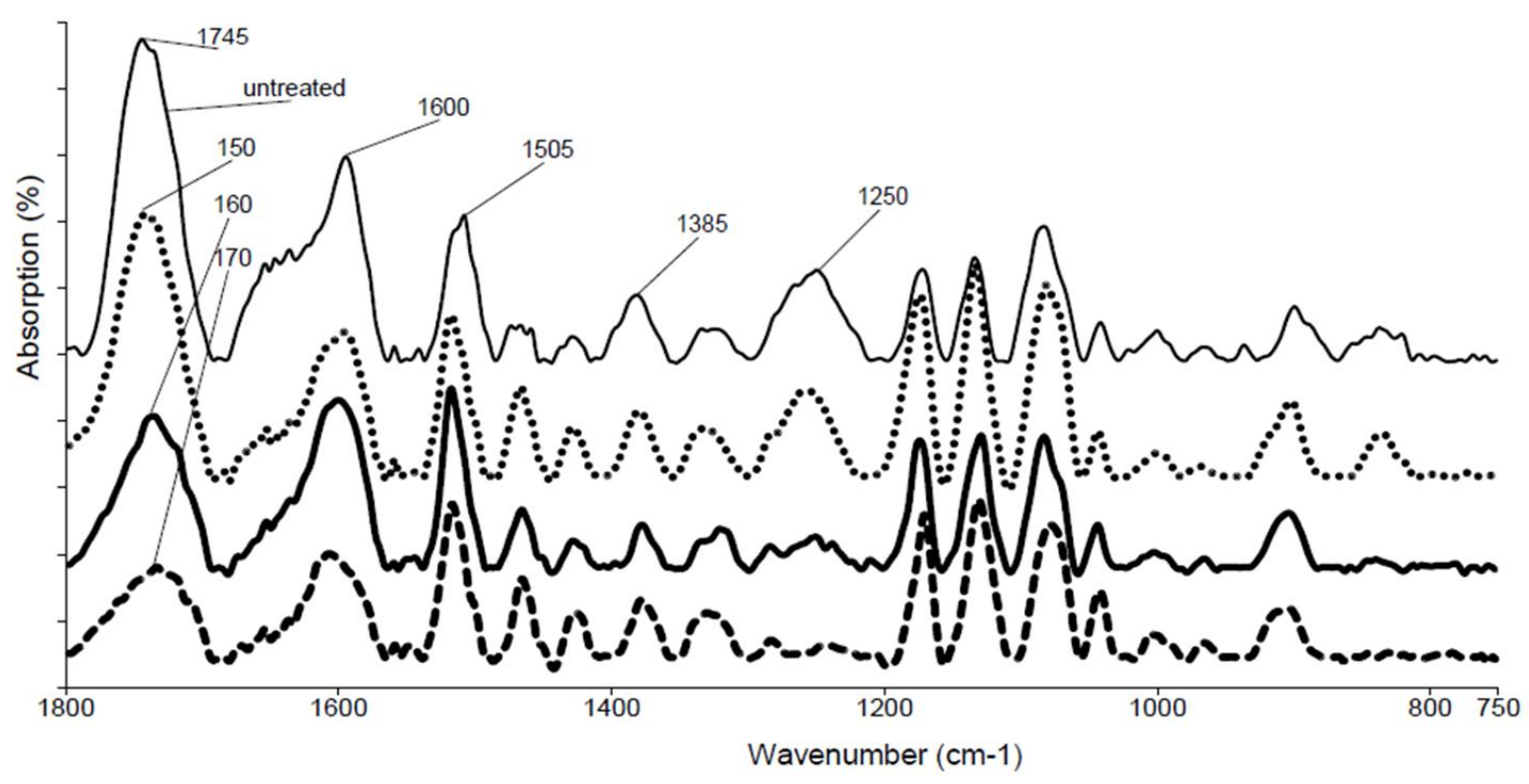

Figure 4.2: FTIR spectra of thermally modified E. nitens under pressure at $100 \% \mathrm{RH}$ and untreated sample. From top to bottom: Untreated, 150,160 and $170^{\circ} \mathrm{C}$ respectively.

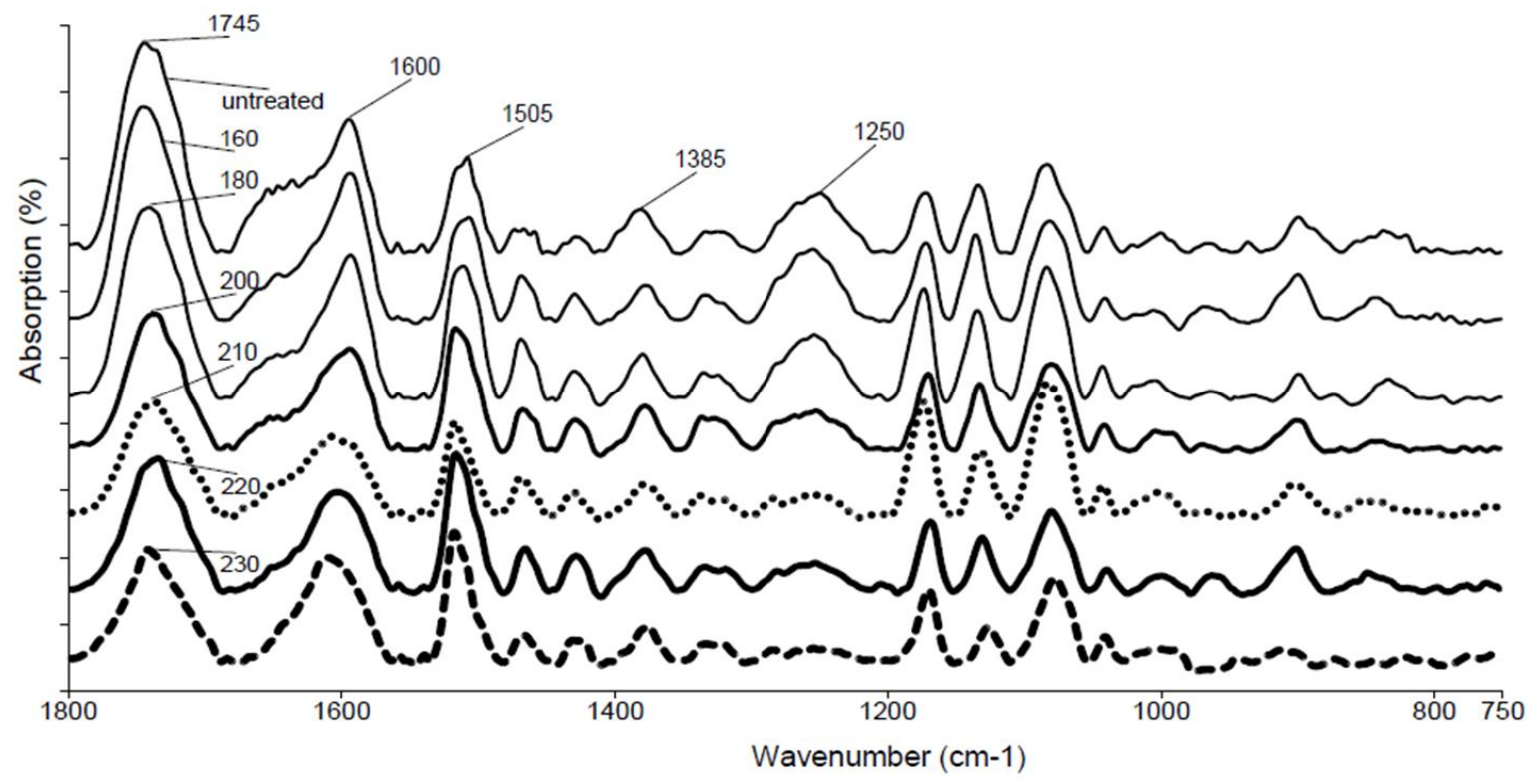

Figure 4.3: FTIR spectra of thermally modified E. nitens at atmospheric pressure and untreated sample. From top to bottom: Untreated, 160, 180, 200, 210, 220, $230^{\circ} \mathrm{C}$ respectively.

Lignin in eucalypts can be seen at the band around 1505-1510 $\mathrm{cm}^{-1}$ (Rodrigues et al. 1998), where the aromatic rings of hardwood lignin (Guaiacyl and Syringyl) are represented (Faix 1991), although it can be difficult to differentiate properly its changes, as it can increase or decrease on whether there is an increase in the relative lignin (Kotilainen et al. 2000; Windeisen et al. 2007) or the aromatic ring opening in the lignin is the one dominating (González-Peña 
and Hale 2009). According to Pandey (1999), Guaiacyl and Syringl can also be seen in the peaks around $1250 \mathrm{~cm}^{-}$, which represent the C-O stretching and bending (Rodrigues et al. 1998; Mitchel and Higgins 2002). These bands shifted in the modified wood, similar to what happened to E. globulus (Esteves et al. 2013) and it shows an increase in the band in all the thermal modifications (Figures 4.1, 4.2 and 4.3). This is related to carbohydrate degradation. Something similar can be seen in the band $1385 \mathrm{~cm}^{-1}$, which represents the $\mathrm{O}-\mathrm{H}$ bending vibrations in phenols (Rodrigues et al. 1998), where the $\mathrm{OH}$ stretching frequencies change and also increase for the thermal modifications. This variation could be influenced by dehydration effects of the modifications (Moharram and Mahmoud 2008; Spiridon et al. 2011). The open system modifications tend to have a lower MC after the process (Table 4.1). The bands show different peaks when compared directly between samples with same CML from a drier modification at atmospheric pressure $\left(210^{\circ} \mathrm{C}\right)$ and a modification under pressure and $100 \% \mathrm{RH}$ $\left(160^{\circ} \mathrm{C}\right.$ and 0.61 bar) (Figure 4.4). There are other vibrations that arise from the aromatic skeletal in lignin (around $1140 \mathrm{~cm}^{-1}$ ) (Faix 1991; Rodrigues et al. 1998; Michell and Higgins 2002) that decline as the temperature of the treatment increases, which probably contribute towards the increase of the $\mathrm{CO}$ band at $1708 \mathrm{~cm}^{-1}$ (González-Peña and Hale 2009). The changes in lignin can be related to the loss of syringyl units, which tend to be liberated easier than the guaiyacyl monomers by a thermal degradation (Faix et al. 1990). The decrease in content of this group could be related to the decrease in the methoxyl groups in lignin, which leads to the loss of a monomer. Previous research indicates that a shift occurs in this group, which can be attributed to the breaking of aliphatic side-chains in lignin and/or condensation reactions (Windeisen et al. 2007). Differences between wet and dry modifications, which could be related to the cross-linking reactions from the degradation of hemicelluloses and lignin, are difficult to make out due to the absorbance of the aromatic rings of furan-type intermediates and lignin overlap (Altgen et al. 2018).

The bands at $1335 \mathrm{~cm}^{-1}$ and $1323 \mathrm{~cm}^{-1}$ represent the $\mathrm{C}-\mathrm{H}$ bending of polysaccharides and the condensed units of syringyl and guayacyl respectively, thus combining most of the structural components of wood (Faix 1991). As it represents many structures, it is difficult to conclude which is the structure that causes the changes to be able to differentiate between the open and closed system. There were distortions in the intensities of the bands in the region close to 1150$950 \mathrm{~cm}^{-1}$, when DRIFT spectra were measured directly from wood surfaces (Pandey 1999). 


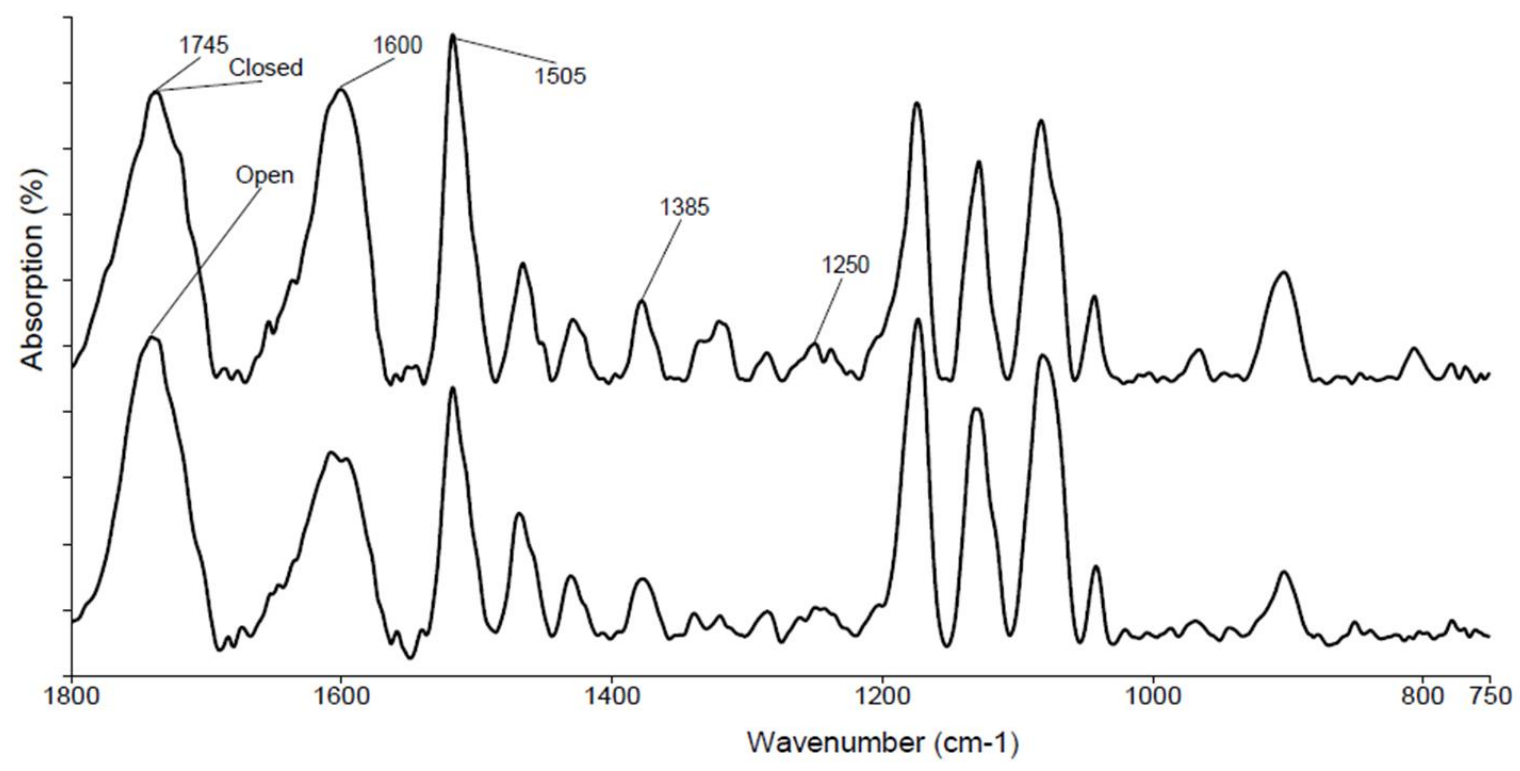

Figure 4.4: Comparison of FTIR spectra of thermally modified E. nitens in the closed system $\left(160^{\circ} \mathrm{C}\right.$ and $\left.0.61 \mathrm{bar}\right)$ (top) and in the open system $\left(210^{\circ} \mathrm{C}\right.$ and atmospheric pressure) (bottom).

These represent the C-O stretch in polysaccharides. Similar distortions can be seen in both open and closed system modifications, but no difference between the modifications can be seen as shown in Figure 4.4.

The crystallinity index measured directly on solid wood samples shows a tendency to increase at elevated pressure under wet conditions and at elevated temperatures and drier conditions under atmospheric pressure, but it shows little to no change at the lower pressures and at lower temperatures (Table 4.2). In the closed system under wet conditions there was an increase at $150^{\circ} \mathrm{C}$ and 0.14 bar and a decrease at $230^{\circ} \mathrm{C}$ under drier conditions. We suspect that this increase is due to the sample surface, as the measurements are done in situ and it could have measured a mixture of early/late wood, thus causing issues in the measurement of the crystallinity. According to Segal (1959), the difference between the intensities or the height of the angles between 18 and $22^{\circ}(2 \theta)$ of the diffraction pattern in relation with the intensity of the crystalline peak at $22^{\circ}$ is the indicator of the degree of crystallinity. This means that a higher difference between the intensity values is an indicator of the prevalence of the crystalline face, on the contrary it means a prevalence of the amorphous part. This could be explained by considering that cellulose chains swell when exposed by high temperature and humidity, thus increasing the distance between the crystal planes, as stated by Cheng et al (2017). 
Table 4.2: Degree of crystallinity (CI) by X-ray diffraction in open and closed thermal modifications of E. nitens.

\begin{tabular}{|c|c|c|c|c|}
\hline Temp & Pressure & Io02 & Iamorph & CI (\%) \\
\hline Ref & ATM & 988 & 308 & 69 \\
\hline 150 & 0.14 & 1363 & 364 & 73 \\
\hline 160 & 0.18 & 881 & 302 & 66 \\
\hline 170 & 0.23 & 1087 & 352 & 68 \\
\hline 150 & 0.47 & 919 & 292 & 68 \\
\hline 160 & 0.61 & 1401 & 298 & 79 \\
\hline 170 & 0.77 & 1398 & 315 & 78 \\
\hline 160 & ATM & 1169 & 366 & 69 \\
\hline 180 & ATM & 1300 & 385 & 70 \\
\hline 200 & ATM & 1301 & 359 & 72 \\
\hline 210 & ATM & 1510 & 399 & 74 \\
\hline 220 & ATM & 1706 & 426 & 75 \\
\hline 230 & ATM & 1200 & 392 & 67 \\
\hline
\end{tabular}

At higher temperatures there are more hemicellulose cleavage products due to depolymerisation and the production of more reactive intermediates, such as furfurals, which cause more cross linking reactions that increase the lignin polymer network (Boonstra and Tjeerdsma 2006), causing probably an increase in the relative proportion of crystalline cellulose due to a rearrangement of the cellulose molecules (Bhuiyan et al. 2000). The acetic acid generated by the modification degrades the hemicelluloses and could also degrade the microfibrils of the amorphous region of the cellulose, even attack the crystalline region (Sivonen et al. 2002). Both chemical changes occur in wet and dry modifications, but the acidity is higher in the wet modification in a closed system (Wentzel et al. 2018b). Omitting the crystalline index at $150^{\circ} \mathrm{C}$ and 0.14 bar, the modifications at lower pressures in the wet process showed no significant difference with the untreated samples (Fig. 5), but at higher pressure there was a noticeable increase in the degree of crystallinity index for the modifications at higher temperatures and pressure (Figure 4.6). Bhuiyan et al. (2000) suggested that under moist conditions there is a stimulating effect on the crystallization of amorphous cellulose. As already established by the FTIR spectra and Wentzel et al. (2018b), the degradation of hemicelluloses is closely related to the xylans, which crystallize due to the controlled pyrolysis during the modification, thus they could also influence the change in the degree of crystallinity (Akgül et al. 2007). As for the open system modification under drier conditions, there is a steady increase of the crystallinity index as the temperature rises, excluding the modification at $230^{\circ} \mathrm{C}$ (Figure 4.7 ), but not a significant difference with the reference with the exception of the modifications at 210 and 
$220^{\circ} \mathrm{C}$ respectively. Besides the increase of acetic acid, the increase in the crystallinity index in the dry modification can be related to the preferred degradation of less ordered molecules (Sivonnen et al. 2002). The results obtained in the open system were in contrast to what was shown by Cheng et al. (2017), where there was a decrease of the crystallinity when the temperature rises and an increase at $220^{\circ} \mathrm{C}$. The difference could be due to the different species used and the types of modifications.

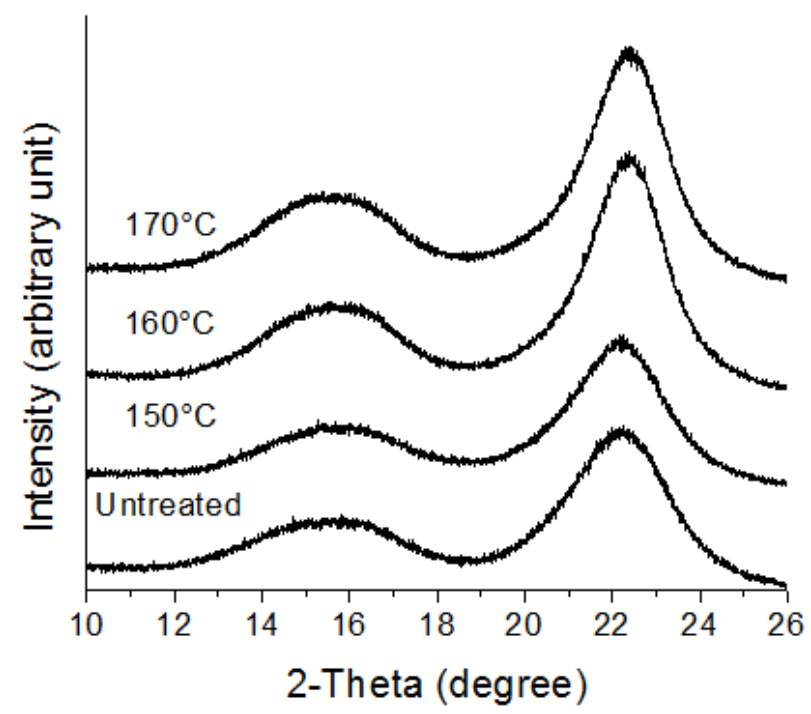

Figure 4.5: X-ray diffraction of thermally modified E.nitens at 30\% RH in the closed system and an untreated sample. From top to bottom: $170,160,150^{\circ} \mathrm{C}$ and untreated specimen.

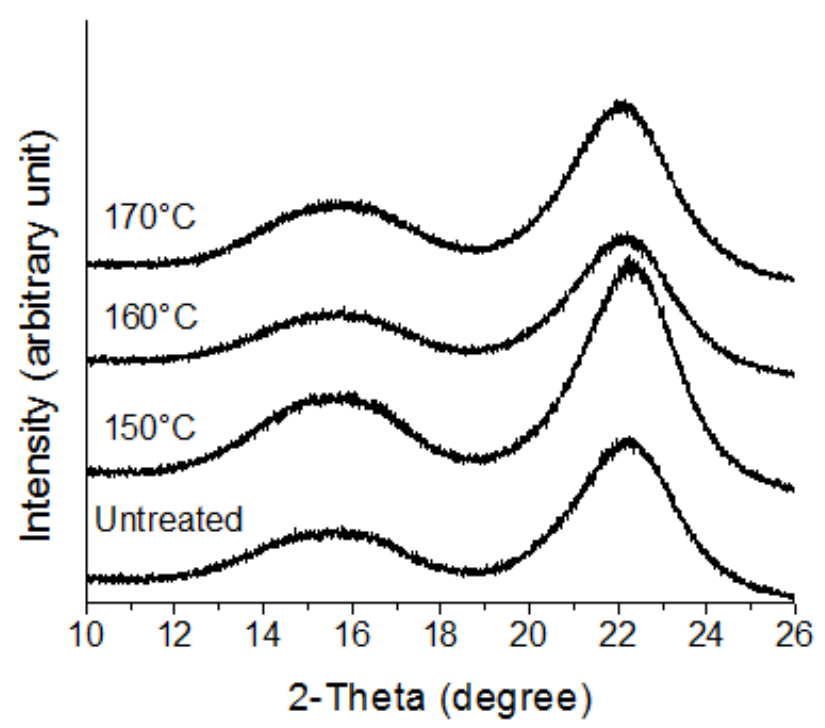

Figure 4.6: X-ray diffraction of thermally modified E.nitens at $100 \% \mathrm{RH}$ in the closed system and an untreated sample. From top to bottom: $170,160,150^{\circ} \mathrm{C}$ and untreated specimen. 


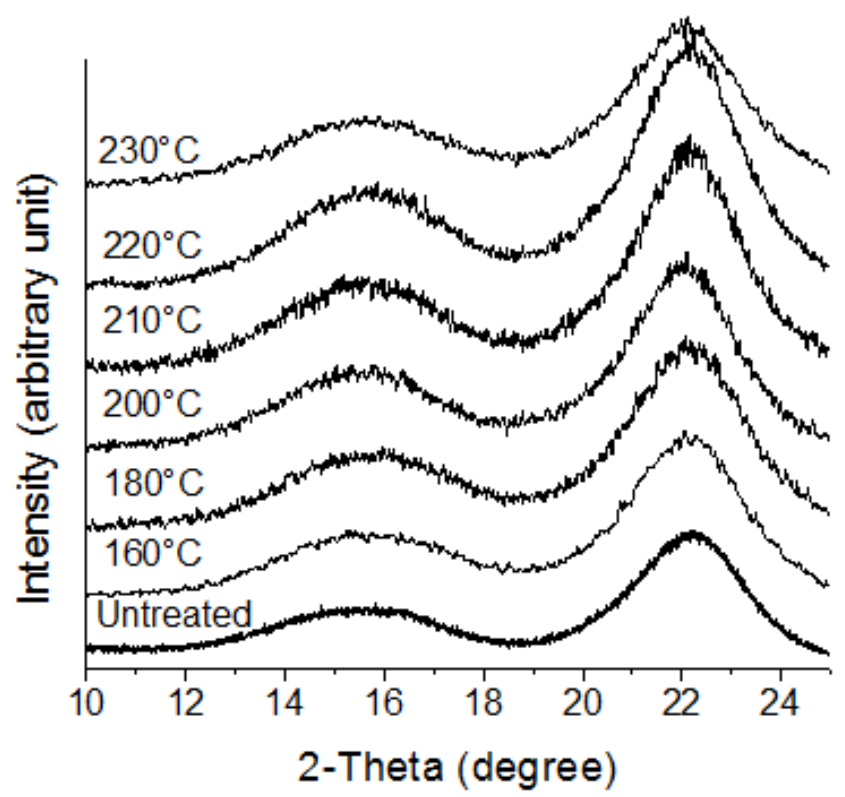

Figure 4.7: X-ray diffraction of thermally modified E.nitens at atmospheric pressure and untreated sample. From top to bottom: 230, 220, 210, 200, 180, $160^{\circ} \mathrm{C}$ and untreated specimen.

When directly comparing wet and dry modifications with processes with the same $\mathrm{CML}\left(210^{\circ} \mathrm{C}\right.$ and atmospheric pressure and $160^{\circ} \mathrm{C}$ and 0.61 bar) the wet modification presents slightly higher crystallinity index than the dry modification, but overall the difference is not significant.

There are differences when directly comparing modifications with the same CML for both FTIR and x-ray diffraction, but it the case of cellulose crystallinity, it is difficult to be certain that there are significant differences between modifications under pressure under wet conditions and without pressure under drier conditions.

\subsection{Conclusions}

The biggest chemical differences between modifications under pressure in wet conditions and without pressure in dry conditions were observed in the variations in the peaks of the $\mathrm{C}=\mathrm{O}$ linkages (1750 and $1700 \mathrm{~cm}^{-1}$ ), which represent carbonyl stretching vibration in non-conjugated ketones and in free aldehyde present in lignin and hemicelluloses and can be related to the formation of acetic acid that accelerates the degradation of the hemicelluloses and the variations in lignin due to esterification, with a decrease of this band in the modifications of the closed system at $100 \% \mathrm{RH}$. The $\mathrm{OH}$ bending also showed different peaks between open and closed system (band $1385 \mathrm{~cm}^{1}$ ), but it was harder to differentiate the lignin peaks between both processes, as it was difficult to separate the different chemical reactions due to the 
depolymerization of lignin by only observing the bands. On the other hand, the degree of crystallinity did not show significant differences between both modifications, although the modifications under wet condition had slightly higher values. Further research on the measurement of the crystallinity in solid wood samples should be done, focusing on differences between late and early wood and the direction of the sample (longitudinal, transversal, radial). There were differences in FTIR spectra and cellulose crystallinity when directly comparing modifications with the same CML under different conditions. This should be taken into consideration in further research of the properties of thermally modified wood.

Acknowledgments: The authors would like to thank the "Comisión Nacional de Investigación Científica y Tecnológica" Conicyt, through their FONDEQUIP Program, for the financial support for the acquisition of research equipment: EQM150019 "Strengthening of interdisciplinary research in materials and biomaterials, FTIR Infrared Imaging System for nondestructive evaluation of surfaces" and the EQM160152 "Attraction of high-impact International Scientific Collaboration using Advanced X-ray Diffraction techniques to integrate interdisciplinary research in the Araucanía Region".

On behalf of all authors, the corresponding author states that there is no conflict of interest. 



\section{Chapter 5: Publication IV}

Analyzing reversible changes in hygroscopicity of thermally modified eucalypt wood from open and closed reactor systems

M. Wentzel ${ }^{1 *}$, M. Altgen ${ }^{2}$, H.Militz ${ }^{1}$

${ }^{1}$ Department of Wood Biology and Wood Products, University of Göttingen, Faculty of Forest Science, Büsgenweg 4, 37077 Göttingen, Germany

${ }^{2}$ Department of Bioproducts and Biosystems, Aalto University, P.O. Box 16300, 00076 Aalto, Finland

*corresponding author:

Phone: +495513922051

Fax: +49551399646

E-mail: mwentze@gwdg.de

ORCID: 0000-0002-5795-7589

Originally published in:

Wood Science and Technology

Springer-Verlag Berlin Heidelberg

ISSN (Print) 0043-7719

ISSN (Online) 1432-5225

DOI: $\quad 10.1007 / \mathrm{s} 00226-018-1012-3$

Received: 9 January 2018

Published online: 4 April 2018

https://link.springer.com/article/10.1007/s00226-018-1012-3

In print: July 2018, Volume 52, Issue 4, pp 889-907 
Abstract: Eucalyptus nitens was thermally modified in either an open or a closed reactor system at different temperatures and water vapor pressures. Reversible changes in equilibrium moisture content $(\mathrm{EMC})$ and volumetric swelling $\left(\mathrm{S}_{\max }\right)$ were analyzed during cycles that included repeated conditioning at $20{ }^{\circ} \mathrm{C} / 65 \% \mathrm{RH}$, water-soaking and vacuum-drying at room temperature. These cycles partially diminished the reduction in EMC and $\mathrm{S}_{\max }$ measured directly after the modification process. The recovery of drying related annealing effects of amorphous polymers was considered the main effect during water soaking cycles of wood from the open reactor system, while the removal of the cell wall bulking effect was the main effect in the wood modified in the closed system in nearly saturated water vapor. Water soaking cycles also changed the dynamic vapor sorption behavior to considerable extent, leading to a lower reduction in EMC by thermal modification over the entire $\mathrm{RH}$ range measured. Exposure of the samples to $95 \% \mathrm{RH}$ during the dynamic vapor sorption measurements was incapable of removing reversible effects to the same extent as repeated water soaking.

Keywords: Thermal modification, Dynamic vapor sorption (DVS), Equilibrium moisture content (EMC), Volumetric swelling, Water soaking cycles

\subsection{Introduction}

Several thermal modification processes have been developed in the past decades that enable the use of fast growing wood species in exterior applications (Esteves et al. 2007a). As reviewed comprehensively (Hill 2006; Esteves and Pereira 2009; Militz and Altgen 2014), the application of modification temperatures between 160 and $240{ }^{\circ} \mathrm{C}$ and the limitation of the oxygen content in the process are common features of all thermal modification processes on the market. However, the main differences in the processes are the shielding gas used (such as steam, nitrogen or others) and the pressure regimes applied in open or closed reactor systems. Open reactor systems operate at atmospheric pressure, with superheated steam being the most used shielding gas. Under these conditions, the relative humidity (RH) and the corresponding wood moisture content (MC) decrease considerably. This requires a high-temperature drying step at the beginning of the process so that excessive drying rates during the actual modification at temperatures around $200{ }^{\circ} \mathrm{C}$ are avoided (Mayes and Oksanen 2002). Closed reactor systems enable the application of elevated pressure levels during the thermal modification. If the pressure is generated by steam, the RH may be controlled and elevated wood moisture contents can be preserved during the process (Willems 2009; Altgen et al. 2016b). The elevated wood MC during the process, together with the accumulation of carboxylic acids in the wood, have 
been suggested as the main causes for accelerated wood degradation in closed reactor systems (Giebeler 1983; Borrega and Kärenlampi 2008a; Willems et al. 2015a; Altgen et al. 2016b). However, up until today, it remains unclear whether the properties of thermally modified wood from open and closed reactor systems differ significantly. Without the existence of any general quality control system for thermally modified wood products available on the market (Willems et al. 2015b), such differences need to be explored to avoid the use of thermally modified wood with properties that are unsuitable for a specific application.

The improvement in dimensional stability and the decrease in water vapor sorption of wood during thermal modification have been known for many decades (Tiemann 1917; Stamm and Hansen 1937; Seborg et al. 1953; Burmester 1975). Besides the increase in biological durability (Weiland and Guyonnet 2003; Hakkou et al. 2006; Boonstra et al. 2007a), this is the main reason for the extended service life of thermally modified wood in many exterior applications. The change in wood properties is linked to the various degradation reactions in the cell wall that are induced by thermal modification. This includes the hydrolysis of amorphous carbohydrates to smaller sugars units, which can undergo dehydration and decarboxylation reactions to be either emitted from the wood as volatile compounds or be involved in condensation reactions with the remaining cell wall polymers (Tjeerdsma et al. 1998; Demirbaş 2000; Alen et al. 2002). Hemicelluloses contain far more water accessible $\mathrm{OH}$ groups than the semi-crystalline cellulose or the lignin (Runkel 1954; Runkel and Lüthgens 1956). Therefore, their preferential degradation during the thermal modification process (Alen et al. 2002) reduces the concentration of water-accessible $\mathrm{OH}$ groups in wood as sorption sites for water. However, a pure change in chemical composition is insufficient to increase the dimensional stability of wood, because the space that was previously occupied by hemicelluloses can still be occupied by water (Burmester 1975). Instead, the formation of additional covalent bonds and cross-links during the thermal modification are necessary to improve the dimensional stability of the wood by hindering the expansion of nanopores in the cell wall matrix upon water uptake (Repellin and Guyonnet 2005; Altgen et al. 2016a). A hindered expansion of nanopores, which may be interpreted as increased cell wall matrix stiffness, has also been suggested to decrease the water vapor sorption of wood in addition to the decrease caused by a preferential degradation of hemicellulose(Hill et al. 2012; Altgen et al. 2016a).

Besides the changes in hygroscopicity that are linked to irreversible chemical changes by thermal degradation during the modification process, there is a number of recent studies that 
provide evidence for a simultaneous occurrence of reversible changes in hygroscopicity (Hill et al. 2012; Altgen and Militz 2016; Endo et al. 2016; Majka et al. 2016). The partial reversibility of the property changes might lead to a discrepancy between the properties of thermally modified wood that are determined directly after the process and those that are evident for thermally modified wood in service. The neglect of this partial reversibility might also lead to false conclusions in mode of action studies on thermally modified wood.

One cause for reversible changes in hygroscopicity is the drying of wood at high-temperatures during the thermal modification process (Borrega and Kärenlampi 2010; Altgen and Militz 2016; Endo et al. 2016). This was first explained by irreversible hydrogen bonding, which is similar to the hornification effect that reduces the water retention value of wood pulp upon drying (Borrega and Kärenlampi 2010). However, this drying related effect was later shown to be reversible. It was suggested that drying wood at elevated temperatures, beyond the softening point of amorphous matrix polymers, causes their annealing and realignment. This results in residual stresses within the cell wall matrix upon cooling. These stresses are then released by swelling and re-exceeding the softening point during high humidity exposure or water-soaking of the wood after the process, which nearly fully removes any drying related effect (Altgen and Militz 2016; Endo et al. 2016). Nonetheless, a study on the hydroxyl accessibility of unmodified wood after drying showed that water vapor exposure only restores the accessibility partly, while a full re-accessibility is only achieved by water-saturation (Thybring et al. 2017).

In addition to drying-related effects, a reversible change in hygroscopicity and dimensional stability may also be related to the presence of degradation products in thermally modified wood. Remaining degradation products may occupy space and decrease the volume of nanopores within the cell wall, similar to the cell wall bulking effect of chemical modification agents (Rowell and Ellis 1978; Hill and Jones 1996). Removal of remaining degradation products during water soaking reduces the dry volume of the wood to increase the maximum swelling, which is calculated as the difference between dry and water-saturated wood volume (Biziks et al. 2015; Altgen and Militz 2016). In sorption experiments, degradation products may also effect the moisture content recorded by providing additional sorption sites on the one hand, while increasing the reference (dry) mass on the other hand.

Although the occurrence of reversible changes in thermally modified wood has already been evidenced, a clear separation of the modes of action involved and their link to the process 
conditions applied is still lacking. This study analyses mass and volumetric changes in thermally modified Eucalypt (Eucalyptus nitens) wood from open and closed systems during water-soaking cycles. Reversible effects related to drying and those related to cell wall bulking of remaining degradation products are considered. Furthermore, the study analyses how the dynamic vapor sorption behavior of thermally modified wood changes by water-soaking cycles.

\subsection{Materials and methods}

\subsubsection{Materials}

Fast grown wood from 19 year old Eucalyptus nitens plantations was obtained from the Región del Bío-Bío in Chile. It was originally grown for the use in solid wood products and an increase in value could be achieved by thermal modification. Slats of $20 \times 50 \times 650 \mathrm{~mm}^{3}$ (radial $\times$ tangential $\times$ longitudinal) size were prepared from kiln-dried wood free of large knots or juvenile wood. The slats had an average moisture content of $12 \%$ before the modification process. Ten slats per modification process were used.

\subsubsection{Thermal modification}

Thermal modification processes were performed in a laboratory-scale treatment reactor. The samples were placed in a stainless steel vessel with a volume of 651 that could be heated up to a maximum of $260{ }^{\circ} \mathrm{C}$ with electric heating cables and cooled down to room temperature with water cooling coils. Water vapor was produced by heating an external water reservoir connected to the vessel. Exhaust valves were used for the release of excess pressure. The treatment reactor functioned either as an open or as a closed system.

When operating as open system, a temperature schedule similar to the ThermoWood ${ }^{\circledR}$ process was applied (Mayes and Oksanen 2002). The temperature in the vessel was first raised at $12{ }^{\circ} \mathrm{C} \mathrm{h}^{-1}$ to $100{ }^{\circ} \mathrm{C}$ and then very slowly at $2{ }^{\circ} \mathrm{C} \mathrm{h}^{-1}$ to $130{ }^{\circ} \mathrm{C}$ to allow the high-temperature drying of the slats to nearly $0 \% \mathrm{MC}$, before increasing the temperature at $12{ }^{\circ} \mathrm{C} \mathrm{h}^{-1}$ until reaching the peak temperatures given in Table 5.1. After a $3 \mathrm{~h}$ holding time at the peak temperature, the temperature was decreased at $20^{\circ} \mathrm{C} \mathrm{h}^{-1}$ until reaching $65^{\circ} \mathrm{C}$, at which the vessel was opened and the samples were removed. When exceeding $100{ }^{\circ} \mathrm{C}$ in the treatment vessel, a steam flow was created by heating the water in the water reservoir to slightly above $100{ }^{\circ} \mathrm{C}$ while opening an exhaust valve of the treatment vessel. Thereby, a mixture of steam and volatile degradation products was released, while pure steam was added constantly. 
When operating as a closed system, the process schedule described by Altgen et al. (2016b) was applied. The temperature schedule was the same as for the open system, except that there was no high-temperature drying step applied. At the beginning of each process, a pre-vacuum (ca. $13 \mathrm{kPa}$ ) was applied. During the process, the water vapor pressure was adjusted by heating the water reservoir and releasing excess pressure to keep the relative humidity $(\mathrm{RH})$ constant, except when reaching a pressure below $0.1 \mathrm{MPa}$ at the end of the process. Peak temperatures, $\mathrm{RH}$ and maximum pressure applied in the closed system are shown in Table 1.

Table 5.1: Peak temperature, maximum pressure, relative humidity $(\mathrm{RH})$, final moisture content (MC), hot water extractives, mass loss $\left(\mathrm{ML}_{\mathrm{TM}}\right)$ and corrected mass loss $\left(\mathrm{CML}_{\mathrm{TM}}\right)$ determined for each process run. The hold time at peak temperature was 3 hours for all processes.

\begin{tabular}{ccccccc}
\hline $\begin{array}{c}\text { Peak } \\
\text { temperature } \\
\left({ }^{\mathbf{C})}\right.\end{array}$ & $\begin{array}{c}\text { Max. } \\
\text { pressure } \\
(\mathbf{M P a})\end{array}$ & $\begin{array}{c}\mathbf{R H} \\
(\boldsymbol{\%})\end{array}$ & $\begin{array}{c}\text { Final } \\
\mathbf{M C} \\
\mathbf{( \% )}\end{array}$ & $\begin{array}{c}\text { Extractives } \\
(\boldsymbol{\%})\end{array}$ & $\begin{array}{c}\mathbf{M L}_{\mathbf{T M}} \\
\mathbf{( \% )}\end{array}$ & $\begin{array}{c}\mathbf{C M L}_{\mathbf{T M}} \\
(\boldsymbol{\%})\end{array}$ \\
\hline Reference & - & - & - & 4.7 & 0 & 0 \\
\hline $\begin{array}{c}\text { Closed system } \\
150\end{array}$ & 0.14 & 30 & 4.5 & 6.0 & 1.3 & 2.6 \\
160 & 0.18 & 30 & 3.9 & 7.6 & 2.0 & 5.0 \\
170 & 0.23 & 30 & 3.2 & 8.4 & 2.5 & 6.3 \\
150 & 0.47 & 100 & 5.3 & 12.7 & 4.0 & 11.4 \\
160 & 0.61 & 100 & 4.9 & 13.2 & 10.7 & 18.6 \\
170 & 0.77 & 100 & 4.6 & 10.1 & 15.8 & 20.5 \\
\hline Open System & & & & & & \\
160 & Atm. $^{\text {a }}{ }^{\text {a }}$ & - & 3.3 & 6.8 & 3.3 & 5.4 \\
180 & Atm. $^{\text {a }}$ & - & 2.0 & 9.0 & 3.5 & 7.9 \\
200 & Atm. $^{\text {a }}$ & - & 2.0 & 12.3 & 7.2 & 14.6 \\
210 & Atm. $^{\text {a }}$ & - & 2.2 & 12.7 & 11.2 & 18.7 \\
220 & Atm. $^{\text {a }}$ & - & 2.3 & 9.1 & 12.8 & 16.8 \\
230 & Atm. $^{\text {a }}$ & - & 2.4 & 7.4 & 16.9 & 19.3 \\
\hline
\end{tabular}

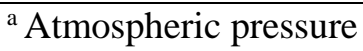

\subsubsection{Determination of mass loss and extractive content}

To determine the mass loss caused by the modification process, the mass and the corresponding moisture content were recorded for each slat before and immediately after the process. About $50 \mathrm{~mm}$ from the ends of each slat was cut off after the weighing to avoid edge effects. The moisture content was determined from small sections taken from the slats, not from the material to be tested itself. The dry mass of each slat before and after the process as well as the mass 
loss caused by the thermal modification ( $\mathrm{ML}_{\mathrm{TM}}$, in \%) were calculated as described by MetsäKortelainen et al. (2006).

To measure the extractive content an adaption of the method described in the Solvent Extractives of Wood and Pulp Test Method T 204 cm-07 (TAPPI 1997) was used. Material from randomly selected pieces of each modification process as well as from unmodified wood was grounded in a cutting mill and sieved to a particle size between $0.2-0.63 \mathrm{~mm}$. For each process, $5 \mathrm{~g}$ of dry wood particles were extracted using a Soxhlet apparatus with $150 \mathrm{ml}$ of deionized hot water during a period of $8 \mathrm{~h}$. The extractive content was then determined gravimetrically in relation to the initial oven dry mass before the Soxhlet process.

The extractive content was subtracted from the dry mass of each slat and the corrected mass loss during the thermal modification process (CML $\left.\mathrm{CM}_{\mathrm{TM}}\right)$ was determined based on the dry and extractive-free mass of each slat before and after the process, using the equations given by Altgen et al. (2016b).

\subsubsection{Water-soaking cycles}

To measure the EMC and the volumetric swelling during water-soaking cycles, 30 specimens per process run with dimensions of $10 \times 10 \times 10 \mathrm{~mm}^{3}$ (tangential $\times$ radial $\times$ longitudinal) were prepared from the modified wood and an unmodified reference. No systematic difference in EMC and volumetric swelling was found in dependence on the location of the samples within the original slats, thus this factor was not considered in the analysis. The mass and dimensions of the specimens were measured after each of the following steps: (step A) conditioning at $20^{\circ} \mathrm{C} / 65 \% \mathrm{RH}$; (step B) air drying at room conditions for ten days followed by vacuum-drying at $20{ }^{\circ} \mathrm{C}$ and $2.5 \mathrm{kPa}$ in a desiccator over silica gel until constant mass; (step C) waterimpregnation for $30 \mathrm{~min}$ at $13 \mathrm{kPa}$ and water soaking for two weeks with daily water changes. Afterwards, the samples were air dried at room conditions for two weeks and the cycle started again from point $\mathrm{A}$. The steps $(\mathrm{A}-\mathrm{C})$ were repeated 4 times.

The equilibrium moisture content $(\mathrm{EMC}$, in $\%)$ at $20{ }^{\circ} \mathrm{C}$ and $65 \% \mathrm{RH}$ was determined for each sample and each water soaking cycle using Eq. 5.1. 


$$
\mathrm{EMC}=100 \times\left(\mathrm{m}_{\mathrm{xA}}-\mathrm{m}_{\mathrm{xB}}\right) / \mathrm{m}_{1 \mathrm{~B}}
$$

Equation 5.1

where $\mathrm{m}_{\mathrm{xA}}$ and $\mathrm{m}_{\mathrm{xB}}$ is the mass (in $\mathrm{g}$ ) at the end of step A and B of cycle $\mathrm{x}$ (1-4), respectively, while $\mathrm{m}_{1 \mathrm{~B}}$ is the mass (in $\mathrm{g}$ ) at the end of step B of cycle 1. Increase in EMC after the fourth cycle was separated into the mass change in dry state after water soaking $\left(\mathrm{M}_{\text {Dry }}\right.$, in \%) and the mass change in conditioned state after water soaking $\left(\mathrm{M}_{20 / 65}\right.$, in \%), as illustrated in Figure 5.1, using eq. 5.2 and 5.3

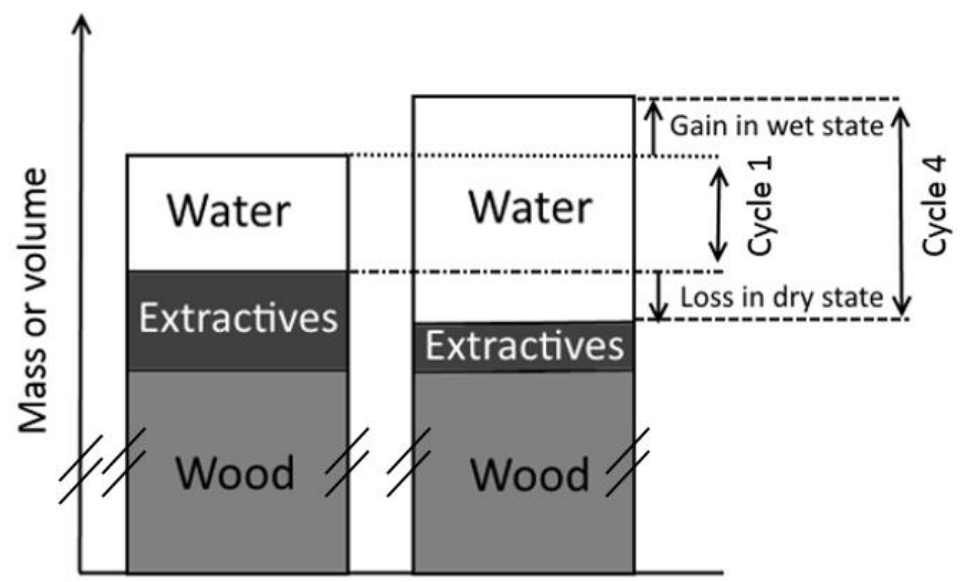

Cycle $1 \quad$ Cycle 4

Figure 5.1: Schematic illustration of the quantification of mass and volume changes during water soaking cycles. The dash and dot line highlights the reference mass/volume.

$$
\begin{aligned}
& \mathrm{M}_{\text {Dry }}=100 \times\left[\left(\mathrm{m}_{4 \mathrm{~B}}-\mathrm{m}_{1 \mathrm{~B}}\right) / \mathrm{m}_{1 \mathrm{~B}}\right] \\
& \mathrm{M}_{20 / 65}=100 \times\left[\left(\mathrm{m}_{4 \mathrm{~A}}-\mathrm{m}_{1 \mathrm{~A}}\right) / \mathrm{m}_{1 \mathrm{~B}}\right],
\end{aligned}
$$

Equation 5.2

Equation 5.3

Volumetric swelling $\left(\mathrm{S}_{\max }\right.$, in \%) was measured based on the sample volume at the end of step $\mathrm{B}$ and $\mathrm{C}$ of each cycle using eq. 5.4.

$$
\mathrm{S}_{\max }=100 \times\left[\left(\mathrm{v}_{\mathrm{xC}}-\mathrm{v}_{\mathrm{xB}}\right) / \mathrm{v}_{1 \mathrm{~B}}\right]
$$

\section{Equation 5.4}

where $\mathrm{v}_{\mathrm{xB}}$ and $\mathrm{v}_{\mathrm{xC}}$ are the sample volumes at the end of step B and C of cycle $\mathrm{x}(1-4)$, respectively, while $\mathrm{v}_{1 \mathrm{~B}}$ is the volume at the end of step B of the first cycle. Increase in $S_{\max }$ after the fourth cycles was separated into the volume change in dry state during water soaking 
$\left(\mathrm{V}_{\text {Dry }}\right.$, in \%) and the volume gain in saturated state during water soaking ( $\mathrm{V}_{\mathrm{Wet}}$, in \%), as illustrated in Figure 5.1 by applying eq. 5.5 and 5.6.

$$
\begin{aligned}
& \mathrm{V}_{\text {Dry }}=100 \times\left[\left(\mathrm{v}_{4 \mathrm{~B}}-\mathrm{v}_{1 \mathrm{~B}}\right) / \mathrm{v}_{1 \mathrm{~B}}\right], \\
& \mathrm{V}_{\text {Wet }}=100 \times\left[\left(\mathrm{v}_{4 \mathrm{C}}-\mathrm{v}_{1 \mathrm{C}}\right) / \mathrm{V}_{1 \mathrm{~B}}\right],
\end{aligned}
$$

Equation 5.5

Equation 5.6

\subsubsection{Dynamic vapor sorption}

Sorption isotherms were measured for selected samples in a dynamic vapor sorption (DVS) apparatus (DVS advantage, Surface Measurement Systems, London, UK). Besides unmodified reference samples, samples modified in a closed system at $160{ }^{\circ} \mathrm{C}$ and $100 \%$ set point $\mathrm{RH}$ and samples modified in an open system at $210^{\circ} \mathrm{C}$ were chosen, since both treatments resulted in similar ML $\mathrm{TM}_{\mathrm{TM}}$ and $\mathrm{CML}_{\mathrm{TM}}$ (Table 5.1). Thin sections (approx. $40 \mu \mathrm{m}$ thickness) with a mass of $20 \mathrm{mg}$ were prepared on a sliding microtome from samples before and after the water soaking cycles. The temperature was kept constant at $20^{\circ} \mathrm{C}$ for all DVS measurements. The RH decreased to $0 \%$ to determine the initial dry weight of the specimen, before increasing at $5 \%$ steps until $95 \% \mathrm{RH}$ followed by a decrease to $0 \%$ in the reverse sequence. This RH sequence was repeated in a second sorption cycle. Each RH step remained constant until a weight change of less than $0.001 \% \mathrm{~min}^{-1}$ (dmdt) over a 10 minute period. This dmdt threshold is lower than typically applied in DVS measurements of wood (dmdt of $0.002 \% \mathrm{~min}^{-1}$ over a $10 \mathrm{~min}$ period) to reduce the risk of mischaracterizing the EMC by short hold times in the DVS (Glass et al. 2017). The final mass of each RH was used for the EMC calculation. The EMC was corrected for differences in extractive content by calculating the corrected $\mathrm{EMC}\left(\mathrm{EMC}_{\mathrm{c}}\right.$, in \%) according to eq. 5.7 .

$$
\mathrm{EMC}_{\mathrm{c}}=\mathrm{EMC} \times(1+\mathrm{E} / 100)
$$

Equation 5.7

where $\mathrm{E}$ is the extractive content (in \%) measured by Soxhlet extraction as described in 5.2.3. $\mathrm{The}_{\mathrm{EMC}}$ ratio was determined for each $\mathrm{RH}$ step in the sorption isotherms using eq. 5.8.

$\mathrm{EMC}_{\mathrm{c}}$ ratio $=$ sample $\mathrm{EMC}_{\mathrm{c}} /$ reference $\mathrm{EMC}_{\mathrm{c}}$, 
where the sample $\mathrm{EMC}_{\mathrm{c}}$ is the $\mathrm{EMC}_{\mathrm{c}}$ of the respective thermally modified sample at a given $\mathrm{RH}$, and the reference $\mathrm{EMC}_{\mathrm{c}}$ is the $\mathrm{EMC}_{\mathrm{c}}$ of the unmodified sample measured at the same $\mathrm{RH}$. To enable comparability, the reference $\mathrm{EMC}_{\mathrm{c}}$ was always derived from first sorption cycle of the unmodified sample before water soaking.

\subsection{Results and discussion}

\subsubsection{Changes in mass, moisture and extractive content by thermal modification}

The results on mass loss and final MC of thermally modified Eucalypt wood are in line with studies on modifying other wood species in closed and open reactor systems. A lower final MC was measured after modification in the open system than in the closed system (Table 5.1). This is caused by the application of a pre-drying step and the low RH that ensues in the open system at elevated temperatures, which caused the wood to dry to nearly oven-dry state. As to be expected, applying a set point $\mathrm{RH}$ of $100 \%$ resulted in a higher final MC than applying a set point RH of $30 \%$ at the same temperature level. However, a decrease from the initial $12 \% \mathrm{MC}$ occurred even at a set point RH of $100 \%$. This was also observed in a previous study and explained by small deviations from the set point parameters, consumption of water in chemical reactions and/or reduction in the number of polar sites in wood (Altgen et al. 2016b). However, it should also be noted that the differences in MC between the different process conditions might be larger during the actual high-temperature exposure. Wood modified in an open system and wood modified at $30 \% \mathrm{RH}$ is likely to take up moisture during the cooling stage, i.e. below $100{ }^{\circ} \mathrm{C}$ when the $\mathrm{RH}$ in the reactor rises.

The extractive content (Table 5.1) increased during all thermal modification processes, indicating that the generation of degradation products as new extractives outweighed their vaporization. This was especially evident for modifications at $100 \%$ set point $\mathrm{RH}$ in the closed system, because the high pressure applied hindered rapid vaporization (Altgen et al. 2016b). Interestingly, the open system resulted in an increase in extractives with increasing peak temperature until reaching $210{ }^{\circ} \mathrm{C}$ and an extractive content of $12.7 \%$, which was followed by a decrease until it reached $7.4 \%$ extractive content at $230{ }^{\circ} \mathrm{C}$ (Table 5.1). This evidences that increasing the temperature beyond $210{ }^{\circ} \mathrm{C}$ increases the vaporization more than the generation of degradation products. Similar results were obtained by modifying Eucalyptus globulus in an autoclave heat treatment and oven heating at longer hold times at a given peak temperature (Esteves et al. 2008a). 
Mass loss based on the dry mass before and after the process $\left(\mathrm{ML}_{\mathrm{TM}}\right)$ is often used as a marker for the thermal degradation of the wood (Zaman et al. 2000), and it is usually referred as an indicator of the quality of the modification (Welzbacher and Rapp 2007). However, Altgen et al. (2016b) pointed out that the accumulation of carbohydrate degradation products results in an underestimation of the actual thermal degradation of wood by MLTM. The calculation of the corrected mass loss $\left(\mathrm{CML}_{\mathrm{TM}}\right)$ by deducting the extractive content from the dry mass of the wood results in much higher values than $\mathrm{ML}_{\mathrm{TM}}$. Modifications at $230{ }^{\circ} \mathrm{C}$ in an open system and at $170{ }^{\circ} \mathrm{C}$ at $100 \%$ set point $\mathrm{RH}$ reached ca. $20 \% \mathrm{CML}_{\mathrm{TM}}$, indicating that a substantial proportion of hemicelluloses were degraded (Table 5.1). This result also underlines the high efficacy of closed systems in causing significant thermal degradation at much lower treatment temperatures than required in open systems. Elevated wood moisture contents and the accumulation of carboxylic acids within the wood in closed systems have been suggested as causes (Borrega and Kärenlampi 2008a; Willems et al. 2015a; Altgen et al. 2016b), which coincides with the final MC and extractive content measured in our study.

However, when measuring EMC and $S_{\max }$ immediately after the process, the accumulated degradation products are still present within the samples and affect the reference mass, provide additional sorption sites for water or cause a cell wall bulking effect. Thus, ML $\mathrm{TM}_{\mathrm{TM}}$ is used as the basis for the comparison of EMC and $S_{\max }$ between the different process conditions in this study.

\subsubsection{Water soaking cycles}

The overall changes of EMC as function of $\mathrm{ML}_{\mathrm{TM}}$ during the water-soaking cycles can be seen in Figure 5.2. In the first cycle, the EMC as a function of $\mathrm{ML}_{\mathrm{TM}}$ differs considerably depending on the process conditions applied (Figure 5.2a). Most noticeable, higher EMC values were obtained after modification at $100 \%$ set point RH than after modification in an open system. Remarkably, the EMC of theses samples did not decrease with increasing MLTM during the first water soaking cycle. With increasing number of water-soaking cycles, all EMC values, including the EMC of the unmodified samples, increased gradually (Figure 5.2b-d). An almost uniform correlation between the EMC and $\mathrm{ML}_{\mathrm{TM}}$ was evident after the last cycle (Figure 5.2d), indicating that the differences in the initial EMC between the process conditions applied were predominantly caused by reversible effects. This is in line with previous studies on Sitka spruce 
wood modified at $120^{\circ} \mathrm{C}$ and different process RH (Endo et al. 2016) and on European beech wood modified between 150 and $180{ }^{\circ} \mathrm{C}$ and different process RH (Altgen and Militz 2016).

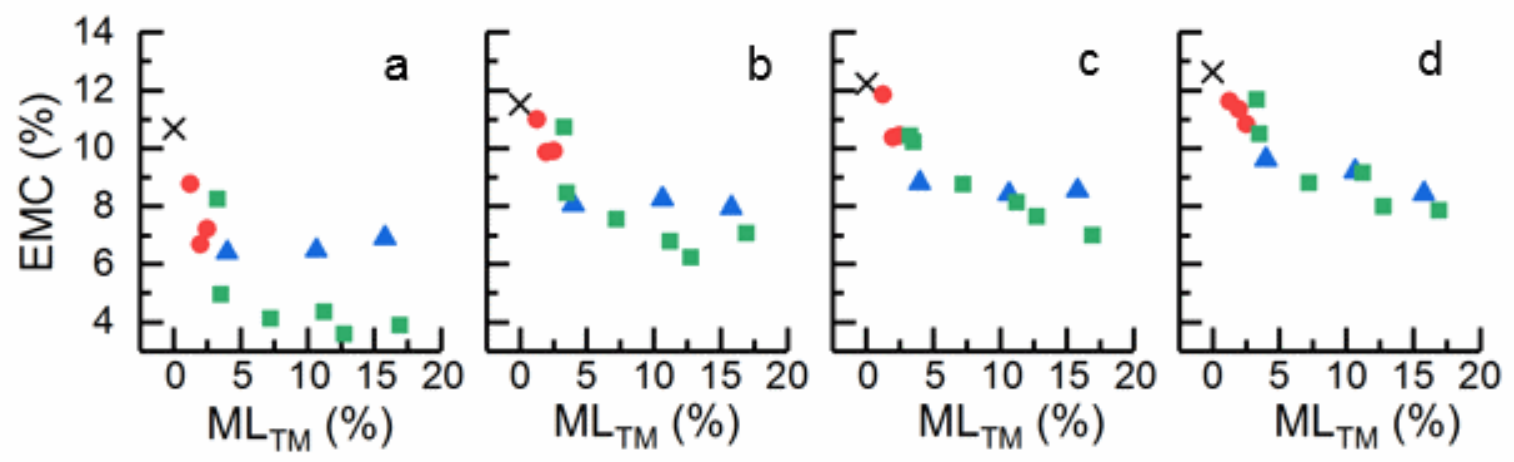

Figure 5.2: EMC at $20{ }^{\circ} \mathrm{C}$ and $65 \% \mathrm{RH}(\mathrm{N}=30)$ in dependence on the mass loss by thermal modification $(\mathrm{N}=10)$ measured during the first (a), second (b), third (c) and fourth (d) water soaking cycle. Cross: reference; circles: modification in closed system at $30 \% \mathrm{RH}$; triangles: modification in closed system at $100 \% \mathrm{RH}$; squares: modification in open system.

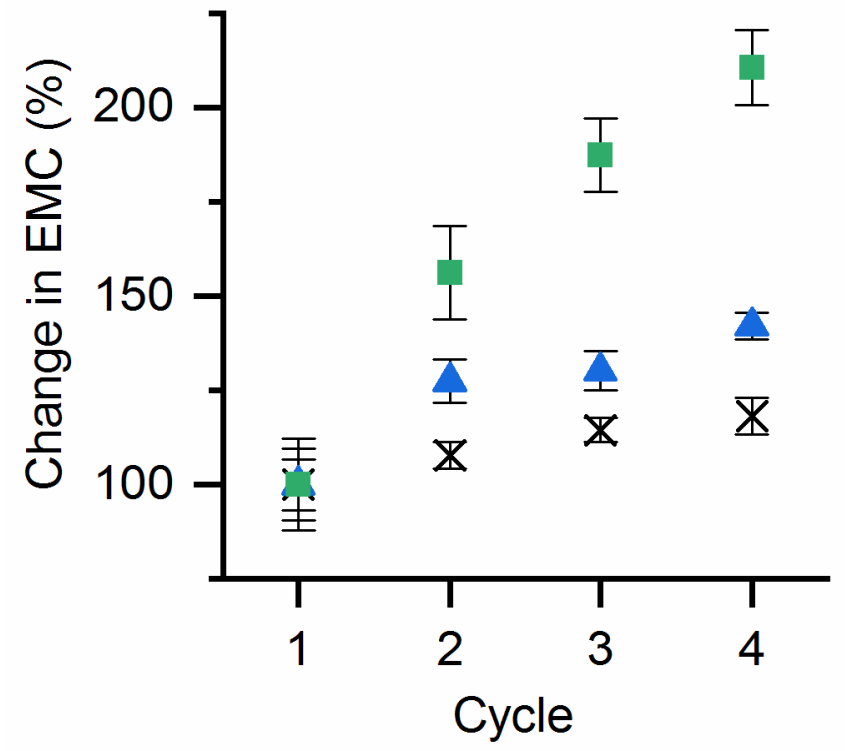

Figure 5.3: Change in EMC in dependence on the number of water soaking cycles. The average EMC of the first cycle was set to $100 \%$ for each sample group. Cross: reference; Triangles: modification at $160{ }^{\circ} \mathrm{C}$ and $100 \%$ set point $\mathrm{RH}$; Squares: modification at $210{ }^{\circ} \mathrm{C}$ in an open system. ( $\mathrm{N}=30, \pm$ standard deviation). 


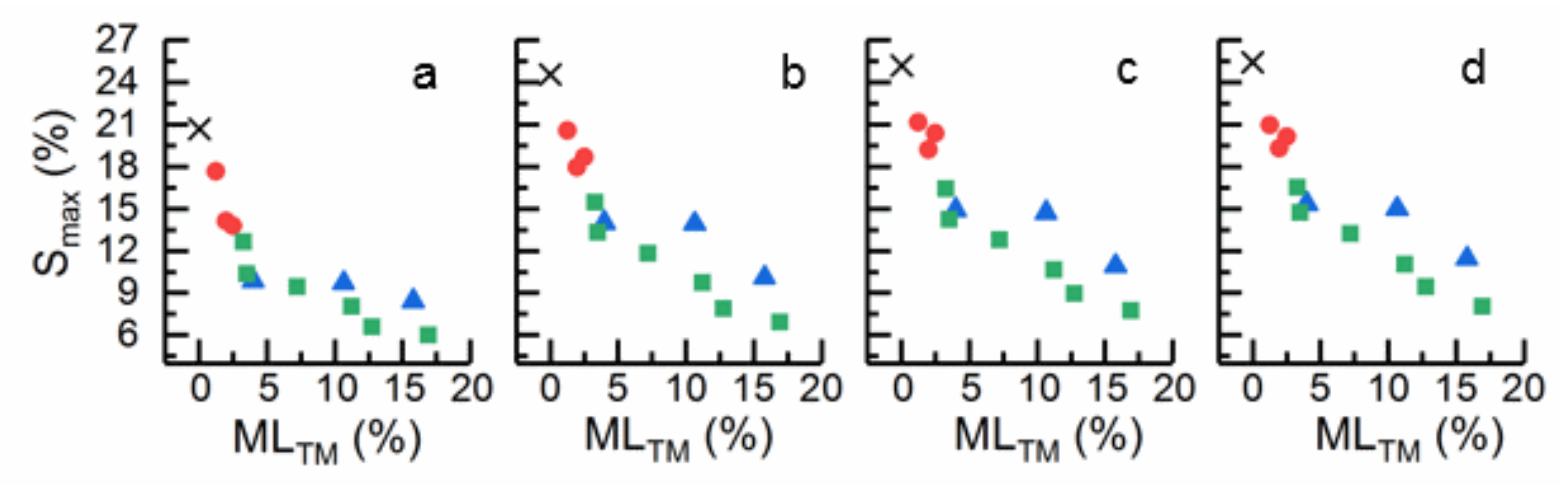

Figure 5.4: Volumetric swelling $(\mathrm{N}=30)$ in dependence on the mass loss by thermal modification $(\mathrm{N}=10)$ measured during the first (a), second (b), third (c) and fourth (d) water soaking cycle. The symbols are the same as in Figure 5.2.

The change in EMC in dependence on the number of water soaking cycles is further illustrated in Figure 5.3 for unmodified eucalypt wood and for wood modified either at $160{ }^{\circ} \mathrm{C}$ and $100 \%$ set point $\mathrm{RH}$ or at $210{ }^{\circ} \mathrm{C}$ in an open system. Both thermal modifications resulted in a similar $\mathrm{ML}_{\mathrm{TM}}$, but the increase in EMC with increasing number of cycles was much larger after the modification in the open system compared to the modification in the closed system. This clearly evidences that additional, reversible effects influence the EMC that are not dependent on $\mathrm{ML}_{\mathrm{TM}}$, but on the conditions applied during the modification process.

Similar to the results on EMC, $\mathrm{S}_{\max }$ as a function of $\mathrm{ML}_{\mathrm{TM}}$ was higher for samples that were modified at $100 \%$ set point RH than for those modified in an open system (Figure 5.4). However, in contrast to the change in EMC, changes in $S_{\max }$ in the course of the water-soaking cycles increased the differences between the process conditions applied. In addition, the $S_{\max }$ increased mainly from the first to the second water soaking cycle and remained almost constant during subsequent cycles. A similar increase in swelling of modified wood after several water soaking cycles has been reported for several other wood species (Biziks et al. 2015; Čermák et al. 2015; Altgen et al. 2016a; Čermák et al. 2016).

Previous studies explain reversible changes in EMC and swelling by two different phenomena - either by the drying-related annealing of amorphous polymers during the process (Altgen and Militz 2016; Endo et al. 2016) or by the cell wall bulking effect of accumulated degradation products (Biziks et al. 2015; Čermák et al. 2015; Altgen et al. 2016a; Obataya and Higashihara 2017). Changes in mass and volume of the samples in dry and wet/conditioned state during the 
water soaking cycles shown in Figure 5.5 indicate that both phenomena occur during the water soaking cycles.

Closed System Open System

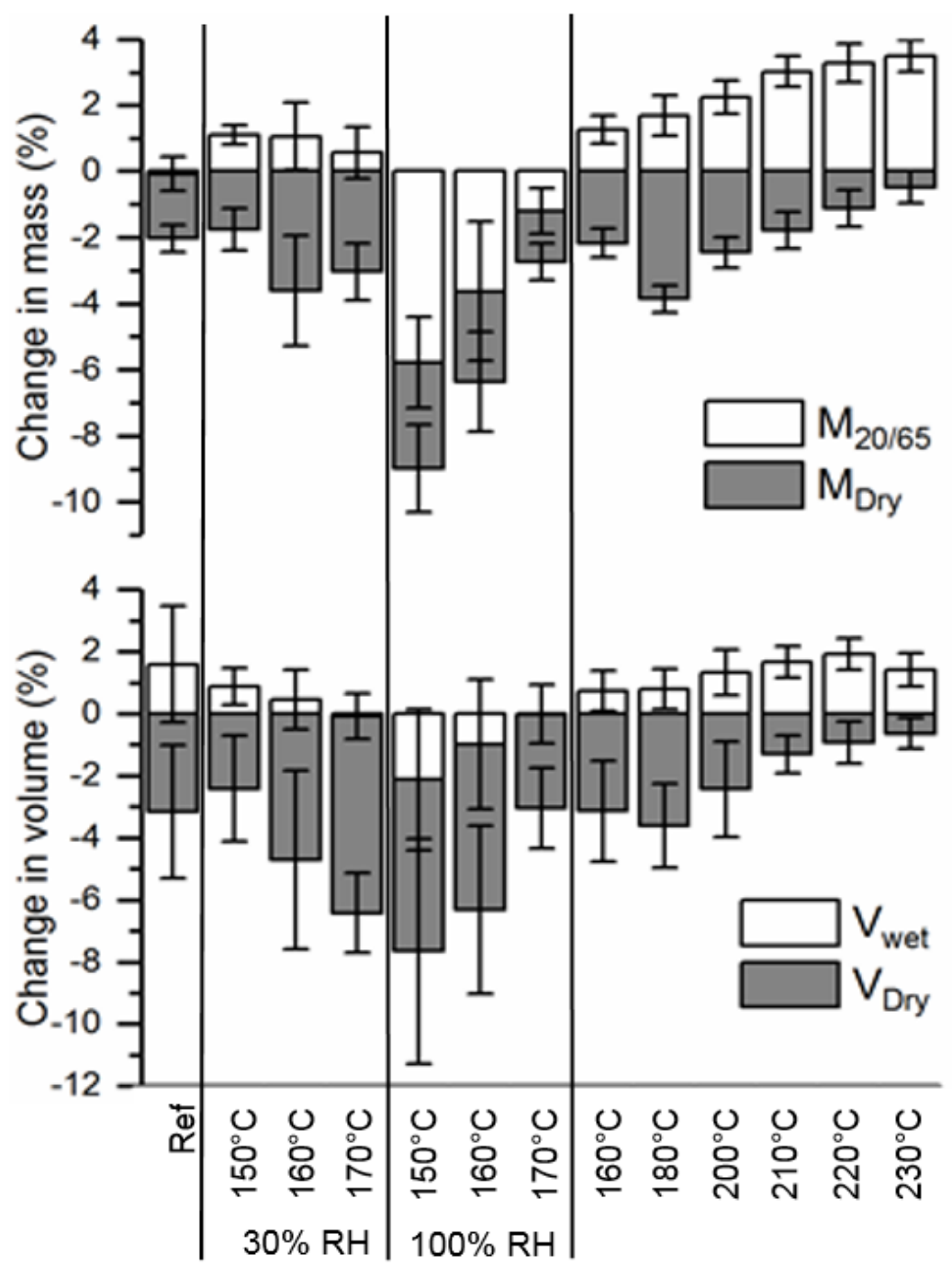

Figure 5.5: Change in mass and volume (\%) of the different modification processes determined for the fourth water-soaking cycle. Changes in mass are separated into the change in mass in dry state $\left(\mathrm{M}_{\text {Dry }}\right)$ and the changes in mass in conditioned state $\left(\mathrm{M}_{20 / 65}\right)$. Changes in volume are separated into the volume change in dry state $\left(\mathrm{V}_{\text {Dry }}\right)$ and the volume change in water-saturated state $\left(\mathrm{V}_{\mathrm{Wet}}\right)$.

The leaching of accumulated degradation products during water soaking caused a loss in dry mass and volume, while the loss in wet/conditioned state was either much smaller or fully absent. Water-soaking thus removed the cell wall bulking effect of accumulated degradation products. Interestingly, however, the loss in dry mass was not a simple function of the extractive 
content. As an example, for wood modified at $150{ }^{\circ} \mathrm{C}$ and $100 \%$ set point $\mathrm{RH}, 7.7 \%$ loss in dry mass was measured after the fourth cycle, while only $1.3 \%$ was lost for wood modified at $210{ }^{\circ} \mathrm{C}$ in an open system, although the same initial extractive content $(12.7 \%)$ was recorded for both samples. Potentially, degradation products found in wood modified at high steam pressure regimes are more water-soluble than those found in wood from open reactors. As suggested by Altgen et al. (2016a), higher wood MC during processes at a nearly saturated steam pressure conditions might hinder the dehydration of highly water-soluble sugars to furantype derivatives, which are less water-soluble.

As suggested by Endo et al. (2016) and Altgen and Militz (2016), re-softening of the amorphous cell wall matrix polymers combined with strong swelling by water-soaking at room temperature removed the annealing effect that is caused by high-temperature drying during the modification process. Removing the annealing effect enhanced the capacity of the cell wall to take up liquid water or water vapor, and thereby increased the wet/conditioned mass and volume. In line with the theory of a drying-related effect, the extent of this increase in mass and volume was somewhat correlated to the final MC measured. Wood modified in an open system, which resulted in very low final MC and thus in strong drying at high temperatures, showed the strongest increase in wet mass and volume during water soaking cycles. In contrast, such an increase in mass and volume was fully absent in wood modified at $100 \%$ set point RH, which featured the highest final MC.

For wood modified at $100 \%$ set point $\mathrm{RH}$, the conditioned mass and wet volume even decreased, which could be related to increased cellulose microfibril aggregation. Microfibril aggregation occurs after removal or relocation of hemicelluloses and/or lignin as spacers between adjacent cellulose microfibrils (Salmen and Burgert 2009; Pönni et al. 2014; Salmén 2015). Microfibril aggregation reduces the capacity of the cell wall for water uptake and is also likely to be caused by thermal modification as a consequence of strong drying and thermal degradation of hemicelluloses as spacers between adjacent microfibrils (Andersson et al. 2005). If thermal degradation products remain within the wood cell wall, they keep occupying space to prevent microfibril aggregation. However, removing a large proportion of accumulated degradation products during water-soaking enables microfibril aggregation during a subsequent drying step. Although a decrease in conditioned mass and wet volume is only evident for wood modified at $100 \%$ set point $\mathrm{RH}$, microfibril aggregation after removal of degradation products as spacers might also occur in other samples. However, the effect of microfibril aggregation on 
the conditioned mass and wet volume and the removal of drying related anealing effects contradict each other. Therefore, no clear separation between these individual effects can be achieved. It is evident, however, that removal of drying related anealing effects is the main cause for reversible changes for samples modified in an open system, while cell wall bulking of remaining degradation products is the main effect for samples modified at $100 \%$ set point RH.

\subsubsection{Dynamic vapor sorption}

When measuring the sample that was modified in a closed system before the water soaking cycles, a significant decrease in dry mass was observed from the first drying step at $0 \% \mathrm{RH}$ to the second drying step (Figure 5.6). A similar observation was made by Vahtikari et al. (2017) for acetone extracted wood, which was explained by the vaporization of residual acetone from the wood during the DVS measurement. We suggest that in a similar fashion, some residual degradation products became volatile during the DVS measurement to decrease the sample mass. However, the dry mass was constant during subsequent drying steps. Therefore, the first sorption cycle was omitted and the dry mass of the first $0 \% \mathrm{RH}$ step of the second sorption cycle was used as reference mass for the EMC calculation. Furthermore, the loss in dry mass $(-1.35 \%)$ was subtracted from $\mathrm{E}$ for the calculation of $\mathrm{EMC}_{\mathrm{c}}$.

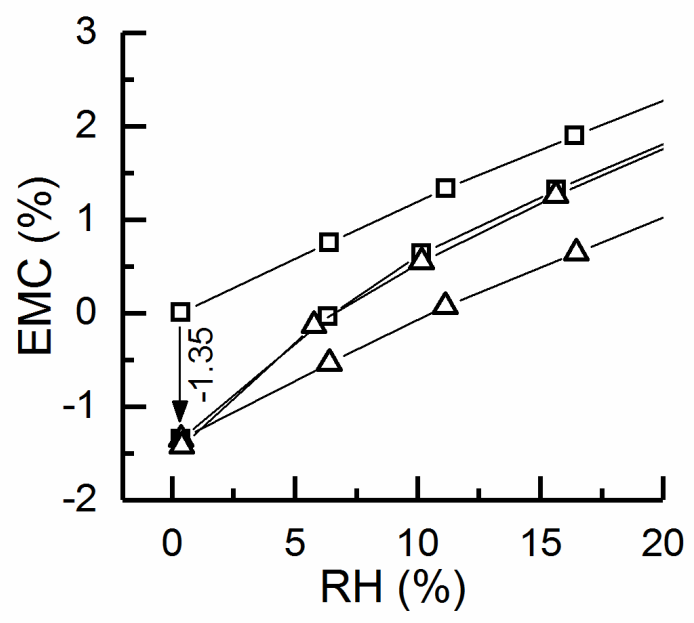

Figure 5.6: EMC (\%) as a function of the RH (\%) measured for the samples modified in a closed system at $160{ }^{\circ} \mathrm{C}$ and $100 \% \mathrm{RH}$ before any water-soaking cycles. The first sorption cycle is indicated by squares, the second cycle by triangles. The arrow indicates the loss in dry mass from the first to the second $0 \% \mathrm{RH}$ step. 
Sorption isotherms and hysteresis of unmodified eucalypt wood, as well as eucalypt wood modified at $160{ }^{\circ} \mathrm{C}$ at $100 \%$ set point $\mathrm{RH}$ and at $210{ }^{\circ} \mathrm{C}$ in an open system are shown in Figure 5.7. For the unmodified reference samples (Figure 5.7a), the sorption isotherms are almost identical before and after the water-soaking cycles. The only deviation from a uniform pattern is a small difference between the first and the second adsorption isotherm measured after the water-soaking cycles, which might be a result of repeated wetting and re-drying during the water-soaking cycles. Such difference between the first and the second adsorption isotherm has also been reported for thermally modified pine (Hill et al. 2012) and spruce wood (Majka et al. 2016). This effect cannot be verified for the sample from the closed system, because the first sorption isotherm before water soaking was omitted. For the sample that was modified at $210^{\circ} \mathrm{C}$ in an open system, however, this effect is clearly evident in the sorption isotherms (Figure 5.7c), as well as an increased hysteresis of the first sorption cycle (Figure 5.7f).
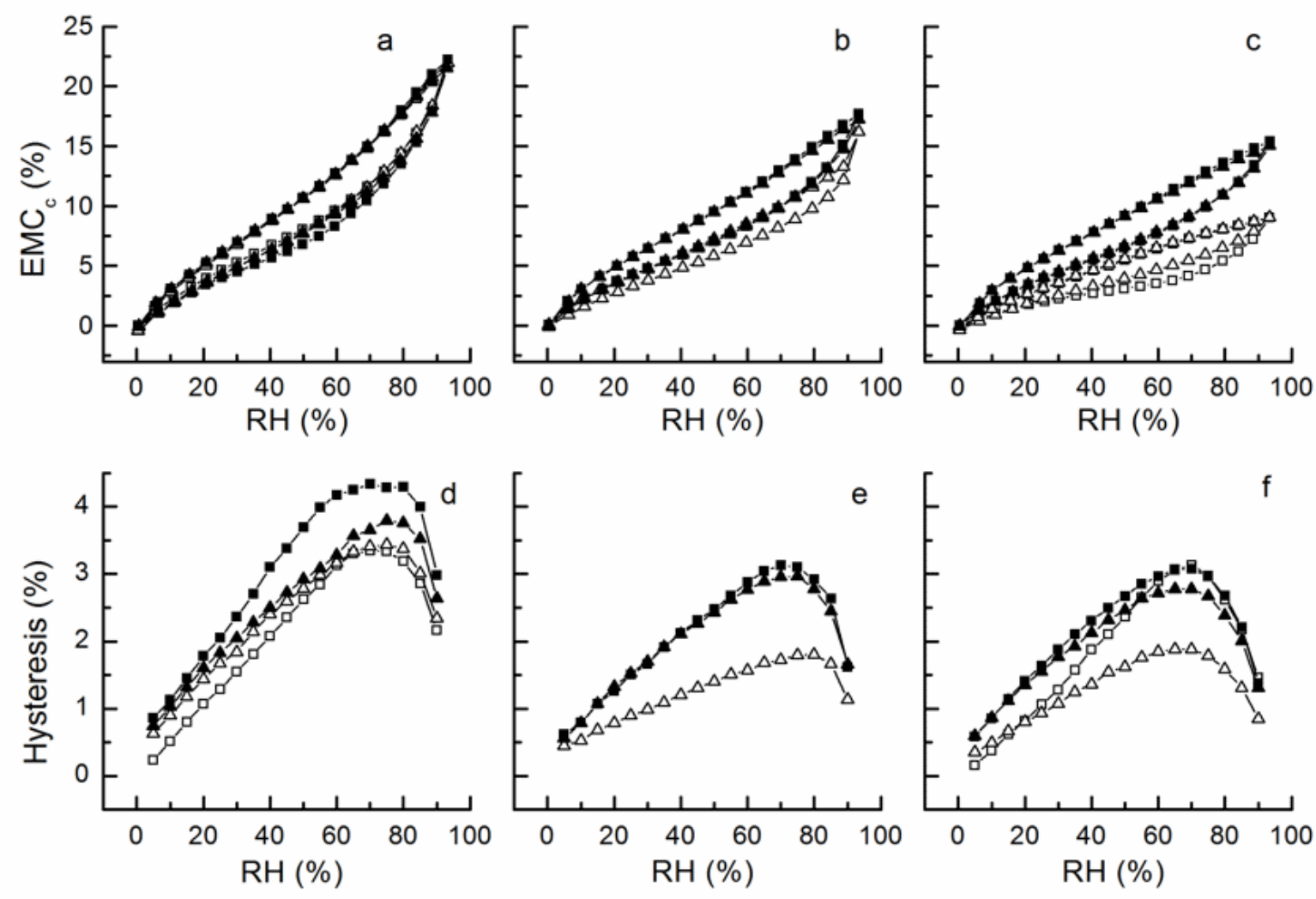

Figure 5.7: Sorption isotherms (a-c) and hysteresis (\%, d-f) of unmodified wood (a and d), wood modified at $160{ }^{\circ} \mathrm{C}$ and $100 \% \mathrm{RH}$ in a closed system (b and e) and wood modified at $210{ }^{\circ} \mathrm{C}$ in an open system ( $\mathrm{c}$ and $\mathrm{f}$ ). Open symbols represent the measurement before, closed symbols the measurement after water soaking cycles. The first sorption cycle is indicated by squares, the second sorption cycle by triangles. 
Water-soaking not only removed differences between the first and second adsorption isotherm, but also resulted in an overall increase of the EMC for thermally modified wood over the entire RH range (Figure 5.7b and c). DVS measurements after water-soaking cycles also resulted in an increase in hysteresis compared to measurements before the cycles. This was less pronounced for the unmodified reference (Figure 5.7d), but clearly evident for the thermally modified samples (Figure 5.7e and f). It evidences that performing a minimum of two sorption cycles in dynamic vapor sorption measurements of wood to account for the sorption history of the wood material, as suggested by Popescu and Hill (2013), does not remove all reversible effects in thermally modified wood. Water soaking removes the cell wall bulking effect efficiently by leaching accumulated degradation products, which does not occur to the same extent during DVS measurements. However, differences in sorption isotherms before and after water-soaking were most pronounced for wood modified at $210{ }^{\circ} \mathrm{C}$ in an open system, although the loss in dry mass during water-soaking was much smaller (-1.1\%) than observed for wood modified at $160{ }^{\circ} \mathrm{C}$ and $100 \%$ set point $\mathrm{RH}(-6.4 \%)$. Therefore, leaching of accumulated degradation products during water-soaking cannot be the sole reason for the differences in the sorption isotherms before and after water-soaking cycles. Thybring et al. (2017) demonstrated recently that hydroxyl inaccessibility caused by wood drying cannot be fully recovered by water vapor exposure, but only by vacuum-impregnation with liquid water. In a similar fashion, water vapor exposure up to $95 \%$ in the DVS might be incapable of fully removing drying related anealing effects caused by a thermal modification, while maximum swelling during watersoaking removes this effect to a much larger extent.

The effectiveness in changing the $\mathrm{EMC}_{\mathrm{c}}$ of unmodified wood by the thermal modification process in dependence on the different $\mathrm{RH}$ levels measured is further illustrated by the $\mathrm{EMC}_{\mathrm{c}}$ ratio shown in Figure 5.8. An $\mathrm{EMC}_{\mathrm{c}}$ ratio of 1 denotes no difference in the $\mathrm{EMC}_{\mathrm{c}}$ between the modified sample and the reference $\mathrm{EMC}_{\mathrm{c}}$ (derived from the first sorption isotherm of the unmodified wood before water soaking). A deviation from an $\mathrm{EMC}_{\mathrm{c}}$ ratio of 1 illustrates either an increase in $\mathrm{EMC}_{\mathrm{c}}$ caused by the modification $\left(\mathrm{EMC}_{\mathrm{c}}\right.$ ratio $\left.>1\right)$ or a decrease $\left(\mathrm{EMC}_{\mathrm{c}}\right.$ ratio < 1). 

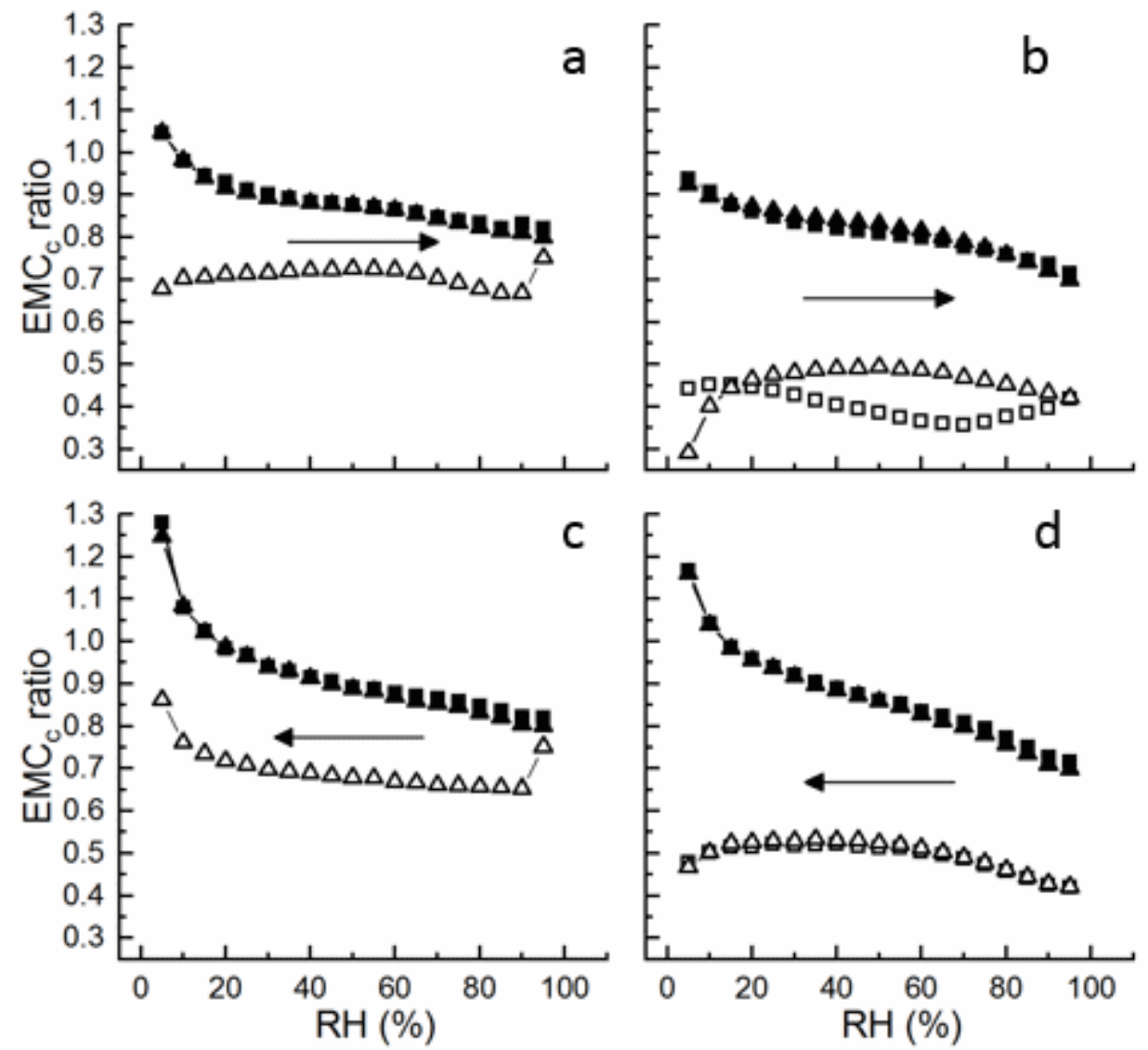

Figure 5.8: $\mathrm{EMC}_{\mathrm{c}}$ ratios in dependence on the RH (\%) applied during the DVS measurements. The $\mathrm{EMC}_{\mathrm{c}}$ ratios are determined in adsorption ( $\mathrm{a}$ and $\mathrm{b}$ ) and in desorption (c and d). Wood modified at $160{ }^{\circ} \mathrm{C}$ and $100 \% \mathrm{RH}$ in a closed system is shown in a and c, wood modified at $210{ }^{\circ} \mathrm{C}$ in an open system is shown in $\mathrm{b}$ and $\mathrm{d}$. The arrows mark the sequence in which the $\mathrm{RH}$ steps were applied. The symbols are the same as in Figure 5.6.

Before water soaking, the $\mathrm{EMC}_{\mathrm{c}}$ ratios evidence that the modification at $210{ }^{\circ} \mathrm{C}$ in an open system was more effective in reducing the $\mathrm{EMC}_{\mathrm{c}}$ than the modification at $160{ }^{\circ} \mathrm{C}$ and $100 \%$ set point $\mathrm{RH}$, even though $\mathrm{ML}_{\mathrm{TM}}$ and $\mathrm{CML}_{\mathrm{TM}}$ were almost identical. This is presumably because high-temperature drying in the open system caused a stronger annealing of amorphous matrix polymers to further reduce the $\mathrm{EMC}_{\mathrm{c}}$ ratio. Differences in the $\mathrm{EMC}_{\mathrm{c}}$ ratio that is calculated for the first and second adsorption isotherm before water soaking for the sample from the open system (Figure 5.8b) is an artifact of this drying-related effect. It further reduces the $\mathrm{EMC}_{\mathrm{c}}$ ratio at low $\mathrm{RH}$ levels, but results in an upwards bend in the $\mathrm{EMC}_{\mathrm{c}}$ ratio above $65 \% \mathrm{RH}$. The latter indicates that softening of amorphous cell wall matrix polymers above ca. $60 \% \mathrm{RH}$ at room temperature partially removes drying related annealing effects, in line with the findings of Endo et al. (2016). 
However, the recovery of reversible effects does not explain the steep increase in $\mathrm{EMC}_{\mathrm{c}}$ ratio from 90 to $95 \%$ RH observed for the samples from the closed reactor system before water soaking, because it is evident in ad- and desorption (Figure 5.8a and c). Wood modified in closed reactor system at (nearly) saturated water vapor conditions contains large amounts of sugars derived from the hydrolysis of hemicelluloses (Altgen et al. 2016a). If they do not crystallize, sugars and other deliquescent compounds follow an IUPAC type III sorption isotherm, thus their presence in wood may decrease the EMC at low RH levels, but increases the EMC at high RH levels to considerable extent (Stamm 1956; Bendtsen 1966; Lesar et al. 2009). After removing residual sugars in the modified wood by water-soaking, the steep increase in $\mathrm{EMC}_{\mathrm{c}}$ ratio above $90 \% \mathrm{RH}$ disappeared.

In line with our explanations of removing reversible effects induced by thermal modification as a consequence of maximum swelling and leaching of degradation products, the $\mathrm{EMC}_{\mathrm{c}}$ ratios increased strongly after the water-soaking cycles. Differences in the $\mathrm{EMC}_{\mathrm{c}}$ ratio between samples from open and closed reactor systems became smaller after water-soaking cycles, with only slightly lower $\mathrm{EMC}_{\mathrm{c}}$ ratios for the sample modified in the open system. At $\mathrm{RH}$ levels lower than $10-15 \%$, thermal modification became ineffective in decreasing the $\mathrm{EMC}_{\mathrm{c}}$ after water soaking cycles and the $\mathrm{EMC}_{\mathrm{c}}$ ratio even raised above 1 during desorption, despite significant $\mathrm{ML}_{\mathrm{TM}}$. Potentially, removing degradation products after the modification leaves the cell wall in a more open state. This might improve the creation and/or accessibility of sorption sites in the wood to compensate for the reduction in $\mathrm{OH}$ group concentration by hemicellulose degradation. Nonetheless, increasing the $\mathrm{RH}$ resulted in a decrease in $\mathrm{EMC}_{\mathrm{c}}$ ratio. Such decreasing $\mathrm{EMC}_{\mathrm{c}}$ ratio has previously been assigned to an enhanced cross-linking within the cell wall matrix of thermally modified wood (Altgen et al. 2016a), due to its similarity to the effect of wood modifications with cross-linking agents on the water sorption (Himmel and Mai 2015). Therefore, it may be speculated that enhanced cross-linking within the cell wall matrix and not the reduction in $\mathrm{OH}$ group concentration by hemicellulose degradation is the predominant cause for the reduction in $\mathrm{EMC}_{\mathrm{c}}$ by thermal modification after water-soaking cycles. Further studies are necessary to study this sorption phenomenon in thermally modified wood. We recommended the incapability of fully removing reversible effects by exposing thermally modified wood to $\leq 95 \%$ RH in DVS instruments to be considered during such studies. 


\subsection{Conclusions}

The effect of reducing the equilibrium moisture content and the volumetric swelling by thermal modification was partially lost during water-soaking cycles. For modification processes in an open system, the removal of drying-related annealing of amorphous polymers was the main cause for recovering reversible changes in hygroscopicity. For modification processes in a closed system at $100 \%$ set point RH, the removal of cell wall bulking caused by accumulated degradation products was the main effect. However, removal of large proportions of degradation products during water soaking also prevented the full re-wetting of the samples in subsequent cycles, presumably due to cellulose aggregation. Dynamic vapor sorption (DVS) analysis yielded different results before and after water soaking of the samples. Exposure of the wood to a maximum of $95 \%$ RH during DVS experiments did not remove reversible effects to the same extent as water-soaking cycles. This incapability of the DVS instrument should be considered when analyzing thermally modified wood, as it hinders the separation of reversible from irreversible effects in mode of action studies. 



\section{Chapter 6: Publication V}

\section{Thermally modified Eucalyptus nitens as material for decking}

Maximilian Wentzel ${ }^{1}$, Óscar González-Prieto ${ }^{2}$, Christian Brischke $^{1}$, Holger Militz $^{1}$

${ }^{1}$ Department of Wood Biology and Wood Products, University of Göttingen, Faculty of Forest Science, Büsgenweg 4, 37077 Göttingen, Germany

${ }^{2}$ Department of Natural Resources and Environment Engineering, University of Vigo, Escuela de Ingeniería Forestal, 36005, Pontevedra, Spain

*corresponding author:

Phone: +495513922051

Fax: +49551399646

E-mail: mwentze@gwdg.de

ORCID: 0000-0002-5795-7589

Manuscript submitted to:

Drvna Industrija

Faculty of Forestry, Zagreb University

ISSN (Print): $\quad$ 0012-6772

ISSN (Online) 1847-1153 
Abstract: Eucalyptus nitens is a fast growing plantation species that has a good acclimation in Spain and Chile. At the moment it is mainly used for pulp and paper production, but there is a growing market for solid wood products made from this species. Thermal modification offers a good alternative to produce high quality material to manufacture products with high added value. This study used unmodified and thermally modified E. nitens wood from Spanish and Chilean plantations to elaborate external decking and examine if it complies with the necessary properties to be a competitive product. A process similar to ThermoWood ${ }^{\circledR}$ was applied with the following temperatures: $185^{\circ} \mathrm{C}, 200^{\circ} \mathrm{C}$ and $215^{\circ} \mathrm{C}$. For each modification and for an unmodified specimen mass loss, volumetric swelling, anti-swelling efficiency (ASE) and equilibrium moisture content (EMC) were determined. Brinell hardness, dynamic hardness, screw and nail withdrawal resistance, and abrasion resistance according to the Shaker method and the Taber abraser method were determined. In summary, thermally modified E. nitens wood showed high potential to be used as decking material outdoors.

Keywords: Eucalyptus nitens, anti-swelling efficiency (ASE), hardness, abrasion resistance, decking

\subsection{Introduction}

Historically, both Chile and Spain are producers of Eucalypt wood, mostly from plantations of Eucalyptus globulus. In the last 30 years there has been a steady growth of Eucalyptus nitens plantations, as it is a species with great adaptability to the climate conditions in both countries. In Chile, there are about 250,000 ha planted as of 2014 (INFOR 2015), while in Spain no official data are available on the eucalypt plantations (including E. globulus, E. nitens and E. camaldulensis), but it is estimated to be 700,000 ha for the entire country. The current review for the Forestry Plan of Galicia (Xunta de Galicia 2018), which analyzed the Spanish Forestry Inventory and the Spanish Forestry Map, gave a value of 500,000 ha in the Galicia region. This reference also suggested for E. nitens in this region forests of approximately 40,000 ha, and proposed an increase of 30.000 ha during the next 20 years. However, it has to be taken into consideration that the figures generated discrepancies in different regions of Spain, as there are no official data available, except the aforementioned reference.

Currently, E. nitens plantation wood is mostly used for pulp and paper or biofuels, but there is an interest to widen the use of this fast growing tree species. Solid wood made out of plantation E. nitens is being sold at the moment in Chile, but it cannot compete with other fast growing 
species, as the volume of plantations of radiata pine in Chile (INFOR 2015) allows the species to maintain a competitive low price, and the dimensional stability and natural durability are not as good as high end wood from native species, like Nothofagus alpina (INFOR 2015). As for Spain, there is still no market for dry E. nitens wood. The wood-working industry must invest in research to use the increasingly available raw material which can be used as alternative for currently used wood species on the Spanish market, such as Castanea sativa (Sweet chestnut), Pinus spp. or E. globulus. Thermal modification offers a good alternative to produce high quality material from this species that could be used for decking, claddings, windows, doors, flooring, garden products and even saunas or bathrooms (Militz and Altgen 2014). Most thermal modification processes apply temperatures between 160 and $240^{\circ} \mathrm{C}$ and limit the oxygen content during the process (Hill 2006; Esteves and Pereira 2009; Militz and Altgen 2014). Eucalypt species, such as E. globulus, E. grandis and E. regnans (durability in ground contact class 3-4, Australian Standard 5604 2005), have been used as material for thermal modification (Esteves et al. 2007a; Esteves et al. 2007b; González-Prieto and Touza Vázquez 2009; Calonego et al. 2012; de Cademartori et al. 2015; Batista et al. 2016). In most cases research has been focused on the variation of color, the changes of the mechanical and physical properties and variations of the chemical composition.

A potential alternative of using thermally modified E. nitens (durability class 4, Australian Standard 5604 2005) is wood decking. Although thermal treatments of other eucalypt species did not affect the natural durability when in direct contact to the ground (Knapic et al. 2018), in general, the mechanical properties of thermally modified eucalypt species, such as MOE and MOR, indicated potential for use as decking (Esteves et al. 2007b; de Cademartori et al. 2015; Knapic et al. 2018). Currently, tropical woods such as Bangkirai (Shorea laevis), Europeangrown timbers such as Douglas fir (Pseudotsuga menziesii) and Larch (Larix spp.), and preservative treated pine are the most commonly used materials for decking. In addition to these traditional decking materials in Europe, wood polymer composite (WPC) decking is gaining market share throughout Europe (Zeller 2018) not at least due to their good capabilities to suppress the moisture uptake and resulting moisture movements. Thermal modification improves natural durability and dimensional stability, and decreases the equilibrium moisture content (EMC) of wood (Stamm and Hansen 1937; Hill 2006; Esteves and Pereira 2009). Thermal modification leads also to an embrittlement of wood coming along with reduced abrasion resistance and the risk of splintering on the wood surface (Kubojima et al. 2000; Phuong et al. 2007). Surface hardness and resistance to abrasion are critical properties in less 
and non-load-bearing applications. In the case of decking, surface hardness turns into a decisive property for its use (Brischke et al. 2005). In this study the abrasion resistance, which is a combination of shearing, impact, friction and compressive stresses, will be measured using a modified taber abraser method (DIN EN 438-2 (2005)), in which sanding paper is pressed on the modified wood decking with a defined force and number of revolutions (Brischke et al. 2005), and the Shaker method according to Brischke et al (2005), where wood is subjected to abrasion by steel balls in an overhead rotational shaker. Additionally, two hardness measurements (Brinell and dynamic), the maximum swelling, the anti-swelling efficiency (ASE) and the equilibrium moisture content (EMC) will be measured, as they are further critical characteristics for the implementation of decking.

\subsection{Materials and methods}

\subsubsection{Material}

The Chilean E. nitens wood came from 19 year old plantations from the Región del Bío-Bío in Chile, while the wood from Spain came from 16 year old plantations from the north of the

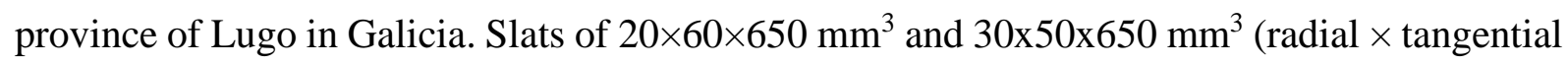
$\times$ longitudinal) size, for the Chilean and Spanish origin respectively, were prepared from kilndried wood free of large knots. Before the modification process the slats from Chile had an average moisture content of $13 \%$, whereas the ones from Spain had an average of $15 \%$. Twelve slats (six for each country of origin) per modification process were used.

\subsubsection{Thermal modification}

Thermal modification was performed in a laboratory-scale treatment reactor. The samples were placed in a stainless steel vessel with a volume of 651 that was heated up with electric heating cables and cooled down to room temperature with a system of water cooling coils. Water vapor was produced by heating an external water reservoir connected to the vessel. Exhaust valves were used for the release of excess pressure.

The process had the following steps: The temperature in the vessel was first raised at $12^{\circ} \mathrm{C} / \mathrm{h}$ to $100^{\circ} \mathrm{C}$ and then at $2^{\circ} \mathrm{C} / \mathrm{h}$ to $130^{\circ} \mathrm{C}$ to allow a high-temperature drying of the slats to nearly $0 \%$ $\mathrm{MC}$, before increasing the temperature again at $12^{\circ} \mathrm{C} / \mathrm{h}$ until reaching the peak temperatures $\left(185,200\right.$ and $\left.210^{\circ} \mathrm{C}\right)$. The peak temperature was hold for $3 \mathrm{~h}$. Afterwards, the temperature was decreased at $20^{\circ} \mathrm{C} / \mathrm{h}$ until reaching $65^{\circ} \mathrm{C}$, at which the vessel was opened and the samples were 
removed. When exceeding $100^{\circ} \mathrm{C}$ in the treatment vessel, a steam flow was created by heating the water in the water reservoir to slightly above $100^{\circ} \mathrm{C}$ while opening an exhaust valve of the treatment vessel. Thus, a mixture of steam and volatile degradation products was released, while pure steam was added constantly to the process.

\subsubsection{Determination of mass loss (ML)}

To determine the mass loss (ML) caused by the thermal modification an adaptation of the procedure reported by Metsä-Kortelainen et al. (2006) was applied. The mass and the corresponding wood moisture content (MC) were recorded for each slat before and immediately after the process. The MC was determined from small sections taken from the slats, not from the material to be tested itself according to eq. 6.1,

$$
M C=\left(m_{x}-m_{\text {dry }} / m_{\text {dry }}\right) * 100,
$$

Equation 6.1

where $m_{x}$ is the mass of the specimen before or after modification and $m_{d r y}$ is the dry mass of the specimen before or after modification. The dry mass $\left(\mathrm{m}_{\mathrm{y}}\right.$ in $\left.\mathrm{g}\right)$ was then calculated using eq. 6.2:

$$
m_{y}=\left(m_{x} / M C+100\right) * 100,
$$

Equation 6.2

where $m_{x}$ is the mass of the specimen before or after modification and MC is the moisture content calculated using eq. 6.1. Finally, the mass loss (ML in \%) was calculated using eq. 6.3:

$$
M L=\left[\left(m_{y b}-m_{y a}\right) / m_{y b}\right] * 100 \%,
$$

Equation 6.3

where $\mathrm{m}_{\mathrm{yb}}$ is the dry mass before modification $(\mathrm{g})$ and $\mathrm{m}_{\mathrm{ya}}$ is the dry mass after the modification $(\mathrm{g})$.

\subsubsection{Determination of oven-dry density}

The oven-dry density was determined using the abrasion specimens, which were oven dried at $103 \pm 2^{\circ} \mathrm{C}$ until constant mass. They were then weighed to the closest $0.01 \mathrm{~g}$ and their dimensions were measured to the nearest $0.01 \mathrm{~mm}$. The oven-dry density was calculated using eq. 6.4: 


$$
D_{o d}=m_{o d} / V_{o d}
$$

Equation 6.4

where $\mathrm{D}_{\text {od }}$ is the oven-dry density $\left(\mathrm{g} / \mathrm{cm}^{3}\right), \mathrm{m}_{\text {od }}$ is the oven-dry mass $(\mathrm{g})$ and $\mathrm{V}_{\text {od }}$ is the oven-dry volume $\left(\mathrm{cm}^{3}\right)$. The data was then transformed in $\mathrm{kg} / \mathrm{m}^{3}$.

\subsubsection{Determination of equilibrium moisture content (EMC), volumetric swelling $\left(\mathbf{S}_{\max }\right)$ and anti-swelling efficiency (ASE)}

To measure EMC, $S_{\max }$ and ASE, 30 specimens per process run with dimensions of $10 \times 10 \times 10$ $\mathrm{mm}^{3}$ (rad. $\times$ tang. $\times$ long.) were prepared from the modified wood and from unmodified references. The mass and dimensions of the specimens were measured after each of the following steps: (step A) conditioning at $20^{\circ} \mathrm{C} / 65 \% \mathrm{RH}$ until constant weight; (step B) air drying at room conditions for a week and oven drying at $103{ }^{\circ} \mathrm{C}$ for two days or until constant mass; (step C) water-impregnation for $30 \mathrm{~min}$ at $13 \mathrm{kPa}$ and water soaking for 14 days, or until constant weight, with daily water changes.

The EMC (in \%) at $20{ }^{\circ} \mathrm{C}$ and $65 \% \mathrm{RH}$ was determined for each sample using eq. 6.5:

$$
\mathrm{EMC}=100 \times\left(\mathrm{m}_{\mathrm{A}}-\mathrm{m}_{\mathrm{B}}\right) / \mathrm{m}_{\mathrm{B}},
$$

Equation 6.5

where $\mathrm{m}_{\mathrm{A}}$ and $\mathrm{m}_{\mathrm{B}}$ is the mass (in $\mathrm{g}$ ) at the end of step A and B respectively.

$\mathrm{S}_{\max }($ in $\%$ ) was measured based on the sample volume at the end of step B and C for each cycle using eq. 6.6:

$$
\mathrm{S}_{\max }=100 \times\left[\left(\mathrm{V}_{\mathrm{C}}-\mathrm{V}_{\mathrm{B}}\right) / \mathrm{V}_{\mathrm{B}}\right]
$$

Equation 6.6

where $V_{B}$ and $V_{c}$ are the sample volumes at the end of step $B$ and $C$ respectively.

ASE (in \%) was measured using the $S_{\max }$ before and after modification using eq. 6.7:

$$
A S E=S u_{\max }-S m_{\max } / S u_{\max } * 100,
$$

Equation 6.7

where $\mathrm{Su}_{\max }$ is the maximum swelling of the unmodified sample and $\mathrm{Sm}_{\max }$ is the maximum swelling of the modified sample respectively. 


\subsubsection{Brinell hardness tests}

The Brinell hardness (static hardness) was measured according to EN 1534 (2011) with a universal testing machine (Zwick Roell Z010, Zwick, Ulm, Germany). A maximum force of $500 \mathrm{~N}$ using a steel ball with a diameter of $10 \mathrm{~mm}$ was applied for 25 seconds on specimens of $15 \times 50 \times 50 \mathrm{~mm}^{3}$ (rad. $\times$ tang. $\times$ long.) for the Chilean wood and $25 \times 50 \times 50 \mathrm{~mm}^{3}$ (rad. $\times$ tang. $\times$ long.) for the Spanish wood. The specimens were conditioned at $20^{\circ} \mathrm{C} / 65 \% \mathrm{RH}$ during seven days until constant weight. The diameter of the residual impression was automatically determined by the testing machine. The Brinell hardness was then calculated according to eq. 6.8:

$$
B H=2 * F / \pi * D\left[D-\sqrt{\left(D^{2}-d^{2}\right)}\right],
$$

Equation 6.8

where $\mathrm{BH}$ is the Brinell hardness $\left(\mathrm{N} / \mathrm{mm}^{2}\right), \mathrm{F}$ is the maximum force used $(\mathrm{N}), \mathrm{D}$ is the diameter of the steel ball $(\mathrm{mm})$ and $\mathrm{d}$ is the diameter of the imprint on the sample $(\mathrm{mm})$.

\subsubsection{Dynamic hardness tests}

The dynamic hardness was determined according to Meyer et al. (2011) using specimens of the same dimensions as for the Brinell hardness tests. An indentation was generated in the surface of the specimen using a steel weight of $500 \mathrm{~g}$ that was dropped down on a steel ball from $300 \mathrm{~mm}$ of height. Four measurements were conducted on five replicates per material. The dynamic hardness was calculated according to eq. 6.9:

$$
D H=m * \sqrt{(2 * g * h)} / r^{2} * \pi,
$$

Equation 6.9

where DH is the dynamic hardness $\left(\mathrm{N} / \mathrm{mm}^{2}\right), \mathrm{m}$ is the mass of the dropping weight $(\mathrm{kg}), \mathrm{h}$ is the dropping height $(\mathrm{m}), \mathrm{r}$ is the radius of the imprint on the sample (mm) and $\mathrm{g}$ is the gravity acceleration $\left(\mathrm{m} / \mathrm{s}^{2}\right)$.

\subsubsection{Resistance to abrasion: Shaker test}

The resistance against abrasion was determined using the Shaker method described by Brischke et al. (2005). Five oven-dry specimens of $8.5 \times 8.5 \times 35 \mathrm{~mm}^{3}$ (rad. $\times$ tang. $\times$ long.) were placed in polyethylene flasks $(\mathrm{V}=500 \mathrm{~mL})$ together with $400 \mathrm{~g}$ stainless steel balls of $6 \mathrm{~mm}$ in diameter and moved in an overhead shaker at 28 revolutions per minute during $72 \mathrm{~h}$. 25 specimens per material were tested. The distances between the opposite corners at oven-dry state were 
measured of each specimen, before and after the abrasion process. The loss in dimension (\%) was determined according to eq. 6.10:

$$
\Delta a b=\left[\left(d_{a 1}+d_{a 2} / 2\right)-\left(d_{b 1}+d_{b 2} / 2\right) /\left(d_{b 1}+d_{b 2} / 2\right)\right] * 100, \text { Equation 6.10 }
$$

where $\Delta \mathrm{ab}$ is the abrasion $(\%), \mathrm{d}_{\mathrm{b} 1}$ is the diagonal 1 before abrasion $(\mathrm{mm}), \mathrm{d}_{\mathrm{b} 2}$ is the diagonal 2 before abrasion $(\mathrm{mm}), \mathrm{d}_{\mathrm{a} 1}$ is the diagonal 1 after abrasion $(\mathrm{mm})$ and $\mathrm{d}_{\mathrm{a} 2}$ is the diagonal 2 after abrasion $(\mathrm{mm})$. The average of the 5 samples per flax bottle was determined for each modification.

\subsubsection{Resistance to abrasion: Taber abraser test}

The resistance against abrasion was determined according to the Taber abraser method (EN 438-2, (2005)). The following modifications of the Taber abraser test were made in order to allow testing of solid wood: Specimens of 100x100x7 $\mathrm{mm}^{3}$ were prepared and conditioned in $20{ }^{\circ} \mathrm{C} / 65 \% \mathrm{RH}$. The tree rings of all specimens were oriented $45^{\circ}$ to their cutting edges. After weighing and measuring of the thickness at four points, the specimens $(n=5)$ were clamped into the Taber abraser and were abraded with sanding paper S-42 with approx. $72 \mathrm{~min}^{-1}$ for 1000 revolutions. Afterwards the decrease in thickness by abrasion was determined. The percentage loss in thickness $(\Delta \mathrm{t})$ was determined as a measure of abrasion according to the following eq. 6.11 for each specimen and an average was calculated:

$$
\Delta \mathrm{t}=\left(t_{b}-t_{a} / t_{b}\right) * 100,
$$

where $t_{b}$ is the thickness (mm) before the Taber abrasion test and $t_{a}$ is the thickness $(\mathrm{mm})$ after the Taber abrasion test.

\subsubsection{Screw withdrawal resistance tests}

Screw withdrawal resistance (SWR) tests were performed according to EN 320 (2011), but modified as follows: The same specimens used for the Brinell hardness test were used. Screws with nominal dimensions of $4.2 \times 38 \mathrm{~mm}$ were used to penetrate the tangential face until $15 \pm 0.5$ $\mathrm{mm}$. Afterwards the screws were attached to a bracket to be pulled out at a constant speed of $10 \pm 1 \mathrm{~mm} \mathrm{~min}{ }^{-1}$. The screw withdrawal resistance corresponds to the maximum force determined to $10 \mathrm{~N}$ and was measured according to eq. 6.12 : 


$$
S W R=N_{\max } / t,
$$

Equation 6.12

where SWR is the screw withdrawal resistance, $\mathrm{N}_{\max }$ the maximum force $(\mathrm{N})$ and $\mathrm{t}$ the thickness of the specimen $(\mathrm{mm})$.

\subsection{Results and discussion}

\subsubsection{Changes in mass, oven dry density, EMC, swelling and ASE by thermal modification}

ML increased with rising treatment temperature (Table 6.1), which is in line with results obtained in tests with other Eucalypt species, such as E. saligna (from $12.77 \%$ at $180^{\circ} \mathrm{C}$ and $19.12 \%$ at $220^{\circ} \mathrm{C}$ ) (de Cademartori et al. 2015) and E. globulus $\left(8.7 \%\right.$ at $190^{\circ} \mathrm{C}$ and $12.1 \%$ at $200^{\circ} \mathrm{C}$ ) (Esteves et al. 2007a). There were no significant differences in ML between the specimens from Chile and Spain. On the other hand, oven-dry density (Table 6.1) decreased as the modification temperature increased, which also occurred in vacuum thermally modified E. pellita wood (Wang et al. 2014) and E. globulus (Calonego et al. 2012). The oven-dry density of the Spanish wood specimens was lower than the Chilean ones, which might be due to the age difference of the plantations.

Table 6.1: Mean mass loss (ML) determined for each process run and oven-dry density for each modification and unmodified reference (standard deviation in parentheses) for both Chilean and Spanish specimens.

\begin{tabular}{|c|c|c|c|}
\hline Country of origin & Temperature $\left({ }^{\circ} \mathrm{C}\right)$ & ML (\%) & OD Density $\left(\mathrm{kg} / \mathrm{m}^{3}\right)$ \\
\hline \multirow{3}{*}{} & Reference & - & $617 \pm(16)$ \\
\cline { 2 - 4 } & 185 & $2.4 \pm(0.4)$ & $603 \pm(39)$ \\
\cline { 2 - 4 } & 200 & $6.1 \pm(1.0)$ & $592 \pm(23)$ \\
\cline { 2 - 4 } & 215 & $12.3 \pm(0.5)$ & $553 \pm(29)$ \\
\hline \multirow{3}{*}{$\Xi$} & Reference & - & $574 \pm(26)$ \\
\cline { 2 - 4 } & 185 & $2.6 \pm(0.9)$ & $555 \pm(35)$ \\
\cline { 2 - 4 } & 200 & $5.7 \pm(1.3)$ & $529 \pm(18)$ \\
\cline { 2 - 4 } & 215 & $12.0 \pm(0.9)$ & $517 \pm(35)$ \\
\cline { 2 - 4 } & & &
\end{tabular}

The EMC of the modified wood was reduced in both the Chilean and Spanish specimens (Figure 6.1) after all the thermal modifications, and so did $S_{\max }$ (Figure 6.2). Similar improvements were obtained with thermally modified E. grandis in both EMC and $\mathrm{S}_{\max }$ 
(Calonego et al. 2012) and EMC in E. globulus (Esteves et al. 2007b). Compared with other tropical wood species used for decking (Choong and Achmadi 1991), the EMC of E. nitens was lower after treatment at $215^{\circ} \mathrm{C}$ and similar at $185^{\circ} \mathrm{C}$ and $200^{\circ} \mathrm{C}$. ASE of E. nitens was lower at modification at $185^{\circ} \mathrm{C}(26.14 \%$ and $23.11 \%$ for Chile and Spain respectively) (Figure 6.3) compared to the modifications at higher temperatures. As for other eucalypt species, the ASE of thermally modified E. globulus reported by Esteves et al. (2007b) was higher.

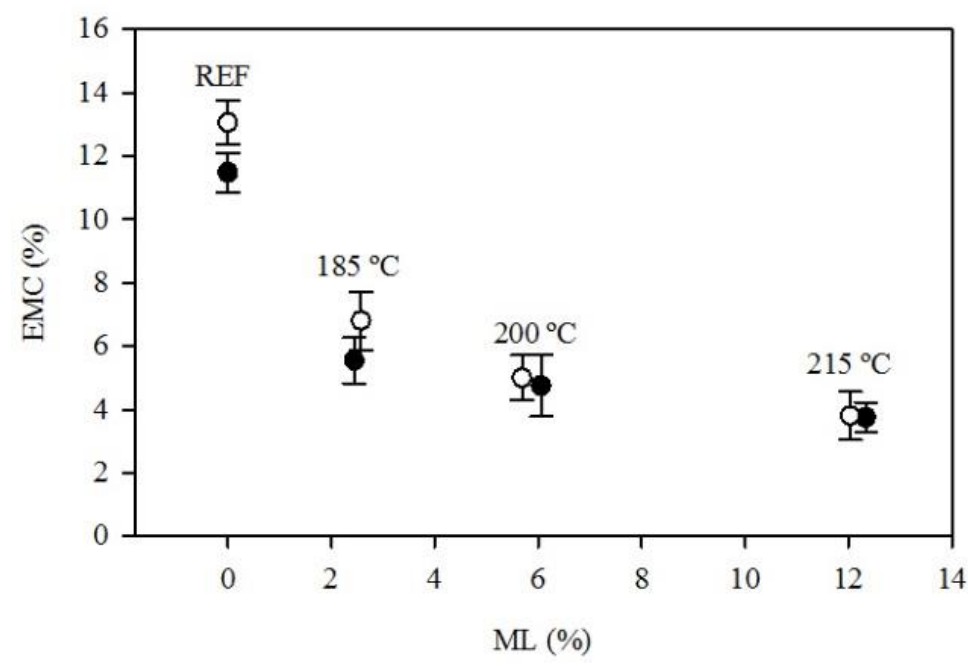

Figure 6.1: EMC of E. nitens at $20{ }^{\circ} \mathrm{C}$ and $65 \% \mathrm{RH}$, in dependence of the mass loss by thermal modification. Black circles: Chilean specimens. White circles, Spanish specimens. Standard deviations are indicated by error bars

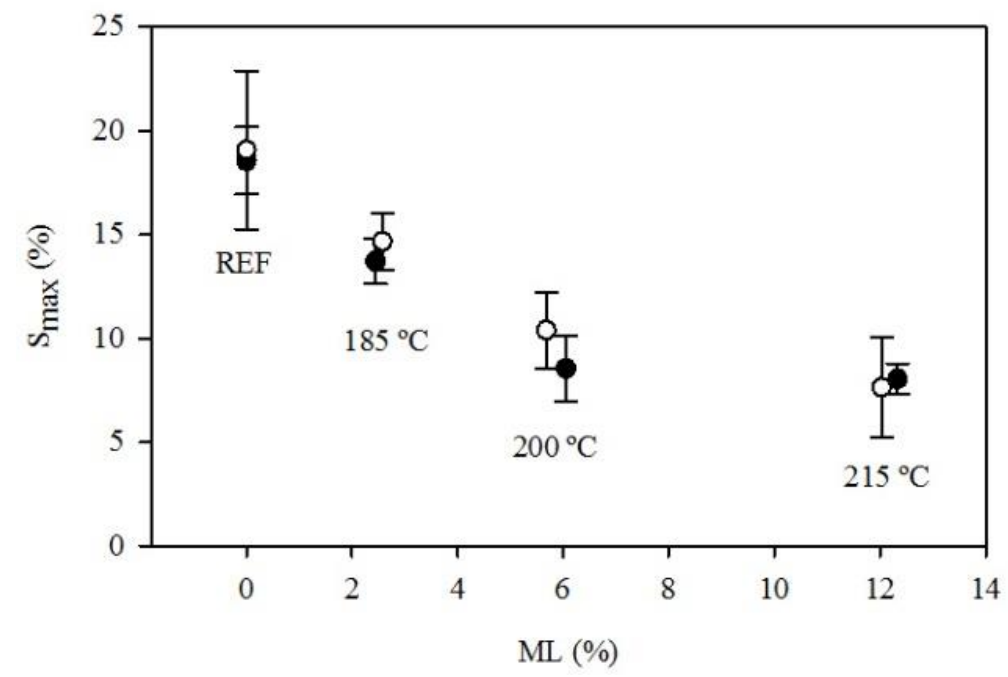

Figure 6.2: $\mathrm{S}_{\max }$ of E. nitens, in dependence of the mass loss by thermal modification. Black circles: Chilean specimens. White circles, Spanish specimens. Standard deviations are indicated by error bars 


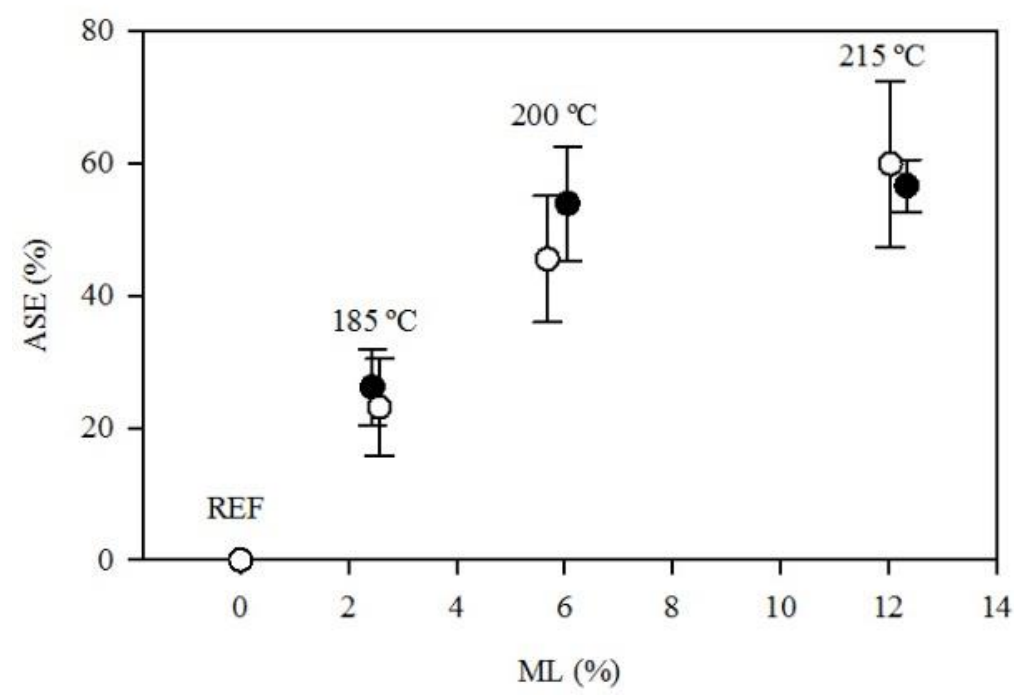

Figure 6.3: ASE of E. nitens, in dependence of the mass loss by thermal modification. Black circles: Chilean specimens. White circles, Spanish specimens. Standard deviations are indicated by error bars

\subsubsection{Changes in hardness, abrasion and screw withdrawal by thermal modification}

Static hardness (Brinell) of Chilean material was higher than of the Spanish, which could be related to the difference in densities and age of the specimens. There was a slight decrease until $200^{\circ} \mathrm{C}$, and then a clear difference between unmodified and $215^{\circ} \mathrm{C}$, while the Spanish material showed a noticeable decrease after all modifications (Figure 6.4). Dynamic hardness decreased with increasing treatment temperature in the Chilean specimens, while at $185^{\circ} \mathrm{C}$ and $200^{\circ} \mathrm{C}$ similar results were obtained in the Spanish specimens (Figure 6.5). The static and dynamic hardness at all temperatures was lower compared to both WPC and tropical species, such as Bongossi (Lophira alata) and Balau (Shorea spp), but similar to Douglas fir and Beech (Brischke et al. 2014) at $200^{\circ} \mathrm{C}$ for the Chilean specimens. The Brinell hardness was similar to thermally treated European beech and European ash (Standfest and Zimmer 2008) and higher than thermally treated birch and aspen (Kocaefe et al. 2008b), while the dynamic hardness was lower than that of European beech (Meyer et al. 2011). 


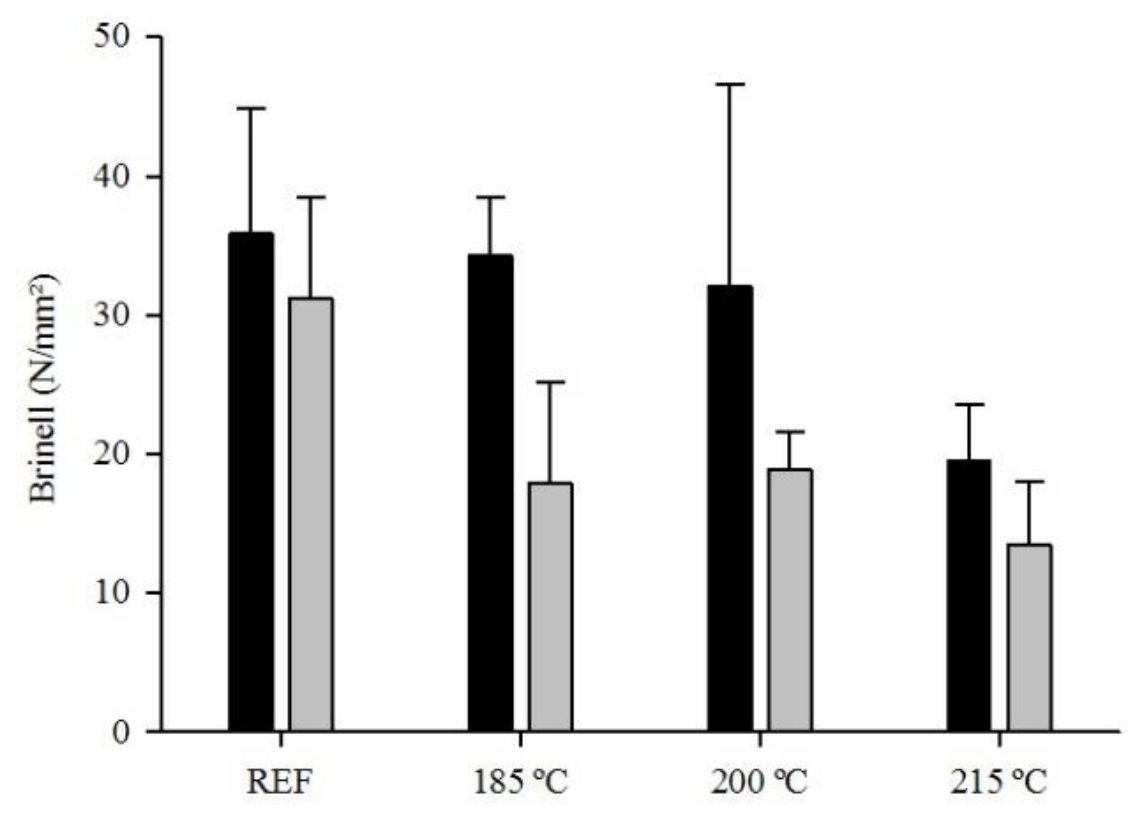

Figure 6.4: Brinell hardness of E. nitens after each thermal modification process. Black column: Chilean specimens. Grey column: Spanish specimens.

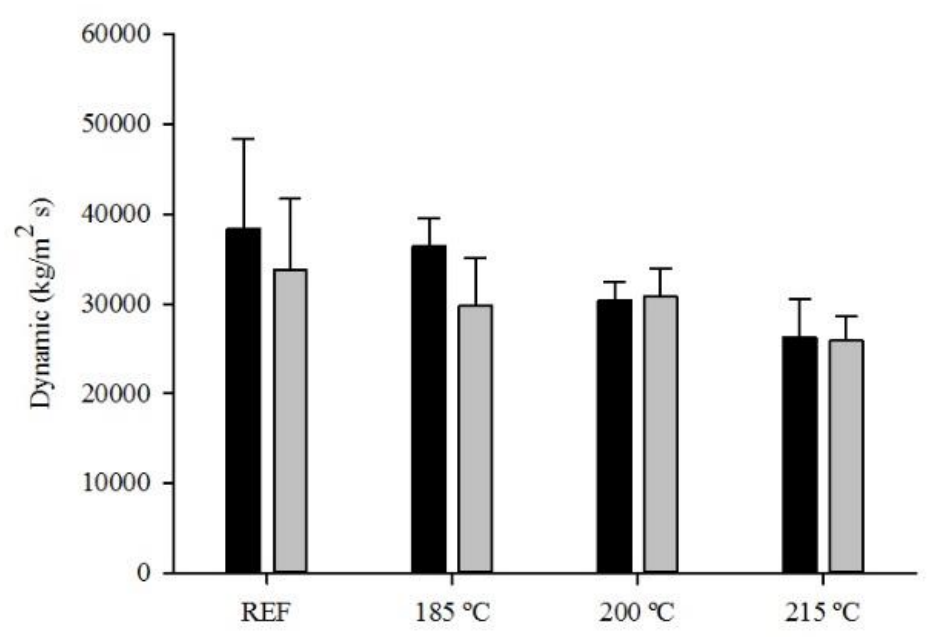

Figure 6.5: Dynamic hardness of E. nitens after each thermal modification process. Black column: Chilean specimens. Grey column: Spanish specimens.

The abrasion resistance of $E$. nitens decreased with increasing treatment intensity in all the specimens (Figure 6.6). Traces of abrasion on unmodified and thermally modified E. nitens at $215^{\circ} \mathrm{C}$ after the shaker test can be seen in Figures 6.7 and 6.8 for Chilean and Spanish specimens respectively. The thermally modified specimen (Figure 6.7c, $d$ and Figure 6.8c, d) had more 
severely rounded edges and a slight loss of material due to splintering. The reduced abrasion resistance is likely due to an increased brittleness of the material (Kubojima et al. 2000; Phuong et al. 2007), and the lower density of the material after thermal modification (Esteves and Pereira 2009). Previous reports indicated that abrasion resistance is positively correlated with wood density (Brischke et al. 2014), which is shown to decrease in Table 6.1. Compared to other flooring materials, the unmodified $E$. nitens showed similar abrasion resistance as woodpolymer composites (WPC) and tropical species such as Balau (2.9 and 3\%), while E. nitens modified at $200^{\circ} \mathrm{C}$ and $215^{\circ} \mathrm{C}$ was slightly more resistant to abrasion than Douglas fir and Norway spruce (Picea abies) (both 6.2\%, (Brischke et al. 2014)).

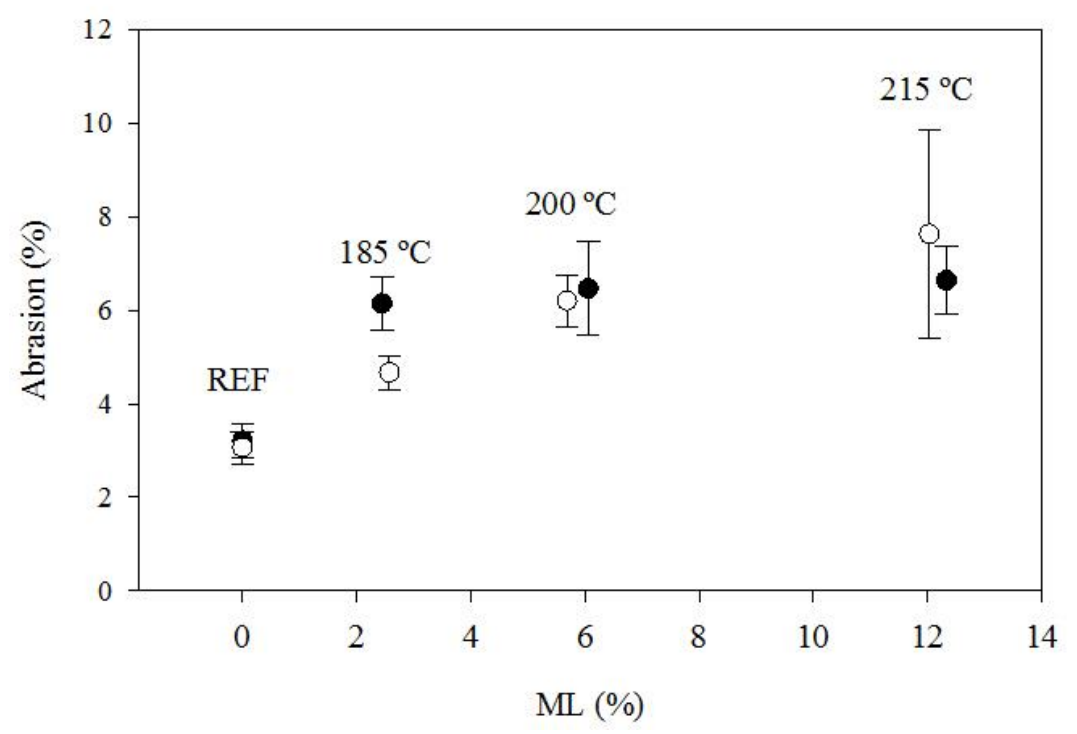

Figure 6.6: Abrasion of E. nitens after shaker tests in dependence of the mass loss by thermal modification. Black circles: Chilean specimens. White circles, Spanish specimens. Standard deviations are indicated by error bars. 

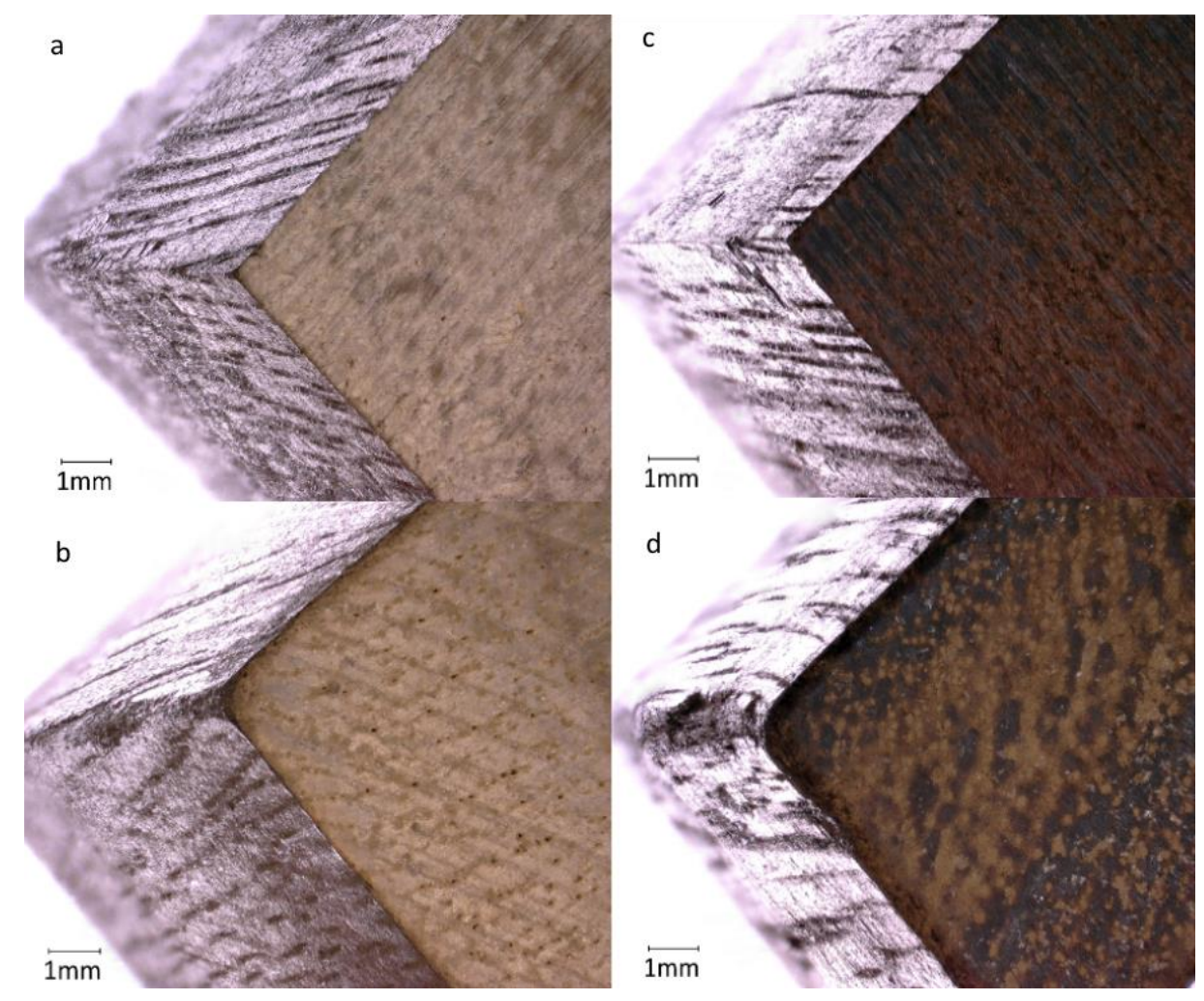

Figure 6.7: Cross section of E. nitens, unmodified and thermally modified at $215^{\circ} \mathrm{C}$ of the Chilean specimens before ( $a$ and $c$ ) and after ( $b$ and d) the shaker abraser test.
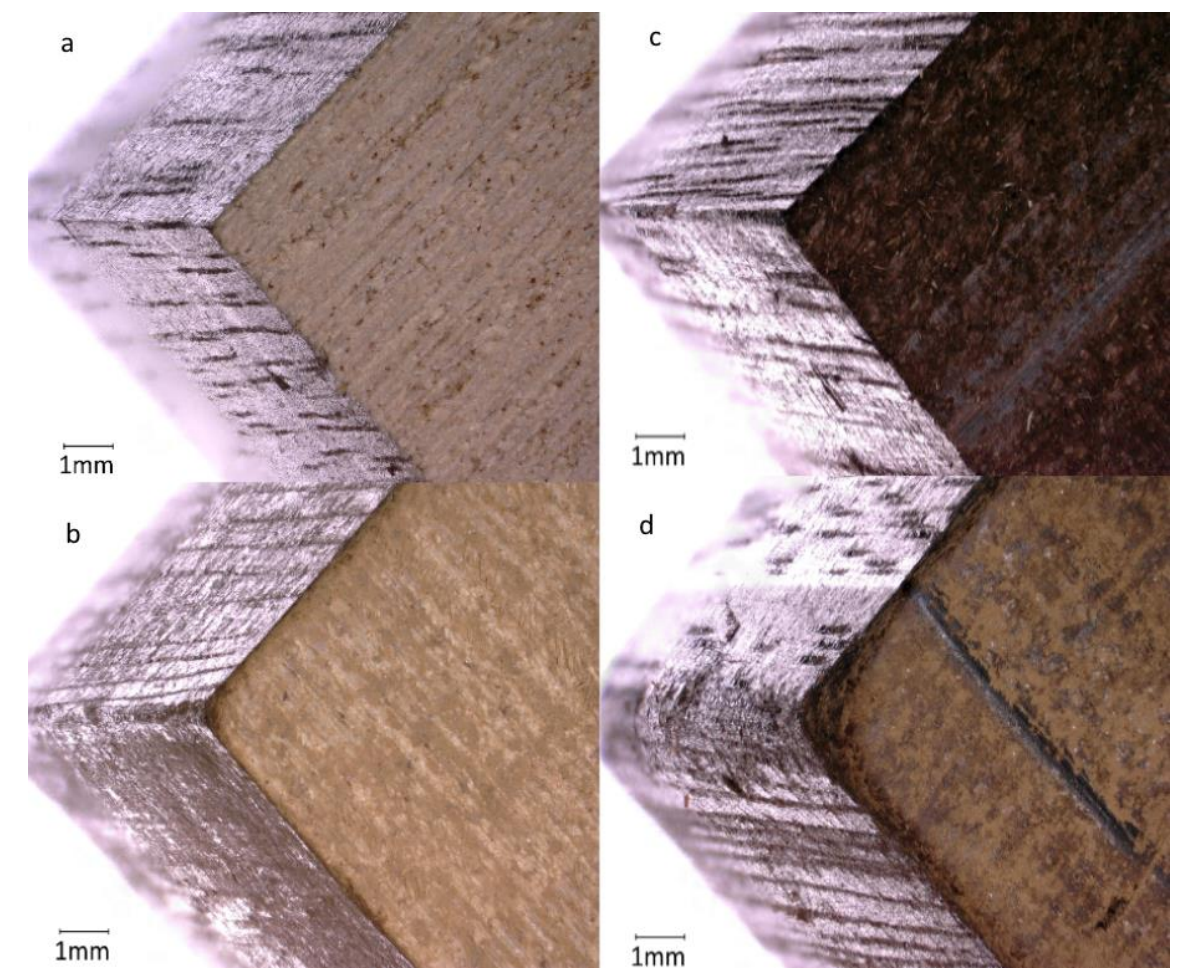

Figure 6.8: Cross section of E. nitens, unmodified and thermally modified at $215^{\circ} \mathrm{C}$ of the Spanish specimens before ( $a$ and $c$ ) and after ( $b$ and d) the shaker abraser test. 
The abrasion expressed as $\Delta t$ increased with increasing modification temperature in the Spanish specimens, while the Chilean specimens showed only small differences between modifications (Figure 6.9). The measurements were performed on finished decking (Figure 6.10), where the difference in $\Delta \mathrm{t}$ can be seen between the modified specimens at $215^{\circ} \mathrm{C}$ (Chile is Figure $6.10 \mathrm{c}$ and Spain 6.10d) where more material was lost in the Spanish specimens.

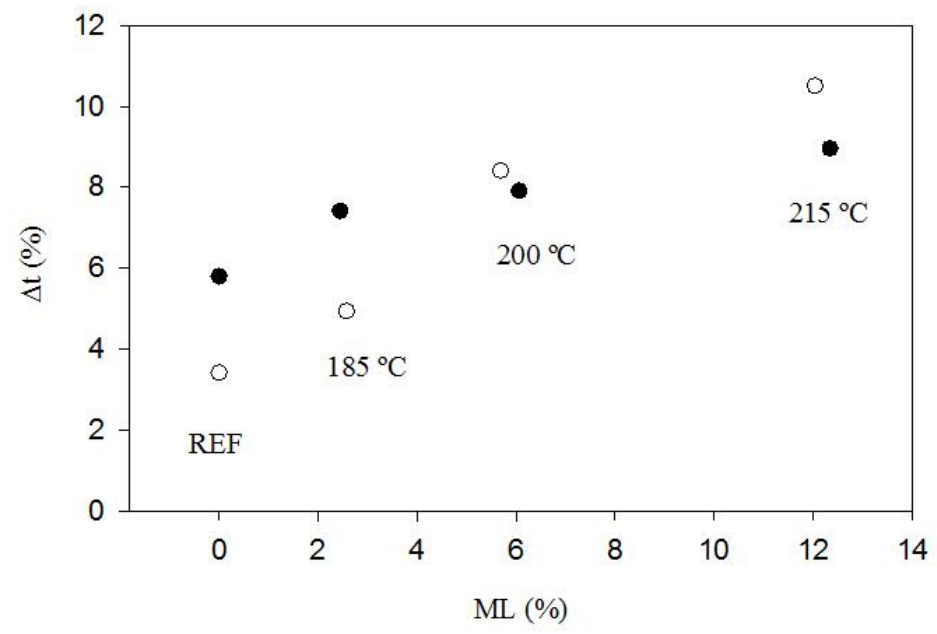

Figure 6.9: Abrasion of E. nitens after Taber abraser tests in dependence of the mass loss by thermal modification. Black circles: Chilean specimens. White circles, Spanish specimens.

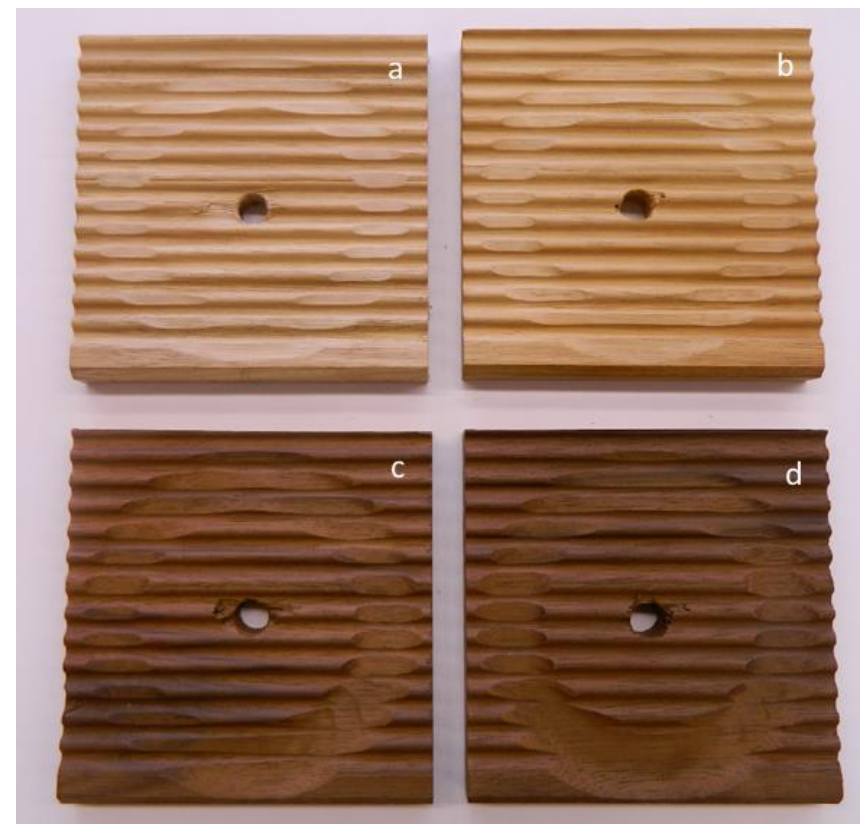

Figure 6.10: Finished decking specimens after the taber abraser test. E. nitens wood, unmodified and thermally modified at $215^{\circ} \mathrm{C}$ of the Chilean and Spanish specimens before ( $a$ and $b$ ) and after (c and d) the taber abraser test. 
The screw withdrawal resistance (SWR) decreased with increasing treatment temperature, but did not differ between Spanish and Chilean E. nitens (Figure 6.11). Similar effects of thermal modification on SWR were previously reported for birch (Poncsák et al. 2006) and spruce (Kariz et al. 2013).

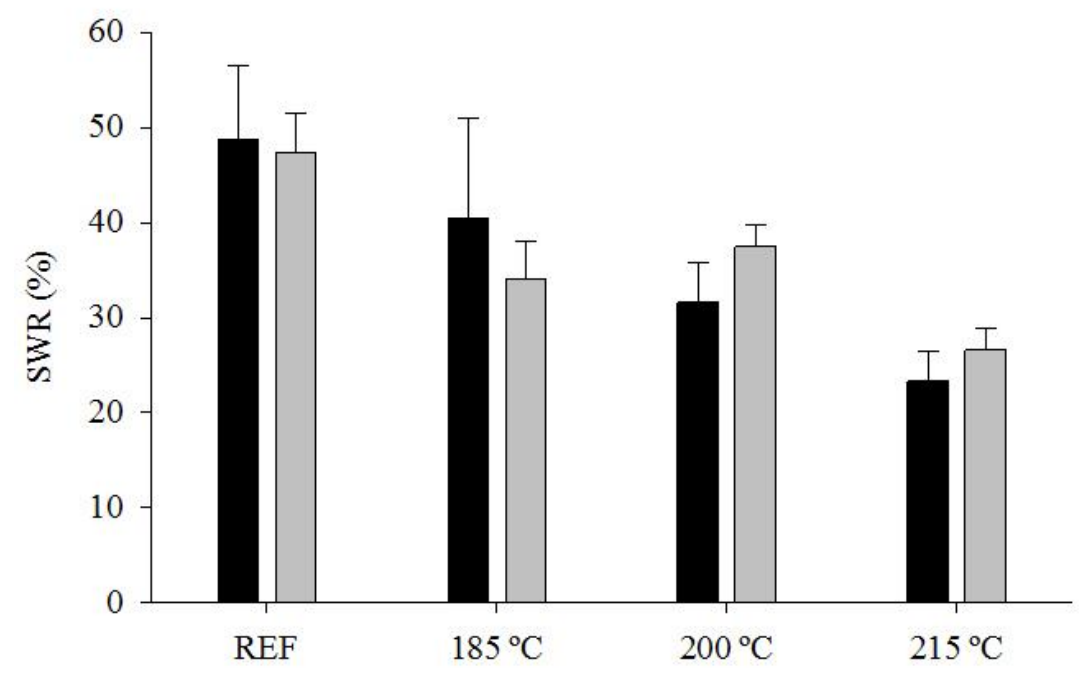

Figure 6.11: Screw withdrawal resistance of E. nitens in dependence of the mass loss by thermal modification. Black column: Chilean specimens. Grey column: Spanish specimens.

The results indicate that the characteristics of thermally treated E. nitens is close to other more commonly used species, and the tested mechanical characteristics indicate that the modified wood could be a probable alternative to be used as decking.

\subsection{Conclusions}

Thermally modified E. nitens, from both Chile and Spain, showed very similar characteristics compared to each other and to other thermally modified species that are currently used for decking. Compared to other potential wood based materials, the modified E. nitens up to $200^{\circ} \mathrm{C}$ had higher abrasion resistance and similar dynamic and static hardness properties in regards to frequently used species such as Douglas fir, but lower than tropical species and WPC. The thermally modified wood from E. nitens fulfilled all the minimal requirements regarding the surface characteristics to be used as decking material. 


\section{Chapter 7: Publication VI}

Anatomical characteristics of thermally modified Eucalyptus nitens wood in an open and closed reactor system

Maximilian Wentzel $^{1}$, Tim Koddenberg ${ }^{1}$, Holger Militz ${ }^{1}$

${ }^{1}$ Department of Wood Biology and Wood Products, University of Göttingen, Faculty of Forest

Science, Büsgenweg 4, 37077 Göttingen, Germany

*corresponding author:

Phone: +495513922051

Fax: +49551399646

E-mail: mwentze@gwdg.de

ORCID: 0000-0002-5795-7589

Originally published in:

Wood Material Science \& Engineering

Taylor \& Francis

ISSN (Print) $\quad$ 1748-0272

ISSN (Online) 1748-0280

DOI: $\quad 10.1080 / 17480272.2019 .1572649$

Received: 9 November 2018

Accepted: 17 January 2019

Published online: 29 January 2019

https://www.tandfonline.com/doi/full/10.1080/17480272.2019.1572649 


\subsection{Abstract}

Eucalyptus nitens specimens were thermally modified under open and closed systems. The anatomical characteristics from selected modifications that presented similar mass losses were investigated by analyzing images taken from scanning electron microscopy, transmission light microscopy, and X-ray micro-computed tomography. Wood cell wall thickness, fiber, and lumen area were measured and compared to unmodified specimens, and the crack formation after modification was also analyzed. There was only a slight decrease in the measured characteristics when compared to unmodified specimens. The wood cell wall thickness was less affected than the fiber and lumen areas, and both modifications presented similar crack formations. Overall, there were no significant differences between open and closed system modifications in the anatomical structure.

Keywords: Eucalyptus nitens, thermal modification, wood anatomy, image analysis

\subsection{Introduction}

The thermal modifications offer a good alternative to improve the properties of fast growing wood species (Esteves and Pereira 2009), such as Eucalyptus nitens. The processes use treatment temperatures that vary between $150^{\circ} \mathrm{C}$ and $240^{\circ} \mathrm{C}$ under different operating conditions, either steam, vacuum, nitrogen that limit the presence of oxygen in the process, and they can be separated in open systems, in which the modification happens at atmospheric pressure or closed systems, where the process occur at subatmospheric pressures or vacuum (Hill 2006; Militz and Altgen 2014). Two of the main benefits from thermal modification are the improvement of biological durability (Hakkou et al. 2006; Welzbacher and Rapp 2007) and dimensional stability (Giebeler 1983; Tjeerdsma and Militz 2005), but on the other hand, the mechanical properties decrease after modification (Tjeerdsma et al. 1998; Kubojima et al. 2000; Boonstra et al. 2007b). Most of the changes in the wood properties can be related to the chemical changes that occur during the modification process, such as the degradation of hemicelluloses by the released carboxylic acids (Boonstra and Tjeerdsma 2006; Sundqvist et al. 2006), modifications of the lignin polymer network (Tjeerdsma et al. 1998; Tjeerdsma and Militz 2005) and an increase of the relative crystallinity of the cellulose (Bhuiyan et al. 2000; Sivonen et al. 2002) to name a few. 
There is an extensive bibliography related to the properties of thermally modified wood (Esteves and Pereira 2009; Militz and Altgen 2014; Sandberg and Kutnar 2016), however, publications related to variation to the anatomical characteristics of the modified wood (cellular elements) are relatively scarce in comparison to other wood properties (Boonstra et al. 2006a; Boonstra et al. 2006b; Awoyemi and Jones 2011; Biziks et al. 2013; Batista et al. 2015; Bernabei and Salvatici 2016). Results indicate variations such as cracks that start in the middle lamella, pit aspiration, damage to the axial tracheid walls and the parenchyma cells in wood rays and resin canals (Boonstra et al. 2006a; Boonstra et al. 2006b; Awoyemi and Jones 2011; Biziks et al. 2013), and a reduction of the wood cell wall thickness at high temperatures (Bernabei and Salvatici 2016). In hardwood species the collapse of vessels and the deformations of fibers near the vessels were some of the main changes observed (Boonstra et al. 2006b). As for eucalypt species, a report presented by Batista et al (2015) on thermally modified Eucalyptus grandis wood showed that there were no significant changes in the structure of ray parenchyma, vessels and fibers.

It has been shown that the chemical properties of thermally modified E. nitens wood presented differences between open and closed system modifications, even when both modifications had similar mass losses (Wentzel et al. 2018b). The samples that presented similar mass loss but different modification process (open and closed) were selected to analyze their anatomical characteristics by measuring the wood cell wall thickness, the fiber and vessel area, and the development of cracks. This was done by using 2D images obtained by transmission light microscopy (TLM) and scanning electron microscopy (SEM) and 3D images using X-ray micro-computed tomography $(\mathrm{X} \mu \mathrm{CT})$. The aim of this study was to analyze the influence of each thermal modification on the anatomical structure of modified E. nitens wood and to observe if there was a significant anatomical difference between these modifications.

\subsection{Materials and methods}

\subsubsection{Material}

E. nitens wood from 19 year old plantations in the Región del Bío-Bío in Chile was used. Selected wood pieces from conventionally kiln-dried mature wood with an average moisture content (MC) of $12 \%$ were used. 


\subsubsection{Thermal modification}

The selected specimens were based on results presented in a previous publication (Wentzel et al. 2018b), where the specimens showed a similar corrected mass loss (CML), which is based on the dry and extractive-free mass of each slat before and after the process (Altgen et al. 2016b). The selected specimens had a CML of $18.7 \%$ for the open system modification $\left(210^{\circ} \mathrm{C}\right)$ and $18.6 \%$ for the closed system modification $\left(160^{\circ} \mathrm{C}\right.$ and $\left.0.61 \mathrm{MPa}\right)$.

These processes were performed in a laboratory-scale treatment reactor. The samples were placed in a stainless steel vessel with a volume of 651 that could be heated up to a maximum of $260^{\circ} \mathrm{C}$ using electric heating cables and cooled down to room temperature with water cooling coils. The water vapor was produced by heating an external water reservoir which is connected to the vessel. Exhaust valves were used for the release of excess pressure. The treatment reactor can be used either as an open or as a closed system.

The open system modification was based on the ThermoWood® process (Mayes and Oksanen 2002). The temperature in the vessel was first raised $12^{\circ} \mathrm{C}$ per hour until it reached $100^{\circ} \mathrm{C}$. The temperature was then increased very slowly $2^{\circ} \mathrm{C}$ per hour until $130^{\circ} \mathrm{C}$. Afterwards, the temperature was increased $12^{\circ} \mathrm{C}$ per hour until it reached $210^{\circ} \mathrm{C}$. After a holding the temperature for $3 \mathrm{~h}$, it was decreased at $20^{\circ} \mathrm{C}$ per hour until reaching $65^{\circ} \mathrm{C}$, at which the vessel was opened and the samples were removed.

The closed system modification was based on the Firmolin process (Willems 2009). It consist of four steps: a 50- min holding step at pre-vacuum at $<14 \mathrm{kPa}$, temperature increase in a rate of $12^{\circ} \mathrm{C}$ per hour until it reaches $160^{\circ} \mathrm{C}$, while the pressure ramps up to $0.61 \mathrm{MPa}$ inside the modification chamber, a holding step at the peak temperature for $3 \mathrm{~h}$ and a temperature decrease in a rate of $20^{\circ} \mathrm{C}$ per hour up to $65^{\circ} \mathrm{C}$. As with the open modification, the vessel was open at this point and the samples were removed from it.

\subsubsection{Scanning electron microscopy}

The sample preparation for the SEM was done using unmodified specimens which were shaped into a cropped pyramid using a sledge microtome equipped with a sharp steel knife. The top of the specimen was cut with the knife in the transverse direction to obtain a smooth surface for a better image analysis. This methodology was recommended by Moon et al (2009). The prepared 
specimens were then mounted on an aluminum stub and carbon coated, with the carbon layer being $15 \mathrm{~nm}$ thick. An example of the finished specimen can be seen in Figure 7.1. The images were taken with the ZEISS EVO LS 15 electron scanning microscope (Carl Zeiss Microscopy $\mathrm{GmbH}$, Jena, Germany). Images were captured through detection of the secondary electrons. The working parameters were set to an accelerating voltage of $5 \mathrm{kV}$, a current of $40 \mathrm{pA}$, and a working distance of $8.5 \mathrm{~mm}$. The magnification used for imaging was 1000x, with an image size of $1024 \times 1024$ pixels. After taking the images, the samples were thermally modified. The carbon coating had no effect on the thermal modification of the specimen. This was done to compare the differences before and after modification and to avoid some issues with the surface preparation, as the thermally treated samples tend to be brittle, making it difficult to obtain a smooth surface.

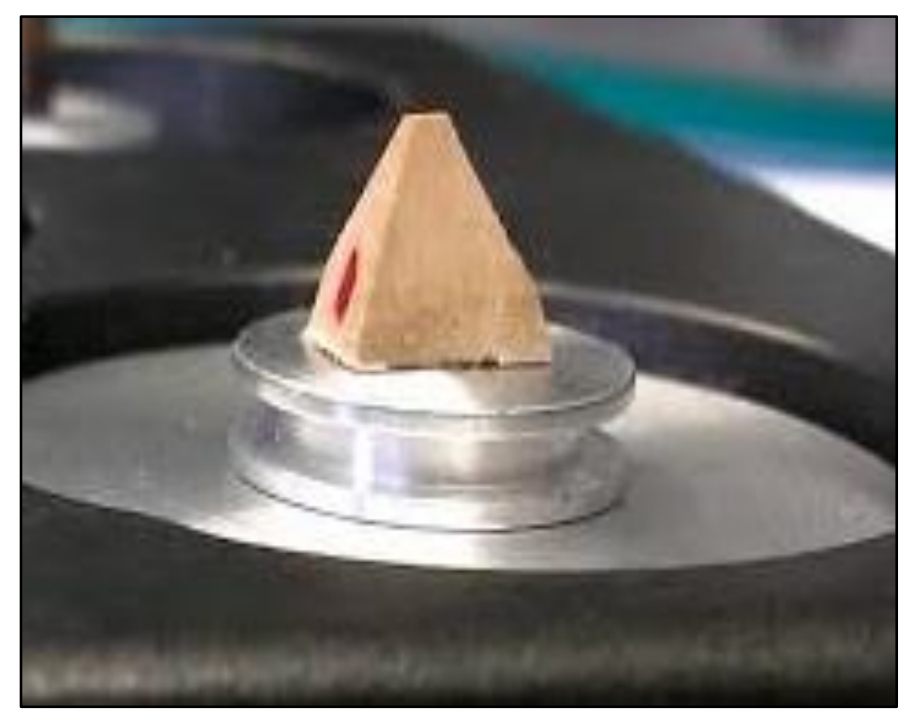

Figure 7.1: Cropped pyramid shape sample for SEM analysis before modification.

\subsubsection{Transmission light microscopy}

The samples used for TLM were sectioned in the transverse plane of both modified and unmodified samples using a sledge microtome. The thickness of the slices was $15 \mu \mathrm{m}$. The images were taken with the equipped digital camera Sight DS-5M-L1 and the NIS-Elements F software for image acquisition (Nikon, Germany). All images were acquired at a magnification of $40 x$, with an image size of $1024 \times 1024$ pixels. 


\subsubsection{X-ray micro-computed tomography}

The $\mathrm{X \mu CT}$ was performed using the nanotom ${ }^{\circledR}$ system (phoenix $\mathrm{x}$-ray; GE Sensing \& Inspection Technologies GmbH, Wunstorf, Germany). The system consists of a transmission molybdenum target, cone-beam geometry, and a CMOS flat panel detector. For X-ray imaging, specimens measuring $1 \times 1 \times 10 \mathrm{~mm}^{3}$ (tan $\mathrm{x}$ rad $\mathrm{x}$ long) were prepared from a single $20 \mathrm{~mm}$ stick. The stick was cut perpendicular to the grain in the middle, the top part was left unmodified and the bottom was modified. The specimens were vertically glued together onto a cylindrical glass rod $5 \mathrm{~mm}$ in diameter using a hot-melt adhesive based on an ethylene vinyl acetate copolymer.

To obtain the images, the micro-computed tomography basically detects the attenuated X-ray radiation. X-ray attenuation happens when the incident radiation penetrates an object and interacts with its matter. Attenuation mainly depends on the object properties, for example elemental composition, density, and thickness. The attenuated radiation enters a detector array in which the different attenuation coefficients are detected and saved into a projection image in grayscale tones. A stack of projection images was produced by rotating the specimen through $360^{\circ}$. The captured stack of projection images was then converted into a volumetric dataset using the datos $\mathrm{x}$ reconstruction software (phoenix $\mathrm{x}$-ray; GE Sensing \& Inspection Technologies GmbH, Wunstorf, Germany).

\subsubsection{Image analysis}

For the TLM image analysis, selected regions of interest (ROI) of the specimens were used to measure the area of the fibers and vessels, before and after modification. This was done by transforming the raw image into a binary image consisting of black and white pixels through thresholding using the open source image software ImageJ 1.48v (Schneider et al. 2012). This software was also used for the automatic measure of fibers. An example can be seen in in Figure 7.2. A visual selection was performed selecting the fibers that were better characterized by the software. The same procedure was done for the vessels. 


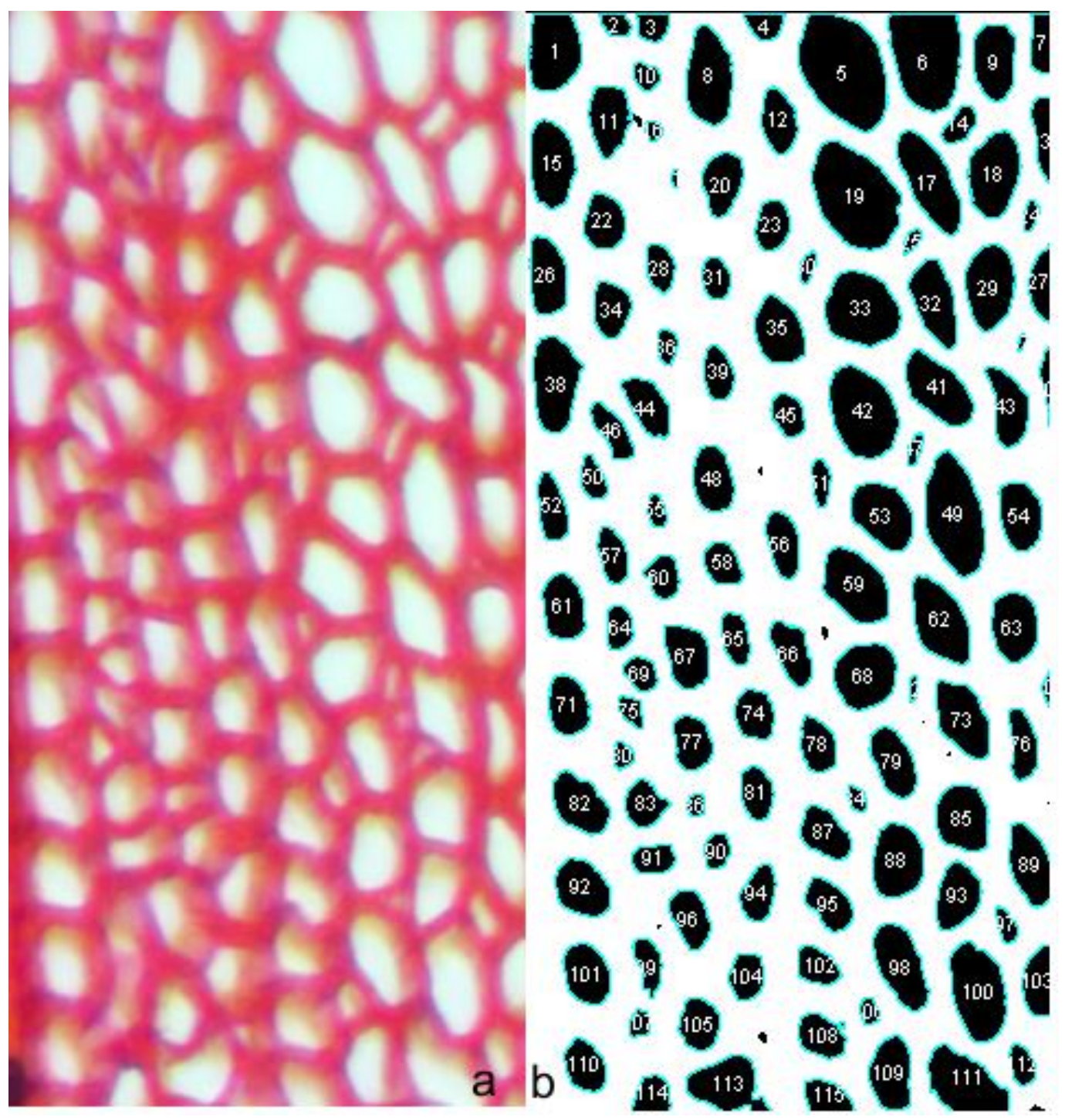

Figure 7.2: Raw (a) and black and white binary image (b) of unmodified E. nitens. The numbers represent the measured fiber areas.

For SEM images, a procedure was performed similar to TLM images. But before binarization, the lumens and vessels were manually darkened to facilitate the image analysis with the ImageJ software (Figure 7.3). 

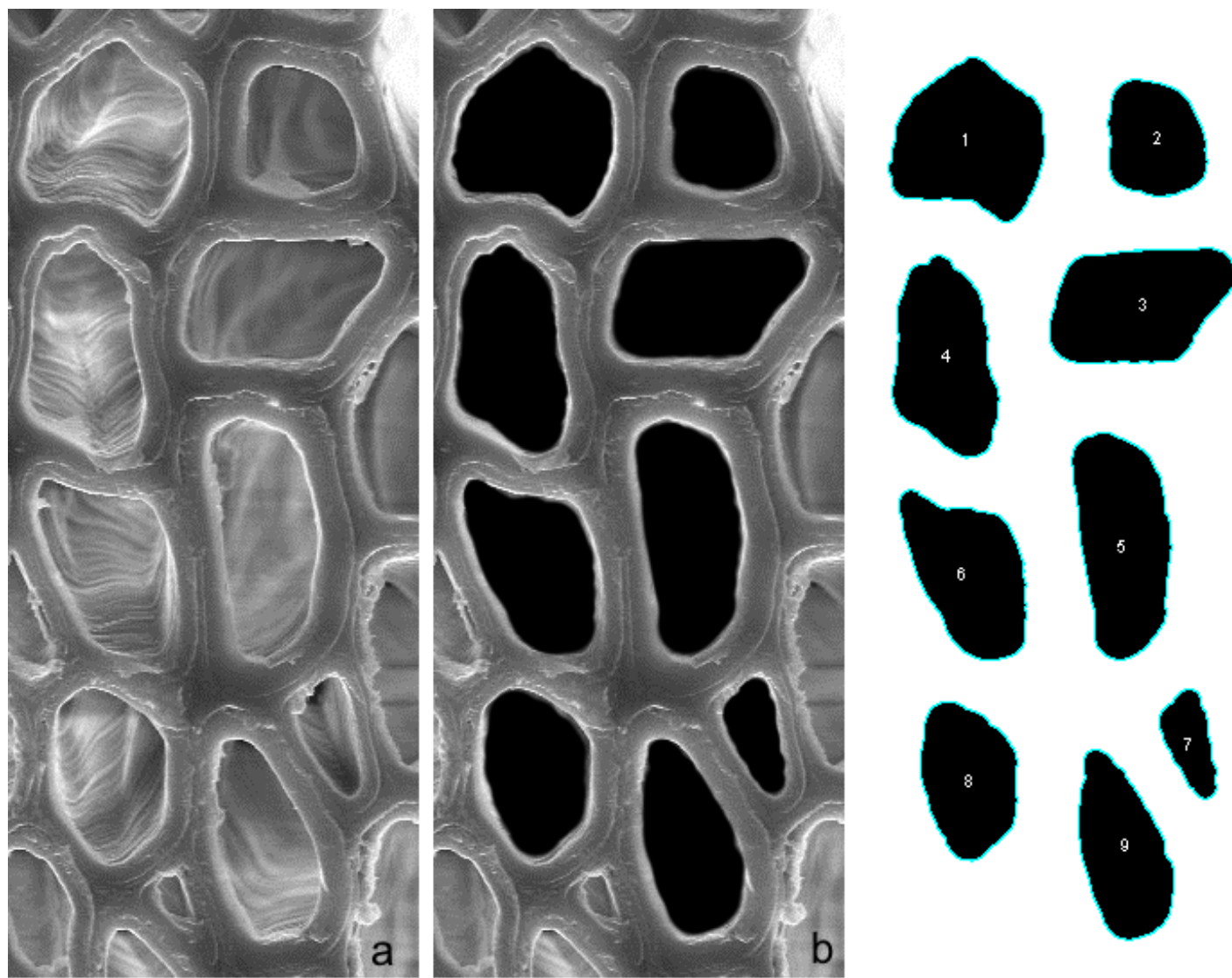

Figure 7.3: Selected fiber cells for measurement (a). Darkened lumens before binarization (b). Selected area of lumen for software measurement. The numbers represent the measured fiber areas.

The single cell wall thickness of cells (i.e. fibers and vessels before and after modification) was measured with SEM images. Selected cells were chosen from the same ROI before and after modification. Manual measurements were done, with a minimum of three measurements per radial and tangential direction of the cell. The measurements were averaged independent of the direction. Late wood and early wood cell walls were measured separately.

The 3D image obtained by $\mathrm{X} \mu \mathrm{CT}$ was used for an overall visual analysis of the anatomical structure before and after modification and to see if it was possible to detect crack formation after the modification.

\subsection{Results and discussion}

A summary of the measurements done using SEM and TLM on the specimens modified in open and closed system described in the materials and methods are shown in Table 7.1. 
Table 7.1: Average results of wood cell wall thickness measured using SEM in early wood (EW) and late wood (LW), fiber lumen area measured using SEM and TLM in EW and LW and vessel lumen area measured using SEM and TLM. Standard deviation shown in parenthesis.

\begin{tabular}{|c|c|c|c|c|c|c|c|c|}
\cline { 2 - 9 } \multicolumn{1}{c|}{} & \multicolumn{2}{c|}{$\begin{array}{c}\text { Wood cell wall } \\
\text { thickness }(\mu \mathrm{m})\end{array}$} & \multicolumn{4}{c|}{ Fiber lumen area $\left(\mu \mathrm{m}^{2}\right)$} & \multicolumn{2}{c|}{$\begin{array}{c}\text { Vessel lumen } \\
\text { area }\left(\mu \mathrm{m}^{2}\right)\end{array}$} \\
\hline Modification & EW & LW & $\begin{array}{c}\text { SEM } \\
\text { EW }\end{array}$ & $\begin{array}{c}\text { SEM } \\
\text { LW }\end{array}$ & $\begin{array}{c}\text { TLM } \\
\text { EW }\end{array}$ & TLM LW & SEM & TLM \\
\hline $\begin{array}{c}\text { Reference } \\
\text { (open } \\
\text { system) }\end{array}$ & $\begin{array}{c}1.440 \\
( \pm 0.344)\end{array}$ & $\begin{array}{c}1.817 \\
( \pm 0.400)\end{array}$ & $\begin{array}{c}75.16 \\
( \pm 19.83)\end{array}$ & $\begin{array}{c}36.29 \\
( \pm 9.29)\end{array}$ & $\begin{array}{c}81.38 \\
( \pm 22.77)\end{array}$ & $\begin{array}{c}41.23 \\
( \pm 10.96)\end{array}$ & $\begin{array}{c}20,212 \\
( \pm 4800)\end{array}$ & $\begin{array}{c}22,160 \\
( \pm 6896)\end{array}$ \\
\hline $210^{\circ} \mathrm{C}$ & $\begin{array}{c}1.406 \\
( \pm 0.356)\end{array}$ & $\begin{array}{c}1.797 \\
( \pm 0.371)\end{array}$ & $\begin{array}{c}72.38 \\
( \pm 18.18)\end{array}$ & $\begin{array}{c}31.55 \\
( \pm 8.73)\end{array}$ & $\begin{array}{c}76.57 \\
( \pm 16.03)\end{array}$ & $\begin{array}{c}35.21 \\
( \pm 9.66)\end{array}$ & $\begin{array}{c}16,875 \\
( \pm 4667)\end{array}$ & $\begin{array}{c}19,347 \\
( \pm 4240)\end{array}$ \\
\hline $\begin{array}{c}\text { Reference } \\
(\text { closed } \\
\text { system) }\end{array}$ & $\begin{array}{c}1.454 \\
( \pm 0.264)\end{array}$ & $\begin{array}{c}1.823 \\
( \pm 0.311)\end{array}$ & $\begin{array}{c}66.03 \\
( \pm 18.91)\end{array}$ & $\begin{array}{c}35.19 \\
( \pm 8.96)\end{array}$ & - & - & $\begin{array}{c}18,334 \\
( \pm 4125)\end{array}$ & - \\
\hline $\begin{array}{c}160^{\circ} \mathrm{C} 100 \% \\
\mathrm{RH}\end{array}$ & $\begin{array}{c}1.367 \\
( \pm 0.269)\end{array}$ & $\begin{array}{c}1.779 \\
( \pm 0.295)\end{array}$ & $\begin{array}{c}62.30 \\
( \pm 18.63)\end{array}$ & $\begin{array}{c}30.90 \\
( \pm 8.10)\end{array}$ & - & - & $\begin{array}{c}15,027 \\
( \pm 3921)\end{array}$ & - \\
\hline
\end{tabular}

The wood cell wall thickness was measured before and after modification in the same fibers. The averages were taken from 1900 measurements from different cuts and ROIs. It can be seen that both specimens used for open and closed systems have similar average values in both early wood and late wood. After modification, both processes showed a decrease in thickness (2.3\% and $5.9 \%$ in EW and $1.1 \%$ and $2.4 \%$ for in LW for the open and closed system respectively), slightly more in the modification in the closed systems. Bernabei and Salvatici (2016) used in situ ESEM observations to determine the effects of the heat treatment on Picea abies cellular structure and determined that the cell wall thickness remained almost constant up to $200^{\circ} \mathrm{C}$ and that at greater temperatures the thickness started to reduce, which in our case can be slightly seen in both modifications. There was no significant difference between either modification (open and closed) with their respective unmodified references, and also between the open and closed modifications (Table 7.1). Similar results were obtained in E. grandis wood using a hydrothermal modification (Batista et al. 2015), where the wood cell wall thickness also only slightly decreased after the modification. It can be said that changes in the wood cell wall thickness were minimal and that they were affected similarly by both types of modifications.

The fiber area was measured using SEM and TLM. There were some challenges to get a good quality sample for the closed system modification for TLM due to the brittleness of specimens used, as it can cause unwanted cracks in the cellular structure and poor surface quality which can difficult the image analysis. For the open system modification, two good quality microtome cuts were obtained and used for the TLM measurements. As with the wood cell wall thickness, 
different cuts and ROIs where used for the measurements. From SEM and TLM 100 and 500 fibers areas were measured respectively, for both early and late wood before and after modification. The results show that the measurements using TLM where slightly higher than the ones using SEM (Table 7.1). This could be related to the image thresholding, which could take into account the borders of the wood cell walls impacting the final outcome of the measurement. Nonetheless, at least in the open system, both SEM and TLM measurements decreased similarly in early wood (3.7\% and 5.9\% respectively) and late wood $(13.1 \%$ and $14.6 \%$ respectively). As for the closed system, the decrease showed a similar tendency (5.6\% for EW and $12.2 \%$ for LW), so there were no marked differences between the modifications. The decrease of fiber area was also present in thermally modified birch (Biziks et al. 2013). They related the changes of the sizes to the decrease of the annual ring width in relation to the mass loss produced by the thermal modification, which in their case was $18 \%$, similar to the CML obtained in the modifications used in this study. The mass loss also influences the overall dimensions of the wood, which can be measured by the overall shrinkage. The average values were $8.2 \%$ in the open system and $9.7 \%$ in the closed system, thus it can be said that the decrease of fiber area from the unmodified to the modified state leads to a decrease in the volume in both modifications. Figure 7.4 shows the slight differences of the fiber lumen area before and after modification and indicates some changes in the wood cell wall. 


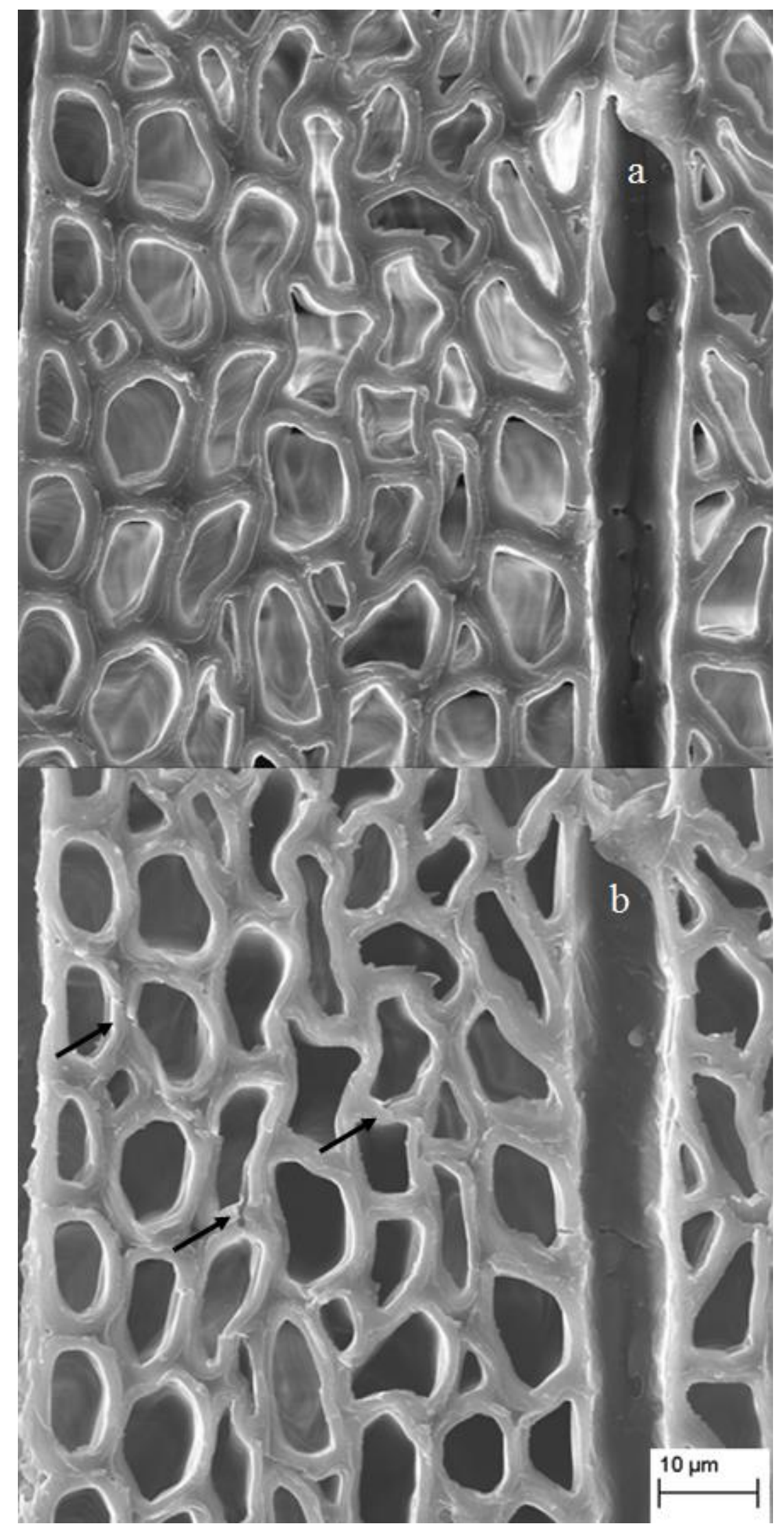

Figure 7.4: Fiber lumen changes after modification at $210^{\circ} \mathrm{C}$. Reference (a), modified specimen (b). Black arrows show changes in the wood cell wall after modification. 
Most of the vessels in E. nitens are exclusively solitary arranged in a diagonal bands (Figure 7.5). The transverse size of vessels varies along the growth ring from moderately large in early wood to small in late wood. In vessels, a high amount of tyloses is present. For the measurement of the vessel area in our study, only early wood vessels were used, as they have a higher influence on other wood properties (such as mechanical and physical) of the material than the late wood vessels (Villegas and Rivera 2002). The open system modifications show a decrease of $16.5 \%$ and $12.7 \%$ using SEM and TLM measurements respectively, while the closed system showed 18\% decrease using SEM measurements (Table 7.1). The results were higher than what was shown in other hardwood species (birch) (Biziks et al. 2013). This could be due to the changes in the lignin structure, as they contain mainly guaiacyl structures (Biziks et al. 2013), which was shown to decrease in thermally modified E. globulus (Esteves et al. 2013), thus it could be argued that the changes in the lignin structure could have been affected by both open and closed system modifications, softening the cell wall of the vessels and decreasing their respective areas. The reduction can also be related to the loss of mass and the volumetric shrinkage, as with the reduction of the fiber lumen area.

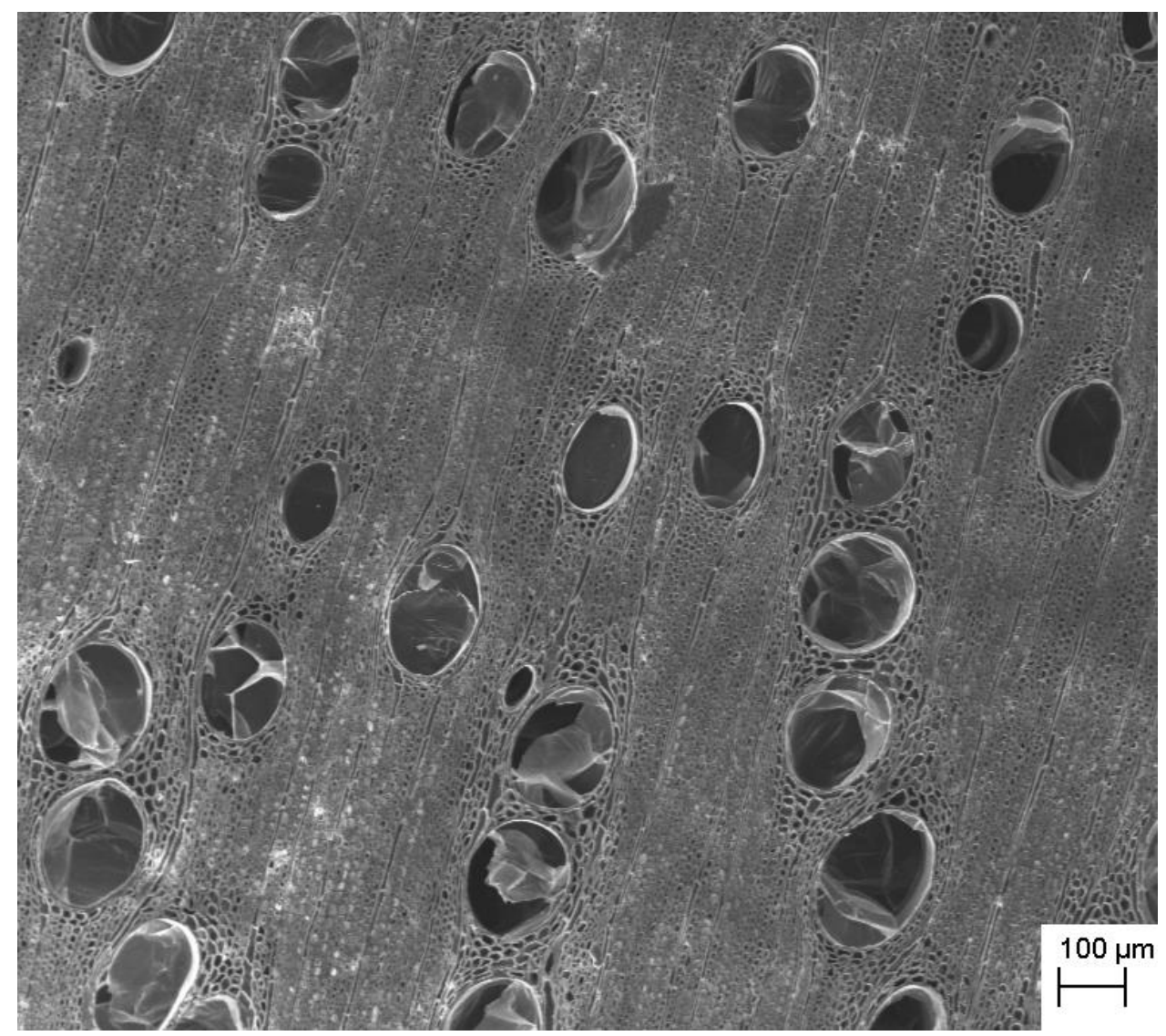

Figure 7.5: Typical vessel distribution in early wood from E. nitens. 
Cracks were formed in both modifications (Figure 7.6). The cracks tended to be formed from the middle lamella and they start to spread to surrounding cells, which could have an influence in the mechanical properties of the material (Boonstra et al. 2006b). It seems that the crack formation was unrelated to the type of modification, as they were present in similar quantities in both modifications used in this study. Bernabei and Salvatici (2016) observed that cracks did not tend to appear due to the rising temperatures, while Awoyemi and Jones (2011) showed that the heat treatment destroyed the tracheid walls and the ray issues and Biziks et al. (2013) mentioned that the separation of fibers and the formation of voids could influence the formation of them. These confirms what Boonstra et al. (2006a) established, which was that the effects to the wood anatomy of the thermal modification are strongly related of the wood species used, thus is difficult to be certain how the cracks develop.

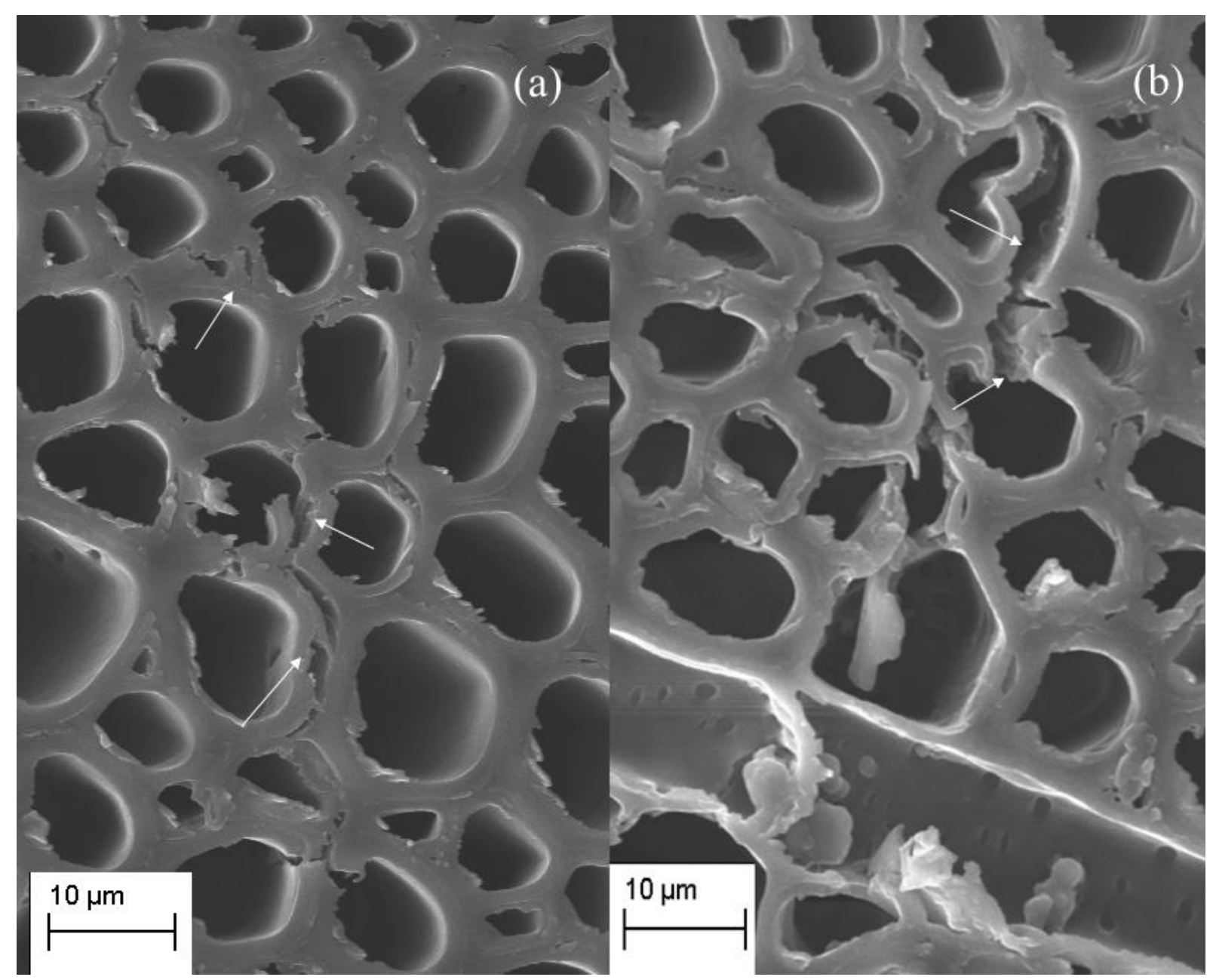

Figure 7.6: Cracks developed after thermal modification in the open (a) and closed systems (b). White arrows indicate the cracks. 
Overall, most of the anatomical changes can be related to the loss of mass that causes volumetric shrinkage in the modified wood, and this shrinkage can be seen in the decrease of the fiber and vessel areas, although no clear difference between open and closed system modifications can be seen.

The 3D image visualization obtained by $\mathrm{X} \mu \mathrm{CT}$ at $1 \mu \mathrm{m}$ resolution shows no particular differences between the reference and the modified specimen (Figure 7.7). An exploratory survey of the 3D structure revealed that it was not possible to detect cracks or other changes in the modified structure. As indicated in SEM images (Figure 7.4), structural changes are hard to visualize even with high-resolution SEM. In tomographic datasets, structural changes are only detectable if their impact on the structure is larger than the spatial resolution used. At $1 \mu \mathrm{m}$ resolution, structures smaller than the resolution will inevitably fade into noise during image acquisition (Trtik et al. 2007; Van den Bulcke et al. 2009).

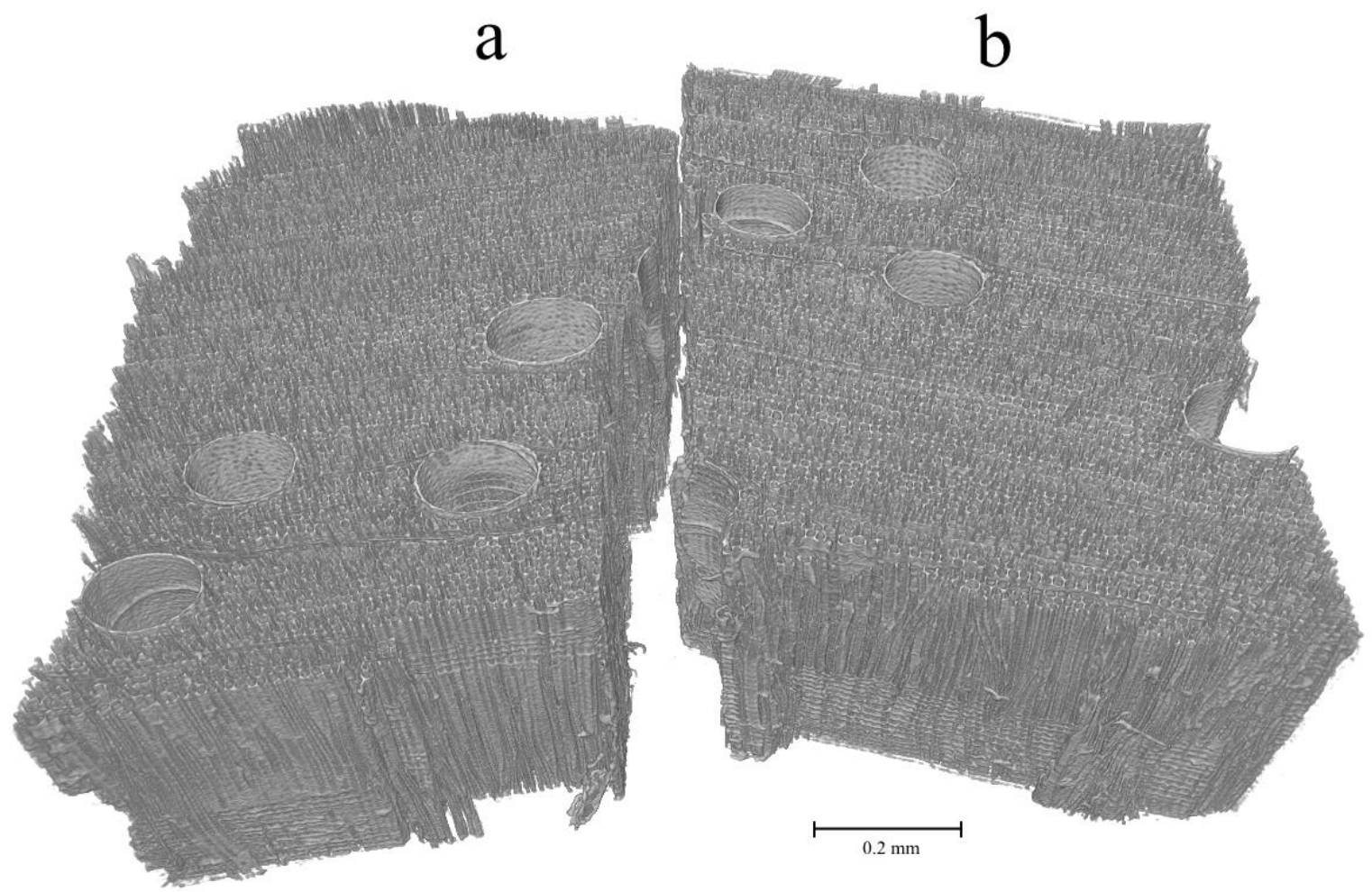

Figure 7.7: $3 \mathrm{D} \mathrm{X} \mu \mathrm{CT}$ image of the reference specimen (a) and modified wood at $160^{\circ} \mathrm{C}$ and $100 \%$ RH (b).

SEM images were better suited for analysis of the anatomical characteristics, as the quality was better than TLM images. It was also not possible to see any differences between open and closed system modifications using any mehodology, so the use of 3D X $\mu \mathrm{CT}$ images to do this kind of 
comparison is not recommended. The 3D X $\mu \mathrm{CT}$ images are more suited to more deep anatomical analysis, such as fiber length and pit distributions along the wood cell wall.

\subsection{Conclusions}

Generally, vessel and fiber areas were affected more by the thermal modifications than the wood cell wall thickness of the fibers. These changes can be related to the mas loss caused by the modifications, which casues the wood to shrink, thus decreasen the areas of the fibers and vessels. Both modifications also presented noticeable crack formations, but overall, there were no differences between open and closed system modifications. The SEM images were better suited for anatomical characterization than the TLM images, as the quality of the images was better than TLM, which made it easier for the measurements to be done, and the use of 3D X $\mu$ CT images is not recommended to differentiate between unmodified and modified wood. Further research should focus on ways to properly measure the crack development and test other methods for cellular structure measurements, such as gray tone image analysis or measurement by pixels. 



\section{Chapter 8: General discussion}

The main objective of the thesis was to evaluate and compare the open and closed system modifications to see if they present significant differences, and the potential of E. nitens as species to be thermally modified to produce high quality material. The overall results indicate that the changes in the chemical properties were a good way to differentiate between both types of modifications, as the mechanical and anatomical variations showed only slight differences. The differences were also noticeable when analyzing the changes in EMC and swelling. The CML was a good indicator for comparing between thermal modifications, as the samples with similar CML showed different properties. The following chapter will connect the discussions of the publications to give a broader overall view of the differences between the modification systems, their influence in E. nitens wood and how it compares to similar modified species. This will be followed by a brief analysis of the potential uses of the modified material based on the variations observed in the properties of each modification.

\subsection{Chemical properties}

The extractive content is one of the chemical properties that varies the most due to the thermal modifications. There is an increase in relation to the reference in all thermal modification processes, which indicates that the generation of degradation products as new extractives offset their vaporization. The modifications at $100 \% \mathrm{RH}$ were a good example of this phenomena because the high pressure hinders the vaporization (Altgen et al. 2016b). It was expected that the closed system modification was going to have higher amounts of extractives, which occurred when the modification temperature was $160^{\circ} \mathrm{C}$ for both modifications (Publication I), but for the modifications with similar CML the differences were not as high as expected, with the extractive content of open and closed system modifications with being about $1 \%$ higher in the closed system (Publication I). This could be explained by the longer time it takes to complete an open system modification, as the modifications in the open system take up to 38 hours to complete, double the time it takes for a closed system modification. This could mean that the degradation started earlier in the pre-drying process and continued during the cool down face. It is also interesting to see that at temperatures over $210^{\circ} \mathrm{C}$ in the open system the extractive content decreased, which evidences that increasing the temperature beyond that point increases the vaporization more than the generation of degradation products. Similar results were obtained by modifying E. globulus in an autoclave heat treatment and oven heating at longer hold times at high temperatures (Esteves et al. 2008a). 
Depolymerization of hemicelluloses was clearly evident by the degradation of xylose, galactose and mannose in all modifications. This was also seen when analyzing the FTIR spectra, as they all showed a decrease in the band that represents $\mathrm{C}=\mathrm{O}$ linkage, which is related to a lower reactivity due to the decrease of the free reactive hydroxyl groups of the holocellulose, represented by the degradation of hemicelluloses (Nguila Inari et al. 2007). This decrease was more noticeable in the modifications at $100 \% \mathrm{RH}$, which is due to the acetic acid concentration, which was higher in the modifications at $100 \%$ RH (Publication I). This was confirmed by the band that represents the acetoxy groups in xylan, and at the band which corresponds to the asymmetric deformation of C-H bond of xylan (Michell and Higgins 2002). These differences were not as noticeable in the bands of the open system modification (Publication III).

As the hemicellulose relative content decreases, the lignin content increases. This occurs in all modifications, as lignin has a higher thermal stability and due to the condensation reactions than are influenced by the high temperatures. The bands representing lignin shifted in all modifications, as it increased where the aromatic rings of hardwood lignin (guaiacyl and syringyl) were represented, but it is not clear if it was related to the increase of relative lignin (Kotilainen et al. 2000; Windeisen et al. 2007), as it can also be interpreted as an aromatic ring opening (González-Peña and Hale 2009). Nonetheless, the changes were visible and are related to carbohydrate degradation and the O-H bending vibrations in phenols (Rodrigues et al. 1998). This was confirmed by the increase in concentration of the phenolic compounds as the temperature rises in the closed system and open system, with the modifications at $100 \% \mathrm{RH}$ showing the highest amounts of phenolic compounds (Publication I).

Cellulose is the least affected wood component by the thermal modification. The relative percentage of cellulose in all the thermal modifications (with exception of the modification at $230^{\circ} \mathrm{C}$ ) increases in relation to the reference. This increase is related to the fast depolymerization of the hemicellulose chains. What changes in the cellulose composition is the cellulose degree of polymerization (cellulose DP), which is the length of the cellulose molecule chain and could be related to the reduction of the mechanical properties (Sweet and Winandy 1999). The closed system modifications showed a decrease in cellulose DP as the temperature increased in both $30 \%$ and $100 \%$ RH processes, reaching a third of the original cellulose DP when it was modified at $170^{\circ} \mathrm{C}$ and $100 \% \mathrm{RH}$. The modification in the open system showed no constant decrease of the cellulose DP as the temperature increased. These differences between processes can be related to the relative hemicellulose content, which is lower in the closed 
system modifications at $100 \% \mathrm{RH}$, thus influencing the hemicellulose-cellulose bond that allows the cellulose molecule chain to maintain its structure.

There were also changes in the amorphous region of the cellulose, as microfibril hydrolytic cleavage occurs, which increases the relative crystallinity (Bhuiyan et al. 2000; Sivonen et al. 2002). The measurements done on solid wood samples showed that there was an increase of the crystallinity at elevated pressure under wet conditions $\left(100^{\circ} \mathrm{RH}\right)$ and at elevated temperatures under atmospheric pressure, but there was little to no change at the lower pressures and at lower temperatures. These variations can be related to the cleavage products caused by the depolymerization of the hemicelluloses and the production of reactives, such as furfurals, which can cause cross link reactions (Boonstra and Tjeerdsma 2006). It can also be related to the rearrangment or reorientation of cellulose molecules, which can cause the crystallization of the celluloses, as it was shown in thermally modified wood under dry and wet conditions by Bhuiyan et al. (2000). This was associated to the formation of acetic and formic acid, which causes partially degraded wood components to become mobile, loosening the inner stresses in the crystalline region of the cellulose (Tanahashi et al. 1989, cited by Bhuiyan and Hirai 2005). It was shown in Publication I that the acetic and formic acid content was higher in the closed system modifications and that in turn causes a decrease in the xylose content, thus it can be said that the degradation of xyloses could influence the crystallization of the celluloses, as the modifications where the crystallinity index started to increase, as shown in Publication III $\left(160^{\circ} \mathrm{C}\right.$ and $170^{\circ} \mathrm{C}$ at $100 \% \mathrm{RH}$ in the closed system and over $200^{\circ} \mathrm{C}$ in the closed system), presented a notable decrease of xylose content. It was also shown that the xylans crystallize due to the controlled pyrolysis during the modification. This could also be a side effect that could also influence the degree of crystallinity of the modified celluloses (Akgül et al. 2007).

It was shown that there were differences between open and closed system modifications in the chemical composition, especially related to the xyloses and the degree of polymerization of the celluloses, which influences the mechanical properties of some modifications.

\subsection{Mechanical properties}

The MOE is one of the wood properties that is less affected by the thermal modification (Tjeerdsma et al. 1998; Kubojima et al. 2000; Santos 2000; Poncsák et al. 2006; Esteves and Pereira 2009). It can be seen in Table 8.1, which shows the lowest and highest MOE and MOR values in different thermal modification trials performed in various eucalypt species, that the 
MOE was not as affected as compared to the MOR. In the case of the modified E. nitens, as shown in publications I and II, MOE tended to increase until the $200^{\circ} \mathrm{C}$ in the open system and then it decreased below the unmodified specimens. This increase was also in relation to the unmodified wood was also present in E. globulus (Santos 2000), E. saligna and E. grandis (de Cademartori et al. 2015) and Betula papyrifera (Canadian white birch) (Lekounougou et al. 2011).

As for the closed system modification, the MOE slightly decreased as the temperature increased, in both $30 \%$ and $100 \%$ RH modifications. In the case of other hardwood species with similar modifications, European beech MOE slightly increased in modifications at $30 \%$ and 100\% RH with similar CML (Altgen and Militz 2016). It seems that the effect on the MOE of modifications under pressure depends on the species, as E. nitens decreased and the European beech increased, but in both cases there was not a considerable increase or reduction of this property.

In the open system modification, MOR increased up to $180^{\circ} \mathrm{C}$. At $200^{\circ} \mathrm{C}$ it had a similar MOR value as the unmodified sample, followed by a decrease at higher temperatures, but there was no correlation between the decreases of MOR in relation to the increase of temperature (Publications I and II). In other eucalypt species (Table 8.1), E. saligna (de Cademartori et al. 2015), E. grandis (Calonego et al. 2012; de Cademartori et al. 2015) and E. globulus (Esteves et al. 2007a) showed higher losses in MOR in comparison to E. nitens. Other hardwood species, such as European beech, also showed minimal decreases in their MOR after modification (Tjeerdsma et al. 1998). There was also an increase in MOR using ThermoWood process at $200^{\circ} \mathrm{C}$ using birch (Betula ssp.) (Shi et al. 2007b).

The closed system presented a decrease in MOR as the temperature increased, with similar values of thermally modified beech using the same type of modifications (Altgen and Militz 2016). Other eucalypt species (Table 8.1), such as E. pellita modified under a vacuum thermal process, presented a slight increase until $160^{\circ} \mathrm{C}$ and a higher decrease of MOR at higher temperatures (Wang et al. 2014) than the E. nitens. Martins et al. (2014) used the hybrid process PlatoWood at $180^{\circ} \mathrm{C}$ and it showed a bigger decrease in the MOR than in the other modifications using eucalypt species, but in general, in both open and closed system modifications, eucalypt species tend to decrease MOR as the temperature increases. 


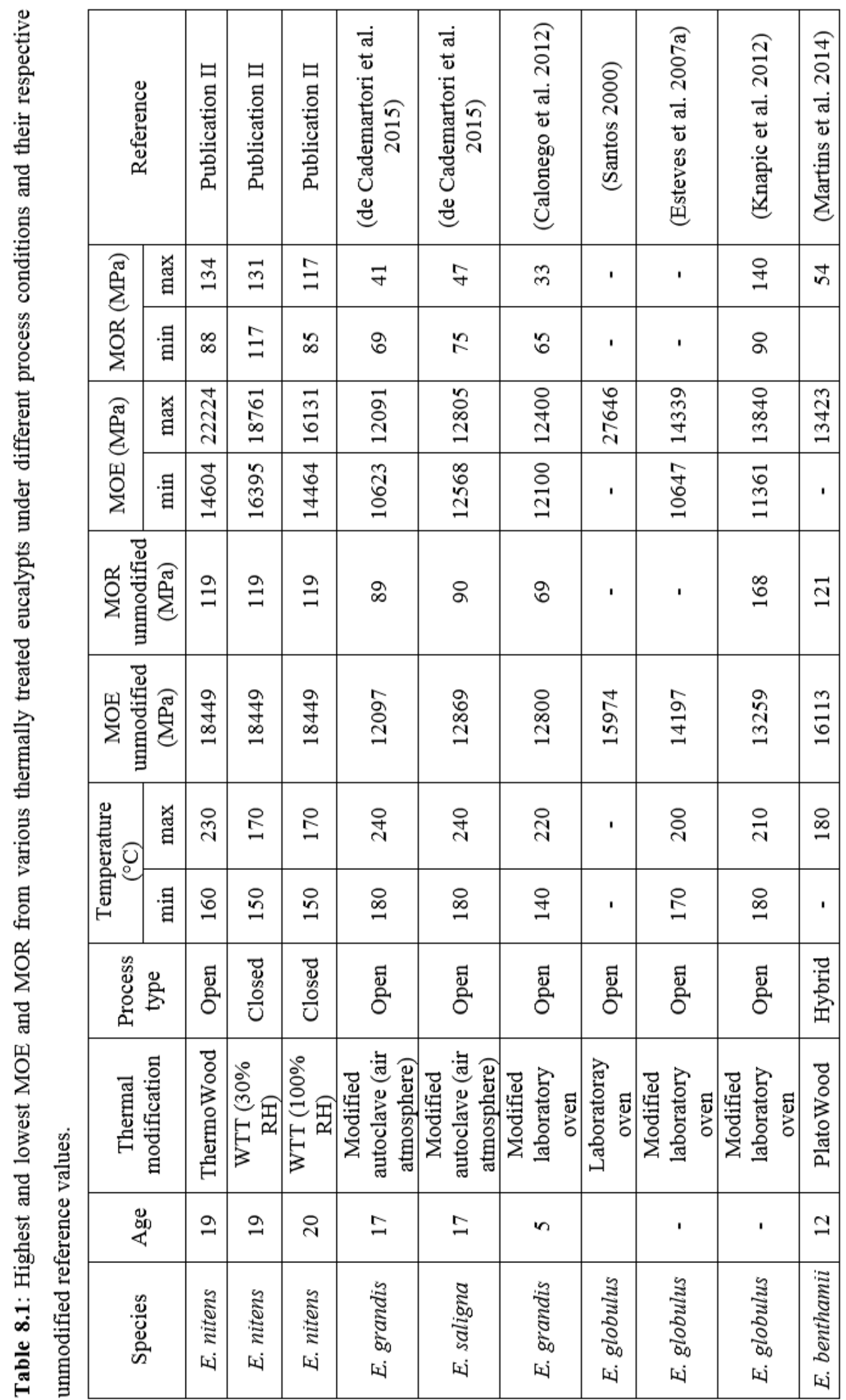


In most cases, the decrease of MOR is a consequence to the reduction in tensile strength and compression strength (Boonstra et al. 2007b), although there are some cases that compression strength stays unchanged (Widmann et al. 2012) or even increases (Boonstra et al. 2007b; Perçin et al. 2016). These changes are related to the chemical composition of the modified wood. The reduction of MOR in relation to the MOE is related to the degradation of structural cell wall components (cellulose, hemicellulose and lignin) produced stress enhancing voids within the wood cell walls, as stated by Borrega and Kärenlampi (2008b). In the case of the hardwood hemicelluloses, the main component of the linear backbone chain is the xylose, which degraded heavily as the temperature increased (Publication I and III). It has been stated that small variations in the side groups can have a large impact on the overall mechanical properties (Sjostrom 1981). There is also the cleavage of these side groups between the lignin and hemicelluloses that releases the linkage by which one microfibril of a wood fiber shares the load with another microfibril, thus disrupting the load-sharing capabilities of the fibers (LeVan et al. 1990). It was also shown that there was an increase in crystallinity in modifications at high temperature in both open and closed systems (Publication III), which also increased the relative cellulose content present in the wood. This causes a decrease in flexibility of the material, as it replaces the flexible hemicellulose-cellulose-hemicellulose bond with the more rigid cellulose-cellulose bond (Kocaefe et al. 2008a). All the previously described changes in the hemicellulose composition correlate with the loss of mechanical properties, especially MOR. This was indicated by the strong relation between its decrease and the degradation of xyloses in open and closed systems (Publication I).

The xylose and the overall relative hemicellulose content were lower in the modifications at $160^{\circ} \mathrm{C}$ and $170^{\circ} \mathrm{C}$ at $100 \% \mathrm{RH}$ than in the high temperature modifications in the open system. These modifications also showed higher relative cellulose content and slightly higher crystallinity index, which indicates that the hemicelluloses were affected more in pressurized modifications. On the other hand, it could explain why there was an increase of MOE in certain modifications in the open system, as it seems that the hemicelluloses were less affected in the open system modifications, thus not affecting as much the flexible hemicellulose-cellulosehemicellulose bond. This could also be an explanation on why this also happened in other eucalypt species, such as E. globulus (Santos 2000), E. saligna and E. grandis (de Cademartori et al. 2015). 
To have a better understanding of the influences of the thermal modifications on the mechanical properties, the deflection and work in bending were analyzed, separating the elastic and inelastic proportions (Publication II). The elastic deflection decreased in all open and closed system modifications, except the modification at $180^{\circ} \mathrm{C}$ in the open system, with the modification at $200^{\circ} \mathrm{C}$ presenting the highest decrease. Although the highest decrease was in a modification in the open system, the closed system modifications tend to decrease more in relation to their CML. The inelastic deflection presented a steeper decrease in relation to the unmodified specimens, with the open system modification having the biggest decrease. Borrega and Kärenlampi (2008b) cited Back and Salmén (1982) to state that the lower inelastic work and deflection in dry climates (in our case, open system modifications) were related to the reduction of the glass transition temperature of the wood polymers, thus the decrease in these properties is less noticeable in wet modifications (closed system in our case). Overall, the decrease in both inelastic work and deflection could be related to ultra-structural realignments that reduce the capabilities of the cell wall components for plastic flow (Altgen and Militz 2016).

These realignments can be related to the changes described in Publication IV, were the drying related annealing effects were more present in the open system modifications and the cell wall bulking was more evident in the closed system modifications, although both effects happen in all modifications. It can be said that the annealing effect causes the wood to be stiffer but less flexible and that the remaining degradation products could be the cause of the higher brittleness of the modifications in the closed system. These phenomena are strongly correlated to the MC after modification. The measured MC was lower in the open than in the closed system (Publication I). This is related to the pre-drying step and the low RH during the process which causes the nearly oven dry. It is important to note that these differences between processes might be larger at the peak temperature exposure. Wood modified in an open system and wood modified at $30 \% \mathrm{RH}$ is more likely to take up moisture during the cooling stage phase, when the RH in the reactor increases. These differences could also further explain why in some of the previous discussed modifications MOR and MOE increased. Probably, depending on the modification, the annealing effect could influence the stiffening effect at certain temperatures, which would be shown in the measurement to the properties.

Brittleness may be the biggest difference between both modifications. Phuong et al (2007) established that higher brittleness could be caused by a relocation of lignin molecules, the loss 
of amorphous polysaccharides, and the inherent crystalline cellulose that is formed during the thermal modification. It was shown that in the closed system presented a stronger degradation of hemicelluloses represented by the loss of xyloses due to the higher concentration of acids, and a slightly higher crystallinity, as shown in Publication III. These changes cause a loss in flexibility of the wood due to the changes of the hemicellulose-cellulose chain (Kubojima et al. 2000; Boonstra et al. 2007b). It seems that the transformation of lignin was similar for both open and closed system modifications, there was a higher phenol content in the closed system, which could produce higher amounts of phenolic extractives. The lower DP of the cellulose can also be a cause of higher brittleness. It can also be argued that the degradation products left inside the wood may also be a cause of higher brittleness. So, even though mechanically the modifications in open and closed systems showed similar characteristics (Publication II), the wood from the closed system could be considered slightly more brittle due to the chemical changes.

There were almost no differences between open and closed system modifications when comparing the RIM and the degree of integrity, as both properties tended to decrease as the temperature increased, which confirms the correlation to the intensity of the treatment (related to CML) shown in previous reports (Brischke et al. 2006a; Welzbacher et al. 2007; Welzbacher et al. 2011). There was one exception, as there was a slight increase in the RIM at $210^{\circ} \mathrm{C}$ in the open system, this is related to the extractive content at that temperature. Higher temperatures increases the vaporization more than the generation of extractives and change the structure of the cellulose (DP of the cellulose and crystallinity). Those changes should be taken into account when analyzing the RIM and the degree of integrity in modifications with temperatures over $210^{\circ} \mathrm{C}$ in the open system. It was also reported that decrease in RIM was related to changes in the wood cell wall level, as it is directly correlated to the decrease in microstructural integrity caused by the thermal modifications (Welzbacher et al. 2011). This could also be explained by the accumulation of degradation products or the annealing effect.

Willems et al (2015b) would recommend the HEMI test as a quick laboratory test to probe mechanical properties when the material is limited. Our results fall in line with that recommendation if one type of modification was used. As to differentiate or test if the modification was performed in an open or closed system, this methodology was not capable to differentiate between them, as the results presented in Publication II show. 


\subsection{Dimensional stability}

The changes caused by degradation reactions in the cell wall that are induced by thermal modification are related to the improvement in dimensional stability and the decrease in water vapor sorption of the modified wood. The degradation of hemicelluloses reduces the concentration of water accessible $\mathrm{OH}$ groups in wood as sorption sites for water, as they contain far more water accessible OH groups than cellulose or lignin (Runkel 1954; Runkel and Lüthgens 1956). The formation of cross-links also contributes to improve the dimensional stability (Repellin and Guyonnet 2005; Altgen et al. 2016a), which was shown that it could be occurring in both open and closed system modifications (Publication IV). This leads to irreversible and reversible chemical changes that are linked to the changes in hygroscopicity. In the case of the EMC and the $S_{\max }$ measured immediately after the process, the accumulated degradation products are still present within the samples and affect the reference mass, provide additional sorption sites for water or cause a cell wall bulking effect, so the regular ML was used instead of the CML for comparison purposes. EMC and $S_{\max }$ were measured during cycles that included repeated conditioning at $20^{\circ} \mathrm{C} / 65 \% \mathrm{RH}$, water-soaking and vacuum-drying at room temperature. This conditions can be considered similar to a weathering cycle, thus closely imitating real uses for the material, such as exterior decking or gardening furniture.

When comparing open and closed system modifications, both thermal modifications resulted in a similar ML, but the increase in EMC with increasing number of cycles was much larger after the modification in the open system compared to the modification in the closed system. This clearly evidences that additional, reversible effects influence the EMC that are not dependent on ML, but on the conditions applied during the modification process. However, in contrast to the change in EMC, changes in $S_{\max }$ in the course of the water-soaking cycles increased the differences between the processes conditions applied. In addition, the $S_{\max }$ increased mainly from the first to the second water soaking cycle and remained almost constant during subsequent cycles. These reversible changes were explained by two distinct phenomena, the drying related annealing of amorphous polymers during the modification process and the cell wall bulking effect caused by the accumulated degradation products, which is measured by relating the dry volume of the thermally modified sample before and after leaching. These phenomena were shown to probably also affect other properties of the modified wood.

The leaching of accumulated degradation products during water soaking caused a loss in dry mass and volume, while the loss in wet/conditioned state was either much smaller or fully 
absent. This is due to the higher extractive content in the modifications where this loss was evident (Publication IV), thus its removal, along other potential degradation products and sugars, removed the cell wall bulking effect created by the thermal modification. This effect was higher in the wet modifications (closed system), as it is theorized that the degradation products (extractives) formed in those modifications tend to be more water soluble due to the high MC during the process that could hinder the dehydration of highly water-soluble sugars to furan-type derivatives (Altgen et al. 2016a).

The decrease in the relative hemicellulose content, DP of the cellulose and a higher crystallinity could explain the theory presented in Publication IV, which related the decrease of the conditioned mass and wet volume of modification at $100 \% \mathrm{RH}$ to an increase of the cellulose microfibril aggregation. This occurs after the removal or relocation of hemicelluloses and/or lignin as the spacers between the cellulose microfibrils (Salmen and Burgert 2009; Pönni et al. 2014; Salmén 2015), which was shown to occur in these thermal modifications. The degradation of hemicelluloses and the structural changes of the cellulose increased the microfibril aggregation, reducing the water uptake of the wood cell wall. This effect was most likely removed after the first water soaking cycle, however, as previously mentioned, it is difficult to separate it to the drying related annealing effects. Though, it was clear to see, thanks to the chemical changes discussed in Publication I and the differences between open and closed systems in relation to their EMC and $S_{\max }$, that the removal of drying related annealing effects is the main cause for reversible changes for samples modified in an open system and the cell wall bulking effect caused by the remaining degradation products is the main effect for samples modified at $100 \% \mathrm{RH}$. This high RH also influenced the decrease of the corrected EMC ratio (EMCc) ratio (Publication IV), which is related to enhanced cross-linking within the wood cell wall (Altgen et al. 2016a) as it was a similar effect shown by modifications with cross linking agents (Himmel and Mai 2015), and also in the increase of phenolic compounds as the temperature rises due to the degradation of hemicelluloses and lignin, especially at $100 \% \mathrm{RH}$. It can be speculated that there is a cross-link effect in the thermal modifications, and that this effect could be the predominant cause of the reduction of EMCc after the water-soaking cycles.

\subsection{Corrected mass loss (CML)}

Usually mass loss (ML) is used as an indicator of the severity of the modification, as it is directly related to the degradation of the wood (Zaman et al. 2000) and linked to the chemical and mechanical properties of the wood (Welzbacher and Rapp 2007; Esteves and Pereira 2009). 
However, when doing a modification under closed conditions, some of degradation products created by the thermal modification accumulate in the wood (Altgen et al. 2016b), which would influence the actual mass loss of the wood after modification. To avoid this issue, the extractive content has to be deducted from the dry mass loss to obtain the corrected mass loss (CML). In this project, the CML was used for both open and closed system modifications. The results obviously showed higher values than using ML, with the modifications at $230^{\circ} \mathrm{C}$ in an open system and at $170^{\circ} \mathrm{C}$ at $100 \%$ reaching about $20 \% \mathrm{CML}$, which underlines the high efficacy of closed systems (wet/moist process) in causing significant thermal degradation at much lower treatment temperatures as the ones usually used for open system modifications (dry process). This degradation is caused by the elevated moisture content of the wood during modification and to the high amounts of formic and acetic acids formed (Publication I) in the closed system (Borrega and Kärenlampi 2008a; Willems et al. 2015a; Altgen et al. 2016b). The CML increased at higher temperatures in both open and closed system modifications, but there were some exceptions in the open system, as the modifications at $220^{\circ} \mathrm{C}$ showed a lower CML than at $210^{\circ} \mathrm{C}$ because of its lower amount of extractives. This results show the importance to modify the way to calculate the ML to be able to see the real effects of the modifications. The CML is recommended for any future analysis of thermal modifications, as it allows the values to be used for comparison purposes between varying thermal modification processes, and to replace the common methods to measure ML to CML, but the time it takes to measure the extractive content makes it difficult to be applied at an industrial level.

Table 8.2 presents the highest and the lowest average ML values from various thermally modified eucalypts at a laboratory scale. They calculated the ML directly after modifications with the extractives and degradation products still present in the wood, so to be able to compare with the results obtained in this study, the regular ML value was used instead of the CML. 
Table 8.2: Highest and lowest average mass loss from various thermally treated eucalypts under different process conditions.

\begin{tabular}{|c|c|c|c|c|c|c|c|c|}
\hline \multirow{2}{*}{ Species } & \multirow{2}{*}{ Age } & \multirow{2}{*}{$\begin{array}{l}\text { Thermal } \\
\text { modification }\end{array}$} & \multirow{2}{*}{$\begin{array}{c}\text { Process } \\
\text { type }\end{array}$} & \multicolumn{2}{|c|}{$\begin{array}{c}\text { Temperature } \\
\left({ }^{\circ} \mathrm{C}\right)\end{array}$} & \multicolumn{2}{|c|}{$\operatorname{ML}(\%)$} & \multirow{2}{*}{ Reference } \\
\hline & & & & $\min$ & $\max$ & $\min$ & $\max$ & \\
\hline E. nitens & 19 & ThermoWood & Open & 160 & 230 & 3.3 & 16.9 & Publication I \\
\hline E. nitens & 19 & WTT (30\% RH) & Closed & 150 & 170 & 1.3 & 2.5 & Publication I \\
\hline E. nitens & 19 & WTT (100\% RH) & Closed & 150 & 170 & 4.0 & 15.7 & Publication I \\
\hline E. grandis & 30 & $\begin{array}{c}\text { Modified } \\
\text { laboratory oven }\end{array}$ & Open & 180 & 220 & 2.5 & 8.0 & $\begin{array}{l}\text { (Almeida et } \\
\text { al. 2009) }\end{array}$ \\
\hline E. saligna & 30 & $\begin{array}{c}\text { Modified } \\
\text { laboratory oven }\end{array}$ & Open & 180 & 220 & 3.0 & 9.0 & $\begin{array}{l}\text { (Almeida et } \\
\text { al. 2009) }\end{array}$ \\
\hline E. grandis & 17 & $\begin{array}{l}\text { Modified } \\
\text { autoclave }\end{array}$ & Open & 180 & 240 & 12.6 & 22.5 & $\begin{array}{c}\text { (de } \\
\text { Cademartori } \\
\text { et al. 2015) }\end{array}$ \\
\hline E. saligna & 17 & $\begin{array}{l}\text { Modified } \\
\text { autoclave }\end{array}$ & Open & 180 & 240 & 12.7 & 21.9 & $\begin{array}{c}\text { (de } \\
\text { Cademartori } \\
\text { et al. 2015) }\end{array}$ \\
\hline E. globulus & - & $\begin{array}{c}\text { Autoclave steam } \\
\text { heat treatment }\end{array}$ & Open & 190 & 210 & 3.7 & 14.5 & $\begin{array}{l}\text { (Esteves et } \\
\text { al. 2007b) }\end{array}$ \\
\hline E. globulus & - & $\begin{array}{c}\text { Modified } \\
\text { laboratory oven }\end{array}$ & Open & 190 & 190 & 4.8 & 9.0 & $\begin{array}{l}\text { (Esteves et } \\
\text { al. 2013) }\end{array}$ \\
\hline E. globulus & - & $\begin{array}{c}\text { Modified } \\
\text { laboratory oven }\end{array}$ & Open & 180 & 210 & 3.0 & 5.0 & $\begin{array}{l}\text { (Knapic et } \\
\text { al. 2012) }\end{array}$ \\
\hline E. pellita & 6 & $\begin{array}{l}\text { Laboratory } \\
\text { vacuum } \\
\text { treatment }\end{array}$ & Closed & 160 & 280 & 2.2 & 25.5 & $\begin{array}{c}\text { (Wang et al. } \\
\text { 2014) }\end{array}$ \\
\hline
\end{tabular}

The tendency shows that the modifications from this study presented higher MLs than the other eucalypt species, with exceptions of the thermally modified E. saligna and E. grandis by de Cademartori et al (2015) and E. pellita by Wang et al (2014), but both processes had higher peak temperatures than the ones used in our study. As mentioned in the introduction the age and type of plantation influences the properties of the eucalypt wood, so the data presented in Table 8.2 should only be taken as an approximate reference of thermally modified wood ML. As for the closed system, there are no data available from other eucalypt species, but the results obtained were similar as the modified European beech, as it showed a similar tendency of an increasing ML and CML as the temperature and pressure rises (Altgen and Militz 2016).

One of the main points was to compare between modifications with similar CML. This was the case for the modifications at $160^{\circ} \mathrm{C}$ and $100 \% \mathrm{RH}$ and $210^{\circ} \mathrm{C}$, which had a CML of $18.6 \%$ and $18.7 \%$ respectively. It was shown that the relative lignin and extractive content were similar between both modifications, but the closed system had lower hemicellulose content, which was 
confirmed by the higher degradation of xylose. The relative cellulose content was also higher, although the DP of the cellulose was lower. This is related to the higher degradation of hemicelluloses and also higher amounts of acetic acid and phenols. These differences were confirmed by the FTIR spectra, as it was possible to differentiate the bands representing hemicelluloses between open and closed systems. There were no significant differences in the cellulose crystallinity, although closed system modifications were slightly higher.

The EMCc ratio (Publication IV) showed that that the modification at $210^{\circ} \mathrm{C}$ was more effective in reducing the EMC than the modification at $160^{\circ} \mathrm{C}$ and $100 \% \mathrm{RH}$. This is related to the annealing effect of the amorphous matrix polymers that contribute to a further reduction of the EMCc ratio.

The anatomy of the thermally modified wood from these two selected modifications did not show differences in the wood cell wall thickness, diameter of fibers and vessels. Both showed development of cracks starting from the middle lamella, which started to spread to the surrounding cells, and from the pit connections. Overall, there were no noticeable differences between the modifications at an anatomical level.

For this project, the CML was a useful indicator to compare between open and closed system modifications and would be recommended to be used in any future studies related to thermally modified wood.

\subsection{Recommended further studies}

Durability tests were not performed during this project, as it was already established that thermally modified wood improved the resistance against fungi attacks as reviewed by Esteves and Pereira (2009), except when it was in direct contact with the soil, which was confirmed recently for thermally modified eucalypt species by Knapic et al. (2018). Chaouch et al. (2013) established correlations between the treatment intensity and wood properties such as durability, elemental composition, ASE and EMC, thus indicating that the chemical modifications of the cell wood wall polymers, something that was shown during our study, was directly responsible of the durability improvement, dimensional stability and reduced water adsorption. This would mean that the thermal modifications performed in this study, especially when the CML was over $10 \%$ both in open and closed systems, most likely improved the durability. On the other hand, it was shown that annealing effects and degradation products after modification 
influenced the swelling and EMC of the modified samples and were shown to be reversible after water soaking cycles. Considering that the improved durability can be related to the modification of the wood polymers, degradation of hemicelluloses, the generation of new extractives and the chemical modification of wood cell wall polymers, which all limit or cause unfavorable conditions for the proliferation on fungi (Weiland and Guyonnet 2003; Hakkou et al. 2006; Lekounougou et al. 2009; Chaouch et al. 2013), it would be interesting to investigate if the durability decreases to a point that the modified wood reacts like the unmodified specimen or that the effect of the thermal modification still is present after water soaking cycles. This would also be recommended to do with the mechanical properties of MOE and MOR. The results could eventually show the long term effect of the thermal modifications and further differentiate between modifications in open and closed systems.

\subsection{Potential of thermally modified $E$. nitens for the Chilean market}

Publication $\mathrm{V}$ described the potential of thermally modified E. nitens wood to be used for decking. The results indicated that the material fulfils all the requirements regarding the surface hardness, anti-swelling efficiency, equilibrium moisture content, volumetric swelling, and abrasion resistance to be used as decking material. Currently, the range of prices of sawnwood of species that dominate the decking market in Chile ranges between the blocks of clear radiata wood (free of knots) that cost 360 US\$ per $\mathrm{m}^{3}$ and the native species Raulí (Nothofagus alpina) at 900 US\$ per $\mathrm{m}^{3}$. Considering that the current sawnwood prices for E. nitens is 225 US\$ per $\mathrm{m}^{3}$ (INFOR 2015), even adding the cost of the thermal modification, the price of the material could be considered competitive and an alternative for the more expensive native wood species. In addition, the mechanical properties shown in Publication II indicate there was not a significant influence of the process conditions on the static and dynamic mechanical properties, only slight differences, such as lower static mechanical properties in the closed system modifications and lower inelastic work and deflections in the open system. These differences were explained by the changes in the chemical structure, and in long term use, the changes in the dimensional stability. Although the mechanical properties seem to suggest that the modified wood can be recommended for many purposes, it should not be used in structures that require dynamic loads, as our material has a brittle behavior and it has already been shown in a report by Widmann et al (2012) that thermally modified structural timber made out of beech should not be used for those purposes. Other important factor to be taken into account, which was not part of this project, is the machinability of the modified material, which influences its sawn and surface quality and can have an effect on the final product. 
Although the results show that the wood for E. nitens was suitable for thermal modification, the material used was dried wood ready to be sold, so common issues of this species, such as the age of the plantation, problems with reaction wood after drying and the effect of knots were avoided. This means that to obtain the better result when modifying this species, the wood has to be selected before the modification, preferably from plantations designed for solid wood material, already dried and without signs of reaction wood, surface cracking and avoiding visible knots as much as possible.

Overall, it would be recommended to use the modified E. nitens wood for decking, cladding, garden furniture or fences, like the current uses of thermally modified wood in the market. There is already a in Spain (MH PARQUETS) that sells products out of thermally modified E. globulus wood and small batches of modified E. globulus and E. nitens are being produced in some industries in Chile, with the material being used for furniture and decorative cladding.

In general, the results obtained in this study can be used as guidelines for the selection of the type of modification to be used for this species. Both modifications can be recommended, but in the end, it will depend on the size and quantity of material to be produced. If the production would lean towards very specific products, the closed system would be recommended, as it uses less space, it is ideal for smaller production runs and it has the advantage of taking less time to finish a complete process cycle than the open modification systems. On the other hand, if there is interest by the bigger industries in Chile, the open modification system would be the one to use, as it has less size limitations than the closed system modification, thus the system can be adapted to modify large quantities of material. 



\section{References}

Akgül M, Gümüşkaya E, Korkut S (2007) Crystalline structure of heat-treated Scots pine [Pinus sylvestris L.] and Uludağ fir [Abies nordmanniana (Stev.) subsp. bornmuelleriana (Mattf.)] wood. Wood Sci Technol 41:281. doi:10.1007/s00226-006-0110-9

Alen R, Kotilainen R, Zaman A (2002) Thermochemical behavior of Norway spruce (Picea abies) at 180-225 degrees C. Wood Sci Technol 36:163-171. doi:10.1007/s00226-0010133-1

Allegretti O, Brunetti M, Cuccui I, Ferrari S, Nocetti M, Terziev N (2012) Thermo-vacuum modification of spruce (Picea abies Karst.) and fir (Abies alba mill.) wood. BioRes 7:3656-3669

Almeida G, Brito JO, Perre P (2009) Changes in wood-water relationship due to heat treatment assessed on micro-samples of three Eucalyptus species. Holzforschung 63:80-88. doi:10.1515/hf.2009.026

Altgen M, Ala-Viikari J, Tetri T, Hukka A, Militz H (2014) Impact of elevated steam pressure during the thermal modification of Scots pine and Norway spruce. In: Proccedings of the COST Action FP0904 workshop, Skelleftea, Sweden.

Altgen M, Hofmann T, Militz H (2016a) Wood moisture content during the thermal modification process affects the improvement in hygroscopicity of Scots pine sapwood. Wood Sci Technol 50:1181-1195. doi:10.1007/s00226-016-0845-x

Altgen M, Militz H (2016) Influence of process conditions on hygroscopicity and mechanical properties of European beech thermally modified in a high-pressure reactor system. Holzforschung 70:971-979. doi:10.1515/hf-2015-0235

Altgen M, Uimonen T, Rautkari L (2018) The effect of de-and re-polymerization during heattreatment on the mechanical behavior of Scots pine sapwood under quasi-static load. Polym Degrad Stabil 147:197-205. doi:10.1016/j.polymdegradstab.2017.12.007

Altgen M, Willems W, Militz H (2016b) Wood degradation affected by process conditions during thermal modification of European beech in a high-pressure reactor system. Eur J Wood Prod 74:653-662. doi:10.1007/s00107-016-1045-y

Andersson S, Serimaa R, Vaananen T, Paakkari T, Jamsa S, Viitaniemi P (2005) X-ray scattering studies of thermally modified Scots pine (Pinus sylvestris L.). Holzforschung 59:422-427. doi:10.1515/hf.2005.069

Araújo SdO, Neiva DM, Gominho J, Esteves B, Pereira H (2017) Chemical effects of a mild torrefaction on the wood of eight Eucalyptus species. Holzforschung 71:291. doi:10.1515/hf-2016-0079

AS 5604 (2005) Australian Standard: Timber-Natural durability ratings. Standards Australia, Sydney, New South Wales, Australia. 
ASTM E1758-01 (2015) Standard test method for determination of carbohydrates in biomass by high performance liquid chromatography. American Society for Testing and Materials, West Conshohocken, Pennsylvania, United States.

Awoyemi L, Jones IP (2011) Anatomical explanations for the changes in properties of western red cedar (Thuja plicata) wood during heat treatment. Wood Sci Technol 45:261-267. doi:10.1007/s00226-010-0315-9

Back EL, Salmén NL (1982) Glass transitions of wood components hold implications for molding and pulping processes. Tappi 65:107-110.

Batista DC, Bolzón de Muñiz GI, da Silva Oliveira JT, Paes JB, Nisgoski S (2016) Effect of the Brazilian thermal modification process on the chemical composition of Eucalyptus grandis juvenile wood: Part 1:Cell wall polymers and extractive contents. MaderasCienc Tecnol 18:273-284. doi:10.4067/S0718-221X2016005000025

Batista DC, Paes JB, Bolzón de Muñiz GI, Nisgoski S, da Silva Oliveira JT (2015) Microstructural aspects of thermally modified Eucalyptus grandis wood. MaderasCienc Tecnol 17:525-532. doi:10.4067/S0718-221X2015005000047

Bekhta P, Niemz P (2003) Effect of high temperature on the change in color, dimensional stability and mechanical properties of spruce wood. Holzforschung 57:539-546. doi:10.1515/hf.2003.080

Belkacemi K, Abatzoglou N, Overend RP, Chornet E (1991) Phenomenological kinetics of complex systems: mechanistic considerations in the solubilization of hemicelluloses following aqueous/steam treatments. Ind Eng Chem Res 30:2416-2425. doi:10.1021/ie00059a009

Bendtsen BA (1966) Sorption and swelling characteristics of salt-treated wood. US Forest Service Research Paper FPL 60, Forest Products Laboratory, Madison, USA.

Bernabei M, Salvatici MC (2016) In situ ESEM observations of spruce wood (Picea abies Karst.) during heat treatment. Wood Sci Technol 50:715-726. doi:10.1007/s00226-0160808-2

Bhuiyan MTR, Hirai N (2005) Study of crystalline behavior of heat-treated wood cellulose during treatments in water. J Wood Sci 51:42-47. doi:10.1007/s10086-003-0615-X

Bhuiyan MTR, Hirai N, Sobue N (2000) Changes of crystallinity in wood cellulose by heat treatment under dried and moist conditions. J Wood Sci 46:431-436. doi:10.1007/bf00765800

Bhuiyan MTR, Hirai N, Sobue N (2001) Effect of intermittent heat treatment on crystallinity in wood cellulose. J Wood Sci 47:336-341. doi:10.1007/bf00766782

Biziks V, Andersons B, Belkova L, Kapaca E, Militz H (2013) Changes in the microstructure of birch wood after hydrothermal treatment. Wood Sci Technol 47:717-735. doi:10.1007/s00226-013-0531-1 
Biziks V, Andersons B, Sansonetti E, Andersone I, Militz H, Grinins J (2015) One-stage thermo-hydro treatment (THT) of hardwoods: an analysis of form stability after five soaking-drying cycles. Holzforschung 69:563-571. doi:10.1515/hf-2014-0083

Bobleter O, Binder H (1980) Dynamic hydrothermal degradation of wood. Holzforschung 34:48-51. doi: 10.1515/hfsg.1980.34.2.48

Boonstra MJ, Rijsdijk JF, Sander C, Kegel E, Tjeerdsma B, Militz H, van Acker J, Stevens M (2006a) Microstructural and physical aspects of heat treated wood. Part 1. Softwoods. Maderas-Cienc Tecnol 8:193-208. doi:10.4067/s0718-221x2006000300006

Boonstra MJ, Rijsdijk JF, Sander C, Kegel E, Tjeerdsma B, Militz H, van Acker J, Stevens M (2006b) Microstructural and physical aspects of heat treated wood: Part 2. Hardwoods. Maderas-Cienc Tecnol 8:209-218. doi:10.4067/s0718-221x2006000300007

Boonstra MJ, Tjeerdsma B (2006) Chemical analysis of heat treated softwoods. Holz Roh Werkst 64:204-211. doi:10.1007/s00107-005-0078-4

Boonstra MJ, Tjeerdsma B, Groeneveld HAC (1998) Thermal modification of non-durable wood species. Part 1. The Plato technology: thermal modification of wood. The International Research Group on Wood Protection Document No IRG/WP 98-40123.

Boonstra MJ, van Acker J, Kegel E, Stevens M (2007a) Optimisation of a two-stage heat treatment process: durability aspects. Wood Sci Technol 41:31-57. doi:10.1007/s00226006-0087-4

Boonstra MJ, van Acker J, Tjeerdsma BF, Kegel EV (2007b) Strength properties of thermally modified softwoods and its relation to polymeric structural wood constituents. Ann For Sci 64:679-690. doi:10.1051/forest:2007048

Borrega M, Kärenlampi P (2008a) Effect of relative humidity on thermal degradation of Norway spruce (Picea abies) wood. J Wood Sci 54:323-328. doi:10.1007/s10086-0080953-9

Borrega M, Kärenlampi P (2008b) Mechanical behavior of heat-treated spruce (Picea abies) wood at constant moisture content and ambient humidity. Holz Roh Werkst 66:63-69

Borrega M, Kärenlampi P (2010) Hygroscopicity of heat-treated Norway spruce (Picea abies) wood. Eur J Wood Prod 68:233-235. doi:10.1007/s00107-009-0371-8

Brischke C (2017) Interrelationship between static and dynamic strength properties of wood and its structural integrity. Drvna Industrija 68:53-60. doi:10.5552/drind.2017.1629

Brischke C, Iseler N, Meyer L, Sawyer G (2014) Testing the mechanical resistance of timber used for construction in the marine environment. Int Wood Products J 5:39-49. doi:10.1179/2042645313Y.0000000050

Brischke C, Koch S, Rapp AO, Welzbacher CR (2005) Surface properties of thermally treated wood-wear abrasion and hardness. In: Militz H, Hill C (eds). Proceedings of the 2nd European Conference on Wood Modification, Göttingen, Germany. 
Brischke C, Rapp AO, Welzbacher CR (2006a) High-energy multiple impact (HEMI)-testPart 1: A new tool for quality control of thermally modified timber. The International Research Group on Wood Preservation Document No 06-20346 IRG/WP.

Brischke C, Welzbacher CR, Brandt K, Rapp AO (2007) Quality control of thermally modified timber: Interrelationship between heat treatment intensities and CIE L* $\mathrm{a}^{*} \mathrm{~b} *$ color data on homogenized wood samples. Holzforschung 61:19-22. doi:10.1515/HF.2007.004

Brischke C, Welzbacher CR, Rapp AO (2006b) Detection of fungal decay by high-energy multiple impact (HEMI) testing. Holzforschung 60:217-222. doi:10.1515/HF.2006.036

Burmester A (1973) Einfluß einer Wärme-Druck-Behandlung halbtrockenen Holzes auf seine Formbeständigkeit. Holz Roh Werkst 31:237-243. doi:10.1007/BF02607268

Burmester A (1975) Zur Dimensionsstabilisierung von Holz [The dimensional slabilization of wood]. Holz Roh Werkst 33:333-335. doi:10.1007/BF02612789

Cabrera J, Martin M, Rojas Y, Avila A, Muñoz JC, Bahamondez C, Peña O, Uribe M, Rojas C (2013) Disponibilidad de Madera de Plantaciones de Pino Radiata y Eucalipto (2010 2040) [Availability of wood from radiata pine and eucalypt plantations (2010-204)]. Informe técnico $\mathrm{N}^{\circ} 194$ Instituto Forestal, Chile.

Calonego FW, Severo ETD, Ballarin AW (2012) Physical and mechanical properties of thermally modified wood from E. grandis. Eur J Wood Prod 70:453-460. doi:10.1007/s00107-011-0568-5

Calonego FW, Severo ETD, Furtado EL (2010) Decay resistance of thermally-modified Eucalyptus grandis wood at 140 degrees C, 160 degrees C, 180 degrees C, 200 degrees $C$ and 220 degrees C. Bioresource Technol 101:9391-9394. doi:10.1016/j.biortech.2010.06.119

Čermák P, Rautkari L, Horáček P, Saake B, Rademacher P, Sablík P (2015) Analysis of dimensional stability of thermally modified wood affected by re-wetting cycles. BioRes 10:3242-3253.

Čermák P, Vahtikari K, Rautkari L, Laine K, Horáček P, Baar J (2016) The effect of wetting cycles on moisture behaviour of thermally modified Scots pine (Pinus sylvestris L.) wood. J Mater Sci 51:1504-1511. doi:10.1007/s10853-015-9471-5

Chaouch M, Dumarcay S, Petrissans A, Petrissans M, Gerardin P (2013) Effect of heat treatment intensity on some conferred properties of different European softwood and hardwood species. Wood Sci Technol 47:663-673. doi:10.1007/s00226-013-0533-z

Cheng WL, Morooka T, Wu QL, Liu YX (2007) Characterization of tangential shrinkage stresses of wood during drying under superheated steam above 100 degrees C. Forest Prod J 57:39-43.

Cheng XY, Li XJ, Xu K, Huang QT, Sun HN, Wu YQ (2017) Effect of Thermal Treatment on Functional Groups and Degree of Cellulose Crystallinity of Eucalyptus Wood (Eucalyptus grandis $\times$ Eucalyptus urophylla). Forest Prod J 67:135-140. doi:10.13073/FPJ-D-15-00075 
Choong ET, Achmadi SS (1991) Effect of extractives on moisture sorption and shrinkage in tropical woods. Wood Fiber Sci 23:185-196.

Chow S-Z (1971) Infrared spectral characteristics and surface inactivation of wood at high temperatures. Wood Sci Technol 5:27-39. doi:10.1007/BF00363118

da Silva MR, de Oliveira Machado G, Deiner J, Calil Jr C (2010) Permeability measuremens of brazilian eucalyptus. Mat Res 13:281-286. doi:10.1590/S1516-14392010000300002

Dagbro O, Torniainen P, Karlsson O, Morén T (2010) Colour responses from wood, thermally modified in superheated steam and pressurized steam atmospheres. Wood Mater Sci Eng 5:211-219. doi:10.1080/17480272.2010.520739

de Cademartori PHG, Missio AL, Mattos BD, Gatto DA (2015) Effect of thermal treatments on technological properties of wood from two Eucalyptus species. An Acad Bras Cienc 87:471-481. doi:10.1590/0001-3765201520130121

de Cademartori PHG, Schneid E, Gatto DA, Stangerlin DM, Beltrame R (2013) Thermal modification of Eucalyptus grandis wood: Variation of colorimetric parameters. Maderas-Cienc Tecnol 15:57-64. doi:10.4067/s0718-221x2013005000005

de Moura LF, Brito JO, da Silva Júnior FG (2012) Effect of thermal treatment on the chemical characteristics of wood from Eucalyptus grandis W. Hill ex Maiden under different atmospheric conditions. CERNE 18:449-455. doi:10.1590/S0104-77602012000300012

de Moura LF, Brito JO, Nolasco AM, Uliana LR, Bolzon De Muniz GI (2013) Evaluation of coating performance and color stability on thermally rectified Eucalyptus grandis and Pinus caribaea var. Hondurensis woods. Wood Res-Slovakia 58:231

Demirbaş A (2000) Mechanisms of liquefaction and pyrolysis reactions of biomass. Energ Convers Manage 41:633-646. doi:10.1016/S0196-8904(99)00130-2

DIN 52186 (1978) Testing of wood: bending test. German Institute for Standardisation, Berlin.

DIN EN 320 (2011) Particleboards and fibreboards - Determination of resistance to axial withdrawal of screws. European Committee for Standardization, Brussels.

DIN EN 438 (2005) High-pressure decorative laminates (HPL) - Sheets based on thermosetting resins (usually called laminates) - Part 2: Determination of properties. European Committee for Standardization, Brussels.

DIN EN 1534 (2011) Wood flooring - Determination of resistance to indentation - Test method. European Committee for Standardization, Brussels.

Dirol D, Guyonnet R (1993) The improvment of wood durability by retification process. The International Research Group on Wood Protection Document No IRG/WP 93-40015.

Dwianto W, Tanaka F, Inoue M, Norimoto M (1996) Crystallinity Changes of Wood by Heat or Steam Treatment. Wood research: bulletin of the Wood Research Institute Kyoto University 83:47-49. 
Emmerich L, Bollmus S, Militz H (2017) Wood modification with DMDHEU (1.3-dimethylol4.5-dihydroxyethyleneurea)-State of the art, recent research activities and future perspectives. Wood Mater Sci Eng. doi:10.1080/17480272.2017.1417907

Endo K, Obataya E, Zeniya N, Matsuo M (2016) Effects of heating humidity on the physical properties of hydrothermally treated spruce wood. Wood Sci Technol 50:1161-1179. doi:10.1007/s00226-016-0822-4

Engelund ET, Thygesen LG, Svensson S, Hill CAS (2013) A critical discussion of the physics of wood-water interactions. Wood Sci Technol 47:141-161. doi:10.1007/s00226-0120514-7

Esteves B, Domingos I, Pereira H (2007a) Improvement of technological quality of eucalypt wood by heat treatment in air at 170-200 degrees ${ }^{\circ} \mathrm{C}$. Forest Prod J 57:47-52.

Esteves B, Graca J, Pereira H (2008a) Extractive composition and summative chemical analysis of thermally treated eucalypt wood. Holzforschung 62:344-351. doi:10.1515/hf.2008.057

Esteves B, Marques AV, Domingos I, Pereira H (2007b) Influence of steam heating on the properties of pine (Pinus pinaster) and eucalypt (Eucalyptus globulus) wood. Wood Sci Technol 41:193-207. doi:10.1007/s00226-006-0099-0

Esteves B, Marques AV, Domingos I, Pereira H (2008b) Heat-induced colour changes of pine (Pinus pinaster) and eucalypt (Eucalyptus globulus) wood. Wood Sci Technol 42:369384. doi:10.1007/s00226-007-0157-2

Esteves B, Marques AV, Domingos I, Pereira H (2013) Chemical changes of heat treated pine and eucalypt wood monitored by FTIR. Maderas-Cienc Tecnol 15:245-258. doi:10.4067/s0718-221x2013005000020

Esteves B, Pereira H (2009) Wood modification by heat treatment: a review. BioRes 4:370404.

Evans R, Wallis AFA (1989) Cellulose molecular-weights determined by viscometry. J Appl Polym Sci 37:2331-2340. doi:10.1002/app.1989.070370822

Faix O (1991) Classification of lignins from different botanical origins by FT-IR spectroscopy. Holzforschung 45:21-28. doi:10.1515/hfsg.1991.45.s1.21

Faix O, Böttcher JH (1992) The influence of particle size and concentration in transmission and diffuse reflectance spectroscopy of wood. Holz Roh Werkst 50:221-226. doi:10.1007/BF02650312

Faix O, Meier D, Fortmann I (1990) Thermal degradation products of wood. Holz Roh Werkst 48:281-285. doi:10.1007/BF02626519 
Fengel D (1966) Über die Veränderungen des Holzes und seiner Komponenten im Temperaturbereich bis $200^{\circ} \mathrm{C}$-Zweite Mitteilung: Die Hemicellulosen in unbehandeltem und in thermisch behandeltem Fichtenholz [On the changes of Wood and its Components in the Temperature Range up to $200^{\circ} \mathrm{C}$-Part II: The Hemicelulloses in Untreated and Thermally Treated Sprucewood]. Holz Roh Werkst 24:98. doi:10.1007/bf02608355

Fengel D (1967) Über die Veränderungen des Holzes und seiner Komponenten im Temperaturbereich bis $200^{\circ} \mathrm{C}$-Vierte Mitteilung: Das Verhalten der Cellulose im Fichtenholz bei thermischer Behandlung [On the changes of the wood and its components within the temperature range up to $200^{\circ} \mathrm{C}$ - Part IV: The behaviour of cellulose in spruce wood under thermal treatment]. Holz Roh Werkst 25:102-111. doi:10.1007/bf02608251

Fengel D, Wegener G (1984) Wood: chemistry, ultrastructure, reactions. Walter de Gruyter, Berlin, Germany.

Garrote G, Dominguez H, Parajo JC (1999) Hydrothermal processing of lignocellulosic materials. Eur J Wood Prod 57:191-202. doi:10.1007/s001070050039

Garrote G, Dominguez H, Parajo JC (2001) Study on the deacetylation of hemicelluloses during the hydrothermal processing of Eucalyptus wood. Holz Roh Werkst 59:53-59. doi:10.1007/s001070050473

Gerardin P (2016) New alternatives for wood preservation based on thermal and chemical modification of wood- a review. Ann For Sci 73:559-570. doi:10.1007/s13595-0150531-4

Gerardin P, Petric M, Petrissans M, Lambert J, Ehrhrardt JJ (2007) Evolution of wood surface free energy after heat treatment. Polym Degrad Stabil 92:653-657. doi:10.1016/j.polymdegradstab.2007.01.016

Giebeler E (1983) Dimensional stabilization of wood by moisture-heat-pressure-treatment. Holz Roh Werkst 41:87-94. doi:10.1007/bf02608498

Glass SV, Boardman CR, Zelinka SL (2017) Short hold times in dynamic vapor sorption measurements mischaracterize the equilibrium moisture content of wood. Wood Sci Technol 51:243-260. doi:10.1007/s00226-016-0883-4

Gonzalez-Peña MM, Curling SF, Hale MDC (2009) On the effect of heat on the chemical composition and dimensions of thermally-modified wood. Polym Degrad Stabil 94:2184-2193. doi:10.1016/j.polymdegradstab.2009.09.003

González-Peña MM, Hale MDC (2009) Colour in thermally modified wood of beech, Norway spruce and Scots pine. Part 1: Colour evolution and colour changes. Holzforschung 63:385-393. doi:10.1515/HF.2009.078

González-Prieto O, Touza Vázquez MC (2009) Properties of thermally modified wood of Eucalyptus globulus from Spanish plantations. The International Research Group of Wood Protection Document No. IRG/WP 09-40469. 
Griebeler C, de Matos JLM, Bolzón de Muniz GI, Nisgoski S, Batista DC, Rodríguez CI (2018) Colour responses of Eucalyptus grandis wood to the brazilian process of thermal modification. Maderas-Cienc Tecnol 20. doi:10.4067/S0718-221X2018005041201

Hakkou M, Pétrissans M, Gérardin P, Zoulalian A (2006) Investigations of the reasons for fungal durability of heat-treated beech wood. Polym Degrad Stabil 91:393-397. doi:10.1016/j.polymdegradstab.2005.04.042

Hallac BB, Ragauskas AJ (2011) Analyzing cellulose degree of polymerization and its relevancy to cellulosic ethanol. Biofuels, Bioprod Bioref 5:215-225. doi:10.1002/bbb.269

Hanhijärvi A, Wahl P, Räsänen J, Silvennoinen R (2003) Observation of development of microcracks on wood surface caused by drying stresses. Holzforschung 57:561-565. doi:10.1515/HF.2003.083

Hill CAS (2006) Wood Modification: Chemical, Thermal and Other Processes. John Wiley \& Sons, Ltd., West Sussex, England.

Hill CAS, Jones D (1996) The dimensional stabilisation of Corsican pine sapwood by reaction with carboxylic acid anhydrides. The effect of chain length. Holzforschung 50:457-462. doi:10.1515/hfsg.1996.50.5.457

Hill CAS, Ramsay J, Keating B, Laine K, Rautkari L, Hughes M, Constant B (2012) The water vapour sorption properties of thermally modified and densified wood. J Mater Sci 47:3191-3197. doi:10.1007/s10853-011-6154-8

Himmel S, Mai C (2015) Effects of acetylation and formalization on the dynamic water vapor sorption behavior of wood. Holzforschung 69:633-643. doi:10.1515/hf-2014-0161

Hofmann T, Wetzig M, Rétfalvi T, Sieverts T, Bergemann H, Niemz P (2013) Heat-treatment with the vacuum-press dewatering method: chemical properties of the manufactured wood and the condensation water. Eur J Wood Prod 71:121-127. doi:10.1007/s00107012-0657-0

Huang X, Kocaefe D, Kocaefe Y, Boluk Y, Pichette A (2012) A spectrocolorimetric and chemical study on color modification of heat-treated wood during artificial weathering. Appl Surf Sci 258:5360-5369. doi:doi.org/10.1016/j.apsusc.2012.02.005

Infante P, Ipinza R, Prado JA (1991) Bases para la mejora genética de las especies del género Eucalyptus en Chile [Bases for genetic improvement of Eucalyptus species in Chile]. CIFOR 5:71-95.

INFOR (2014) Mejoramiento genético de los eucaliptos en Chile [Genetic improvment of Eucalypts in Chile]. Instituto Forestal de Chile, Santiago de Chile.

INFOR (2015) Statistical bulletin N¹54 - Chilean statistical yearbook of forestry 2016. Instituto Forestal de Chile, Santiago de Chile.

Isogai A, Usuda M (1990) Crystallinity indexes of cellulosic materials. Sen'i Gakkaishi 46:324329. doi:10.2115/fiber.46.8_324 
Jahan MS, Mun SP (2005) Effect of tree age on the cellulose structure of Nalita wood (Trema orientalis). Wood Sci Technol 39:367-373. doi:10.1007/s00226-005-0291-7

Jalaludin Z, Hill CAS, Xie YJ, Samsi HW, Husain H, Awang K, Curling SF (2010) Analysis of the water vapour sorption isotherms of thermally modified acacia and sesendok. Wood Mater Sci Eng 5:194-203.

Jämsä S, Ahola P, Viitaniemi P (2000) Long-term natural weathering of coated ThermoWood. Pigm Resin Technol 29:68-74. doi:doi:10.1108/03699420010317807

Johansson D, Moren T (2006) The potential of colour measurement for strength prediction of thermally treated wood. Holz Roh Werkst 64:104-110. doi:10.1007/s00107-0050082-8

Kačíková D, Kačík F, Čabalová I, Ďurkovič J (2013) Effects of thermal treatment on chemical, mechanical and colour traits in Norway spruce wood. Bioresource Technol 144:669674. doi:10.1016/j.biortech.2013.06.110

Kamden DP, Pizzi A, Jermannaud A (2002) Durability of heat-treated wood. Holz Roh Werkst 60:1-6. doi:10.1007/s00107-001-0261-1

Kariz M, Kuzman MK, Sernek M (2013) The effect of heat treatment on the withdrawal capacity of screws in spruce wood. BioRes 8:4340-4348.

Knapic S, Santos J, Pereira H (2012) Thermal Modification on Eucalyptus wood: An Essay (Poster presentation). In: Jones. D, Militz. H, Petrič. M, Pohleven. F, Humar. M, Pavlič. M (eds). Proceedings of the 6th European Conference on Wood Modification Ljubijana, Slovenia.

Knapic S, Santos J, Santos J, Pereira H (2018) Natural durability assessment of thermomodified young wood of eucalyptus. Maderas-Cienc Tecnol 20. doi:10.4067/S0718221X2018005031801

Kocaefe D, Poncsak S, Boluk Y (2008a) Effect of thermal treatment on the chemical composition and mechanical properties of birch and aspen. BioRes 3:517-537.

Kocaefe D, Shi JL, Yang D-Q, Bouazara M (2008b) Mechanical properties, dimensional stability, and mold resistance of heat-treated jack pine and aspen. Forest Prod J 58:88.

Kollmann F, Fengel D (1965) Änderungen der chemischen Zusammensetzung von Holz durch thermische Behandlung [Changes in the theroical composition of Wood by Thermal Treatment]. Holz Roh Werkst 23:461. doi:10.1007/bf02627217

Kollmann F, Schmidt E, Kufner M, Fengel D, Schneider A (1969) Gefüge- und Eigenschaftsänderungen im Holz durch mechanische und thermische Beanspruchung [The Alteration of Texture and Properties of Wood by Mechanical and Thermal Stresses]. Holz Roh Werkst 27:407-425. doi:10.1007/bf02604735

Kollmann F, Schneider A (1963) Über das Sorptionsverhalten wärmebehandelter Hölzer [On the sorption-behavior of heat stabilized wood]. Holz Roh Werkst 21:77-85. doi:10.1007/BF02609705 
Korkut S, Kok MS, Korkut DS, Gurleyen T (2008) The effects of heat treatment on technological properties in Red-bud maple (Acer trautvetteri Medw.) wood. Bioresource Technol 99:1538-1543. doi:10.1016/j.biortech.2007.04.021

Kotilainen RA, Toivanen T-J, Alén RJ (2000) FTIR monitoring of chemical changes in softwood during heating. J Wood Chem Technol 20:307-320. doi:10.1080/02773810009349638

Kubojima Y, Okano T, Ohta M (2000) Bending strength and toughness of heat-treated wood. J Wood Sci 46:8-15. doi:10.1007/bf00779547

Lande S, Westin M, Schneider M (2008) Development of modified wood products based on furan chemistry. Mol Cryst Liq Cryst 484:1/[367]-312/[378]. doi:10.1080/15421400801901456

Lekounougou S, Kocaefe D (2012) Comparative study on the durability of heat-treated White Birch (Betula papyrifera) subjected to the attack of brown and white rot fungi. Wood Mater Sci Eng 7:101-106. doi:10.1080/17480272.2012.663407

Lekounougou S, Kocaefe D, Oumarou N, Kocaefe Y, Poncsak S (2011) Effect of thermal modification on mechanical properties of Canadian white birch (Betula papyrifera). Int Wood Products J 2:101-107.

Lekounougou S, Pétrissans M, Jacquot JP, Gelhaye E, Gérardin P (2009) Effect of heat treatment on extracellular enzymatic activities involved in beech wood degradation by Trametes versicolor. Wood Sci Technol 43:331-341. doi:10.1007/s00226-008-0236-z

Lesar B, Gorišek Ž, Humar M (2009) Sorption properties of wood impregnated with boron compounds, sodium chloride and glucose. Dry Technol 27:94-102. doi:10.1080/07373930802565947

LeVan S, Ross RJ, Winandy JE (1990) Effects of fire retardant chemicals on the bending properties of wood at elevated temperatures. Madison, WI: US Department of Agriculture, Forest Service, Forest Products Laboratory:1-24.

Majka J, Czajkowski Ł, Olek W (2016) Effects of cyclic changes in relative humidity on the sorption hysteresis of thermally modified spruce wood. BioRes 11:5265-5275.

Martins SA, del Menezzi CHS, Pizzi A, Boonstra M (2014) Properties of Brazilian Eucalyptus benthamii wood modified by PlatoWood process (Poster presentation). In: Nunes L, Jones D, Hill C, Militz H (eds). Proceedings of the 7th European Conference on Wood Modification Lisboa, Portugal.

Mayes D, Oksanen O (2002) ThermoWood Handbook. Finnish Thermowood Association, Helsinki, Finland.

Mburu F, Dumarçay S, Huber F, Petrissans M, Gérardin P (2007) Evaluation of thermally modified Grevillea robusta heartwood as an alternative to shortage of wood resource in Kenya: Characterisation of physicochemical properties and improvement of bioresistance. Bioresource Technol 98:3478-3486. doi:10.1016/j.biortech.2006.11.006 
Metsä-Kortelainen S (2011) Differences between sapwood and heartwood of thermally modified Norway spruce (Picea abies) and Scots pine (Pinus sylvestris) under water and decay exposure. PhD thesis, VTT Technical Research Centre of Finland, Helsinki, Finland.

Metsä-Kortelainen S, Antikainen T, Viitaniemi P (2006) The water absorption of sapwood and heartwood of Scots pine and Norway spruce heat-treated at $170^{\circ} \mathrm{C}, 190^{\circ} \mathrm{C}, 210^{\circ} \mathrm{C}$ and $230^{\circ}$ C. Holz Roh Werkst 64:192-197. doi:10.1007/s00107-005-0063-y

Meyer L, Brischke C, Welzbacher CR (2011) Dynamic and static hardness of wood: method development and comparative studies. Int Wood Products J 2:5-11. doi: 10.1179/2042645311Y.0000000005

Michell AJ, Higgins HG (2002) Infrared spectroscopy in Australian forest products research. CSIRO Forestry and Forest Products, Melbourne, Australia.

Militz H, Altgen M (2014) Processes and properties of thermally modified wood manufactured in Europe. In: Schultz TP, Goodell B, Nicholas DD (eds). Deterioration and protection of sustainable biomaterials. ACS Symposium Series 1158. Oxford University Press, pp 269-285.

Mohareb A, Sirmah P, Petrissans M, Gerardin P (2012) Effect of heat treatment intensity on wood chemical composition and decay durability of Pinus patula. Eur J Wood Prod 70:519-524. doi:10.1007/s00107-011-0582-7

Moharram MA, Mahmoud OM (2008) FTIR spectroscopic study of the effect of microwave heating on the transformation of cellulose I into cellulose II during mercerization. J Appl Polym Sci 107:30-36. doi:10.1002/app.26748

Moon RJ, Jakes JE, Beecher JF, Frihart CR, Stone DS (2009) Relating nanoindentation to macroindentation of wood. In: Hse C-Y, Jiang Z, Kuo M-L (eds). Procedings of the Advanced biomass science and technology for bio-based products, Beijing, China. Chinese Academy of Forestry \& USDA Forest Service, Southern Research Station.

Morita S, Yamazumi T (1987) Coloring of wood by high pressure steam. Coloring degree and appearance of defects depending on treatment condition. Wood Ind 42:266-272.

Muñoz F, Espinosa M, Herrera MA, Cancino J (2005) Características del crecimiento en diámetro, altura y volumen de una plantación de Eucalyptus nitens sometida a tratamientos silvícolas de poda y raleo [Growth characteristics in diameter, height, and volume of a Eucalyptus nitens plantation with different silvicultural treatment for pruning and thinning]. BOSQUE 26:93-99. doi:10.4067/S0717-92002005000100009

Nguila Inari G, Petrissans M, Gerardin P (2007) Chemical reactivity of heat-treated wood. Wood Sci Technol 41:157. doi:10.1007/s00226-006-0092-7

Niemz P, Mariani S, Torres M (2004) Einfluss der hydrothermischen Behandlung von Picea abies (L.) Karsten und Eucalyptus nitens (Deane \& Maiden) auf die chemische Zusammensetzung des Holzes [Influence of hydrothermal treatment on the chemical composition of Picea abies (L.) Karsten and Eucalyptus nitens (Deane \& Maiden)]. Schweiz Z Forstwes 155:544-547. doi:10.3188/szf.2004.0544 
NISTS (2015) Standard Reference Material 660c: Line Position and Line Shape Standard for Powder Diffraction (Lanthanum Hexaboride Powder). National Institute of Standards and Technology,Gaithersburg, Maryland, United States.

Nuopponen M, Vuorinen T, Jämsä S, Viitaniemi P (2005) Thermal modifications in softwood studied by FT-IR and UV resonance Raman spectroscopies. J Wood Chem Technol 24:13-26. doi: 10.1081/WCT-120035941

Obataya E, Higashihara T (2017) Reversible and irreversible dimensional changes of heattreated wood during alternate wetting and drying. Wood Sci Technol 51:739-749. doi:10.1007/s00226-017-0918-5

Obataya E, Higashihara T, Tomita B (2002) Hygroscopicity of heat-treated wood III. Effect of steaming on the hygroscopicity of wood (in Japanese). Mokuzai Gakkaishi 48:348-355.

Obataya E, Tomita B (2002) Hygroscopicity of heat-treated wood II: Reversible and irreversible reductions in the hygroscopicity of wood due to heating (in Japanese). Mokuzai Gakkaishi 4:288-295.

Oltean L, Teischinger A, Hansmann C (2007) Influence of temperature on cracking and mechanical properties of wood during wood drying-A review. BioRes 2:789-811.

Özgenç Ö, Durmaz S, Boyaci IH, Eksi-Kocak H (2017) Determination of chemical changes in heat-treated wood using ATR-FTIR and FT Raman spectrometry. Spectrochim Acta A 171:395-400. doi:10.1016/j.saa.2016.08.026

Pandey KK (1999) A study of chemical structure of soft and hardwood and wood polymers by FTIR spectroscopy. J Appl Polym Sci 71:1969-1975. doi:10.1002/(SICI)10974628(19990321)71:12<1969::AID-APP6>3.0.CO;2-D

Pandey KK, Theagarajan KS (1997) Analysis of wood surfaces and ground wood by diffuse reflectance (DRIFT) and photoacoustic (PAS) Fourier transform infrared spectroscopic techniques. Holz Roh Werkst 55:383-390. doi:10.1007/s001070050251

Paz J, Pérez L (1999) Análisis comparativo de las propiedades microscópicas y macroscópicas de la madera de Eucalyptus nitens y Eucalyptus globulus [Comparative analysis of the microscopic and macroscopic properties of Eucalyptus nitens and Eucalyptus globulus wood]. In: Proccedings of the Silvotecna XII. Realidad potencial del Eucalyptus en Chile: Cultivo Silvícola y su uso industrial, Concepción, Chile.

Perçin O, Peker H, Atilgan A (2016) The effect of heat treatment on the some physical and mechanical properties of beech (Fagus orientalis lipsky) wood. Wood Res-Slovakia 61:443-456.

Peredo M (1999) Aptitud Pulpable de Eucalyptus globulus, E. nitens y E. regnans cultivados en Chile [Pulpable Aptitude of Eucalyptus globulus, E. nitens and E. regnans cultivated in Chile]. In: Proccedings of the Silvotecna XII. Realidad potencial del Eucalyptus en Chile: Cultivo Silvícola y su uso industrial, Concepeción, Chile. 
Peters J, Pfriem A, Horbens M, Fischer S, Wagenführ A (2009) Emissions from thermally modified beech wood, their reduction by solvent extraction and fungicidal effect of the organic solvent extracts. Wood Mater Sci Eng 4:61-66. doi:10.1080/17480270903340562

Petrissans M, Gerardin P, El Bakali I, Serraj M (2003) Wettability of heat-treated wood. Holzforschung 57:301-307. doi:10.1515/hf.2003.045

Phuong LX, Shida S, Saito Y (2007) Effects of heat treatment on brittleness of Styrax tonkinensis wood. J Wood Sci 53:181-186. doi:10.1007/s10086-006-0841-0

Poblete H, Burgos R (2010) Eucalyptus nitens como materia prima para tableros de particulas [Eucalyptus nitens as raw material for particleboards]. Maderas-Cienc Tecnol 12:25-35. doi:10.4067/S0718-221X2010000100003

Poncsák S, Kocaefe D, Bouazara M, Pichette A (2006) Effect of high temperature treatment on the mechanical properties of birch (Betula papyrifera). Wood Sci Technol 40:647-663. doi:10.1007/s00226-006-0082-9

Poncsak S, Kocaefe D, Simard F, Pichette A (2009) Evolution of extractive composition during thermal treatment of Jack pine. J Wood Chem Technol 29:251-264. doi:10.1080/02773810902928582

Pönni R, Galvis L, Vuorinen T (2014) Changes in accessibility of cellulose during kraft pulping of wood in deuterium oxide. Carbohyd Polym 101:792-797. doi:10.1016/j.carbpol.2013.10.001

Popescu CM, Hill CAS (2013) The water vapour adsorption-desorption behaviour of naturally aged Tilia cordata Mill. wood. Polym Degrad Stabil 98:1804-1813. doi:10.1016/j.polymdegradstab.2013.05.021

Prado JA, Barros S, Wrann J, Rojas P, Barros D, Aguirre S (1986) Especies forestales exóticas de interés económico para Chile [Exotic forest species of economic interest for Chile]. Instituto Forestal - Corporación de Fomento de la Producción, Santiago, Chile.

Rapp AO, Brischke C, Welzbacher CR (2006) Interrelationship between the severity of heat treatments and sieve fractions after impact ball milling: a mechanical test for quality control of thermally modified wood. Holzforschung 60:64-70. doi:10.1515/HF.2006.012

Rapp AO, Sailer M (2000) Heat treatment in Germany. In: Seminar: Production and development of heat treated wood in Europe, Helsinki, Finland.

Rautkari L, Hill CAS (2014) Effect of initial moisture content on the anti-swelling efficiency of thermally modified Scots pine sapwood treated in a high-pressure reactor under saturated steam. Holzforschung 68:323-326. doi: 10.1515/hf-2013-0078

Rautkari L, Honkanen J, Hill CAS, Ridley-Ellis D, Hughes M (2014) Mechanical and physical properties of thermally modified Scots pine wood in high pressure reactor under saturated steam at 120,150 and $180{ }^{\circ} \mathrm{C}$. Eur J Wood Prod 72:33-41. doi:10.1007/s00107-013-0749-5 
Repellin V, Guyonnet R (2005) Evaluation of heat-treated wood swelling by differential scanning calorimetry in relation to chemical composition. Holzforschung 59:28-34. doi:10.1515/hf.2005.005

Ringman R, Pilgård A, Brischke C, Richter K (2014) Mode of action of brown rot decay resistance in modified wood: a review. Holzforschung 68:239-246. doi:10.1515/hf2013-0057

Rodrigues J, Faix O, Pereira H (1998) Determination of lignin content of Eucalyptus globulus wood using FTIR spectroscopy. Holzforschung 52:46-50. doi:10.1515/hfsg.1998.52.1.46

Rowell RM (2014) Acetylation of wood - A review. Int j lignocellul prod 1:1-27.

Rowell RM, Ellis WD (1978) Determination of dimensional stabilization of wood using the water-soak method. Wood Fiber Sci 10:104-111

Runkel ROH (1951) Zur Kenntnis des thermoplastischen Verhaltens von Holz. Erste Mitteilung. [Information on the thermoplastic behavior of wood. First communication]. Holz Roh Werkst 9:41-53. doi.org/10.1007/BF02617537

Runkel ROH (1954) Studien über die Sorption der Holzfaser. Erste Mitteilung: Die Sorption der Holzfaser in morphologisch-chemischer Betrachtung [Studies on the sorption of wood fiber. First communication: The sorption of wood fiber in morphologicalchemical view]. Holz Roh Werkst 12:226-232. doi:10.1007/bf02617520

Runkel ROH, Lüthgens M (1956) Studien über die Sorption der Holzfaser. Zweite Mitteilung: Untersuchungen fiber die Heterogenität der Wassersorption der chemischen und morphologischen Komponenten verholzter Zellwände [Studies on the sorption of wood fiber. Second Communication: Investigations on the heterogeneity of water sorption of the chemical and morphological components of cell walls]. Holz Roh Werkst 14:424. doi:10.1007/bf02614975

Salmén L (2015) Wood morphology and properties from molecular perspectives. Ann For Sci 72:679-684. doi:10.1007/s13595-014-0403-3

Salmen L, Burgert I (2009) Cell wall features with regard to mechanical performance. A review. Special issue of COST Action E35 2004-2008: Wood machining - micromechanics and fracture. Holzforschung 63:121-129. doi:10.1515/hf.2009.011

Sandberg D, Kutnar A (2016) Thermally modified timber: Recent developments in Europe and North America. Wood Fiber Sci 48:28-39.

Santos JA (2000) Mechanical behaviour of Eucalyptus wood modified by heat. Wood Sci Technol 34:39-43. doi:10.1007/s002260050006

Scheiding W (2018) TMT in the year 2018 - an update. In: Proceedings of the 10th European TMT Workshop, Dresden, Germany.

Schneider CA, Rasband WS, Eliceiri KW (2012) NIH Image to ImageJ: 25 years of image analysis. Nat Methods 9:671. 
Schultz TP, Nicholas DD (2008) Long-term outdoor efficacy trials of wood treated with organic biocides and co-added non-biocidal additives. In: Proceedings of the 104th annual meeting of the American Wood Protection Association, Portland, Oregon.

Seborg RM, Tarkow H, Stamm AJ (1953) Effect of heat upon the dimensional stabilisation of wood. J Forest Prod Res Soc 3:59-67.

Segal L, Creely JJ, Martin Jr AE, Conrad CM (1959) An empirical method for estimating the degree of crystallinity of native cellulose using the X-ray diffractometer. Text Res J 29:786-794. doi:10.1177/004051755902901003

Shi JL, Kocaefe D, Amburgey T, Zhang J (2007a) A comparative study on brown-rot fungus decay and subterranean termite resistance of thermally-modified and ACQ-C-treated wood. Holz Roh Werkst 65:353-358. doi:10.1007/s00107-007-0178-4

Shi JL, Kocaefe D, Zhang J (2007b) Mechanical behaviour of Quebec wood species heattreated using ThermoWood process. Holz Roh Werkst 65:255-259. doi:10.1007/s00107-007-0173-9

Shitola H, Kyrklund B, Laamanen L, Palenius I (1963) Comparison and conversion of viscosity and DP-values determined by different methods. Paperi ja puu 45:225-323.

Sivonen H, Maunu SL, Sundholm F, Jamsa S, Viitaniemi P (2002) Magnetic resonance studies of thermally modified wood. Holzforschung 56:648-654. doi:10.1515/hf.2002.098

Sjostrom E (1981) Wood chemistry: fundamentals and applications. Academic Press, INC, London, United Kingdom.

Sluiter A, Hames B, Ruiz R, Scarlata C, Sluiter J, Templeton D, Crocker D (2008) Determination of structural carbohydrates and lignin in biomass. US National Renewable Energy Laboratory, Golden, Colorado.

Spiridon I, Teaca CA, Bodîrlău R (2011) Structural changes evidenced by FTIR spectroscopy in cellulose materials after pre-treatment with ionic liquid and enzymatic hydrolysis. BioRes 6:400-413.

Stamm AJ (1956) Dimensional stabilization of wood with carbowaxes. Forest Prod J 6:201204.

Stamm AJ, Burr HK, Kline AL (1946) Heat stabilized wood (staybwood). Ind Eng Chem 39:630-634.

Stamm AJ, Hansen LA (1937) Minimizing wood shrinkage and swelling effect of heating in various gases. Ind Eng Chem 29:831-833. doi:10.1021/ie50331a021

Standfest G, Zimmer B (2008) The surface hardness of thermally treated woods (Poster presentation). In: Proceedings of the 62nd International Convention of the Forest Products Society, St. Louis, USA. 
Suchy M, Kontturi E, Vuorinen T (2010) Impact of drying on wood ultrastructure: Similarities in cell wall alteration between native wood and isolated wood-based fibers. Biomacromolecules 11:2161-2168. doi: 10.1021/bm100547n

Sundqvist B, Karlsson O, Westermark U (2006) Determination of formic-acid and acetic acid concentrations formed during hydrothermal treatment of birch wood and its relation to colour, strength and hardness. Wood Sci Technol 40:549. doi:10.1007/s00226-0060071-z

Surini T, Charrier F, Malvestio J, Charrier B, Moubarik A, Castéra P, Grelier S (2012) Physical properties and termite durability of maritime pine Pinus pinaster Ait., heat-treated under vacuum pressure. Wood Sci Technol 46:487-501.

Sweet MS, Winandy JE (1999) Influence of degree of polymerization of cellulose and hemicellulose on strength loss in fire-retardant-treated southern pine. Holzforschung 53:311-317. doi:10.1515/hf.1999.051

Tanahashi M, Goto T, Horii F, Hirai A, Higichi T (1989) Characterization of stem-exploded woo. III. Transformation of cellulose crystals and changes of crystallinity (in Japanese). Mokuzai Gakkaishi 35:654-662

TAPPI (1997) Solvent extractives of wood and pulp. Test method T $204 \mathrm{~cm}-07$. Technical Association of the Pulp and Paper Industry, Atlanta, Georgia, United States.

TAPPI (2009) Alpha-, beta- and gamma-cellulose in pulp. Test method T $203 \mathrm{~cm}-09$. Technical Association of the Pulp and Paper Industry, Atlanta, Georgia, United States.

TAPPI (2013) Viscosity of pulp (capillary viscometer method). Test method T 230 om-13. Technical Association of the Pulp and Paper Industry, Atlanta, Georgia, United States.

Thybring EE, Thygesen LG, Burgert I (2017) Hydroxyl accessibility in wood cell walls as affected by drying and re-wetting procedures. Cellulose 24:2375-2384. doi:10.1007/s10570-017-1278-x

Thygesen A, Oddershede J, Lilholt H, Thomsen AB, Ståhl K (2005) On the determination of crystallinity and cellulose content in plant fibres. Cellulose 12:563-576. doi:10.1007/s 10570-005-9001-8

Tiemann HD (1915) The effect of different methods of drying on the strength of wood. Lumber World Review 28:19-20.

Tiemann HD (1917) Effect of different methods of drying on the strength and the hygroscopicity of wood. In: Tiemann HD (ed). The kiln drying of lumber - A practical and theoretical treastie. 3rd Ed. edn. J. P. Lippincott Co., Philadelphia and London, pp 256-264

Tjeerdsma BF, Boonstra M, Pizzi A, Tekely P, Militz H (1998) Characterisation of thermally modified wood: molecular reasons for wood performance improvement. Holz Roh Werkst 56:149-153. doi:10.1007/s001070050287 
Tjeerdsma BF, Militz H (2005) Chemical changes in hydrothermal treated wood: FTIR analysis of combined hydrothermal and dry heat-treated wood. Holz Roh Werkst 63:102-111. doi:10.1007/s00107-004-0532-8

Touza Vázquez MC (2001) Tensiones de crecimiento en Eucalyptus globulus de Galicia (España): influencia de la silvicultura y estrategias de aserrado [Growth tensions in Eucalyptus globulus from Galicia (Spain): influence of silviculture and sawing strategies]. Maderas-Cienc Tecnol 3:68-89. doi:10.4067/S0718-221X2001000100008

Townsend T, Dubey B, Tolaymat T, Solo-Gabriele H (2005) Preservative leaching from weathered CCA-treated wood. J Environ Manage 75:105-113. doi:10.1016/j.jenvman.2004.11.009

Trtik P, Dual J, Keunecke D, Mannes D, Niemz P, Stahli P, Kaestner A, Groso A, Stampanoni M (2007) 3D imaging of microstructure of spruce wood. J Struct Biol 159:46-55. doi:10.1016/j.jsb.2007.02.003

Vahtikari K, Rautkari L, Noponen T, Lillqvist K, Hughes M (2017) The influence of extractives on the sorption characteristics of Scots pine (Pinus sylvestris L.). J Mater Sci 52:1084010852. doi:10.1007/s 10853-017-1278-0

Valencia JC, Cabrera J (2007) Análisis económico de opciones productivas para plantaciones de Eucalyptus nitens en el sur de Chile [Economic analysis of productive options for plantations of Eucalyptus nitens in southern Chile]. CIFOR 13:23-41.

Van den Bulcke J, Boone M, Van Acker J, Stevens M, Van Hoorebeke L (2009) X-ray tomography as a tool for detailed anatomical analysis. Ann For Sci 66. doi:10.1051/forest/2009033

Villegas MS, Rivera SM (2002) Revisión xilológica de las principales especies del género Eucalyptus L'Herit. cultivadas en Argentina [Xilological review of the main species of the genus Eucalyptus L'Herit. grown in Argentina]. Rev Fac Agron 105:9-28.

Voss A, Willeitner H (1993) Possibility and problems of characterizing treated wood after service with regard to disposal. The International Research Group on Wood Preservation Document No. IRG/WP 93-5006.

Wang XH, Fei BH, Liu JL (2014) Effect of vacuum heat treatment temperature on physical and mechanical properties of Eucalyptus pellita wood. Wood Fiber Sci 46:368-375

Washusen R (2009) The influence of plantation silviculture on tension wood formation. In: Apiolaza L, Chahuan SS, Walker J (eds). Revisiting eucalypts 2009. University of Canterbury, Canterbury, pp 91-100.

Washusen R, Ilic J, Waugh G (2003) The relationship between longitudinal growth strain and the occurrence of gelatinous fibers in 10 and 11-year-old Eucalyptus globulus Labill. Holz Roh Werkst 61:299-303. doi:10.1007/s00107-003-0388-3

Weigl M, Muller U, Wimmer R, Hansmann C (2012) Ammonia vs. thermally modified timbercomparison of physical and mechanical properties. Eur J Wood Prod 70:233-239. doi:10.1007/s00107-011-0537-z 
Weiland JJ, Guyonnet R (2003) Study of chemical modifications and fungi degradation of thermally modified wood using DRIFT spectroscopy. Holz Roh Werkst 61:216-220. doi:10.1007/s00107-003-0364-y

Welzbacher CR, Brischke C, Rapp AO (2007) Influence of treatment temperature and duration on selected biological, mechanical, physical and optical properties of thermally modified timber. Wood Mater Sci Eng 2:66-76. doi:10.1080/17480270701770606

Welzbacher CR, Rapp AO (2002) Comparison of thermally modified wood originating from four industrial scale processes - durability. The International Research Group on Wood Preservation Document No. IRG/WP 02-40229.

Welzbacher CR, Rapp AO (2007) Durability of thermally modified timber from industrial-scale processes in different use classes: Results from laboratory and field tests. Wood Mater Sci Eng 2:4-14. doi:10.1080/17480270701267504

Welzbacher CR, Rassam G, Talaei A, Brischke C (2011) Microstructure, strength and structural integrity of heat-treated beech and spruce wood. Wood Mater Sci Eng 6:219-227. doi:10.1080/17480272.2011.622411

Wentzel M, Altgen M, Militz H (2018a) Analyzing reversible changes in hygroscopicity of thermally modified eucalypt wood from open and closed reactor systems. Wood Sci Technol 52:889-907. doi:10.1007/s00226-018-1012-3

Wentzel M, Fleckenstein M, Hofmann T, Militz H (2018b) Relation of chemical and mechanical properties of Eucalyptus nitens wood thermally modified in open and closed systems. Wood Mater Sci Eng. Online first.

Wetzig M, Niemz P, Sieverts T, Bergemann H (2012) Mechanische und physikalische Eigenschaften von mit dem Vakuumpress-Trocknungsverfahren thermisch behandeltem Holz [Mechanical and physical properties of thermally treated wood using the vacuum press drying method]. Bauphysik 34:1-10. doi:10.1002/bapi.201200001

Widmann R, Fernandez-Cabo JL, Steiger R (2012) Mechanical properties of thermally modified beech timber for structural purposes. Eur J Wood Prod 70:775-784. doi:10.1007/s00107-012-0615-x

Willems W (2009) A novel economic large-scale production technology for high quality thermally modified wood. In: Engelund F, Hill CAS, Militz H, Segerholm BK (eds). Proceedings of the 4th European Conference on Wood Modification, Stockholm, Sweden.

Willems W (2014a) Experiences with an industrial system for controlled thermal wood modification in pressurized unsaturated steam. The International Research Group on Wood Protection Document No. IRG/WP 14-40678.

Willems W (2014b) The water vapor sorption mechanism and its hysteresis in wood: the water/void mixture postulate. Wood Sci Technol 48:499-518. doi:10.1007/s00226-0140617-4 
Willems W, Altgen M, Militz H (2015a) Comparison of EMC and durability of heat treated wood from high versus low water vapour pressure reactor systems. Int Wood Products J 6:21-26. doi:10.1179/2042645314Y.0000000083

Willems W, Lykidis C, Altgen M, Clauder L (2015b) Quality control methods for thermally modified wood. Holzforschung 69:875-884. doi:10.1515/hf-2014-0185

Willems W, Tausch A, Militz H (2010) Evidence for an antioxidant mechanism in the durability of high-pressure steam modified wood. In: Hill CAS, Militz H, Andersons B (eds). Proceedings of the 5th European Conference on Wood Modification, Riga, Latvia.

Winandy JE, Lebow PK (2001) Modeling strength loss in wood by chemical composition. Part I. An individual component model for southern pine. Wood Fiber Sci 33:239-254.

Winandy JE, Rowell RM (1984) Chapter 5: The Chemistry of strength. In: Rowell RM (ed). The Chemistry of Solid Wood (Advances in Chemistry Series 207). IBD, Washington, DC, pp 211-255.

Windeisen E, Bachle H, Zimmer B, Wegener G (2009) Relations between chemical changes and mechanical properties of thermally treated wood. Holzforschung 63:773-778. doi:10.1515/hf.2009.084

Windeisen E, Strobel C, Wegener G (2007) Chemical changes during the production of thermotreated beech wood. Wood Sci Technol 41:523-536. doi:10.1007/s00226-007-0146-5

Wise LE, Murphy M, Daddieco AA (1946) Chlorite holocellulose, its fractionation and bearing on summative wood analysis and on studies on the hemicelluloses. Technical Association Papers 29:210-218.

Xie Y, Krause A, Militz H (2014) Wood protection with dimethyloldihydroxy-ethyleneurea and its derivatives. In: Schultz TP, Goodell B, Nicholas DD (eds). Deterioration and protection of sustainable biomaterials. ACS Symposium Series 1158. Oxford University Press, pp 287-299.

Xunta de Galicia (2018) $1^{\text {a }}$ Revisión del Plan Forestal de Galicia [1st Review of the Forestry Plan of Galicia]. Santiago de Compostela, Spain.

Yang JL, Waugh G (1996) Potential of plantation-grown eucalypts for structural sawn products. II. Eucalyptus nitens (Dean \& Maiden) Maiden and E. regnans F. Muell. Aus For 59:99107. doi:10.1080/00049158.1996.10674674

Zaman A, Alen R, Kotilainen R (2000) Thermal behavior of scots pine (Pinus sylvestris) and silver birch (Betula pendula) at 200-230 degrees $C^{\circ}$. Wood Fiber Sci 32:138-143.

Zeller F (2018) Terrasse - Fassade - Gartenholz: Produktarten und Markverteilung [Decking Facade - Garden Timber: Product types and market share]. In: Proceedings of the 10th European TMT Workshop, Dresden, Germany. 



\section{Curriculum vitae}

Name Maximilian Wentzel Vietheer

Born $\quad 26$ of July 1984 in Santiago, Chile

Nationality German/Chilean

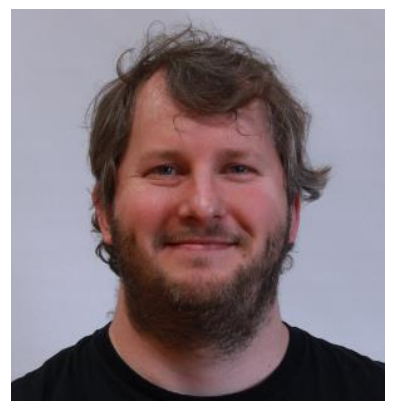

\section{Education}

2014-2018 PhD student, Department of Wood Biology and Wood Products, Faculty of Forest Sciences and Forest Ecology, Georg-August University, Goettingen, Germany

2010-2012 Master of Philosophy (MPhil), Department of Forest and Ecosystem Science, The University of Melbourne, Melbourne, Australia

2003-2009 Wood Engineering, Institute for Forest Products Technology, Faculty of Forest Sciences, Universidad Austral de Chile, Valdivia, Chile

\section{Work Experience}

2013-2014 Research assistant in Universidad Austral de Chile.

\section{Scholarships}

2014-2018 BecasChile Scholarship for post graduate studies in the Department of Wood Biology and Wood Products, Faculty of Forest Sciences and Forest Ecology, Georg-August University, Goettingen, Germany

2010-2012 BecasChile Scholarship for post graduate studies in the Department of Forest and Ecosystem Science, The University of Melbourne, Melbourne, Australia

2006-2007 DAAD Scholarship for a Student exchange during August 2006 - July 2007 in the Wood Biology and Wood Products, Faculty of Forest Sciences and Forest Ecology, Georg-August University, Goettingen, Germany

2004-2008 Scholarship of the Institute for Forest Products Technology 2004, 2005, 2008. 
